\title{
EU climate law through the lens of the Aarhus Convention
}

Citation for published version (APA):

Nóbrega, S. (2020). EU climate law through the lens of the Aarhus Convention: Access to environmental information and public participation in EU climate change decision making. [Doctoral Thesis, Maastricht University]. ProefschriftMaken. https://doi.org/10.26481/dis.20201028sn

Document status and date:

Published: 01/01/2020

DOI:

10.26481/dis.20201028sn

Document Version:

Publisher's PDF, also known as Version of record

\section{Please check the document version of this publication:}

- A submitted manuscript is the version of the article upon submission and before peer-review. There can be important differences between the submitted version and the official published version of record.

People interested in the research are advised to contact the author for the final version of the publication, or visit the DOI to the publisher's website.

- The final author version and the galley proof are versions of the publication after peer review.

- The final published version features the final layout of the paper including the volume, issue and page numbers.

Link to publication

\footnotetext{
General rights rights.

- You may freely distribute the URL identifying the publication in the public portal. please follow below link for the End User Agreement:

www.umlib.nl/taverne-license

Take down policy

If you believe that this document breaches copyright please contact us at:

repository@maastrichtuniversity.nl

providing details and we will investigate your claim.
}

Copyright and moral rights for the publications made accessible in the public portal are retained by the authors and/or other copyright owners and it is a condition of accessing publications that users recognise and abide by the legal requirements associated with these

- Users may download and print one copy of any publication from the public portal for the purpose of private study or research.

- You may not further distribute the material or use it for any profit-making activity or commercial gain

If the publication is distributed under the terms of Article $25 \mathrm{fa}$ of the Dutch Copyright Act, indicated by the "Taverne" license above, 
EU Climate Law Through the Lens of the Aarhus Convention Access to Environmental Information and Public Participation in EU Climate Change Decision Making

Sandra Nóbrega 
Copyright $\odot 2020$ by Sandra Nóbrega

All rights reserved

No part of this publication may be reproduced, stored in an automated data system or transmitted in any form or by any means, electronic, mechanical or photocopying, recording, or otherwise, without the prior written permission from the author.

ISBN : 978-94-6380-996-2

Printed by: ProefschriftMaken || www.proefschriftmaken.nl

Cover design by: ProefschriftMaken || Stefanie van den Herik 


\title{
EU Climate Law Through the Lens of the Aarhus Convention
}

\author{
Access to Environmental Information and Public Participation \\ in EU Climate Change Decision Making
}

\section{DISSERTATION}

to obtain the degree of Doctor at the Maastricht University, on the authority of the Rector Magnificus,

Prof.dr. Rianne M. Letschert

in accordance with the decision of the Board of Deans,

to be defended in public

on Wednesday 28 October 2020, at 16 hours

by

Sandra Nóbrega 
Supervisor(s):

Prof.dr. Marjan Peeters

Prof.dr Mariolina Eliantonio

Assessment Committee:

Prof.dr. Ellen Vos (chair)

Prof.dr. Bruno de Witte

Prof.dr. Ellen Hey, Erasmus University, The Netherlands

Prof.dr. Michael Faure

Prof.dr. Stefan Weishaar, Rijksuniversiteit Groningen, The Netherlands 
To my beloved family 



\section{Acknowledgements}

Writing this thesis would certainly not have been possible without the support of great many people who accompanied me through this journey and to whom I would like to express my gratitude in the following lines.

First of all, I thank Prof. Marjan Peeters and Prof. Mariolina Eliantonio for all the comments, questions, corrections, inspiring discussions and patience, which have made the conclusion of this $\mathrm{PhD}$ possible. Since meeting Marjan, when I was her master student, she has advised and supported me in finishing both my master and my $\mathrm{PhD}$ thesis, and she gave me the enriching opportunity to teach environmental law. Mariolina provided me with clear comments and helped me to take the reader by the hand. Thank you both for making this project happen!

I am grateful for the feedback received from the members of the reading committee for my PhD dissertation, namely Prof. Ellen Vos (chair), Prof. Ellen Hey, Prof. Stefan Weishaar, Prof. Bruno de Witte and Prof. Michael Faure.

A big thanks goes to my colleagues from the Faculty of Law who shared the experience of doing a PhD over coffee and lunches: Taotao, Yuan, Ancui, Constantijn, Sejla, Andrea, Mayke.

Furthermore, for their continuous support and encouragement I would like to thank my friends and family. It is difficult to find the words to express my gratitude and to translate how important they are. Thank you, Family Cidral and Family Scarpelli, for bringing joy when I struggled along the way. Thank you Joana, Laura, Luisa and Ana Paula for sharing the hardship and the joy of doing a PhD, and becoming my friends along this journey. To all my friends from before and the ones I have made during my $\mathrm{PhD}$ and are now scattered around the globe: Thank you for being part of my life!

The conclusion of this thesis would not be possible without the ceaseless support of my family. For allowing me to dream, I would like to thank my parents, Osman and Jussara, who gave everything so that their daughters could be happy. I am truly grateful for your faith in me! Also, my sisters, Rafaella and Thaíse for dreaming with me. You both are a beautiful part of my existence. Querida família, obrigada por serem meu porto seguro.

Furthermore, for giving me the joy of watching how beautiful it is to learn and grow every day, I would like to thank my son Hugo and my daughter Alice. Thank you both for loving me every day, which gives me energy to keep on going even when the going got tough (even if sometimes it was your own doing...(;) 
Last but by far not least, my final words go to my husband Olivier to whom I am profoundly indebted. I know that I can always count on you and this is priceless. Along these years, you told me every day that I could make it. You have supported me in all aspects incessantly. Thank you for knowing how to balance professional and family life and for teaching me this. Without you, I would never have completed this research. Thank you for building a family with me in a caring and loving environment. You are more than I could wish for a partner in life! Obrigada, Coração! 


\section{Chapters}

Chapter I - Introduction

Chapter II - The UNFCCC requirements for access to climate information and public participation in climate change decision making

Chapter III - The Aarhus Convention, the EU and Climate Change

Chapter IV - The EU Emissions Trading System: Access to environmental information and public participation at EU level

Chapter V - Certification of Biofuels: Access to environmental information and public participation at EU Level

Chapter VI - Conclusion 


\section{Detailed Table of Contents}

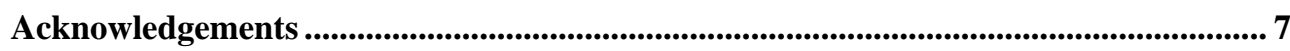

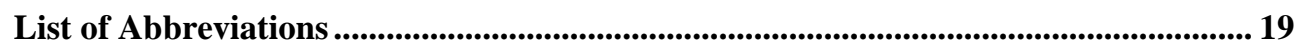

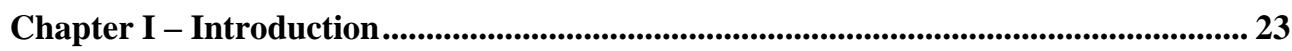

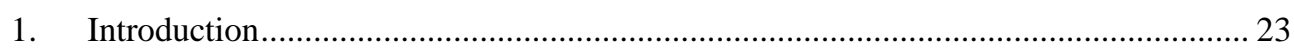

1.1. Procedural obligations in the field of EU climate change law ......................... 23

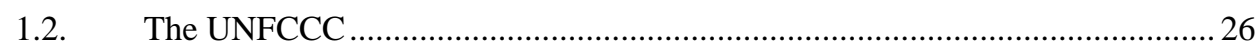

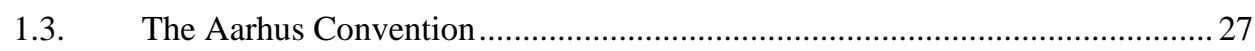

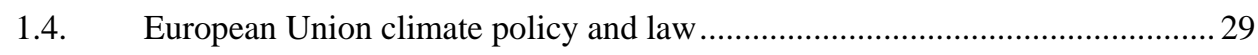

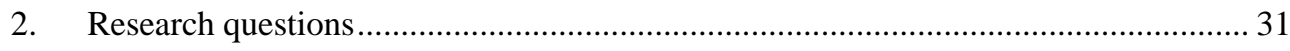

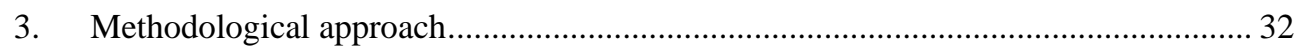

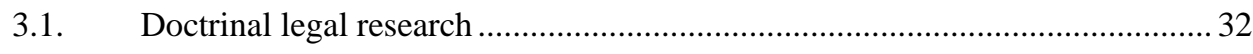

3.2. Case-based approach: focus on specific elements of EU climate change law .. 34

3.2.1. Case study 1: The EU Emissions Trading System Directive ...................... 35

3.2.2. Case study 2: The Renewable Energy Directive ........................................... 37

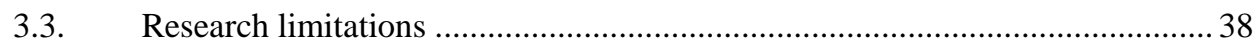

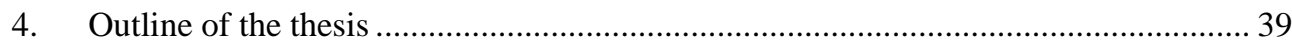

Chapter II - The UNFCCC requirements for access to climate information and public participation in climate .......................................................................................................................... 41

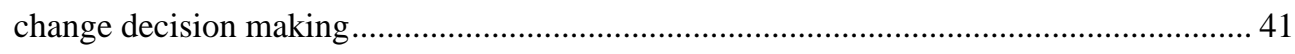

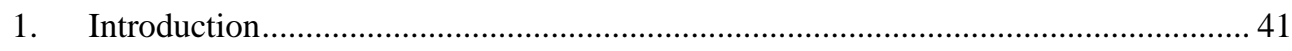

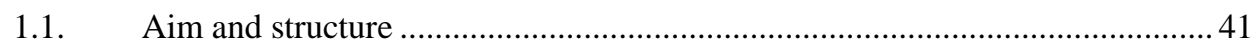

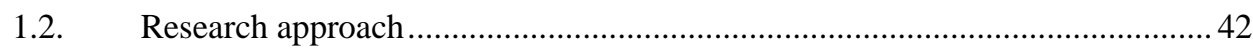

2. Access to information and public participation under the UNFCCC ........................ 46

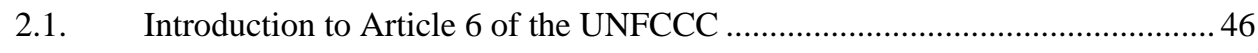

2.2. Circumstances of the drafting and conclusion of the UNFCCC ......................4 47

2.2.1. Circumstance of the drafting: a choice for a framework convention ........... 47

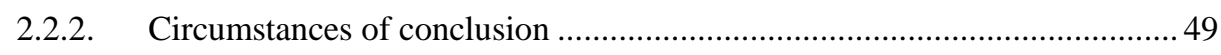


2.3. Plain meaning of the terms in context and in the light of object and purpose of

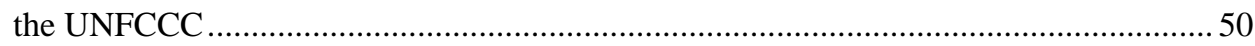

2.3.1. "In accordance with national laws and regulations" ................................ 51

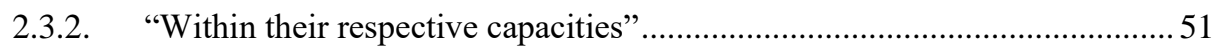

2.3.3. "Public access to information on climate change and its effects"................53

2.3.4. "Public participation in addressing climate change and its effects and developing adequate responses" ................................................................... 55

2.4. Subsequent agreement and subsequent practice: work programmes ...............55

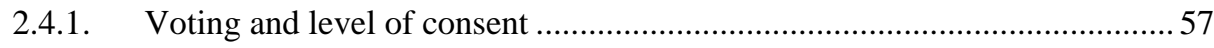

2.4.2. Level of authorisation in the treaty - Delegated consent ...........................58

2.4.3. Obligation contained in the language of the CoP Activity - Intent .............59

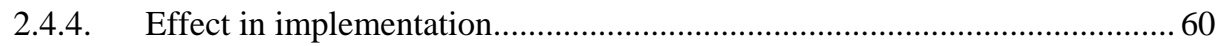

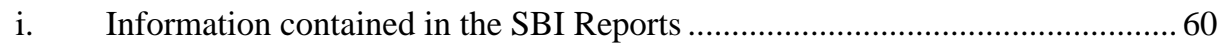

ii. Review of implementation of the work programmes on Article 6 UNFCCC... 61

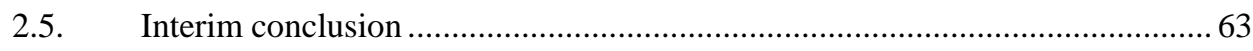

3. Access to information and public participation under the Kyoto Protocol ................. 64

4. Access to information and public participation under the Paris Agreement ............... 66

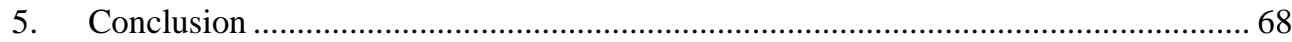

Chapter III - The Aarhus Convention, the EU and Climate Change .......................... 71

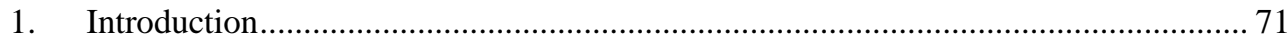

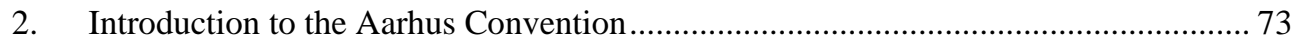

2.1. A convention about procedural rights.................................................... 73

2.2. A regional convention with global relevance ........................................... 77

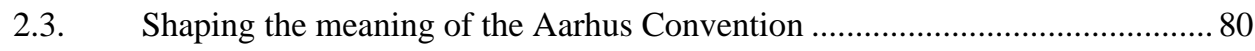

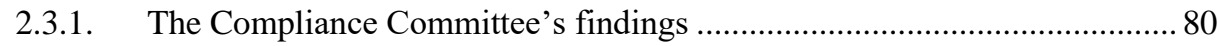

2.3.2. The Aarhus Convention Implementation Guide ...................................... 83

2.3.3. The Court of Justice of the European Union............................................. 85

3. The Aarhus Convention and climate change....................................................... 85

3.1. Circumstances of drafting and conclusion of the Aarhus Convention.............. 86

3.2. Climate (change) in the preparatory documents of the Aarhus Convention ..... 86

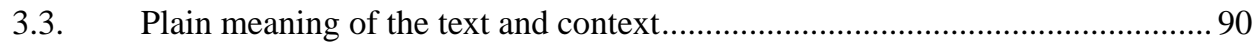


3.3.1. Interpretation of the term environmental information.............................. 90

3.3.2. Climate change as part of the definition of environmental information ...... 91

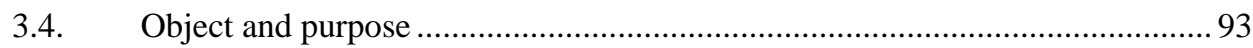

3.5. Subsequent Agreement and Subsequent Practice ......................................... 93

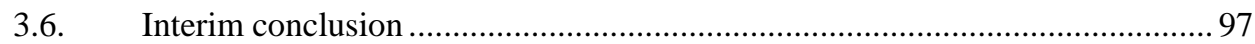

4. Access to environmental information under the Aarhus Convention and its

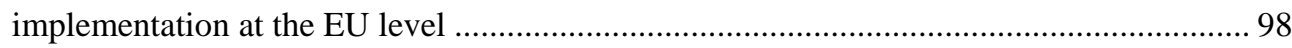

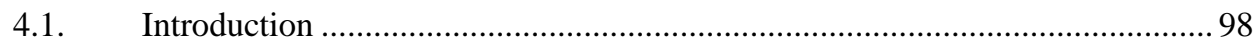

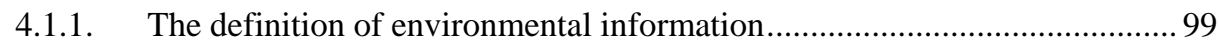

4.1.2. The addressees of the right to environmental information: the public .........99

4.1.3. The authorities who are (and are not) subjected to the obligation to provide

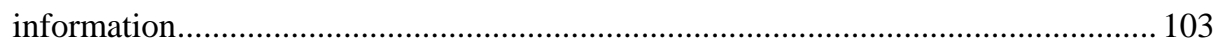

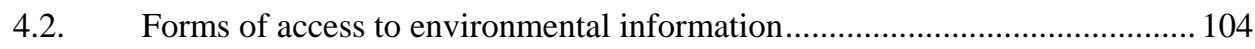

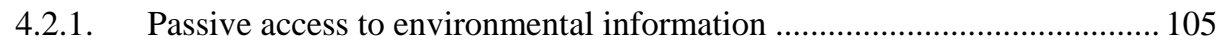

4.2.2. Active access to environmental information............................................. 108

4.3. Grounds for refusal to provide public access to environmental information .. 110

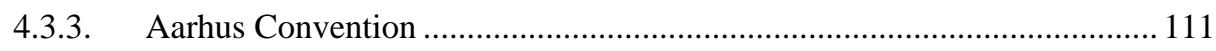

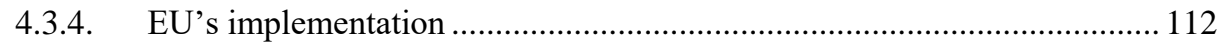

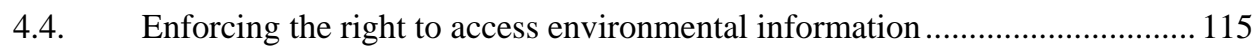

5. Public participation in environmental decision making under the Aarhus Convention and its implementation at the EU level ...................................................................... 118

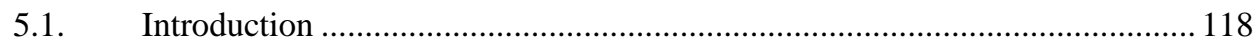

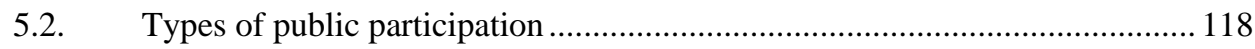

5.2.1. Public participation in decisions on specific activities............................. 118

5.2.2 Public participation concerning plans, programmes and policies relating to the

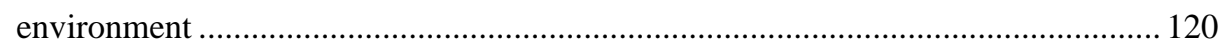

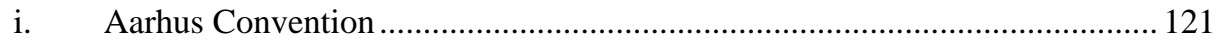

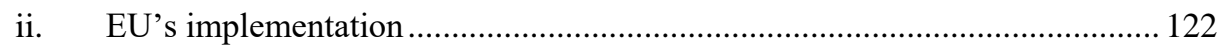

5.2.3 Public participation concerning executive regulation and/or generally

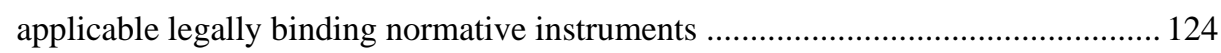

5.3. Enforcing the right to public participation in environmental decision making..... 
6. Conclusion

Chapter IV - The EU Emissions Trading System: Access to environmental information and public participation at the EU level

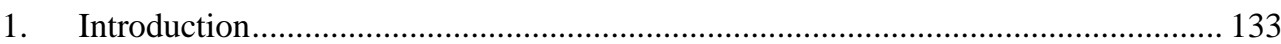

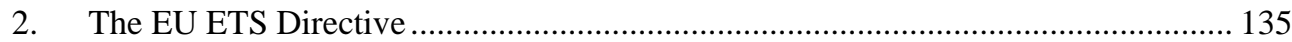

3. Access to environmental information under the EU ETS ....................................... 138

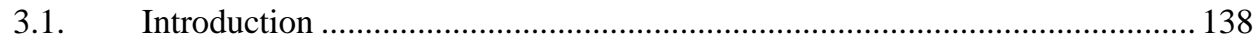

3.2. The legal framework for access to EU ETS-related information.................... 138

3.2.1. The EU ETS Directive and the Aarhus Regulation................................... 139

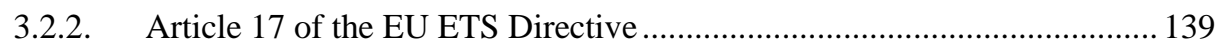

3.2.3. Article 15a of the EU ETS Directive ..................................................... 142

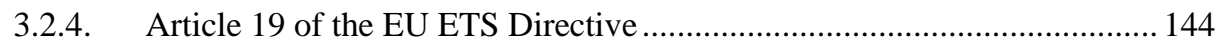

3.3. Passive Access to EU ETS-related information............................................. 147

3.3.1. Definition of environmental information: the extent to which EU ETS-related

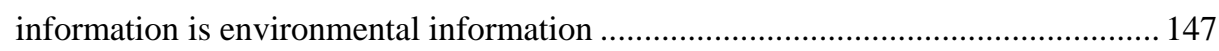

i. Access to data for the calculation of the Cross-Sectoral Correction Factor.... 147

ii. Request for a document on the allocation of free allowances submitted by a

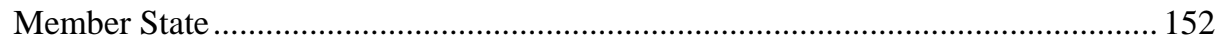

iii. Request for data related to the transfer of allowances under national registry 153

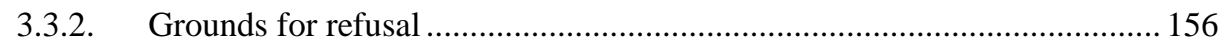

i. Non-disclosure of information which relates to ongoing decision making .... 156

ii. Confidentiality of commercial and industrial information ............................. 159

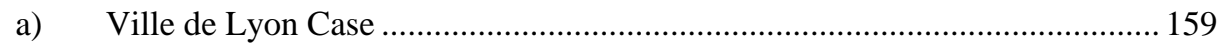

a.1) The opinion of the Advocate General and Judgment of the Court of Justice...

a.2) Are greenhouse emission allowances 'emissions into the environment'? 161

b) Cross-Sectoral Correction Factor Case .......................................................... 164

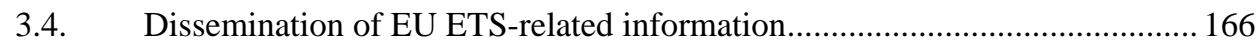

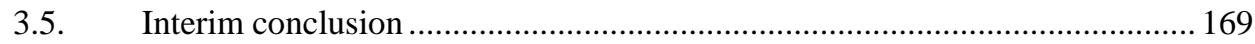

4. Public Participation in the decision making of the EU ETS .................................. 171

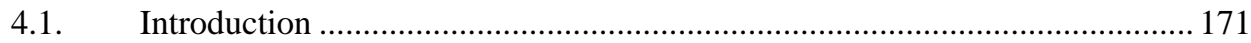


4.2. Public participation under the EU ETS Directive at the EU level

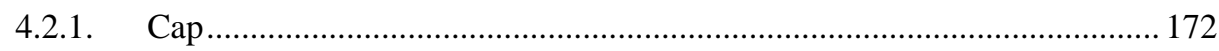

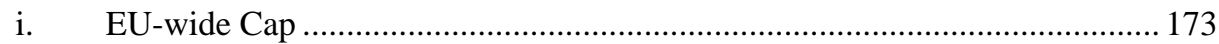

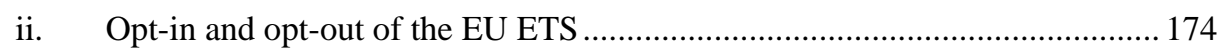

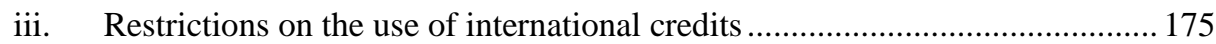

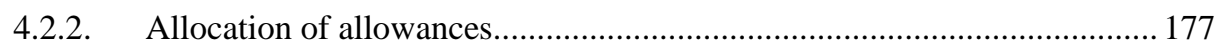

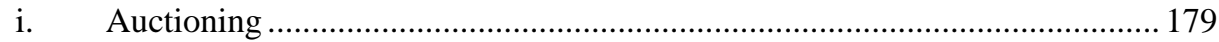

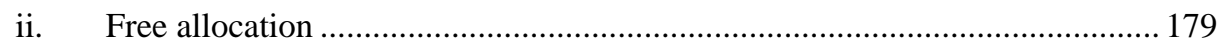

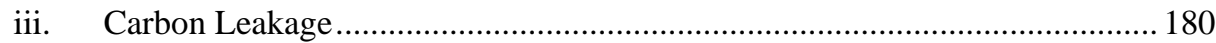

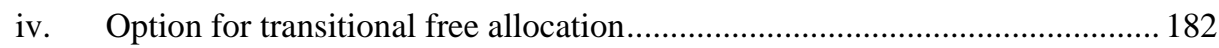

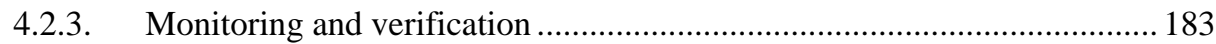

4.3. The Aarhus Regulation and the EU ETS Directive ……………………......... 183

4.4. Public participation under the EU ETS: an analysis of the compatibility with the

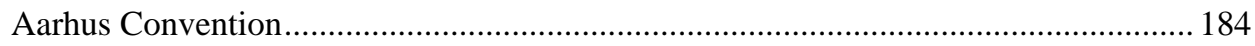

4.4.1. Public Participation in Decisions on Specific Activities (Article 6 of the

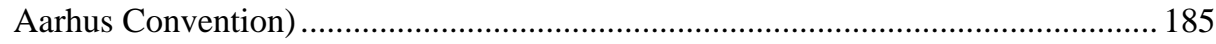

4.4.2. Public Participation concerning plans, programmes and policies relating to the environment (Article 7 of the Aarhus Convention)................................................... 186

4.4.3. Public Participation during the Preparation of Executive Regulations and/or Generally Applicable Legally Binding Normative Instruments (Article 8 of the Aarhus Convention) 187

i. Executive regulations and other generally applicable legally binding normative

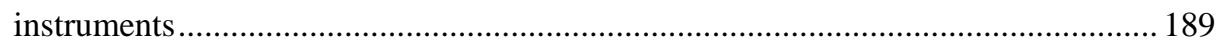

ii. Significant effect on the environment........................................................... 190

a) The criteria for determining significant effect on the environment ................. 190

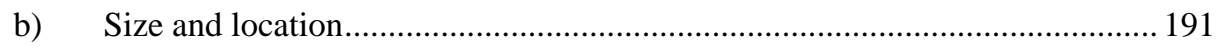

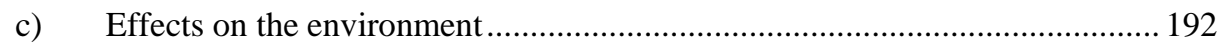

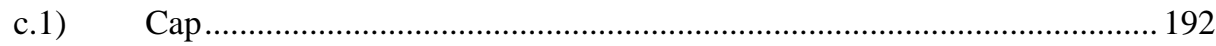

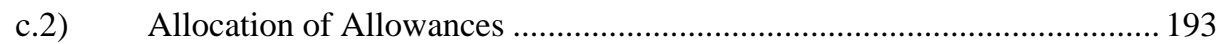

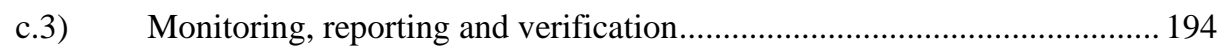

4.5. The extent to which the European Commission complies with Article 8 of the Aarhus Convention requirements 
4.5.1. Legal Framework for public participation for acts adopted under the EU ETS Directive 196

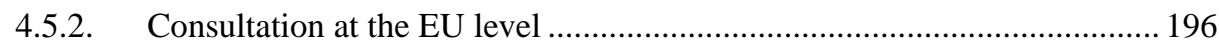

4.5.3. Compliance with Article 8 of the Aarhus Convention ................................ 198

i. Could a soft law instrument fulfil the obligations under Article 8 of the Aarhus

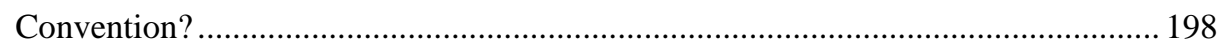

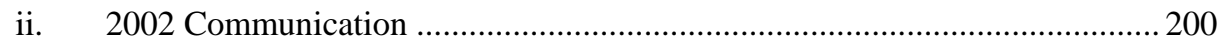

iii. 2015 and 2017 Better Regulation Guidelines ............................................. 201

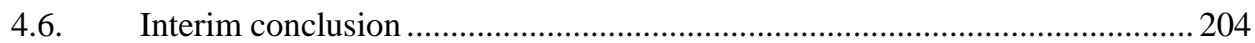

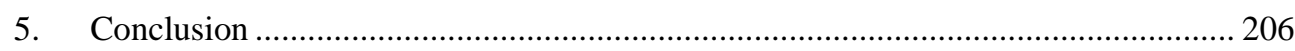

Chapter V - Certification of Biofuels: Access to environmental information and public participation at the EU Level.............................................................................................209

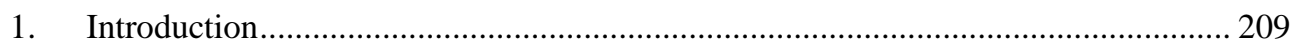

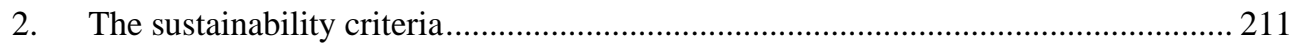

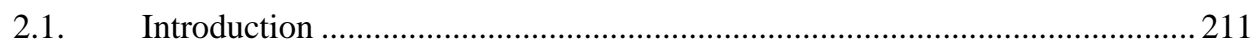

2.2. The voluntary schemes to demonstrate compliance of biofuels with the

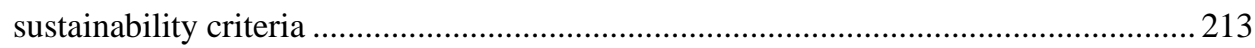

2.3. Identifying the actors involved in the recognition process .......................... 218

2.4. The requirement of an adequate standard of transparency for the recognition of

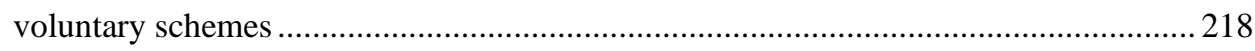

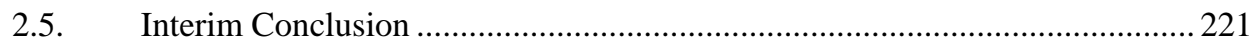

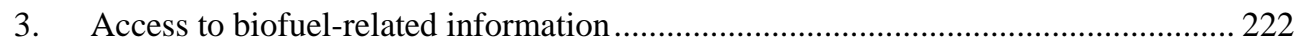

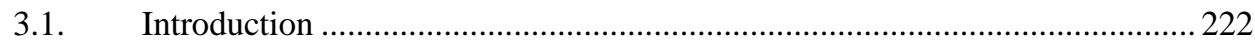

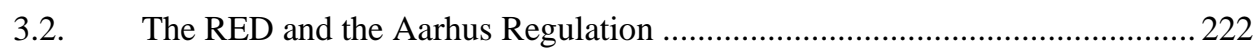

3.3. Setting the scene for access to environmental information........................... 223

3.3.1. The definition of environmental information: Biofuel-related information 223

3.3.2. The definition of public authority: Commission, evaluator/contractor and

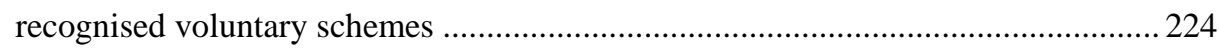

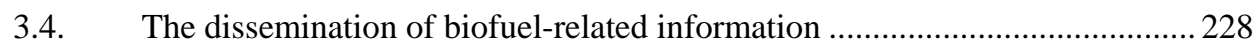

3.4.1. Limited dissemination of biofuel-related information: recognition of

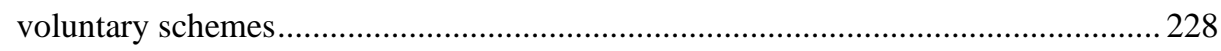


3.4.2. Limited dissemination of biofuel-related information: certification of biofuels 230

3.5. Requesting biofuel-related information

3.5.1. Delay to disclose information on the application for recognition of biofuels voluntary schemes.

3.5.2. Delay to disclose information on studies on the impact of biofuels........... 233

3.5.3. Exception for disclosure to protect commercial interest ............................ 237

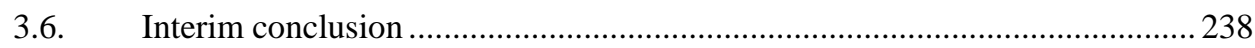

4. Public participation in voluntary schemes decision making ................................. 240

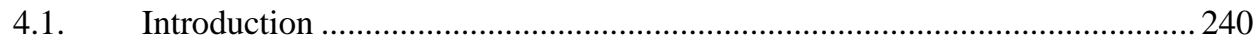

4.2. Public participation under the Renewable Energy Directive ........................ 241

4.3. The Aarhus Regulation and the recognition of voluntary schemes ................ 242

4.4. Public participation in the recognition process of voluntary schemes and the certification of biofuels: an analysis of the compatibility with the Aarhus Convention 244

4.4.1. Public participation in decisions on specific activities.............................. 244

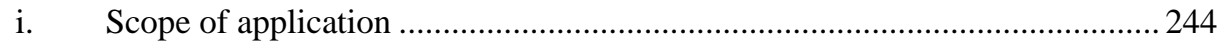

a) What are specific activities or proposed activities? ..................................... 244

b) The potential limits on the discretion of the Parties on the application of Article

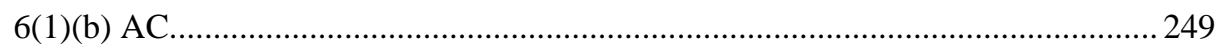

ii. Possible interpretation of the recognition of voluntary schemes and certification of biofuels as decisions which may have a significant impact on the environment .. 251

iii. The extent to which the European Commission and the voluntary schemes comply with Article 6 of the Aarhus Convention requirements................................253

4.4.2. Public Participation during the preparation of plans and programmes and

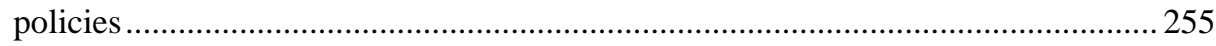

4.4.3. Public participation during the preparation of executive regulations and/or generally applicable legally binding normative instruments..............................256

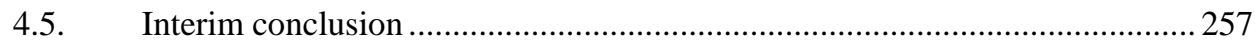

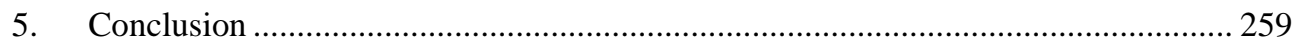

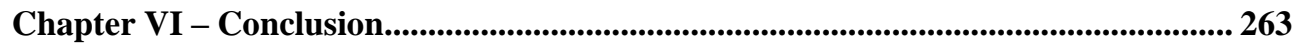

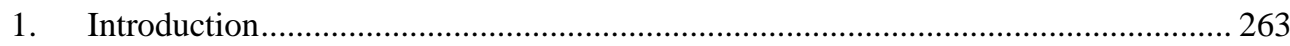


2. The UNFCCC requirements for access to climate information and public participation

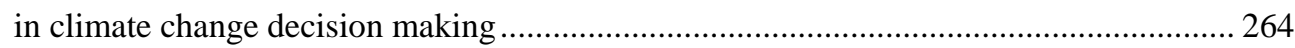

3. The Aarhus Convention, the EU and climate change .......................................... 265

3.1. The definition of environmental information and climate change ................. 266

3.2. Access to environmental information under the Aarhus Convention and its

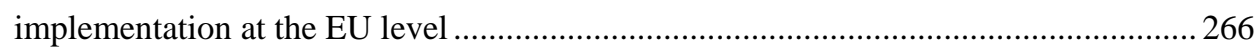

3.3. Public participation in environmental decision making................................. 267

4. The EU Emissions Trading System: Access to environmental information and public

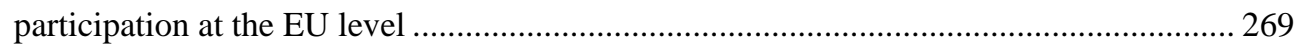

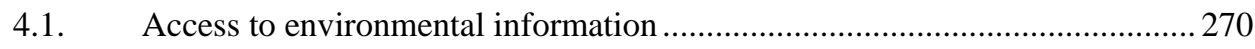

4.2. Public Participation in Environmental Decision Making .............................. 273

5. Certification of Biofuels: Access to environmental information and public participation

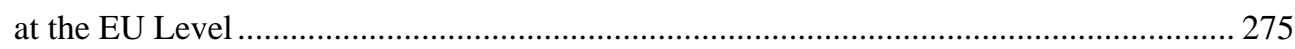

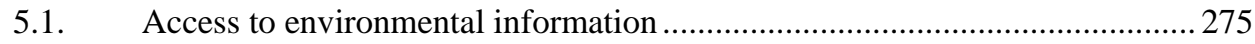

5.2. Public Participation in Environmental Decision Making ............................. 278

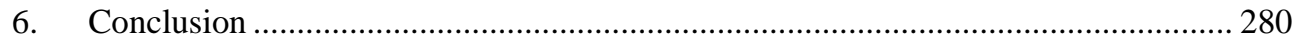

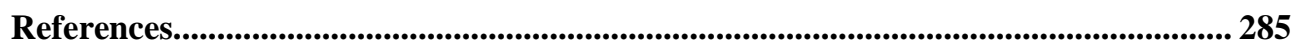

Annex - Voluntary schemes approved by the European Commission ......................... 325

Summary .................................................................................................................................. 327

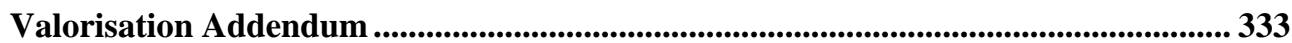

Curriculum Vitae.............................................................................................................. 337 


\section{List of Abbreviations}

$\mathrm{AC}$

ACCC

AG

BAU

CAN

CBDR

CBDR\&RC

CCS

CDM

CERS

CJEU

CMP

$\mathrm{CoP} / \mathrm{COP}$

CSCF
Aarhus Convention

Aarhus Convention Compliance Committee

Advocate General

Business-As-Usual

Climate Action Network

Common but Differentiated Responsibilities

Common but Differentiated Responsibilities

\& Respective Capabilities

Carbon and Capture Storage

Clean Development Mechanism

Certified Emission Reductions

Court of Justice of the European Union

Conference of the Parties serving as the Meeting of the Parties to the Kyoto Protocol

Conference of the Parties 
DG ENER

Directorate-General for Energy

ECE

Economic Commission for Europe

ECO Forum

Environmental Citizens' Organisations Forum

\section{EIA}

Environmental Impact Assessment

\begin{tabular}{lll}
\hline \multirow{2}{*}{ ENGO } & Environmental & Non-Governmental \\
& Organisation & \\
\end{tabular}

EPAW

European Platform Against Windfarms

ERUS

Emission Reduction Units

EU

European Union

EU ETS

European Union Emissions Trading System

EUTL

European Union Transaction Log

GHG

Greenhouse Gas

ICJ

International Court of Justice

ILUC

Indirect Land Use Change

INC

Intergovernmental Negotiating Committee 
Joint Implementation

MoP/MOP Meeting of the Parties

MRV Monitoring, reporting and verification

NAP National Allocation Plan

NGO Non-Governmental Organisation

PRTR Pollutant Release and Transfer Register

RED Renewable Energy Directive

SBI Subsidiary Body for Implementation

\begin{tabular}{ll}
\hline SBSTA & Subsidiary Body for Scientific and \\
& Technological Advice
\end{tabular}

SEA

Strategic Environmental Assessment

TEU

Treaty of the European Union

TFEU

Treaty on the Functioning of the European Union 
UNCED

\section{UNECE}

UNFCCC

VCLT
United Nations Conference on Environment and Development

United Nations Economic Commission for Europe

United Nations Framework Convention on Climate Change

Vienna Convention on the Law of the Treaties

World Wide Fund for Nature 


\section{Chapter I - Introduction}

\section{Introduction}

\subsection{Procedural obligations in the field of EU climate change law}

A clear link between climate change and the increase of greenhouse gas emissions in the Earth's atmosphere is now firmly scientifically established, and the interference with the climate system caused by humans is undeniable. According to the Intergovernmental Panel on Climate Change (IPCC), the anthropogenic sources of greenhouse gases play an irrefutable role in the global average surface temperature. ${ }^{1}$ For Europe, it is predicted that, in a business-as-usual scenario, ${ }^{2}$ disasters resulting from weather conditions could affect about two-thirds of the European population annually by the end of this century. ${ }^{3}$

The looming threat of climate change and the perceived lack of a strong political response to it has led the public to call more directly for decisive action to be taken. In Europe, organisations, such as the Campaign against Climate Change started to organise mass

\footnotetext{
${ }^{1}$ The IPCC stated: "It is extremely likely that more than half of the observed increase in global average surface temperature from 1951 to 2010 was caused by the anthropogenic increase in GHG concentrations and other anthropogenic forcings together." Intergovernmental Panel on Climate Change, Climate Change 2014: Synthesis Report. Summary for Policymakers, 2014b, https://www.ipcc.ch/pdf/assessment-report/ar5/syr/AR5_SYR_FINAL_SPM.pdf, p. 5.

${ }^{2}$ With a 'business-as-usual' baseline case, it is assumed that future development trends follow those of the past and no changes in policies will take place, see A. Markandya, K. Halsnaes, A. Lanza, Y. Matsuoka, S. Maya, J. Pan, J. Shogren, R. Seroa de Motta, T. Zhang and T. Taylor, 'Costing Methodologies', in B. Metz and O. Davidson (eds.), Climate change 2001: mitigation: contribution of Working Group III to the third assessment report of the Intergovernmental Panel on Climate Change, Vol. 3 (Cambridge University Press, 2001), pp. 455-498, p. 470.

However, "the term BAU has fallen out of favour because the idea of business as usual in century-long socio-economic projections is hard to fathom" K. J. Mach, S. Planton and C. von Stechow(eds.), 'Annex II: Glossary ', in R. K. Pachauri, M. R. Allen, V. R. Barros, J. Broome, W. Cramer, R. Christ, J. A. Church, L. Clarke, Q. Dahe and P. Dasgupta (eds.), Climate change 2014: synthesis report. Contribution of Working Groups I, II and III to the fifth assessment report of the Intergovernmental Panel on Climate Change, (Geneva, Switzerland: IPCC, 2014), pp. 117-130, p. 119.

${ }^{3}$ The study was conducted in the 28 EU Member States and Switzerland, Norway, and Iceland. G. Forzieri, A. Cescatti, F. B. e Silva and L. Feyen, 'Increasing risk over time of weather-related hazards to the European population: a data-driven prognostic study' 1(5) The Lancet Planetary Health, (2017), pp. e200-e208, p. e200 and e206.
} 
demonstrations in 2001 to raise awareness of the threats of climate change. ${ }^{4}$ Another example of individuals taking the streets to demand government action against climate change are the student strikes that took place in 2019. This movement, started by the Swedish teenager Greta Thunberg in August 2018, motivated thousands of students around the world to walk out of their classrooms and engage in demonstrations calling for action against climate change. ${ }^{5}$

In addition to these expressions of increased public engagement, there have also been important developments in the use of legal instruments to attempt to force action on climate change-related issues. Generally, there are many non-governmental organizations (NGOs) which rely on the power of the law to protect the environment. In Europe, ClientEarth and Friends of the Earth are among the environmental NGOs (ENGOs) which believe that adequate laws are the main instrument to guarantee a safe environment. Their actions include, inter alia, litigation to try to influence the decision making by governments in a more environmentally friendly direction. ${ }^{6}$

The apparent engagement from civil society, particularly ENGOs, asking for more ambitious climate change action raises the question of what rights members of the public actually have to access climate change-related information and to participate in climate change decision making. To answer this question, legal instruments, which deal with climate change and procedural rights, need to be studied.

In terms of the legal response to climate change, the first global agreement to tackle climate change was adopted in 1992. This is the United Nations Framework Convention on Climate Change (UNFCCC), ${ }^{7}$ which was later supplemented by the Kyoto Protocol in $1997 .{ }^{8}$ A new

\footnotetext{
${ }^{4}$ Campaign against Climate Change. Mission Statement, 18 June 2020, https://www.campaigncc.org /aboutus/missionstatement.

${ }^{5}$ S. Laville, M. Taylor and D. Hurst, 'It's our time to rise up': youth climate strikes held in 100 countries, The Guardian, 15 March 2019, https://www.theguardian.com/environment/2019/mar/15/itsour-time-to-rise-up-youth-climate-strikes-held-in-100-countries.

${ }^{6}$ At the EU level, these NGOs, for instance, have started legal action against the European Union (EU) in view of the denial to access environmental information. See Case T-278/11, ClientEarth, Friends of the Earth Europe, Stichting FERN and Stichting Corporate Europe Observatory v. European Commission, 13 November 2012, ECLI:EU:T:2012:593.

${ }^{7}$ United Nations Framework Convention on Climate Change, New York, 9 May 1992, United Nations Treaty Series, vol. 1771, No. 30822, p. 107 (entrered into force on 21 March 1994).

${ }^{8}$ Kyoto Protocol to the United Nations Framework Convention on Climate Change, Kyoto, 11 December 1997, United Nations Treaty Series, vol. 2303, No. 30822, p. 162 (entrered into force on 16 February 2005). The protocol was adopted in 1997 and was ratified eight years later, in 2005. The first commitment period ran from 2008 to 2012 . The second commitment period was planned to run from 2013 until 2020. However, the Doha Amendment, which regulates the targets for the second amendment period, had not yet been ratified at the time of writing. Doha Amendment to the Kyoto Protocol, Qatar, 8 December 2012, C.N.718.2012.TREATIES-XXVII.7.c (not into force).
} 
international instrument has been introduced with the adoption of the Paris Agreement in which the Parties agreed to keep the temperature increase of the global average temperature to well below $2^{\circ} \mathrm{C}$ above pre-industrial levels and to pursue efforts to limit the temperature increase to $1.5^{\circ} \mathrm{C}$ above pre-industrial levels. ${ }^{9}$

Meanwhile, in the area of environmental procedural rights (access to information, public participation and access to justice in environmental matters), a far-reaching regional agreement was adopted in 1998: the Aarhus Convention. ${ }^{10}$ The EU, as well as all EU Member States, is a Party to both the international climate change treaties and the Aarhus Convention. ${ }^{11}$ Regarding the Aarhus commitments of EU institutions, the EU adopted Regulation 1367/2006. ${ }^{12}$ However, thus far, the academic literature has not yet provided a comprehensive analysis of the interaction of, on the one hand, international climate change obligations with, on the other hand, environmental procedural rights. This thesis, therefore,

${ }^{9}$ Article 2, Paris Agreement, Paris, 12 December 2015, United Nations Treaty Series, No. 54113. C.N.63.2016.TREATIES-XXVII.7.d of 16 February 2016 (Opening for signature) and C.N.92.2016.TREATIES-XXVII.7.d of 17 March 2016 (Issuance of Certified True Copies) (entered into force on 4 November 2016). Hereinafter Paris Agreement.

${ }^{10}$ Convention on Access to Information, Public Participation in Decision-making and Access to Justice in Environmental Matters, Aarhus, Denmark, 25 June 1998, United Nations, Treaty Series, vol. 2161, p. 447 (entered into force on 30 October 2001). Henceforth the Aarhus Convention, the Convention or AC.

${ }^{11}$ To clarify the responsibility of the EU and its Member States vis-à-vis the Aarhus Convention, a declaration was submitted by the EU to the Convention secretariat. See $<$ https://treaties.un.org/pages/ViewDetails.aspx?src=TREATY\&mtdsg_no=XXVII-

13\&chapter=27\&lang=en >. The CJEU found that Article 9(3) of the Aarhus Convention does not have direct effect, because the provision does not 'contain any clear and precise obligation capable of directly regulating the legal position of individuals'. Case C-240/09, Lesoochranárske zoskupenie VLK v. Ministerstvo životného prostredia Slovenskej republiky, 8 March 2011, ECLI:EU:C:2011:125, para 45. On 17 February 2005, the EU (at that time the European Community) adopted the Decision on the conclusion of the Aarhus Convention. Decision 2005/370/EC on the Conclusion, on Behalf of the European Community, of the Convention on Access to Information, Public Participation in DecisionMaking and Access to Justice in Environmental Matters, OJ L124/1. At that point, the Convention became part of EU law and binding upon the EU institutions (Article 216(2), TFEU). M. HedemannRobinson, 'EU enforcement of International Environmental Agreements: The Role of the European Commission' 21(1) European Energy and Environmental Law Review, (2012), pp. 2-31, p. 2.

${ }^{12}$ Regulation (EC) No 1367/2006 of the European Parliament and of the Council of 6 September 2006 on the application of the provisions of the Aarhus Convention on Access to Information, Public Participation in Decision-making and Access to Justice in Environmental Matters to Community institutions and bodies, OJ L 264/13 [hereinafter Aarhus Regulation]. Regarding access to information, it complements the scope of Regulation (EC) No 1049/2001 of the European Parliament and of the Council of 30 May 2001 regarding public access to European Parliament, Council and Commission documents, OJ L145/43, and it extends its applicability to Community institutions and bodies. 
will aim to fill this gap partially with an in-depth exploration of these legal interactions by examining how this plays out in the European Union (EU) legal order.

To this end, two case studies have been selected: the Emissions Trading System (EU ETS) Directive and the Renewable Energy Directive (RED). The following Venn diagram (figure 01) highlights the legal instruments that will be studied in this thesis.

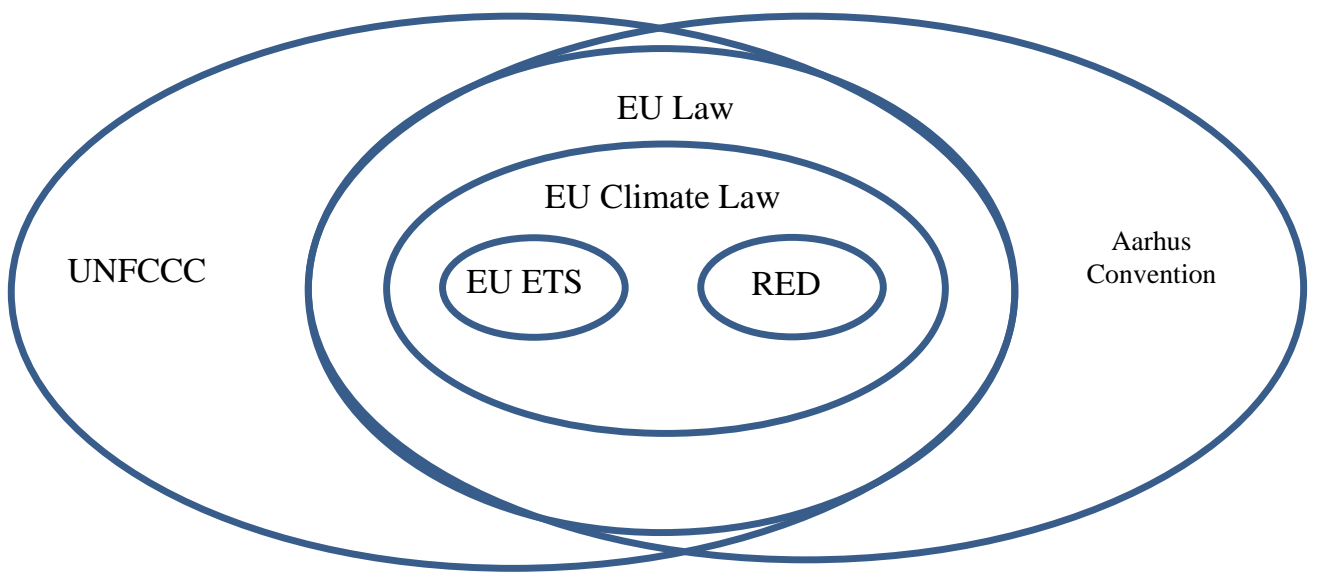

Figure 01: Legal instruments discussed in this thesis. ${ }^{13}$

The next sections will briefly present the UNFCCC, the Aarhus Convention and EU climate law in turn.

\subsection{The UNFCCC}

The United Nations Framework Convention on Climate Change (UNFCCC) emerged from the United Nations Conference on Environment and Development (UNCED) held in Rio de Janeiro in 1992. The UNFCCC is a global agreement that aims to respond to the threats posed by climate change. The primary goal of the agreement is to reduce the level of greenhouse gas (GHG) emissions entering the atmosphere. ${ }^{14}$ In addition, the Convention includes provisions to promote public awareness, public access to information and public participation. Particularly, in its Articles 4.1(i) and 6 (ii) and (iii), the UNFCCC stipulates that its Parties shall promote public awareness related to climate change and encourage the

\footnotetext{
${ }^{13}$ Diagram designed by the author.

${ }^{14}$ Article 2, UNFCCC.
} 
widest participation in this process, public access to information on climate change and its effects, and public participation in addressing climate change and its effects, respectively.

Under the umbrella of the UNFCCC, two other instruments have been adopted: the Kyoto Protocol and the Paris Agreement. The Kyoto Protocol is the first international agreement to establish quantified greenhouse gas emissions targets complemented by a market-based approach. With regard to procedural rights, Article 10(e) emphasises the need for access to information and for public participation in the implementation of the Protocol's mechanisms to achieve a reduction of emissions of at least $5 \%$ compared to the emissions levels in $1990 .{ }^{15}$ The 2015 Paris Agreement leaves the targets and climate policies to be decided at the national level and then communicated to the international level. ${ }^{16}$ Next to various provisions on mitigation and adaptation, Article 12 of the Paris Agreement refers briefly to access to information and public participation, thereby - at least - acknowledging the importance of involving the public in climate change decision making.

\subsection{The Aarhus Convention}

Among the 196 UNFCCC Parties, ${ }^{17} 44$ European countries ${ }^{18}$ are also Parties to the United Nations Economic Commission for Europe Convention on Access to Information, Public Participation in Decision-making and Access to Justice in Environmental Matters: the Aarhus

15 The first commitment period shall represent a reduction of at least 5\% GHG emissions compared to
1990 levels (Article 3(1), Kyoto Protocol). The second commitment period, 2013 to 2020, has a target
of at least $18 \%$ reduction of GHG emissions below 1990 levels (Article 3, (1 bis), Doha Amendment).
For the most updated information on the state of ratification, see: United Nations Treaty Collection.
Chapter XXVII - Environment - 7. c Doha Amendment to the Kyoto Protocol, 15 April 2019,
https://treaties.un.org/Pages/ViewDetails.aspx?src=TREATY\&mtdsg no=XXVII$13 \&$ chapter $=27 \&$ lang=en.)

16 "This [the NDCs of the Paris Agreement are a] bottom-up approach is in contrast to an approach whereby targets are imposed from 'above' in a treaty. The Kyoto Protocol has become a symbol of this failed top-down approach, and, hence, the idea of a new approach has since prevailed, creating an opportunity for another normative model" L. Boisson de Chazournes, 'One Swallow Does Not a Summer Make, but Might the Paris Agreement on Climate Change a Better Future Create?; 27(2) European Journal of International Law, (2016), pp. 253-256, p. 254.

"The Paris Agreement is an experiment in a bottom-up, managerial, transparency-building, and normbuilding approach to global cooperation. The shift in approach is a reasonable gamble in light of the failed efforts over the past two decades to implement the top-down approach under the Kyoto Protocol" M. Doelle, 'The Paris Agreement: Historic Breakthrough or High Stakes Experiment?' 6(1-2) Climate law, (2016), pp. 1-20, p. 20.

17195 States plus the European Union.

${ }^{18}$ European countries refers to the countries which comprise the geographical region of Europe in accordance with the division used by Statistics Division of the United Nations in its publications and databases. For more information see: https://unstats.un.org/unsd/methodology/m49/. 
Convention. The Convention, the first legally binding instrument that covers all fields of environmental law, codifies Principle 10 of the Rio Declaration. ${ }^{19}$ This principle highlights the importance of public participation in decision making processes, the right of the public to get access to environmental information held by public authorities and access to justice. Regarding access to information, the Aarhus Convention defines a citizen's right to request environmental information held by the government (Article 4). Moreover, the government should provide information on its own initiative in case of any imminent threat to human health or to the environment, whether caused by human activities or due to natural causes (Article 5). With regard to public participation, the Aarhus Convention foresees public participation in decisions on specific activities (Article 6); public participation concerning plans, programmes and policies relating to the environment (Article 7); and public participation during the preparation of executive regulations and/or generally applicable legally binding normative instruments (Article 8). The Aarhus Convention also contains the right of the public to address courts to enforce their right to have access to environmental information and of the public concerned to enforce their right to participate in governmental decision making (Article 9, paragraphs 1 and 2, respectively).

By incorporating ENGOs in the definition of the public and the public concerned, the Aarhus Convention gives them a status of addressees of all the rights enshrined in the Convention. It consequently empowers ENGOs to become key players in the area of procedural environmental rights. In certain areas, such as technically complex climate change decision making, ENGOs may have an advantage, relative to individuals, due to the time and resources (financial, technical and human) they possess. The complexity of climate change issues has, in turn, stimulated the specialisation of certain ENGOs in this topic. Already well-established ENGOs have created sections within their institutional framework in order to deal with climate change issues exclusively, as in the case of the World Wide Fund for Nature (WWF $)^{20}$ and Greenpeace. ${ }^{21}$ There are even ENGOs that focus only on one very precise climate change-related topic (e.g. carbon markets with Carbon Market Watch ${ }^{22}$ and Carbon Trade Watch ${ }^{23}$ ). ENGOs with the same objective also organise in networks. An example of such a network is the Climate Action Network (CAN), which aggregates 1,100 NGOs and is

\footnotetext{
${ }^{19}$ Rio Declaration on Environment and Development, UN Doc. A/CONF.151/26 (vol. I) / 31 ILM 874 (1992).

${ }^{20}$ WWF. Climate and Energy, 18 June 2020, http://wwf.panda.org/our_work/climate_and_energy/.

${ }^{21}$ Greenpeace. \#Climate, 18 June 2020, https://www.greenpeace.org/international/tag/climate/.

${ }^{22}$ Carbon Market Watch. About, 18 June 2020, http://carbonmarketwatch.org/about/.

${ }^{23}$ Carbon Trade Watch. Filling a critical vacuum, 18 June 2020, http://www.carbontradewatch.org /about-us.html.
} 
dedicated to "working to promote government and individual action to limit human-induced climate change to ecologically sustainable levels." 24

In 2011, Jeremy Wates, who, for more than a decade, served as Secretary to the Aarhus Convention, ${ }^{25}$ put forward a number of questions about the future of the Aarhus Convention: "What will be the challenges for the Convention in the second decade of the new century? Will it be a matter of incremental progress within the same basic model, or will new frontiers be opened up?"26 In the meantime, as mentioned in section 1.1, civil society increasingly takes action, including legal action, trying to stimulate governments to adopt more ambitious climate actions. One of the current challenges is therefore to what extent the Aarhus Convention indeed enables society, including ENGOs, to use procedural rights in the field of climate law, including EU climate law.

\subsection{European Union climate policy and law}

The threat of climate change has provoked a variety of legal responses aimed at mitigating greenhouse gases emissions. ${ }^{27}$ The EU, in response to its international commitments under the UNFCCC, has adopted a diverse climate change policy to reduce the greenhouse gas emissions produced by its Member States. In 2008, the European Commission announced the ' 2020 by 2020 - Europe's climate change opportunity' ${ }^{28}$ which comprised the $20-20-20$ targets: ${ }^{29}$ a) a $20 \%$ reduction in greenhouse gas emissions relative to the 1990 levels; b)

\footnotetext{
${ }^{24}$ Climate Action Network. About CAN, 18 June 2020, http://www.climatenetwork.org/about/aboutcan.

${ }^{25}$ European Environmental Bureau. What we do, 18 June 2020, https://eeb.org/work-areas/.

${ }^{26} \mathrm{~J}$. Wates, 'The future of the Aarhus Convention: Perspectives Arising from the Third Session of the Meeting of the Parties', in M. Pallemaerts (ed.), The Aarhus Convention at Ten: Interactions and Tensions between Conventional International Law and EU Environmental Law, (Groningen: Europa
} Law Publishing, 2011), p. 385.

${ }^{27}$ B. David and J. Andrew, 'Climate policy instrument choices', in D. Farber and M. Peeters (eds.), Climate change law, (Cheltenham: Edward Elgar Publishing, 2016), pp. 57-67, p. 59.

${ }^{28}$ European Commission, Communication from the Commission to the European Parliament, the Council, the European Economic and Social Committee and the Committee of the Regions 2020 by 2020 Europe's climate change opportunity, COM(20008) 30 final (2008a).

${ }^{29}$ European Council, Conclusions on 2030 Climate and Energy Policy Framework (SN 79/14) (2014b). The EU's $20 \%$ target of emissions reductions by 2020 has been contested. "The triple 20 approach as pursued by the EU is according to the IPCC projections not ambitious enough to deal effectively with climate change: developed countries should aim at 25 to $40 \%$ emission reductions by 2020" (M. Peeters, 'Instrument mix or instrument mess? The administrative complexity of the EU legislative package for climate change', in Peeters, M. and Uylenburg, R. (eds.), EU Environmental Legislation: Legal Perspectives on Regulatory Strategies, (Cheltenham: Edward Elgar, 2014), pp. 173-192, p. 184). According to the IPCC (2007), Annex-I countries (which include all EU Member States) should target between $25 \%$ to $40 \%$ emissions reductions by 2020 . S. Gupta, D. A. Tirpak, N. Burger, J. Gupta, N. 
having $20 \%$ of energy consumption produced from renewable resources, and; c) a $20 \%$ improvement in energy efficiency. In 2009, the European Union translated these commitments with the adoption of four key pieces of legislation addressing different aspects of climate and energy policy but all with the objective of reducing GHG emissions: (i) an extensive revision of the European Union Emissions Trading System (EU ETS); ${ }^{30}$ (ii) the Effort Sharing Decision, establishing targets for non-EU ETS sectors; ${ }^{31}$ (iii) the Renewable Energy Directive with renewable energy targets for the Member States; ${ }^{32}$ and (iv) a Directive on Carbon and Capture Storage. ${ }^{33}$ The area of energy efficiency was dealt with two years later starting with the 2011 Energy Efficiency Plan ${ }^{34}$ and later the Energy Efficiency Directive. ${ }^{35} \mathrm{~A}$ vast volume of literature has examined these key pieces of legislation, but there is as yet no research into whether they contain provisions regarding access to information and public participation and if so what those provisions encompass. This thesis will thus investigate how procedural rights (with a focus on access to information and public participation) are provided for at the EU level in the context of EU climate change law.

Höhne, A. I. Boncheva, G. M. Kanoan, C. Kolstad, J. A. Kruger, A. Michaelowa, S. Murase, J. Pershing, T. Saijo, A. Sari, '2007: Policies, Instruments and Co-operative Arrangements' in B. Metz, O.R. Davidson, P.R. Bosch, R. Dave, L.A. Meyer (eds), Climate Change 2007: Mitigation. Contribution of Working Group III to the Fourth Assessment Report of the Intergovernmental Panel on Climate Change, (Cambridge, New York: Cambridge University Press, 2007), p. 776.

${ }^{30}$ Directive 2009/29/EC of the European Parliament and of the Council of 23 April 2009 amending Directive 2003/87/EC so as to improve and extend the greenhouse gas emission allowance trading scheme of the Community, OJ L 140/63.

${ }^{31}$ Decision No 406/2009/EC of the European Parliament and of the Council of 23 April 2009 on the effort of Member States to reduce their greenhouse gas emissions to meet the Community's greenhouse gas emission reduction commitments up to 2020, OJ L 140/136.

32 Directive 2009/28/EC of the European Parliament and of the Council of 23 April 2009 on the promotion of the use of energy from renewable sources and amending and subsequently repealing Directives 2001/77/EC and 2003/39, OJ L 140/63, as amended by Directive (EU) 2015/1513 of the European Parliament and of the Council of 9 September 2015 amending Directive 98/70/EC relating to the quality of petrol and diesel fuels and amending Directive 2009/28/EC on the promotion of the use of energy from renewable sources, OJ L 239/1.

33 Directive 2009/31/EC of the European Parliament and of the Council of 23 April 2009 on the geological storage of carbon dioxide and amending Council Directive 85/337/EEC, European Parliament and Council Directives 2000/60/EC, 2001/80/EC, 2004/35/EC, 2006/12/EC, 2008/1/EC and Regulation (EC) No 1013/2006, OJ L 140/114.

${ }^{34}$ European Commission, Communication from the Commission to the European Parliament, the Council, the European Economic and Social Committee and the Committee of the Regions - Energy Efficiency Plan 2011(COM(2011) 109 final) (2011a).

${ }^{35}$ Directive 2012/27/EU of the European Parliament and of the Council of 25 October 2012 on energy efficiency, amending Directives 2009/125/EC and 2010/30/EU and repealing Directives 2004/8/EC and 2006/32/EC, OJ L 315/1. Hereinafter Energy Efficiency Directive or Directive 2012/27/EU. 


\section{Research questions}

Peeters emphasised more than a decade ago that "we still need to explore what the possible role of public participation and other forms of citizen involvement might [...] be within climate change policies." ${ }^{36}$ Since then, many legal measures have been adopted at the national and international level targeting the reduction of greenhouse gas emissions. However, the question of how exactly the public has access to climate-related information and how the public can participate in the climate change decision making process remains unresolved. ${ }^{37}$

The EU is a Party to the UNFCCC, which is a global treaty on combating climate change, and to the Aarhus Convention, which deals with procedural rights in all environmental areas. Therefore, the EU itself needs to comply with the international obligations stemming from these conventions and implement these obligations at the EU level. In addition, the EU has an advanced approach to reducing greenhouse gas emissions. In this vein, the combination of, on the one hand, the access to environmental information and public participation in environmental decision making, and on the other hand, the reduction of greenhouse gases, is clearly presented together in EU climate law. This combination makes the EU a very important case study to assess whether and how the two dimensions are integrated. Thus, this thesis will examine the EU's international commitments to assess which kind of obligations these entail in terms of access to environmental information and public participation in environmental decision making. Furthermore, this thesis will scrutinise how procedural rights are provided for in secondary EU climate legislation.

On this basis, the central research question examined in this thesis is:

To what extent do rights of access to environmental information and participation in governmental environmental decision making have to be provided for individuals and ENGOs at the EU level in the field of EU climate change law in the light of international treaty law, more particularly the UNFCCC and the Aarhus Convention?

\footnotetext{
${ }^{36}$ M. Peeters, 'Legislative choices and legal values: considerations on the further design of the European greenhouse gas Emissions Trading Scheme from a viewpoint of democratic accountability', in M. Faure and M. Peeters (eds.), Climate change and European emissions trading: lessons for theory and practice, (Cheltenham: Edward Elgar Publishing, 2008), pp. 17-52, p. 50.

37 This thesis concentrates on the first two pillars: access to environmental information and public participation in environmental decision making. The third pillar of environmental procedural rights is access to justice. Given its research focus, this thesis will only explore access to justice to the extent that it relates to access to environmental information and participation in environmental decision making. The multiple other aspects of the right of access to justice in environmental matters could only be properly addressed in a separate piece of research beyond the scope of this thesis.
} 
In order to answer this main question, the following four sets of sub-questions will be addressed:

- Which provisions regarding access to information and public participation are established in the UNFCCC? What kind of obligations do they entail for the Parties? (Chapter II)

- $\quad$ Does the climate change phenomenon fall under the scope of the Aarhus Convention? If yes, which obligations regarding access to information and public participation are established in the Aarhus Convention? How are they implemented at the EU level, as far as the EU institutions and bodies are concerned? (Chapter III)

- $\quad$ How does the EU legal framework provide for access to information and public participation in the context of acts adopted at the EU level under the auspices of the EU Emissions Trading System Directive? How compatible is this framework with the EU's international obligations? (Chapter IV)

- $\quad$ How does the EU legal framework provide for access to information and public participation in the context of acts adopted at the EU level for the recognition of biofuels voluntary schemes under the auspices of the Renewable Energy Directive? How compatible is this framework with the EU's international obligations? (Chapter V)

\section{Methodological approach}

\subsection{Doctrinal legal research}

Legal methodology seems to be an area in which legal scholars often avoid clear discussions. It has been said that "most jurists know how to do doctrinal work, but are not able to tell how they do what they do." ${ }^{38}$ With this in mind, the purpose of this section is to clarify how the doctrinal work was carried out for this thesis. This thesis is a doctrinal piece of legal research. The objective of this approach is to provide a "systematic description of the law in a certain field." 39 This type of research approach - which is sometimes regarded unfavourably for displaying a lack of creativity $-{ }^{40}$ still requires a creative process since the researcher, while providing such a systematic description, selects the material to be analysed, develops a

\footnotetext{
${ }^{38}$ J. Smits, 'What is Legal Doctrine?: On the Aims and Methods of Legal-Dogmatic Research' in R. van Gestel, H.-W. Micklitz and E. L. Rubin (eds.), Rethinking scholarship: a transatlantic dialogue (Cambridge, Cambridge University Press, 2017), pp. 207-228, p. 221.

39 J. Smits, 'The mind and method of the legal academic', (Cheltenham: Edward Elgar, 2012), p. 11.

${ }^{40}$ J. Smits, op. cit. (2012), p. 13.
} 
consistent and coherent interpretation and shapes the presentation of the findings. ${ }^{41}$ Furthermore, such a systematic description of the law is essential for the development of legal research and demands legal academics to have thorough knowledge of the subject matter, as explained by Richard Posner:

"The messy work product of the judges and legislators requires a good deal of tidying up, of synthesis, analysis, restatement, and critique. These are intellectually demanding tasks, requiring vast knowledge and the ability (not only brains and knowledge and judgment, but also Sitzfleisch) to organize dispersed, fragmentary, prolix, and rebarbative materials. These are tasks that lack the theoretical breadth or ambition of scholarship in more typically academic fields. Yet they are of inestimable importance to the legal system and of greater social value than much esoteric interdisciplinary legal scholarship." 42

The doctrinal research employed in this thesis first concentrates on identifying the current international legal framework for access to information and public participation in climate change decision making. It starts with the UNFCCC and then addresses the Aarhus Convention and its implementation in the European Union, as far as the EU institutions and bodies are concerned. The second part of this thesis is dedicated to the examination of the design of the aforementioned procedural rights as they operate in two legal measures adopted by the EU to tackle climate change: the EU ETS Directive and the Renewable Energy Directive. The description of the current state of the law is followed by the analysis of the compatibility of the current framework with the EU's international commitments. In fact, the thesis unveils what precise procedural rights exist in the area of EU climate law, which facilitates an improved understanding of the current state of the law, and it serves as a stepping stone towards the discussion on the future of climate change decision making.

The conclusions of the thesis are also based on the methodology of doctrinal legal research. However, there are normative consequences, as the conclusions may provide arguments and possible solutions for the potential issues discussed in the case studies. ${ }^{43}$ In this case, normative consequences do not mean trying to find what the EU ought to do beyond the framework of the legal texts by making policy recommendations, but they merely indicate how, in the case studies, the legal framework needs to be designed in order to comply with EU treaties and EU international commitments.

\footnotetext{
${ }^{41}$ J. Smits, op. cit. (2012), p. 13.

${ }^{42}$ R. A. Posner, 'In Memoriam: Bernard D. Meltzer (1914-2007)' 74(2) University of Chicago Law Review, (2007), pp. 435-438, p. 437.

${ }^{43}$ On the normative consequence of systematisation see: J. Smits, op. cit. (2012), pp. 17-20.
} 


\subsection{Case-based approach: focus on specific elements of EU climate change law}

In its geographical scope, this thesis is limited to the European Union. The EU and all its Member States are signatories to both the UNFCCC and the Aarhus Convention. However, this thesis will be limited to actions taken by the EU institutions and will, therefore, exclude national (meaning at the Member State level) actions in the field of climate change taken by Member States to implement EU law.

Furthermore, this research will focus exclusively on mitigation policy which aims to reduce GHG emissions. ${ }^{44}$ Another important area in tackling the climate change problem is adaptation policy which puts measures in place to prevent or minimise the adverse effects posed by climate change. ${ }^{45}$ Due to regional specificities and vulnerability, climate impacts are experienced differently among regions and, consequently, this demands a variety of adaptation responses. The EU strategy on adaptation takes the differences in regional needs into consideration ${ }^{46}$ and leaves the "primary responsibility for the development of adaptation strategies" with the Member States. ${ }^{47}$ Although adaptation policy is a key element in combating the impact of climate change, it is mainly developed at the Member State level. Therefore, adaptation is beyond the scope of this thesis, which aims to investigate the climate measures adopted at the EU level. ${ }^{48}$

Among the five key pieces of legislation addressing different aspects of climate mitigation policy, two core instruments were chosen to serve as a case study: the EU Emissions Trading

\footnotetext{
${ }^{44}$ K. J. Mach, S. Planton and C. von Stechow (eds.), op. cit. (2014), p. 125.

${ }^{45}$ K. J. Mach, S. Planton and C. von Stechow (eds.), op. cit. (2014), p. 118.

${ }^{46}$ European Commission, 'Questions and Answers: EU strategy on adaptation to climate change. Memo from 16 April 2013', 2013, https://ec.europa.eu/commission/presscorner/detail/en/MEMO_13_334, p. 2 .

47 D. Ellison, 'Addressing adaptation in the EU policy framework', in E. C. H. Keskitalo (ed.), Developing adaptation policy and practice in Europe: Multi-level governance of climate change, (Dordrecht: Springer, 2010), pp. 39-96, p. 47.

${ }^{48}$ Of course, the EU has an impact on the development of adaptation policies by the Member States. Apart from the EU Adaptation Strategy Package, legal measures from other different areas of the EU policy (such as transport and agriculture) may influence the adaptation strategy of Member States. E. C. H. Keskitalo, 'Introduction - Adaptation to Climate Change in Europe: Theoretical Framework and Study Design', in E. C. H. Keskitalo (ed.), Developing adaptation policy and practice in Europe : multilevel governance of climate change, (Dordrecht: Springer, 2010), pp. 1-38, p. 3.
} 
Directive (EU ETS) ${ }^{49}$ and the Renewable Energy Directive (RED). ${ }^{50}$ The justification for the selection of these two case studies is outlined below.

\subsubsection{Case study 1: The EU Emissions Trading System Directive}

The EU Emissions Trading System Directive (EU ETS) established a scheme for greenhouse gas emission allowances trading within the European Union, which began to operate in January 2005. The EU Emissions Trading Scheme, described as a "flagship measure", ${ }^{51}$ a "centre piece" 52 and a "parade horse" $" 53$ of EU climate policy, is applicable to more than 11,000 installations, which represent around $45 \%$ of the greenhouse gas emissions of the 28 Member States together with the three EEA-EFTA states. ${ }^{54}$ It also applies to the aviation sector concerning flights within this territory. ${ }^{55}$ The quantity of emissions covered and the attention it received as a core EU climate policy tool demonstrates the relevance of the ETS. Since the 2009 amendments, the structure of the EU ETS relies on a centralised approach at the EU level, which means that key decisions, such as the cap level and the allocation of allowances, are now taken by European institutions, with a key role for the European Commission. After eight years of functioning, the legal consequences of the centralisation of decision making at the EU level have started to take shape to the extent that today the legal measures adopted at the EU level and case law can be analysed. Due to its key relevance for EU climate law and the specificities of centralisation at the EU level, this directive was selected as one of the case studies.

Thus far, only a few academic papers have explored the interplay between procedural rights and the EU ETS Directive. ${ }^{56}$ Before the 2009 amendments, Jendrośka discussed how the

\footnotetext{
${ }^{49}$ Directive 2003/87/EC of the European Parliament and of the Council of 13 October 2003 establishing a scheme for greenhouse gas emission allowance trading within the Community and amending Council Directive 96/61/EC, OJ L 275/32 (consolidated version).

${ }^{50}$ Renewable Energy Directive, consolidated version.

51 S. Dimas, 'The Commission's initiatives for shaping future policy', 2005, http://europa.eu/rapid/press-release_SPEECH-05-567_en.pdf.

${ }_{52}$ M. Lee, EU environmental law, governance and decision-making, Second edition (Oxford: Hart Publishing, 2014), p. 101.

${ }^{53}$ M. Peeters and K. Deketelaere, 'Key challenges of EU climate change policy: competences, measures and compliance', in M. Peeters and K. Deketelaere (eds.), EU climate change policy: the challenge of new regulatory initiatives, (Cheltenham: Edward Elgar Publishing, 2006), pp. 3-21, p. 8.

${ }^{54}$ Norway, Liechtenstein and Iceland. As is the case in 13 of December 2019, see European Commission - DG Climate. EU Emissions Trading System (EU ETS), 20 June 2020, https://ec.europa.eu/clima/policies/ets_en.

55 The aviation sector was included under the EU ETS by an amendment introduced by Directive 2009/29/EC.

${ }^{56}$ The author would like to thank Marjan Peeters and Dyonisios Stivas for sharing their compilation on the EU ETS literature.
} 
provisions on access to information and public participation lived up to the requirements of the UNFCCC and the Aarhus Convention. He concluded that, regarding access to information and public participation, the EU ETS Directive met the requirements of the UNFCCC. ${ }^{57}$ However, in his opinion, the provisions of the Directive were not clear and detailed enough to meet the Aarhus Convention requirements. ${ }^{58}$ De Cendra de Larragán and Grimaud examined the EU ETS in view of procedural rights with a focus on access to justice. They identified the most conflictive provisions of the EU ETS Directive and the possible legal scenarios in which these provisions could be challenged. ${ }^{59}$ MacDonald and Makuch provided an interesting and thorough comparison between the EU ETS Directive, as applicable in 2006, and the Aarhus Convention. ${ }^{60}$ They found that the EU ETS Directive had some shortcomings regarding the requirements of the Aarhus Convention, but they were, mostly, overcome by amendments to the EU ETS Directive combined with other legal instruments on public participation and access to environmental information. ${ }^{61}$ By 2008, in view of the European Commission proposal to review the EU ETS Directive, Peeters had already highlighted that there was a "need to consider what the consequences of a further harmonization through the emissions trading instrument would be for public participation". ${ }^{6}$ After the 2009 amendments, which led to the centralisation of the decision making at the EU level, De Cendra de Larragán posed the question as to whether the public would be involved in the harmonised allocation measures but did not study all the provisions of the EU ETS Directive in light of public participation. ${ }^{63}$ In 2014, Van Zeben ${ }^{64}$ highlighted the importance of the discussion of procedural rights in the EU ETS context. However, none of these studies was specifically dedicated to a systematic analysis of the legal framework for access to

57 J. Jendrośka, 'Public Participation and Information in the Emissions Trading Directive' (1) Environmental Law Network International Review, (2004), pp. 7-11, p. 11.

${ }^{58}$ J. Jendrośka, op. cit. (2004), p. 11.

${ }^{59}$ D. Grimeaud and J. de Cendra de Larragán, 'Procedural rights concerning the start of the European emissions trading scheme for greenhouse gases: (information, participation and) access to justice Industry Project on equal competition and emissions trading', 2005, p. 3.

${ }^{60} \mathrm{~K}$. MacDonald and Z. Makuch, 'Emissions Trading and the Aarhus Convention: A Proportionate Symbiosis?', in Peeters, M. and Deketelaere, K. (eds.), EU Climate Change Policy: The Challenge of New Regulatory Initiatives, (Cheltenham, Northampton: Edward Elgar Publishing, 2006), pp. 125-152. ${ }^{61}$ K. MacDonald and Z. Makuch, op. cit. (2006), pp. 147-148. The authors mentioned, for instace, the amendment of Article 17 on access to information, which included the Kyoto Protocol project mechanisms and the amendment of Article 19(3) on registries, which required that information concerning the identification and use of CERs and ERUs within the ETS should also be made available on the registry. These amendments were brought by Directive 2004/101/EC.

${ }^{62}$ M. Peeters, op. cit. (2008), p. 50.

${ }^{63} \mathrm{~J}$. de Cendra de Larragán, Distributional choices in EU climate change law and policy: towards a principled approach?, (Alphen aan den Rijn: Kluwer Law International, 2011), p. 464.

${ }^{64} \mathrm{~J}$. Van Zeben, The allocation of regulatory competence in the EU emissions trading scheme, (Cambridge: Cambridge University Press, 2014), pp. 217-218. 
information and public participation within the EU ETS after its reform in 2009, including the EU's international commitments. To a certain extent, Peeters and Nóbrega fill this gap by discussing EU ETS-related cases regarding environmental procedural rights before the Court of Justice of the European Union (CJEU). ${ }^{65}$ Nevertheless, the purpose of their paper was not to provide a comprehensive analysis of the EU ETS legal framework in view of procedural rights; this analysis still needs to be undertaken.

\subsubsection{Case study 2: The Renewable Energy Directive}

The Renewable Energy Directive (RED) was adopted in 2009 with legally enforceable targets for the Member States as the main objective: i.e. achieving 20\% of renewable energy consumption in the European Union (EU) by $2020 .{ }^{66}$ Member States must also ensure that at least $10 \%$ of their transport fuels come from renewable sources by this deadline. ${ }^{67}$ The RED incentivises the use of biofuels and bioliquids by the Member States in order to achieve this $10 \%$ renewables target in transport. ${ }^{68}$ However, only sustainable biofuels can be counted by the Member States in achieving this target. ${ }^{69}$ A way of recognising these biofuels as sustainable is via the certification granted by voluntary schemes. The European Commission is responsible for recognising biofuels voluntary certification schemes, which makes this a relevant case to understand how procedural rights have been integrated into this process. The sustainability criteria ${ }^{70}$ and the recognition process of biofuels voluntary schemes have been the subject of considerable discussions, ${ }^{71}$ but an in-depth analysis of this process in view of procedural rights has yet to be undertaken.

${ }^{65}$ M. Peeters and S. Nóbrega, 'Climate Change-related Aarhus Conflicts: How Successful are Procedural Rights in EU Climate Law?' 23(3) Review of European, Comparative \& International Environmental Law, (2014), pp. 354-366, pp. 358-360. This research discussed case law until 30 November 2013.

${ }^{66}$ Article 3(1), Renewable Energy Directive, consolidated version.

${ }^{67}$ Article 3(4), Renewable Energy Directive, consolidated version.

${ }^{68}$ Recital 69, Preamble, Renewable Energy Directive, consolidated version. The directive which will address the period after 2020 foresees a renewable target in the transport sector of at least $14 \%$ by 2030. Article 25, Directive (EU) 2018/2001 of the European Parliament and of the Council of 11 December 2018 on the promotion of the use of energy from renewable sources, OJ L 328/82.

${ }^{69}$ The sustainability criteria are described in Article 17of the Renewable Energy Directive and will be explained further in Chapter V.

${ }^{70}$ T. Yue, 'Different paths towards sustainable biofuels? A Comparative Study of the International, EU, and Chinese Regulation of the Sustainability of Biofuels', (Cambridge, Antwerp, Portland: Intersentia, 2016).

${ }^{71}$ S. Ugarte, J. van Dam, S. Spijkers and M. Gaebler, 'Recognition of Private Certification Systems for Public Regulation: Lessons Learned from the EU Renewable Energy Directive', (Bonn-Berlin: Deutsche Gesellschaft für Internationale Zusammenarbeit (GIZ) GmbH, 2013). Some authors have discussed the question of the transparency of the voluntary schemes, but there is no mention of the 


\subsection{Research limitations}

Most other existing legislative acts on EU climate change and energy package are less relevant to answer the research question, since they do not foresee much action to be taken at the EU level. The Effort Sharing Decision establishes binding annual greenhouse gas emission targets for the Member States for emissions from most non-EU ETS sectors. ${ }^{72}$ In contrast, with the EU ETS, the Member States are responsible for defining and implementing measures to curb emissions from the sectors covered by the Effort Sharing Decision. ${ }^{73}$

The Energy Efficiency Directive was adopted to reach the EU's target of $20 \%$ energy efficiency by $2020 .{ }^{74}$ It establishes a number of binding measures for the Member States which are required, in all stages of the energy chain, to use energy more efficiently. The role of the European Commission is limited to guiding the Member States to implement the directive and reviewing and monitoring its implementation by the Member States. ${ }^{75}$ Therefore, the Commission does not have any role in further implementing this directive, unlike the case of the EU ETS and RED.

The same reasoning applies to another legal measure which is part of the package, namely the Carbon and Capture Storage (CCS) Directive. ${ }^{76}$ The CCS "is a suite of technological processes which involve capturing carbon dioxide $\left(\mathrm{CO}_{2}\right)$ from the gases discarded by industry and transporting and injecting it into geological formations." 77 The process is costly and the Member States are not obliged to adopt this technique in their territory. The European Commission is responsible for reporting on the implementation of the CCS Directive ${ }^{78}$ and may adopt guidelines. ${ }^{79}$ The Commission may also issue non-binding opinions on draft

Aarhus Convention. See: S. Romppanen, 'The EU's Biofuels: Certified as Sustainable?' 3(3) Renewable Energy Law \& Policy Review, (2012a), pp. 173-186, pp. 183-184.; J. Lin, 'Governing Biofuels: A principal-agent Analysis of the European Union Biofuels Certification Regime and the Clean Development Mechanism' 24(1) Journal of Environmental Law, (2011), pp. 43-73, p. 56; P. Paiement, 'Transnational delegation, accountability and the administrative governance of biofuel standards', in S. Wood, R. Schmidt, K. Abbott, B. Eberlein and E. Meidinge (eds.), Transnational business governance interactions: Enhancing regulatory capacity, ratcheting up standards and empowering marginalized Actors (Cheltenham: Edward Elgar Publishing, 2019), pp. 227-252, pp. 234-236.

${ }^{72}$ Decision No 406/2009/EC, see footnote 30.

73 The sectors which are covered by the Effort Sharing Decision are, for instance, transport, construction, agriculture, and waste.

${ }^{74}$ Directive 2012/27/EU, see footnote 34 for complete reference.

${ }^{75}$ Article 24, Directive 2012/27/EU.

${ }^{76}$ Directive 2009/31/EC, see footnote 32.

${ }^{77}$ European Commission, 'Questions and Answers on the directive on the geological storage of carbon dioxide', 2008b, https://ec.europa.eu/clima/policies/innovation-fund/ccs_en\#tab-0-3.

${ }^{78}$ Article 38(1), Directive 2009/31/EC.

${ }^{79}$ Articles 12(2), 18(2) and 20(2), 2009/31/EC. 
storage permits. ${ }^{80}$ Therefore, the duty of implementing the CCS Directive is concentrated at the Member State level with a limited role for European institutions. For this reason, it is logical to exclude the CCS Directive from the choice of case studies. Of course, for these remaining measures, research on access to information and public participation is relevant in order to gain a full picture of the developments of these rights in the national frameworks, but it falls outside of the purpose of this thesis, which aims to provide a thorough understanding of the role of procedural rights in the field of EU climate change law in as far as the EU institutions and bodies are concerned.

\section{Outline of the thesis}

In its quest to provide an understanding of procedural rights in the field of EU climate change law, this thesis proceeds as follows.

Chapters II and III set the ground for the analysis of the case studies. Chapter II examines the provisions regarding access to information and public participation contained in the international climate treaties, particularly the UNFCCC, and explores what kind of obligations these entail for the Parties. Chapter III complements the international picture by identifying the obligations emanating from the Aarhus Convention and by examining how these obligations have been implemented by the EU, as far as the EU institutions and bodies are concerned.

Chapters IV and V provide the case studies. They delve into the question of how procedural rights are provided for in two of the legal measures adopted under the EU climate policy, namely the EU ETS Directive (Chapter IV) and the Renewable Energy Directive (Chapter $\mathrm{V})$, and they assess the EU's compliance with its obligations under international law.

Chapter VI concludes by highlighting the main findings drawn from the thesis. If legal problems or shortcomings are identified, it will propose ways for the EU to ensure compliance with its international commitments regarding access to information and public participation in the field of EU climate law.

\footnotetext{
${ }^{80}$ Article 10, Directive 2009/31/EC. The European Commission has so far delivered two opinions: Commission Opinion of 28.2.2012 relating to the draft permit for the permanent storage of carbon dioxide in block section P18-4 of block section P18a of the Dutch continental shelf, in accordance with Article 10(1) of Directive 2009/31/EC of 23 April 2009 on the geological storage of carbon dioxide; and Commission Opinion of 20.1.2016 on a draft permit for the permanent storage of carbon dioxide in the depleted Goldeneye gas condensate field located in blocks 14/28b, 14/29a, 14/29e, 20/3b, 20/4b and 20/4c on the United Kingdom Continental Shelf, in accordance with Article 10(1) of Directive 2009/31/EC of 23 April 2009 on the geological storage of carbon dioxide C(2016) 152 final.
} 


\section{Chapter II - The UNFCCC requirements for access to climate information and public participation in climate change decision making}

\section{Introduction}

\subsection{Aim and structure}

The 1992 United Nations Framework Convention on Climate Change (UNFCCC) is a global treaty that aims to respond to the threats posed by climate change. The primary goal of the treaty is to reduce the level of greenhouse gas emissions entering the atmosphere. In addition to its primary goal, the Convention also stipulates in Article 6 that Parties should promote and facilitate public access to information on climate change and its effects and also public participation in addressing climate change and its effects and developing adequate responses. At the same time, Article 10(e) of the Kyoto Protocol, adopted under the umbrella of the UNFCCC, emphasises the need for access to information and for public participation in the implementation of the Protocol's mechanisms to achieve a reduction of emissions by 5\% compared to emissions in 1990. ${ }^{1}$ The Paris Agreement, which was adopted by the Parties to the UNFCCC, is the most recent international agreement in the area of climate change. ${ }^{2}$ It provides for an international regulatory structure to keep the rise in temperature well below $2^{\circ} \mathrm{C}$ above pre-industrial levels and to pursue efforts to limit the temperature increase to $1.5^{\circ} \mathrm{C}$ above pre-industrial levels. ${ }^{3}$ The Paris Agreement, in Article 12, also requires Parties to cooperate in taking measures to enhance public access to information and public participation.

\footnotetext{
${ }^{1}$ Kyoto Protocol. The first commitment period shall represent a reduction of at least $5 \%$ GHG emissions compared to 1990 levels (Article 3(1), Kyoto Protocol.) The second commitment period, 2013 to 2020, has a target of at least 18\% reduction of GHG emissions below 1990 levels (Article 3, (1 bis), Doha Amendment. For the state of ratification, see: United Nations Treaty Collection. Chapter XXVII Environment - 7. c Doha Amendment to the Kyoto Protocol, 15 April 2019, https://treaties.un.org/Pages/ViewDetails.aspx?src=TREATY\&mtdsg_no=XXVII-

13\&chapter $=27 \&$ lang=en.)

${ }^{2}$ Conference of the Parties to the UNFCC, Decision 1/CP.21 Adoption of the Paris Agreement FCCC/ /CP/2015/10/Add.1.

${ }^{3}$ Article 1, Paris Agreement.
} 
While Article 6 of the UNFCCC contains six priority areas (education, training, public awareness, public participation, public access to information, and international cooperation on these issues), this chapter focuses on the two areas which are within the scope of the main research question: access to information and public participation. By identifying which provisions are established in the UNFCCC, the Kyoto Protocol and the Paris Agreement regarding access to information and public participation and understanding what kind of obligation they entail for the Parties, including the EU, this chapter will place the first necessary building block to answer the overarching question of this thesis: To what extent do rights of access to environmental information and participation in governmental environmental decision making have to be provided for individuals and ENGOs at the EU level in the field of EU climate law?

The chapter is structured as follows. The current section continues with an explanation of the research approach applied in this chapter. Section 2 provides a legal interpretation of Article 6 of the UNFCCC through the rules enumerated in the Vienna Convention on the Law of Treaties. ${ }^{4}$ Section 3 examines Article 10(e) of the Kyoto Protocol and section 4 examines Article 12 of the Paris Agreement in order to identify whether these provisions go beyond Article 6 of the UNFCCC or not. Section 5 provides concluding remarks as to which kind of obligations concerning access to information and public participation in climate change decision making are established that the Parties should implement at the domestic level under the three agreements.

\subsection{Research approach}

This chapter intends to identify which kind of obligations regarding access to information and public participation in climate change decision making emanate from the international level for the EU and other treaty Parties.

As Mayer explained, two types of obligations can be distinguished. ${ }^{5}$ The first type of obligations require a specific result, while the second type of obligations require that an honest endeavour is made. ${ }^{6}$ The first type of obligations are called obligations of result, and the second type of obligations are commonly referred to as obligations of conduct. The distinction can be used as a tool to interpret obligations with regard to climate change

\footnotetext{
${ }^{4}$ Vienna Convention on the Law of Treaties, Vienna on 23 May 1969, Treaty Series, vol. 1155, p. 331 (entered into force on 27 January 1980).

${ }^{5}$ B. Mayer, 'Obligations of conduct in the international law on climate change: A defence' 27(2) Review of European, Comparative \& International Environmental Law, (2018), pp. 130-140, p. 130.

${ }^{6}$ B. Mayer, op. cit. (2018), p. 130. Or differently phrased by Mayer: "An obligation of conduct requires one to try", B. Mayer, op. cit. (2018), p. 137.
} 
mitigation. ${ }^{7}$ However, in the area of international environmental law, for instance, Rajamani ${ }^{8}$ and $\mathrm{Hey}^{9}$ have used the terminology obligations of effort (instead of obligation of conduct) to characterise an obligation to make best efforts to achieve an objective. This aligns with the definition elaborated in civil law typology, ${ }^{10}$ in which an obligation of conduct is an "obligation de s'efforcer", i.e., an obligation to strive for or to make an effort towards a certain result. ${ }^{11}$ Therefore, the terms obligations of conduct and obligations of effort define the same kind of obligations. In this thesis, the term obligations of effort will be used throughout the text, since the term gives a clear and straightforward message that such obligations require efforts from the Parties towards the achievement of a goal.

The distinction between obligations of effort and of result has been applied by the International Court of Justice (ICJ). The ICJ found regarding the obligation of result that:

"[...] the obligation [...] is one of result — that is to say, an obligation which requires a specific outcome. [...] The Court observes that this obligation of result is one which must be met within a reasonable period of time." 12

Concerning the obligation of effort, for which the Court prefers to use the term obligation of conduct over obligation of effort, the ICJ affirmed that:

"it is clear that the obligation in question is one of conduct and not one of result, in the sense that a State cannot be under an obligation to succeed, whatever the circumstances, in preventing the commission of genocide: the obligation of States parties is rather to employ all means reasonably available to them, so as to prevent genocide so far as possible. A State does not incur responsibility simply because the desired result is not achieved; responsibility is however incurred if the State

\footnotetext{
${ }^{7}$ As stated by B. Mayer, op. cit. (2018), p. 130.

${ }^{8}$ L. Rajamani, 'The United Nations Framework Convention on Climate Change: a framework approach to climate change', in D. A. Faber and M. Peeters (eds.), Climate Change Law, (Cheltenham, UK: Edward Elgar Publishing, 2016), pp. 205-216, p. 208.

${ }^{9}$ E. Hey, Advanced Introduction to International Environmental Law, (Cheltenham, Northampton: Edward Elgar Publishing, 2016), p. 92.

${ }^{10}$ P.-M. Dupuy, 'Reviewing the difficulties of codification: on Ago's classification of obligations of means and obligations of result in relation to state responsibility' 10(2) European Journal of International Law, (1999), pp. 371-385, p. 375. See also Mayer, 2018, p.130, who states that the distinction is drawn from civil law tradition.

${ }^{11} \mathrm{~J}$. Combacau, 'Obligations de résultat et obligations de comportement: quelques questions et pas de réponse' Le droit international: unité et diversité. Mélanges offerts à Paul Reuter, (1981), pp. 181204, p. 194.

${ }^{12}$ Request for Interpretion of the Judgment of 31 March 2004 in the Case Concerning Avena and other Mexican Nationals (Mexico v. United States of America), 19 January 2009, para 27.
} 
manifestly failed to take all measures to prevent genocide which were within its power, and which might have contributed to preventing the genocide."13

Nonetheless, the use of the distinction between obligations of effort and of result is not uncontroversial. ${ }^{14}$ The Draft Articles on Responsibility of States for Internationally Wrongful Acts adopted by the International Law Commission do not require a distinction to be made between obligations of effort and obligations of result.$^{15}$ The final idea presented in the draft is that the differentiation among obligations does not help to define the breach, but rather it "depends on the precise terms of the obligation, its interpretation and application, taking into account its object and purpose and the facts of the case." ${ }^{\prime 16}$ While taking into account that, a precise interpretative exercise always has to be carried out for each provision, the distinction between obligations of effort and obligations of result remains relevant in the area international law, in general, ${ }^{17}$ and of international environmental law, in particular, as it has been used while investigating the nature of the legal obligations of environmental treaty provisions in order to ascertain what conduct should be expected from the Contracting Parties. ${ }^{18}$ According to Bodansky, "international environmental lawyers commonly refer to requirements to do particular things as obligations of conduct, and obligations to achieve particular results as obligations of result." ${ }^{19}$ Considering the distinction between obligations of effort and of result a non-excessively complicated way of demonstrating which kind of

\footnotetext{
${ }^{13}$ Application of the Convention on the Prevention and Punishment of the Crime of Genocide (Bosnia and Herzegovina v. Serbia and Montenegro), 26 February 2007, para 430.

${ }^{14}$ T. M. Thorp, Climate justice: a voice for the future, (New York: Palgrave Macmillan, 2014), p. 197. Thorp uses the term obligation of conduct.

${ }^{15}$ Nevertheless, paragraph 11 of the commentary to article 12 is dedicated to the distinction between obligations of conduct and of result. International Law Commission, 'Draft articles on responsibility of states for internationally wrongful acts, with commentaries' 2 (Part II) Yearbook of the International Law Commission, A/56/10, (2001), pp. 31-143, pp. 56-57. The future steps to be taken regarding the draft articles on the responsibility of states for internationally wrongful acts is still under discussion by the General Assembly of the United Nations. For further details on the developments, see: https://www.un.org/en/ga/sixth/74/resp_of_states.shtml, 10 January 2020.

${ }^{16}$ International Law Commission, op. cit. (2001), p. 54 (commentary in Article 12, para 1).

${ }^{17}$ C. P. Economides, 'Content of the Obligation: Obligation of Means and Obligation of Result', in J. Crawford, A. Pellet, S. Olleson and K. Parlet (eds.), The Law of International Responsibility, (Oxford: Oxford University Press, 2010), pp. 371-381, pp. 377-379.

${ }^{18}$ For examples of authors in the area of environmental law who apply this distinction, see: C. Voigt, 'The Paris Agreement: What is the Standard of Conduct for Parties?' 24 Questions of International Law, (2016), pp. 17-28, and L. Rajamani, op. cit. (2016) and C. P. Economides, op. cit. (2010).
}

19 D. Bodansky, 'The art and craft of international environmental law', 2010, http://public.eblib.com/choice/publicfullrecord.aspx?p=3300858, p. 76. 
conduct is required by the Parties, ${ }^{20}$ this classification will be used throughout this thesis as a way of encompassing in one term the result of the interpretation of a provision.

Given that a thorough interpretation of the treaty provisions requires that all aspects of the agreement are taken into account, ${ }^{21}$ the next section will carry out an interpretation of Article 6 (a)(ii) and (iii) of the UNFCCC relying on the rules of interpretation of the Vienna Convention on the Law of the Treaties (VCLT), especially on Articles 31 and 32. Paragraphs 1 and 2 Article 31 of the VCLT establish that a treaty should be interpreted through the ordinary meaning, context, object, and purpose; and paragraph 3 allows for subsequent agreement and practice in the application or interpretation of a treaty to be taken into account while interpreting a treaty. ${ }^{22}$ Article 32 of the VCLT foresees that recourse may be had to

\footnotetext{
${ }^{20}$ T. M. Thorp, op. cit. (2014), p. 197.

${ }^{21}$ M. N. Shaw, International law, Seventh Edition (Cambridge: Cambridge University Press, 2014), p. 676.

${ }^{22}$ Article 31 of the VCLT reads as follow:
}

"1. A treaty shall be interpreted in good faith in accordance with the ordinary meaning to be given to the terms of the treaty in their context and in the light of its object and purpose.

2. The context for the purpose of the interpretation of a treaty shall comprise, in addition to the text, including its preamble and annexes:

(a) any agreement relating to the treaty which was made between all the parties in connection with the conclusion of the treaty;

(b) any instrument which was made by one or more parties in connection with the conclusion of the treaty and accepted by the other parties as an instrument related to the treaty.

3. There shall be taken into account, together with the context:

(a) any subsequent agreement between the parties regarding the interpretation of the treaty or the application of its provisions;

(b) any subsequent practice in the application of the treaty which establishes the agreement of the parties regarding its interpretation;

(c) any relevant rules of international law applicable in the relations between the parties.

4. A special meaning shall be given to a term if it is established that the parties so intended. This provision establishes that a treaty should be interpreted through ordinary meaning, context, object and purpose." 
supplementary means of interpretation of a treaty. ${ }^{23}$ These rules are widely accepted and fall within the realm of customary law, ${ }^{24}$ and they are, consequently, applicable to all treaties. ${ }^{25}$

\title{
2. Access to information and public participation under the UNFCCC
}

\subsection{Introduction to Article 6 of the UNFCCC}

An interpretation of Article 6 of the UNFCCC will allow for it to be clarified what Parties have to do precisely in order to comply with it. ${ }^{26}$ Article 6 contains six priority areas: education, training, public awareness, public participation, public access to information, and

${ }^{23}$ Article 32 of the VCLT reads as follow:

\begin{abstract}
"Recourse may be had to supplementary means of interpretation, including the preparatory work of the treaty and the circumstances of its conclusion, in order to confirm the meaning resulting from the application of article 31 , or to determine the meaning when the interpretation according to article 31 :
\end{abstract}

(a) leaves the meaning ambiguous or obscure; or

(b) leads to a result which is manifestly absurd or unreasonable."

${ }^{24}$ R. K. Gardiner, Treaty interpretation, (Oxford: Oxford University Press, 2008), pp. 12-13.

${ }^{25}$ M. M. Mbengue, 'Rules of Interpretation (Article 32 of the Vienna Convention on the Law of Treaties)' 31(2) ICSID Review-Foreign Investment Law Journal, (2016), pp. 388-412, p. 388.

${ }^{26}$ Article 6 reads as follows:

"In carrying out their commitments under Article 4, paragraph 1 (i), the Parties shall:

(a) Promote and facilitate at the national and, as appropriate, subregional and regional levels, and in accordance with national laws and regulations, and within their respective capacities:

(i) the development and implementation of educational and public awareness programmes on climate change and its effects;

(ii) public access to information on climate change and its effects;

(iii) public participation in addressing climate change and its effects and developing adequate responses; and

(iv) training of scientific, technical and managerial personnel;

(b) Cooperate in and promote, at the international level, and, where appropriate, using existing bodies:

(i) the development and exchange of educational and public awareness material on climate change and its effects; and

(ii) the development and implementation of education and training programmes, including the strengthening of national institutions and the exchange or secondment of personnel to train experts in this field, in particular for developing countries." 
international cooperation on these issues. ${ }^{27}$ In view of the focus of this thesis, only two of these areas will be analysed: access to information (paragraph (a)(ii)) and public participation (paragraph (a)(iii)). ${ }^{28}$

In the vein of the VCLT, as explained in section 1.2, the following section 2.2 will provide an analysis of the literal meaning of the terms contained in Article 6 (a)(ii) and (iii) in context with the other provisions and the purpose and objective of the UNFCCC. Section 2.2.3 will analyse whether decisions by the CoP regarding Article 6 may be understood as subsequent agreement and practice within the meaning of Article 31(3) VCLT and, consequently, used for the interpretation of Article 6 (a)(ii) and (iii).

According to Article 32 of the VCLT, preparatory works and the circumstances of the conclusion of the treaty are to be used as a supplementary means of interpreting a treaty. The fact that this approach is supplementary does not mean that the analysis must be done in sequence. As stated by Gardiner, in some cases, it becomes more practical to first present the history of the provision and then follow with the application of the general rules of Article $31 .^{29}$ Although the circumstances of the time of the adoption of the text of the UNFCCC will be presented first in section $2.2 .1{ }^{30}$ they will only be used in combination with the interpretation that follows from the application of the general rules contained in Article 31 VCLT. ${ }^{31}$ For the purpose of the analysis carried out in this chapter, not to follow the sequence provided in the articles does make sense, since the contextualisation of the historical aspects will, in this way, be presented in a more coherent manner. Furthermore, starting the analysis with the historical circumstances leading up to the signing of the convention follows a chronological order that will ensure clearer results of the interpretative exercise.

\subsection{Circumstances of the drafting and conclusion of the UNFCCC}

2.2.1. Circumstance of the drafting: a choice for a framework convention

\footnotetext{
${ }^{27}$ L. Paas, Action for climate empowerment: guidelines for accelerating solutions through education, training and public awareness (Paris: UNESCO Publishing, 2016), p. VI.

${ }^{28}$ International cooperation, which is dealt with in paragraph b of Article 6, is also excluded, since the aim is to examine which obligations the Parties will have to implement at the national level ultimately.

${ }^{29}$ R. K. Gardiner, op. cit. (2008), p. 10.

${ }^{30}$ It has also been done in treaty interpretations by courts, as exemplified by R. K. Gardiner, op. cit. (2008), p. 41.

${ }^{31}$ In this vein, Article 32 VCLT is not used as "autonomous method $\mathrm{f}$ or interpretation, divorced from the general rule." I Sinclair, The Vienna Convention on the Law of Treaties (1984), 116 cited by A. Orakhelashvili, The interpretation of acts and rules in public international law, (Oxford: Oxford University Press, 2008), p. 312.
} 
The UNFCCC is part of a broader movement that began in the 1970s which regulated international environmental issues using a framework treaty. ${ }^{32}$ This trend involved the adoption of a treaty with general provisions which, at a later stage, could be complemented by more specific international regulations, usually in the form of protocols. As was the case for many other environmental issues, the flexible characteristics of a framework convention were suitable for addressing climate change. ${ }^{33}$ Despite the fact that there exists no precise definition of the term framework convention in international law, ${ }^{34}$ it is possible to say that framework conventions generally follow two steps: i) the adoption of a convention with general provisions; ii) followed by the adoption of subsequent instruments with more detailed obligations. ${ }^{35}$ The first step helps in achieving an agreement collectively, while the second step allows for further commitments in the form of more specific obligations which have to be negotiated and ultimately adopted by the Parties. In other words, in a framework convention, the scope and content of the provisions are first put forward in a general way, while the more specific provisions should follow in a subsequent legal instrument, such as a protocol or a regulatory annex. ${ }^{36}$ Most of the framework provisions function as guidelines for further decision making. The UNFCCC has been considered to be somewhere between a framework and a substantive agreement, ${ }^{37}$ since it also contains provisions that attempt to impose specific commitments on the Parties, ${ }^{38}$ such as the obligation to reduce GHG emissions and a time limit for achieving this obligation. ${ }^{39}$ As Bodansky highlights, this is a

32 N. Matz-Luck, 'Framework conventions as a regulatory tool' 1(3) Goettingen Journal of International Law, (2009), pp. 439-458, p. 440.

${ }^{33}$ For an analysis of framework conventions, see N. Matz-Luck, op. cit. (2009). For an analysis of the framework approach to climate change, see L. Rajamani, op. cit. (2016), pp. 215-216.

34 D. Bodansky, 'The Framework Convention/Protocol Approach' Paper 1(WHO/NDC/TFI/99.1) Framework Convention on Tobacco Control - Technical Briefing Series, (1999), pp. 15-40, p. 15.

35 According to Bodansky, "a variety of international agreements whose principal function is to establish a general system of governance for an issue area, and not detailed obligations. [...] The socalled framework convention/protocol approach to international lawmaking allows States to proceed incrementally. First, the framework convention establishes the general norms and institutions of the regime $[\ldots]$. Then, the protocols build on the parent agreement through the elaboration of additional (or more specific) commitments and institutional arrangements" D. Bodansky, op. cit. (1999), p. 15.

Kiss and Shelton states that "the technique of 'framework convention' means that a convention of general scope is adopted, proclaiming basic principles on which consent can be achieved. The parties foresee the elaboration of additional protocols containing more detailed obligations.” A. Kiss and D. Shelton, International Environmental Law, 3rd [rev.] ed. (Ardsley: Transnational Publishers, 2004), p. 78.

${ }^{36}$ D. Bodansky, op. cit. (1999), p. 21.

${ }^{37}$ D. Bodansky, 'The United Nations Framework Convention on Climate Change: a commentary' 18(2) Yale Journal of International Law, (1993), pp. 451-558, p. 496. L. Rajamani, op. cit. (2016), p. 206.

${ }^{38}$ Rajamani has stated that "FCCC Article 4(2) containing specific and quantitative commitments is limited to Annex I Parties”, L. Rajamani, op. cit. (2016), p. 207.

${ }^{39}$ Article 4 (2), UNFCCC. 
result of some Parties' wishes to include specific commitments in the convention, but the result is a rather unclear provision, the legal effects of which are uncertain. ${ }^{40}$ Furthermore, as argued by Rajamani, even the specific and quantitative commitment of reducing GHG emissions is characterised by an obligation of effort, since the provision prescribes a target for developed countries but it only requires Parties to aim at achieving it. ${ }^{41}$

\subsubsection{Circumstances of conclusion}

The UNFCCC took a different step than previous framework conventions by introducing provisions in its text on education, training, and public awareness. ${ }^{42}$ In order to understand the reason the Parties decided to incorporate provisions on education, training and public awareness, despite the UNFCCC not being a human rights treaty, an investigation of the documents from the negotiations and from the literature on the topic follows below.

The UNFCCC emerged from the United Nations Conference on Environment and Development (UNCED) held in Rio de Janeiro in $1992 .{ }^{43}$ At the time of the negotiations and this is still the case today - there was no global convention addressing environmental procedural rights. ${ }^{44}$ It was during the Rio de Janeiro Earth Summit - which resulted in, among other documents, the Rio Declaration and the UNFCCC - that attention was given to procedural rights. Principle 10 of the Rio Declaration calls on states to find ways to facilitate access to information and public participation and, at the same time, to create mechanisms to enforce these rights via judicial remedies. ${ }^{45}$ The decision to include Article 6 in the UNFCCC

${ }^{40}$ D. Bodansky, op. cit. (1999), p. 21.
${ }^{41}$ L. Rajamani, op. cit. (2016), p. 208.
${ }^{42}$ D. Bodansky, op. cit. (1993), pp. 510 , footnote 355.1992 introduced the inclusion of such provisions. The other two conventions that were opened for signature at the Earth Summit in Rio also contain provisions in the area of access to information and public participation. The Convention on Biological Diversity foresees public education and awareness in Article 13, and public participation in the context of impact assessment and minimising adverse impacts in Article 14. The Convention to Combat Desertification provides for capacity building, education and public awareness in Article 19.

${ }^{43}$ United Nations Conference on Environment and Development (UNCED), (Rio de Janeiro, 3-14 June 1992).

${ }^{44}$ J. Razzaque, 'Human rights to a clean environment: procedural rights', in M. Fitzmaurice, D. M. Ong and P. Merkouris (eds.), Research handbook on international environmental law, (Cheltenham, Northampton: Edward Elgar, 2010), pp. 284-300, p. 292.

${ }^{45}$ Principle 10 of the Rio Declaration states: "Environmental issues are best handled with participation of all concerned citizens, at the relevant level. At the national level, each individual shall have appropriate access to information concerning the environment that is held by public authorities ... and the opportunity to participate in decision-making processes. States shall facilitate and encourage public awareness and participation by making information widely available. Effective access to judicial and administrative proceedings, including redress and remedy, shall be provided." 
was, possibly, influenced by the general atmosphere of negotiations at the Earth Summit, which also included the adoption of principle 10 of the Rio Declaration. ${ }^{46}$

The negotiations of the UNFCCC were conducted by an Intergovernmental Negotiating Committee (INC). Provisions on access to information and public participation were not included in its consolidated draft version of the future text of the convention for negotiation. ${ }^{47}$ The negotiating documents reveal that one delegation introduced a draft proposal orally on "Education, training and public awareness", but it does not make clear which one. ${ }^{48}$ Bodansky states that later, "a small group met in Nairobi to draft what is now Article 6" without, however, mentioning the name of the members of this group. ${ }^{49}$ Therefore, the documents from the negotiations do not shed light on the reasons for the adoption of Article 6 of the UNFCCC nor which countries (or persons) paved the way for its inclusion.

2.3. Plain meaning of the terms in context and in the light of object and purpose of the UNFCCC

Article 6(a)(ii) and (iii) of the UNFCCC reads as follows:

"In carrying out their commitments under Article 4, paragraph 1 (i), the Parties shall:

Promote and facilitate at the national and, as appropriate, subregional and regional levels, and in accordance with national laws and regulations, and within their respective capacities:

$[\ldots]$

(ii) public access to information on climate change and its effects;

(iii) public participation in addressing climate change and its effects and developing adequate responses." (emphasis added)

The discrete elements of Article 6 highlighted above will be addressed in turn.

\footnotetext{
${ }^{46}$ Even if it is outside of the scope of the present research, it is interesting to note that, although Principle 10 of the Rio Declaration emphasises the importance of access to justice to handle environmental issues, Article 6 of the UNFCCC is silent on this issue and, therefore, does not impose obligations regarding access to justice.

${ }^{47}$ Intergovernmental Negotiating Committee for a Framework, 'Single Text on Elements Relating to Mechanisms', 1991b.

${ }^{48}$ Intergovernmental Negotiating Committee for a Framework, Report of the Intergovernmental Negotiating Committee for a Framework Convention on Climate Change on the Work of its Third Section, held at Nairobi from 9 to 20 September 1991 (A/AC.237/12) (1991a), para 44.

${ }^{49}$ D. Bodansky, op. cit. (1993), p. 488.
} 


\subsection{1. "In accordance with national laws and regulations"}

While promoting and facilitating public access to information on climate change and public participation in addressing climate change, Article 6 requires Parties to do so in accordance with national laws and regulations. This suggests that, although Parties have to implement Article 6 obligations, it can be done with some flexibility, particularly in view of the rules established at the national level. In other words, this terminology gives Parties some room with regard to how they implement the provision.

\subsection{2. "Within their respective capacities"}

Article 6 of the UNFCCC is under the title of education, training and public awareness, and it is connected to Article 4(1)(i) of the UNFCCC, meaning that the Parties need to fulfil their obligations as prescribed by Article 4(1)(i) while observing the requirements of Article 6. Article 4 is under the title commitments, ${ }^{50}$ and it addresses different kinds of commitments the Parties need to fulfil in relation to the objective of the Convention to stabilise greenhouse gases in order to prevent hazardous anthropogenic interference with the climate system.

Article 4(1)(i), to which Article 6 refers, determines that all Parties must be committed to promoting education, training, public awareness, and encourage the widest participation in this process, including that of non-governmental organisations. These duties have to be carried out according to their common but differentiated responsibilities. ${ }^{51}$ States' common but differentiated responsibilities (CBDR) are recognised in Article 3(1) of the UNFCCC. ${ }^{52}$ The concept of CBDR basically entails that, due to differences in states' economic and technical capacities, and also due to the varying contributions of developing and developed countries to global environmental degradation, Parties should not be subjected to the same responsibilities under international environmental law. ${ }^{53}$ In the context of Article 4(1)(i), CBDR implies that all Parties have a common responsibility to promote and cooperate in education, training and public awareness and to encourage participation, but this responsibility is to be implemented in a differentiated manner among Parties, in view of their

\footnotetext{
${ }^{50}$ Titles of the articles do not reveal content as explained by footnote in Article 1 of the UNFCCC, which states that "Titles of articles are included solely to assist the reader."

${ }^{51}$ Article 4, heading, UNFCCC.

${ }^{52}$ It is also recognised in Principle 7 of the Rio Declaration.

${ }^{53}$ U. Beyerlin, 'Different Types Of Norms In International Environmental Law Policies, Principles, And Rules', in D. Bodansky, J. Brunnée and E. Hey (eds.), The Oxford Handbook of International Environmental Law, (Oxford: Oxford University Press, 2007), pp. 441-442. D. Shelton, 'Equity', in D. Bodansky, J. Brunnée and E. Hey (eds.), The Oxford Handbook of International Environmental Law, (Oxford: Oxford University Press, 2007), pp. 639-662, pp. 656-658.
} 
regional development priorities, objectives and circumstances. ${ }^{54}$ It is still not clear how the reference to CDBR in Article 4(1)(i) of the UNFCCC should be interpreted in view of Article 6. For instance, it may be questioned whether the same interpretation of this principle should be applied as of that which was developed in the context of emission reductions where particularly the economic situation of the country is decisive ${ }^{55}$ For example, in the Kyoto Protocol, emission-reduction targets were adopted only for developed countries. Applying the same reasoning to the procedural requirements would mean that a developing country would have a less stringent obligation to promote public awareness and encourage participation in climate change-related issues. Thus, a country such as Tuvalu, whose emissions "are less than $0.000005 \%$ of global emissions", ${ }^{56}$ but which will very likely face the devastating consequences of climate change in this century, ${ }^{57}$ would have a less onerous obligation to inform the public of the threats of climate change than a country responsible for a larger proportion of GHG emissions. This seems to be an unreasonable outcome of applying CBDR since, in fact, the Tuvaluan public needs access to a great deal of information on climate change and its effects in order to develop adequate responses. In order to be consistent in relation to the purpose of the UNFCCC to achieve the "stabilization of greenhouse gas concentrations in the atmosphere at a level that would prevent dangerous anthropogenic interference with the climate system", ${ }^{58}$ Article 4(1)(i) of the UNFCCC could rather be interpreted as requiring developed countries to help developing countries to implement their awareness and participation obligations properly, in light of the reduced capacity of the latter group of countries to do so.

Furthermore, some textual remarks can be made as to how CBDR is formulated in the UNFCCC. The CBDR principle is first mentioned in the UNFCCC in Article 3(1), which is under the title of principles. ${ }^{59}$ There, the CBDR principle is accompanied by the term "respective capabilities". This has led authors to call it the principle of CBDR\&RC. ${ }^{60}$

\footnotetext{
${ }^{54}$ Article 4 of the UNFCCC reads: " 1 . All Parties, taking into account their common but differentiated responsibilities and their specific national and regional development priorities, objectives and circumstances, shall: [...]".

55 Article 4(4), Paris Agreement, where developed countries should continue taking the lead by undertaking economy-wide absolute emission reduction targets.

56 Government of Tuvalu, 'Intended Nationally Determined Contributions Communicated to the UNFCCC on 27 November 2015', 2015, p. 4.

${ }^{57}$ Intergovernmental Panel on Climate Change, Climate Change 2014: Synthesis Report. Contribution of Working Groups I, II and III to the Fifth Assessment Report of the Intergovernmental Panel on Climate Change (2014c), 67.

${ }^{58}$ Article 2, UNFCCC.

${ }^{59}$ Titles of the articles do not reveal content as explained by footnote in Article 1 of the UNFCCC, which states that "Titles of articles are included solely to assist the reader."

${ }^{60}$ D. Bodansky, J. Brunnée and L. Rajamani, 'International climate change law': Oxford University Press, 2017); C. Voigt and F. Ferreira, “Dynamic Differentiation': The Principles of CBDR-RC,
} 
Rajamani and Winkler argue that "the use of the term 'respective capabilities' in addition to CBDR suggests that there are two bases for differentiation - one based on capability, and another that draws from Rio Principle 7 which contains a definition of CBDR based on the contribution to environmental harm."

In Article 4.1 of the Convention, instead of "respective capabilities", the CBDR is accompanied by "their specific national and regional development priorities, objectives and circumstances" when referring to the commitments of the Parties. It could be argued that "their specific national and regional development priorities, objectives and circumstances" is equivalent to "respective capabilities", since both terms allow for a balance of responsibilities between countries with different capabilities. In this vein, the two bases for differentiation described by Rajamani and Winkler would also be covered in Article 4(1), since CBDR and a differentiation based on the capability are both mentioned.

Interestingly, Article 6 mentions "respective capacities" instead of "respective capabilities". Rajamani seems to use these terms interchangeably since, while referring to the two bases of differentiation, she also refers to differing capacities: "the notion of differentiated responsibility derives both from the differing contributions of states to climate change and the differing capacities of states to take remedial measures." (emphasis added) ${ }^{62}$ Assuming that the terms are interchangeable, there is no doubt that one needs to take into account the potential of each Party to implement the commitments.

\subsection{3. "Public access to information on climate change and its effects"}

Article 6 (a)(ii) of the UNFCCC requires Parties to promote and facilitate "public access to information on climate change and its effects". The term climate change is defined by the Convention as "a change of climate which is attributed directly or indirectly to human activity that alters the composition of the global atmosphere and which is in addition to natural climate variability observed over comparable time periods". ${ }^{63}$ The term effects is used without making a distinction between positive and adverse effects. The text of the convention only defines adverse effects of climate change as "changes in the physical environment or biota resulting from climate change which have significant deleterious effects on the composition, resilience or productivity of natural and managed ecosystems or on the

\footnotetext{
Progression and Highest Possible Ambition in the Paris Agreement' 5(2) Transnational Environmental Law, (2016), pp. 285-303; H. Winkler and L. Rajamani, 'CBDR\&RC in a regime applicable to all' 14(1) Climate Policy, (2014), pp. 102-121.

${ }^{61}$ H. Winkler and L. Rajamani, op. cit. (2014), p. 104.

${ }^{62}$ L. Rajamani, 'The Nature, Promise, and Limits of Differential Treatment in the Climate Regime' 16(1) Yearbook of International Environmental Law, (2005), pp. 81-118, doi: 10.1093/yiel/16.1.81, p. 100.

${ }^{63}$ Article 1(2), UNFCCC.
} 
operation of socio-economic systems or on human health and welfare."64 Since Article 6(a)(ii) makes no distinction between the effects, it can validly be argued that both positive and negative effects are encompassed by the use of the term effects. The inclusion of positive effects might be relevant in cases such as the one described by the IPCC: with medium confidence, "climate change is likely to increase cereal crop yields in northern Europe". ${ }^{65}$ Considering that Article 6(a)(ii) makes no distinction among the types of effect, information on these possible positive effects are also included among the effects of climate change. In sum, it can be argued that all effects, whether positive or negative, should be subject to public access to information obligations.

Regarding the beneficiaries of the provision, Article 6(a)(ii) points to public access without any definition of the term. Therefore, in the absence of a definition, it is possible to assume that Article 6 of the UNFCCC does not intend to limit this to any segment of society. In this sense, anyone, including both legal and natural persons, are beneficiaries and there is no restriction as to who may have access to information.

Article 6 (a)(ii) does not explicitly regulate to what extent information used by governments for decision making related to climate change and its effects must also be made accessible to the public. This decision making, for instance, concerns the climate change mitigation policies and particularly measures to reduce greenhouse gas emissions. It is, however, not clearly stipulated whether Parties are under the obligation to promote and facilitate public access to information regarding these policies, since it is not certain how broad the access to information provision which relates to "climate change and its effects" is to be interpreted and whether specific information held by the government has to be disclosed to the public. ${ }^{66}$ It is for instance not clear whether the amount of emissions produced by a sector or an individual installation is covered by Article 6. Given the institutional framework of the UNFCCC, which allows the Conference of the Parties (CoP) "to make recommendations on any matters necessary for the implementation of the Convention", ${ }^{67}$ the CoP could provide for clarification on the interpretation of the exact coverage and application of Article 6.

\footnotetext{
${ }^{64}$ Article 1(1), UNFCCC.

${ }^{65}$ Intergovernmental Panel on Climate Change, Climate Change 2014: Impacts, Adaptation, and Vulnerability. Part A: Global and Sectoral Aspects. Contribution of Working Group II to the Fifth Assessment Report of the Intergovernmental Panel on Climate Change (2014a), p. 75.

${ }^{66}$ Regarding grounds for refusal as regulated by the Aarhus Convention and implemented by the EU, see Chapter III, section 5.3.

${ }^{67}$ Article 7(2)(g), UNFCCC.
} 
2.3.4. "Public participation in addressing climate change and its effects and developing adequate responses"

According to Article 6 (a)(iii) of the UNFCCC, Parties shall also promote and facilitate "public participation in addressing climate change and its effects and developing adequate responses". Due to the broad formulation mentioning "addressing climate change and its effects", and particularly by referring to "developing adequate responses", both mitigation and adaptation measures are covered by the provision. The fact that Parties are under an obligation to promote and facilitate public participation implies that sufficient information needs to be made available in order to allow the public to participate effectively in the decision making process.

Regarding the beneficiaries in relation to access to information, Article 6 (a)(iii) of the UNFCCC mentions public participation without making any exception. Therefore, a reasonable interpretation is to consider all individual and legal persons as potential beneficiaries. In conclusion, given the broad formulation of the provision, the latter can be interpreted as meaning that governments should involve the public while developing their climate policies. ${ }^{68}$

\subsection{Subsequent agreement and subsequent practice: work programmes}

According to Article 31(3)(a) and (b) of the VCLT, an interpretation of a treaty may take into account, together with the context, "any subsequent agreement between the parties regarding the interpretation of the treaty or the application of its provision," and "any subsequent practice in the application of the treaty which establishes the agreement of the parties regarding its interpretation", respectively.

Article 6 of the UNFCCC was further developed by work programmes adopted through the Conference of the Parties (CoP) decisions. ${ }^{69}$ The CoP was established "to make, within its mandate, the decisions necessary to promote the effective implementation of the Convention". ${ }^{70}$ Therefore, the CoP decisions may not deviate from obligations established in the UNFCCC. Furthermore, the Convention does not establish a clear mandate for the CoP to adopt legally binding decisions. There is currently no consensus on whether CoP decisions are legally binding. Bodle and Oberthür state that CoP decisions are not legally binding per

\footnotetext{
68 Thus far, no further discussion has been carried out on the meaning of this provision in the legal scholarship.

${ }^{69}$ Using the format of work programmes contrasts with the quantified emissions targets, which are regulated within a protocol establishing binding commitments. The protocol can either deal with substantive and/or procedural matters.

${ }^{70}$ Article 7(2), UNFCCC.
} 
se. ${ }^{71}$ They explain that one of the reasons that CoP decisions are not legally binding is that, in dualistic systems, countries would require parliamentary approval in order to be bound internationally in a way which is similar to a ratification procedure. ${ }^{72}$ Furthermore, "there is hardly any state practice confirming that states are willing to accept formal bindingness of cop decisions per se, even if in practice they find it difficult not to follow such decisions."73 However, other authors, such as Brunnée, see that some CoP decisions could impose consequences on the Parties that, although not legally binding, would amount to de facto consequences comparable to legally binding decisions. ${ }^{74}$

Even considering that $\mathrm{CoP}$ decisions are not legally binding, the adoption of work programmes on Article 6 UNFCCC by the CoP can be considered a subsequent agreement between the parties regarding the application of its provisions, since the work programmes intend to help the Parties to implement Article 6. Consequently, these decisions can be taken into account to interpret Article 6 of the UNFCCC, according to Article 31 (3)(a) VCLT. ${ }^{75}$

Having established that the decisions of the CoP regarding work programmes on Article 6 UNFCCC can be used to interpret Article 6 of the UNFCCC, the next step is to investigate whether the content of these decisions gives more body to Article 6 of the UNFCCC.

For this examination, the methodology proposed by Wiersema will be used. Wiersema breaks free from traditional categories of sources of international law and proposes an analysis of the legal status of the consensus-based CoP activities based on four different axes: voting and

\footnotetext{
${ }^{71}$ S. Oberthür and R. Bodle, 'Legal Form of the Paris Agreement and Nature of Its Obligations', in D. Klein, M. Pía Carazo, M. Doelle, J. Bulmer and A. Higham (eds.), The Paris Agreement on Climate Change: Analysis and Commentary, (Oxford: Oxford University Press, 2016b), pp. 91-103, p. 93.

${ }^{72}$ S. Oberthür and R. Bodle, 'Legal form and nature of the Paris outcome' 6(1-2) Climate law, (2016a), pp. 40-57, pp. 43-44.

${ }^{73}$ S. Oberthür and R. Bodle, op. cit. (2016a), p. 44.

${ }^{74}$ D. Bodansky, J. Brunnée and L. Rajamani, op. cit. (2017), p. 91. J. Brunnée, 'COPing with consent: law-making under multilateral environmental agreements' 15(1) Leiden Journal of International Law, (2002), pp. 1-52, p. 26.

${ }^{75}$ Some would rather classify a CoP decision under Article 31(3)(b) VCLT, such as Churchill and Ulfstein who state that "an interpretation adopted by a COP could be considered subsequent practice by the parties to a treaty, which, according to Article 31 (3) (b) of the Vienna Convention on the Law of Treaties, is an element that may be taken into account in interpreting the treaty." (R. R. Churchill and G. Ulfstein, 'Autonomous institutional arrangements in multilateral environmental agreements: a little-noticed phenomenon in international law' 94(4) American Journal of International Law, (2000), pp. 623-659, p. 641). However, it does change the outcome that the decision may be taken into account for the purpose of treaty interpretation.
} 
level of consent, level of authorisation by the treaty, intent, and effect. ${ }^{76}$ She proposes such a method of interpretation, because the traditional classification into hard law, soft law and non-law would not reflect "the complex relationship between consensus-based COP activity and the underlying treaty obligations of the parties to that treaty." 77 The four axes need to be used in combination, since the use of one axis in isolation cannot give the full picture of the relationship between consensus-based CoP decision and international legal obligation. ${ }^{78}$

By relying on Wiersema's method, the CoP decisions related to Article 6 of the UNFCCC will be analysed to determine whether they thicken the obligations on access to information and public participation contained in Article 6. The CoP adopted three work programmes on Article 6: the 2002 New Delhi Work Programme; ${ }^{79}$ the 2007 Amended New Delhi Work Programme; ${ }^{80}$ and the Doha Work Programme, which runs until $2020 .{ }^{81}$

\subsubsection{Voting and level of consent}

The analysis of the level of consent aims to explore whether a decision "has achieved the status of either a new agreement between the parties or some form of instant or emerging customary international law." $" 82$

The work programmes on Article 6 do not mention which voting procedure was used for the decisions through which they were adopted. However, it can be assumed that these decisions were adopted by consensus for two reasons. First, the Draft Rules of Procedure of the Conference of the Parties and its Subsidiary Bodies have not yet been adopted, but the UNFCCC factually operates under the existing draft rules. Even though the CoP has agreed to apply the draft rules of procedure, the draft rule 42, which would potentially allow for majority in decision making, was excluded. ${ }^{83}$ Second, consensus means "the practice of

\footnotetext{
76 A. Wiersema, 'The new international law-makers? Conferences of the parties to multilateral environmental agreements' 31(1) Michigan Journal of International Law, (2009), pp. 231-287, pp. 250259.
}

${ }^{77}$ A. Wiersema, op. cit. (2009), p. 233.

${ }^{78}$ A. Wiersema, op. cit. (2009), p. 256.

79 Decision 11/CP.8 New Delhi work programme on Article 6 of the Convention FCCC/CP/2002/7/Add.1.

${ }^{80}$ Decision 9/CP.13 Amended New Delhi work programme on Article 6 of the Convention FCCC/CP/2007/6/Add.1.

${ }^{81}$ Decision 15/CP.18 Doha work programme on Article 6 of the Convention FCCC/CP/2012/8/Add.2. ${ }^{82}$ A. Wiersema, op. cit. (2009), p. 251.

${ }^{83}$ Paragraph 2 of the note by the secretariat, Conference of the Parties to the UNFCCC, Organizational Matters - Adoption of the Rules of Procedure (1996).

The Draft Rules of Procedure of the Conference of the Parties and its Subsidiary Bodies has still not been adopted but will continue to be applicable. (Paragraphs 4-6, Conference of the Parties to the 
adoption of resolutions or decisions by general agreement without resort to voting in the absence of any formal objection that would stand in the way of a decision being declared adopted in that manner." 84 In the reports of the CoP in which the decisions on work programmes were adopted, there is no concern noted or formal objection. ${ }^{85}$

Taking into consideration that the decisions adopting the work programmes were adopted via consensus, it can be argued that these decisions acquired a significant degree of consent from the Parties. Furthermore, a meeting as large as the $\mathrm{CoP}$ of the UNFCCC requires substantial investment from governments to have skilled negotiators to defend their interests. This can hinder the active participation of countries with limited resources in decision making. Even in the case of weak representation, these Parties "will still be part of the consensus, and will still be affected by any legal implications that flow from it." ${ }^{86}$ In view of this, Parties may also prioritise putting effort into the more contentious aspects of the Convention (in this case: emission reduction, finance and adaptation to climate change), while surrounding aspects of the Convention, such as access to information and public participation, will be given less attention, especially because the decisions are assumed not to be legally binding. Therefore, supposing that these decisions would gain a status of a new agreement would risk creating obligations that are not foreseen by the Parties. Nonetheless, this aspect also needs to be considered in view of the other three axes.

\subsubsection{Level of authorisation in the treaty - Delegated consent}

Relying on "a notion of consent to delegated law-making power" ${ }^{87}$ Wiersema proposes that the decisions, such as those which adopted the work programmes on Article 6, can have their

UNFCCC, Report of the Conference of the Parties on its twenty-fourth session, held in Katowice from 2 to 15 December 2018 (2018).

${ }^{84}$ Letter from Hans Corell, Under-Secretary-General for Legal Affairs, Office of Legal Council, United Nations, to Hamdallah Zedan, Executive Secretary, Convention on Biological Diversity 1 (June 6, 2002) cited by R. C. Gardner, 'Perspectives on Wetlands and Biodiversity: International Law, Iraqi Marshlands, and Incentives for Restoration' Colorado Journalof International Environmental Law \& Policy Yearbook, (2003), pp. 1-18, p. 4.

${ }^{85}$ See Conference of the Parties to the UNFCCC, Report of the Conference of the Parties on its eighth session (Part One: Proceedings), held in New Delhi from 23 October to 1 November 2002 (2002); Conference of the Parties to the UNFCCC, Report of the Conference of the Parties on its thirteenth session (Part One: Proceedings), held in Bali from 3 to 15 December 2007 (2007) and Conference of the Parties to the UNFCCC, Report of the Conference of the Parties on its eighteenth session (Part One: Proceedings), held in Bali 26 November to 8 December 2012 (2012).

A formal objection could have blocked the adoption, while an expression of concern by one of the Parties would highlight a specific position but the result would be the adoption by consensus. R. C. Gardner, op. cit. (2004), p. 4.

${ }^{86}$ R. C. Gardner, op. cit. (2004), p. 9.

${ }^{87}$ A. Wiersema, op. cit. (2009), p. 253. 
legal status evaluated according to the degree of authorisation contained in the treaty. The UNFCCC does not empower the CoP with the specific capacity to adopt a work programme on Article 6. Therefore, these decisions on work programmes fall within the general authorisation of the CoP to adopt decisions to promote the effective implementation of the UNFCCC, ${ }^{88}$ read in combination with the commitments of Parties in Article 4(i) and Article 6. Against this background, the decisions which adopted the work programmes on Article 6 have a "lesser legal status than specifically authorized activities", ${ }^{89}$ such as on the rules of procedure $^{90}$ and financial mechanisms. ${ }^{91}$

\subsubsection{Obligation contained in the language of the CoP Activity - Intent}

This axis aims to assess the normative force of the CoP decisions through the analysis of the language used in the text. A reading of all work programmes carried out by this author revealed that the $\mathrm{CoP}$ decisions on work programmes are mainly in soft language, which repeatedly uses terms such as encourages,${ }^{92}$ recognises ${ }^{93}$ and invites. ${ }^{94}$ This provides a clear message that the CoP had no intention to move in the direction of defining specific commitments for Parties on how to implement Article 6. In contrast, the same decisions use mandatory terms when dealing with internal actions or addressing the UNFCCC bodies. For instance, the decisions request the Global Environmental Facility to provide for financial support ${ }^{95}$ and request actions from the secretariat. ${ }^{96}$ Nonetheless, even the requests made to the secretariat are softened by the condition that the actions are subject to the availability of financial support. ${ }^{97}$ These findings are consistent with the comments from Wiersema who observed that "sometimes differences in language seem to track whether a COP is addressing parties directly with regard to their external obligations, where less forceful language might be used, or whether it is addressing its own internal operations or its subsidiary organs, where

\footnotetext{
${ }^{88}$ Article 7(2), UNFCCC.

${ }^{89}$ A. Wiersema, op. cit. (2009), p. 253.

${ }^{90}$ Article 7(3), UNFCCC.

${ }^{91}$ Article 11(4), UNFCCC.

${ }_{92}$ Decision 11/CP.8, para 4 and 7. Decision 9/CP.13, para 4. Decision 15/CP.18, para 5.

${ }^{93}$ Decision 11/CP.8, para 4. Decision 9/CP.13, para 5. Decision 15/CP.18, para 7.

${ }^{94}$ Decision 11/CP.8, para 4 and Annex, para 17, 18, 23 and 24. Decision 9/CP.13, Annex para 20, 21, 26 and 28. Decision 15/CP.18, para 3, 4, 6, Annex para 22(k), 24, 25, 26, among others.

${ }^{95}$ Decision 11/CP.8, para 4. Decision 9/CP.13, para 5. Decision 15/CP.18, para 7.

${ }^{96}$ Decision 11/CP.8, Annex para 25. Decision 9/CP.13, Annex para 29. Decision 15/CP.18, Annex para 35. Other examples of the use of mandatory terms: decided that the efforts under Article 6 should be titled Action for Climate Empowerment and not Article 6 as previously was the case (Decision 17/CP.22 Improving the effectiveness of the Doha work programme on Article 6 of the Convention FCCC/CP/2016/10/Add.2, para 14); and decided on the format and content of the annual in-session dialogue on Article 6 (as an example of an internal practical decision) (Decision 15/CP.18, Annex para 10).

${ }^{97}$ Decision 17/CP.22, para 16.
} 
more forceful language is used." 98 In this sense, the language used by the CoP regarding Article 6 obligations addressed to the Parties is clearly less forceful than those addressed to the secretariat or when deciding internal practical matters and it leans towards soft rather than hard legal commitments.

\subsubsection{Effect in implementation}

The fourth axis focuses on the practical significance of these decisions. The idea is to examine to what extent the Parties implement the decisions, in this case, the work programmes, as if they were legally binding.

To investigate whether Parties implement the decisions on work programmes as if they were legally binding, the reports elaborated by the Subsidiary Body for Implementation (SBI) on the progress of the work programmes will be analysed, focusing on the progress regarding access to information and public participation. ${ }^{99}$ So far, there are two reports from the SBI: one on the implementation of the 2002 New Delhi Work Programme ${ }^{100}$ and one on the implementation of the 2007 Amended New Delhi Work Programme, the terms of which expired in 2007 and 2012 respectively. ${ }^{101}$ For the Doha Work Programme, which is running until 2020, only the report on the intermediate review of progress is thus far available and therefore this is the document which will be analysed. ${ }^{102}$ The final SBI report will only be ready in 2020 when the term of this programme ends.

\section{i. Information contained in the SBI Reports}

Before the reports are analysed, a brief explanation of the information contained in these documents may be helpful. The reports elaborated by the SBI are based on the national communications (NCs) that the Parties submit to the secretariat. ${ }^{103}$ The time schedule for submission and the review process of these communications are different for Annex I and

\footnotetext{
${ }^{98}$ A. Wiersema, op. cit. (2009), p. 254.

${ }^{99}$ The SBI, which is one of the two permanent subsidiaries bodies - the other being the Subsidiary Body for Scientific and Technological Advice (SBSTA) - is responsible for assisting the CoP in conducting the assessment and review of the effective implementation of the Convention and, consequently, has the duty of elaborating the reports on the progress of the work programmes. Article 10, UNFCCC.

${ }^{100}$ Subsidiary Body for Implementation of the UNFCCC, Review of the implementation of the New Delhi work programme on Article 6 of the Convention FCCC/SBI/2007/22.

101 Subsidiary Body for Implementation of the UNFCCC, Report on progress made in, and the effectiveness of, the implementation of the amended New Delhi work programme on Article 6 of the Convention FCCC/SBI/2012/3 (2012), para 51.

102 Subsidiary Body for Implementation of the UNFCCC, Progress made in implementing the Doha work programme on Article 6 of the Convention FCCC/SBI/2016/6.

${ }^{103}$ Article 12(1), UNFCCC.
} 
non-Annex I Parties in accordance with the common but differentiated responsibility principle. Annex I Parties were required to submit their first communication within six months of the entry into force of the Convention for that Party; while non-Annex I Parties must submit within three years or in accordance with their financial capacity; and least developed countries may submit their first $\mathrm{NC}$ at their discretion. ${ }^{104}$ The periodicity of the submission of subsequent NCs was decided by CoP decisions and currently both Annex I and non-Annex I Parties are required to submit them every four years. ${ }^{105}$ Nonetheless, for nonAnnex I Parties, the requirement of how often the NC should be submitted is conditional upon the provision of financial resources to cover the agreed full costs which must be spent in preparing their NCs. ${ }^{106}$ The NCs are subject to a technical review, which is coordinated by the Secretariat of the UNFCCC.

Almost all Annex I countries have submitted all required NCs, with very few exceptions. ${ }^{107}$ In contrast, the submission of NCs by non-Annex I Parties is not that robust. ${ }^{108}$ For instance, significant emitters such as Brazil, India and China, for whom the Convention entered into force in 1994, only submitted their first NCs in 2004. It is important to note that, although the reports of the SBI on implementation gives a picture of the implementation of Article 6 by the Parties, these reports lack information from many non-Annex I Parties.

ii. Review of implementation of the work programmes on Article 6 UNFCCC

The review of the implementation of the 2007 New Delhi Work Programme conducted by the SBI found that public participation played an important role in climate change decision making processes in Annex I Parties. ${ }^{109}$ This was reflected by the practice of Parties to hold national consultations with the general public and interested stakeholders regarding action plans and policies in the area of climate change. ${ }^{110}$ The report showed that most Annex I

\footnotetext{
${ }^{104}$ Article 12(5), UNFCCC.

105 Decision 2/CP.17 Outcome of the work of the Ad Hoc Working Group on Long-term Cooperative Action under the Convention FCCC/CP/2011/9/Add.1 para 14. Decision 1/CP.16 The Cancun Agreements: Outcome of the work of the Ad Hoc Working Group on Long-term Cooperative Action under the Convention FCCC/CP/2010/7/Add.1, para 60.

${ }^{106}$ Decision 1/CP.16, para 60b.

107 The information on the submissions can be found here: http://unfccc.int/national_reports/national_communications_and_biennial_reports/submissions/items/ 7742.php, accessed on 18 June 2020.

${ }^{108}$ A full overview of the Submitted National Communications from Non-Annex I Parties can be found here: http://unfccc.int/national_reports/non-annex_i_natcom/items/10124.php, accessed on 18 June 2020.

${ }^{109}$ Review of the implementation of the New Delhi work programm, para 31.

${ }^{110}$ Ibid.
} 
Parties made an effort to disseminate information and to encourage public participation, while also noting that the same actions had been undertaken by many non-Annex I Parties. ${ }^{111}$

In 2012, the review of the implementation of the amended New Delhi Work Programme mentions the Aarhus Convention for the first time as a framework to regulate public participation and public access to information. ${ }^{112}$ The review highlights positively how countries that are signatories to the Aarhus Convention have binding procedural obligations, which are implemented via national legislation and policies. Furthermore, in Latin America and the Caribbean, "all countries in the region have a mechanism to promote public participation in climate change-related decision-making processes"; ${ }^{113}$ while in Africa "(62 per cent) of countries in that region have such a mechanism". ${ }^{114}$ The report does not clarify whether these mechanisms are prescribed by legislation or are only policies. Still, mechanisms for public participation can only be effective if the public is provided with adequate information, and the review noted that more than half of the people in these regions were still unaware that climate change was happening. ${ }^{115}$ This low level of awareness persists, despite the fact that the number of national focal points for Article 6 increased in both developed and developing countries. ${ }^{116}$

The intermediate review of the Doha Work Programme conducted in 2012 again highlights that, for Parties which are signatories of the Aarhus Convention, the latter is the main international framework on environmental procedural rights. ${ }^{117}$ The report also notes that certain Parties, including those that are Parties to the Aarhus Convention, have adopted legal frameworks for public access to environmental information, which also includes information on climate change. ${ }^{118}$ Although the CoP recognised that progress had been made in the six areas covered by Article $6,{ }^{119}$ for instance, the simple but crucial action of establishing focal

\footnotetext{
${ }^{111}$ Review of the implementation of the New Delhi work programm, para 53 and Annex I, para h and I. The document does not specify which countries have taken the actions.

${ }^{112}$ Report on progress made in, and the effectiveness of, the implementation of the amended New Delhi work, para 50 and 61. It is quite late, considering that the Aarhus Convention has been in force since 2001.

${ }^{113}$ Report on progress made in, and the effectiveness of, the implementation of the amended New Delhi work, para 51.

${ }^{114}$ Ibid.

${ }^{115}$ Report on progress made in, and the effectiveness of, the implementation of the amended New Delhi work, para 43.

${ }^{116}$ Counting, in December 2012, 19 focal points for Annex I parties and 52 for non-Annex I parties.

${ }^{117}$ Intermediate Review on the Doha work programme, para 46.

${ }^{118}$ Intermediate Review on the Doha work programme, para 52.

${ }^{119}$ Decision 17/CP.22, para 1.
} 
points for Article 6 of the UNFCCC is still only undertaken by a limited number of the Parties: only 94 out of the 197 Parties nominated focal points. ${ }^{120}$

From the information available in the reports, it becomes clear that many Parties are trying to implement some recommendations suggested in the work programmes. However, the implementation attempts vary substantially between the Parties. It is however perhaps not surprising, since, with such a diverse group, it is to be expected that implementation will differ, especially due to the different degrees of financial and technical capacity among them. As described earlier, even the most basic actions, such as the nomination of focal points, still need to be implemented by many Parties. It is thus not possible to argue conclusively that non-implementation is a sign that the Parties do not see the provisions of the work programmes as non-binding, since it could be mainly due to a lack of financial and technical capacity. However, it is possible to affirm that the relatively slow implementation, coupled with the great degree of differentiation between Parties is a sign that the CoP work programmes have not been seen as legally binding.

\subsection{Interim conclusion}

Based on a textual analysis, it can be argued that Article 6(a)(ii) and (iii) of the UNFCCC cover a diverse range of information on climate change and its effects, to be made available to the public proprio motu by public authorities or upon request from a member of the public, although the limits of the scope of this provision must still be tested. Regarding public participation, the provision also seems to encompass the widest participation of members of the public. However, the implementation of such broad formulations by the Parties are restricted by the terms within their respective capacities and the national laws and regulations.

The analysis also considered whether the work programmes on Article 6 of the UNFCCC thicken the obligation contained in Article 6 of the UNFCCC. Using the four axes suggested by Wiersema, the following results were found. First, despite the fact that the decisions on work programmes were consensus based, there is no evidence that the level of consent could give these decisions the status of a new binding agreement among the Parties. Second, the $\mathrm{CoP}$ is not specifically authorised in the UNFCCC to take decisions to adopt work programmes on Article 6 of the UNFCCC, which make them fall within the general authorisation and, therefore, gives them a lesser level of authorisation than specifically authorised activities. Third, the language used in these decisions to address the Parties is less forceful than those addressed to the secretariat or when deciding internal practical matters, which shows that the obligations lean towards soft legal commitments. Fourth, based on the analysis of the reports on the implementation of the work programmes, it is possible to affirm

${ }^{120}$ Intermediate Review on the Doha work programme, para 8. 
that the implementation differentiates vastly among the Parties and that there is no evidence that the Parties implement the decisions on the work programmes as if they were legally binding.

In conclusion, Article 6 of the UNFCCC lacks clear and specific commitments, which renders the provision lacking a precise result to be achieved. According to its text, Parties need to promote and facilitate access to information on climate change and its effects and public participation in addressing climate change and its effects and developing adequate responses. However, these obligations are not accompanied by a specific action or a target that must be complied with by the Parties. Therefore, since the Parties only have to honestly apply their best efforts, which does not necessarily mean that they have to achieve a specific result, Article 6 of the UNFCCC contains obligations of effort.

\section{Access to information and public participation under the Kyoto Protocol}

The Parties to the UNFCCC adopted the Kyoto Protocol in $1997 .{ }^{121}$ The Kyoto Protocol is a legally binding agreement under the auspices of the UNFCCC, which contains substantive provisions - particularly explicit targets for the emission reduction of GHG for developed countries - and procedural provisions regarding its institutions. The Protocol entered into force in 2005, eight years after its adoption. The first commitment period ran from 2008 to 2012. The second commitment period was planned to run from 2013 until 2020. However, the Doha Amendment to the Kyoto Protocol, which regulates the emission reduction targets for the second amendment period, has not been ratified by a sufficient number of Parties in order for it to enter into force. ${ }^{122}$

The Kyoto Protocol reiterates the importance of Article 6 UNFCCC in its Article 10(e):

“All Parties [..] shall:

(e) Cooperate in and promote at the international level, and, where appropriate, using existing bodies, the development and implementation of education and training programmes, including the strengthening of national capacity building, in particular human and institutional capacities and the exchange or secondment of personnel to train experts in this field, in particular for developing countries, and facilitate at the

\footnotetext{
${ }^{121}$ Article 17, UNFCCC.

${ }^{122}$ Status of ratification available at: United Nations Treaty Collection. Chapter XXVII - Environment - 7. c Doha Amendment to the Kyoto Protocol, 15 April 2019, https://treaties.un.org/Pages/ViewDetails.aspx?src=TREATY\&mtdsg no=XXVII$13 \&$ chapter $=27 \&$ lang=en.
} 
national level public awareness of, and public access to information on, climate change. Suitable modalities should be developed to implement these activities through the relevant bodies of the Convention, taking into account Article 6 of the Convention"

Just like Article 6 of UNFCCC, the provision explicitly mentions public access to information on climate change. However, Article 10(e) of the Kyoto Protocol does not refer to effects, as Article 6 of the UNFCCC, although such a terminological difference is not necessarily a cause for concern.

A similarity between the provisions is the use of the term shall, which indicates a strong commitment, but which is followed by terms such as cooperate and promote without referring to clear and specific commitments, echoing what was explained in section 2.3 with respect to the UNFCCC. As Article 6 of the UNFCCC, Article 10(e) of the Kyoto Protocol constructs an open-ended obligation from which it is very difficult to extract clear rules that Parties need to comply with. ${ }^{123}$

A clear difference with Article 6 of the UNFCCC is that Article 10(e) of the Kyoto Protocol does not refer to public participation explicitly. Hence, in a textual sense, the content of Article 10(e) of the Kyoto Protocol is narrower than what is provided in Article 6. However, the Kyoto Protocol is linked to the UNFCCC and should be read in accordance with the commitments already established in this framework convention. Moreover, Article 10(e) of the Kyoto Protocol explicitly refers to Article 6 of the UNFCCC. In this context, the same level of information and public participation which is required under Article 6 also applies to the Protocol and there is no indication that public participation should be restricted when implementing the Kyoto Protocol. However, it is important to mention that Article 10(e) of the Kyoto Protocol is very vague. More detailed provisions can be found in the decisions of the Conference of the Parties serving as the meeting of the Parties to the Kyoto Protocol (CMP). This is particularly true in relation to market-based mechanisms which Parties to the Kyoto Protocol may use to comply with their targets.

The Protocol establishes three mechanisms: clean development mechanism (CDM), joint implementation (JI) and emissions trading. The CMP has adopted decisions on how these instruments must be applied. The decisions on project-based instruments (CDM and JI) contain some provisions on access to information and public participation. ${ }^{124}$ Also, the decision on the transaction of the assigned amounts which are applicable to emissions trading

\footnotetext{
${ }^{123}$ P. M. Lawrence, Justice for future generations: climate change and international law, (Cheltenham: Edward Elgar, 2014), p. 109.

124 Decision 9/CMP.1 Guidelines for the implementation of Article 6 of the Kyoto Protocol FCCC/KP/CMP/2005/8/Add.2 and Decision 3/CPM.1 Modalities and procedures for a clean development mechanism as defined in Article 12 of the Kyoto Protocol FCCC/KP/CMP/2005/8/Add.1.
} 
contains provisions on publicly accessible information. ${ }^{125}$ However, these CMP decisions are confined within the boundaries of the implementation of these market-based instruments and, consequently, cannot be used to support an analysis of the application of Article 10(e) in general. Moreover, by now, the Paris Agreement has been adopted and the practical value of the Kyoto Protocol for addressing climate change in the near future is non-existent.

In conclusion, Article 10(e) of the Kyoto Protocol does not provide elements that deepen the obligations of Article 6 UNFCCC. Furthermore, due to the lack of clear and specific commitments, it can be concluded that Article 10(e) of the Kyoto Protocol also contains obligations of effort.

\section{Access to information and public participation under the Paris Agreement}

The Paris Agreement was adopted on 12 December $2015^{126}$ and entered into force less than one year later, on 4 November $2016 .{ }^{127}$ It sets a goal of keeping the increase in "the global average temperature to well below $2{ }^{\circ} \mathrm{C}$ above pre-industrial levels and pursuing efforts to limit the temperature increase to $1.5^{\circ} \mathrm{C}$ above pre-industrial levels". ${ }^{128}$ To achieve this goal, all Parties are obliged to submit nationally determined contributions (NDCs) based on which Parties are expected to progress over time. ${ }^{129}$

The preamble of the Paris Agreement affirms the importance of the six areas covered by Article 6 of the UNFCCC, among which are public participation and public access to information. ${ }^{130}$ This purpose is further elaborated on in Article 12 of the Paris Agreement, which specifically focuses on public participation and access to information. It reads as follows:

"Parties shall cooperate in taking measures, as appropriate, to enhance climate change education, training, public awareness, public participation and public access to information, recognizing the importance of these steps with respect to enhancing actions under this Agreement."

\footnotetext{
${ }^{125}$ Decision 13/CMP.1 Modalities for the accounting of assigned amounts under Article 7, para 4, of the Kyoto Protocol FCCC/KP/CMP/2005/8/Add.2.

${ }^{126}$ Decision 1/CP.21 Adoption of the Paris Agreement FCCC/CP/2015/10/Add.1.

127 Paris Agreement - Status of Ratification. Available at: http://unfccc.int/paris_agreement/items/9444.php, accessed on 18 June 2020.

${ }_{128}$ Article 2, Paris Agreement.

${ }^{129}$ Article 2, Paris Agreement. D. Bodansky, J. Brunnée and L. Rajamani, op. cit. (2017), p. 210.

${ }^{130}$ Recital 14, Preamble, Paris Agreement.
} 
Similar to Article 6 of the UNFCCC, Article 12 of the Paris Agreement explicitly mentions public access to information and public participation, but the obligations in the two provisions seem different from those contained in Article 6 of the UNFCCC. Article 6 of the UNFCCC states that parties shall promote and facilitate "public access to information on climate change and its effects" and "public participation in addressing climate change and its effects and developing adequate responses". Article 12 of the Paris Agreement also uses the imperative shall, but it imposes an obligation of cooperation among Parties while taking measures to enhance public participation and public access to information.

While Article 6 UNFCCC imposes an obligation for the Parties to promote and facilitate access to information and public participation at the national level and Article 10(e) of the Kyoto Protocol imposes an obligation for the Parties to facilitate public access to information at the national level, Article 12 of the Paris Agreement focuses on cooperation among Parties without focusing on the national dimension. Unlike Article 6 UNFCCC and Article 10(e) of the Kyoto Protocol, Article 12 of the Paris Agreement therefore has predominately an international dimension. ${ }^{131}$

In contrast to Article 10(e) of the Kyoto Protocol, Article 12 of the Paris Agreement does not recall Article 6 UNFCCC. However, even if it does not refer to Article 6 UNFCCC, it ought to be read in light of the UNFCCC since the Paris Agreement has been considered subsidiary to the UNFCCC. ${ }^{132}$ This subsidiary status is confirmed by the Durban Mandate, which says that the future agreement was to be "under the Convention", ${ }^{133}$ and Article 2 of the Paris Agreement, which states that the agreement is "enhancing the implementation of the Convention". Therefore, the interpretation of the Paris Agreement should be guided by the UNFCCC. In this vein, Article 12 of the Paris Agreement adds to the already existent obligation to promote and facilitate access to information and public participation and an obligation for the Parties to cooperate while taking the measures to enhance access to information and public participation. However, it fails to introduce the more specific language that one may have expected, since the Paris Agreement is intended to further implement the obligations of the UNFCCC. ${ }^{134}$

\footnotetext{
${ }^{131}$ D. Misonne, 'Access to Information and the Paris Agreement', in J. Jendrośka and M. Bar (eds.), Procedural Environmental Rights: Principle X in Theory and Practice (Cambridge: Intersentia, 2017), p. 473.

${ }^{132}$ M. Wewerinke-Singh and C. Doebbler, 'The Paris agreement: Some critical reflections on process and substance' 39(4) The University of New South Wales Law Journal, (2016), pp. 1486-1517, p. 1516. ${ }^{133}$ Decision 1/CP.17 Establishment of an Ad Hoc Working Group on the Durban Platform for Enhanced Action, UN Doc FCCC/CP/2011/9/Add.1, para 2.

${ }^{134}$ M. Wewerinke-Singh and C. Doebbler, op. cit. (2016), p. 1512.
} 
In summary, Article 12 of the Paris Agreement is formulated in a vague and imprecise manner without prescribing any specific commitments, which makes the obligations contained in the provision exclusively obligations of effort.

\section{Conclusion}

This chapter investigated which kind of obligations are established for the Parties concerning access to information and public participation in climate change decision making, which are intended to be implemented at the domestic level under the UNFCCC, the Kyoto Protocol and the Paris Agreement. The analysis disclosed the following.

Based on a textual analysis, Section 2 argued that Article 6(a)(ii) and (iii) of the UNFCCC cover a diverse range of information on climate change and its effects to be made available to the public by public authorities own initiative or upon request from a member of the public. Section 2 also found that the Convention requires public participation, which seems to encompass the widest participation of members of the public.

Nevertheless, such broad formulations are restricted by the terms within their respective capacities and the national laws and regulations. This means that Parties have to fulfil their obligations only to the extent that their capacity to do so allows and in accordance with their domestic laws. For instance, to verify whether a Party has satisfied its obligation, it would first be necessary to determine what would be the real capacity in view of the promotion and access to information and public participation. Furthermore, the provision demands Parties to promote and facilitate access to information and public participation without referring to clear and specific commitments.

The textual and contextual analysis of Article 6 of the UNFCCC was followed by the analysis of the work programmes on Article 6. This examination was carried out because Article 31(3)(a) of the VCLT establishes that "any subsequent agreement between the parties regarding the interpretation of the treaty or the application of its provision," together with the context, may be taken into account for treaty interpretation. By applying the four axes suggested by Wiersema, the analysis of the work programmes on Article 6 of the UNFCCC disclosed that these work programmes do not expand the obligation contained in Article 6 of the UNFCCC. Since there is no clear result that needs to be achieved in order to render a Party in compliance, it was concluded that Article 6 contains obligations of effort.

In section 3, the analysis moved to examine Article 10(e) of the Kyoto Protocol. It was shown that this provision only deals with access to information and it does so in a vague and imprecise manner. Thus, this obligation has also been characterised as an obligation of effort. Furthermore, public participation is not even mentioned in its text. By now, however, the Kyoto Protocol is no longer relevant for addressing climate change, since no new emission reduction targets have been adopted for the period after 2020 . 
Finally, section 4 discussed Article 12 of the Paris Agreement. It was shown that this provision focuses on international cooperation and does not provide for more specific provisions compared to Article 6 of the UNFCCC. Furthermore, it was concluded that the mandatory character of Article 12 of the Paris Agreement is the same: it creates legal obligations for Parties to make an effort without stipulating specific results, which are also characterised as obligations of effort.

In sum, the importance of a procedural approach is recognised in the UNFCCC, revealing a new approach in international environmental law to incorporate procedural provisions in treaties. However, while the importance of access to information and public participation is acknowledged, no precise commitments and certainly no obligation of result can be identified. Consequently, there are no clearly identifiable results that need to be implemented by Parties at the national level. The next chapter will continue to explore the EU's international obligations with regard to procedural rights by examining the Aarhus Convention. 


\section{Chapter III - The Aarhus Convention, the EU and Climate Change}

\section{Introduction}

The United Nations Economic Commission for Europe (UNECE) Convention on Access to Information, Public Participation in Decision-making and Access to Justice in Environmental Matters ${ }^{1}$ recognizes that enhanced access to information and public participation in decision making can improve the quality of decision making in environmental matters, lead to public awareness of environmental concerns, and can provide more effective participation by allowing the public to put forward its concerns and enabling public authorities to take due account of the expressed concerns. ${ }^{2}$ Ultimately, the Aarhus Convention is based on the premise that access to information, public participation in decision making and access to justice are condiciones sine quibus non in guaranteeing the right for everyone to live in an environment that is adequate for their health and well-being. ${ }^{3}$

Although it has only been ratified by European countries, ${ }^{4}$ the entry into force of the Aarhus Convention was an important milestone in International Environmental Law. The Convention can be seen as the first international agreement that specified rights and duties regarding access to environmental information and provided clear rules for the right to public participation in governmental environmental decision making that are applicable to the whole field of environmental law. Both rights can be enforced by related rights to access to courts. These procedural rights can theoretically play an important role in combating climate change..$^{5}$

\footnotetext{
${ }^{1}$ Convention on Access to Information, Public Participation in Decision-making and Access to Justice in Environmental Matters, Aarhus, Denmark, 25 June 1998, United Nations, Treaty Series, vol. 2161, p. 447 (entered into force on 30 October 2001). Henceforth the Aarhus Convention, the Convention or AC.

2 Preamble, Aarhus Convention.

${ }^{3}$ Article 1, Aarhus Convention.

${ }^{4}$ For the current status on the ratification, see United Nations Treaty Collection (Aarhus Convention). Available at: https://treaties.un.org/Pages/ViewDetails.aspx?src=TREATY\&mtdsg_no=XXVII$13 \&$ chapter=27\&lang=en, accessed 18 June 2020.

${ }^{5}$ S. Kravchenko, 'Procedural Rights as a Crucial Tool to Combat Climate Change' 38(3) Georgia Journal of International and Comparative, (2009), pp. 613-648, p. 617.
} 
The purpose of this chapter is threefold: first, to investigate if and to what extent the climate change problem is part of the scope of the Aarhus Convention even while the Convention does not include the terms climate change and GHG emissions in its text; second, to introduce the rights to access environmental information and to public participation, as foreseen by the Aarhus Convention; and third to examine the implementation of these rights at the EU level. In the context of the EU, Article 10(3) TEU (which prescribes that decisions shall be taken as openly and as closely as possible to the citizen) and Article 11 TEU (which requires institutions to have an open, transparent and regular dialogue with representative associations and civil society, including the carrying out of consultation) should be considered while giving an interpretation of the rights of access to information and public participation in EU law. However, the tangible legal effects that can be derived from these provisions are still uncertain. ${ }^{6}$ Without denying the relevance of the discussion on the possible legal effects of these articles from the TEU, ${ }^{7}$ this chapter will focus on the specific procedural provisions that confer rights of access to environmental information and of public participation in governmental environmental decision making for individuals and representative associations in their relationships with EU institutions.

This chapter, therefore, lays the foundation for the analysis of the case studies contained in the subsequent chapters, which will examine and clarify the extent to which the requirements concerning access to environmental information and public participation in governmental environmental decision making, as provided for by the Aarhus Convention, are applicable to the field of EU climate law. To that end, this chapter is divided into seven sections. Section 2 introduces the Aarhus Convention. Section 3 carries out an analysis of the potential coverage of climate change by the Aarhus Convention. This analysis is undertaken using the rules of interpretation of the Vienna Convention. ${ }^{8}$ Section 4 describes the manner in which the Aarhus Convention has been integrated into the EU legal framework. Section 5 discusses the right to access environmental information as provided for by the Aarhus Convention, and its implementation at the EU level. Section 6 introduces the right to public participation in governmental environmental decision making as provided for by the Aarhus Convention and its implementation at the EU level. Finally, section 7 draws a conclusion on the relevance of the Aarhus Convention for climate change decision making.

\footnotetext{
6 "While Article 11 TEU is framed in obligatory terms, there is also discretion accorded to the EU institutions, as manifest in language such as 'by appropriate means', within Article 11(1) TEU. It is as yet unclear how the CJEU will interpret Article 11 TEU.” P. P. Craig, H. Hofmann, J.-P. Schneider and J. Ziller, ReNEUAL model rules on EU administrative procedure (Oxford: Oxford University Press, 2017), p. 126. See also: P. P. Craig, The Lisbon Treaty: law, politics, and treaty reform (Oxford: Oxford University Press, 2013), p. 70; J. Mendes, 'Participation and the Role of Law after Lisbon: A Legal View on Article 11 TEU' 48(6) Common Market Law Review, (2011), pp. 1849-1878, p. 1866.

${ }^{7}$ As proposed, for instance, by P. P. Craig, op. cit. (2013) and J. Mendes, op. cit. (2011).

${ }^{8}$ Henceforth the Vienna Convention or VCLT.
} 


\section{Introduction to the Aarhus Convention}

\subsection{A convention about procedural rights}

During the 1995 Third Ministerial Environment for Europe Conference in Sofia, Bulgaria, Ministers of Environment from 49 countries in the UNECE region endorsed the Guidelines on Access to Environmental Information and Public Participation in Environmental Decision-Making" and agreed on "the development of a regional Convention on Public Participation [...] with appropriate involvement of NGOs." 10 The fourth Ministerial Europe for Environment Conference was held in June 1998 in Aarhus, Denmark; it marked the signing of the UNECE Convention on Access to Information, Public Participation in Decision-making and Access to Justice in Environmental Matters. ${ }^{11}$ In accordance with Article 20(1), the Convention entered into force on 30 October 2001.

The Aarhus Convention builds its legal framework on the rights of freedom of environmental information, public participation and access to justice based on a number of previous international texts. It is the first treaty to translate Principle 10 of the 1992 Rio Declaration into a binding international document. ${ }^{12}$ This Principle 10 highlights the importance of public participation in decision making processes, access to environmental information held by

\footnotetext{
${ }^{9}$ These guidelines, which shaped the scope of the future convention, are known as the Sofia Guidelines, in reference to Sofia, Bulgaria where the conference took place. The Sofia Guidelines are specifically mentioned in the preamble of the Aarhus Convention: "Conscious of the role played in this respect by ECE and recalling, inter alia, the ECE Guidelines on Access to Environmental Information and Public Participation in Environmental Decision-making endorsed in the Ministerial Declaration adopted at the Third Ministerial Conference 'Environment for Europe' in Sofia, Bulgaria, on 25 October 1995”.

${ }_{10}$ Declaration by the Ministers of Environment of the region of the United Nations Economic Commission for Europe (UNECE), para 47.

${ }^{11}$ J. Ebbesson, H. Gaugitsch, J. Jendrośka, F. Marshall and S. Stec, 'The Aarhus Convention: an implementation guide', $2^{\text {nd }}$ edition (Geneva: United Nations, 2014), p. 15.

${ }^{12}$ C. Pitea, 'Procedures and Mechanisms for Review of Compliance under the 1998 Aarhus Convention on Access to Information, Public Participation and Access to Justice in Environmental Matters', in T. Treves (ed.), Non-compliance procedures and mechanisms and the effectiveness of international environmental agreements; Non-compliance Procedures and Mechanisms and the Effectiveness of International Environmental Agreements, (The Hague: T.M.C. Asser Press, 2009), p. 221.
} 
public authorities and access to justice. ${ }^{13}$ The Convention was also inspired by Principle 1 of the 1972 Stockholm Declaration, ${ }^{14}$ which states that:

"Man has the fundamental right to freedom, equality and adequate conditions of life, in an environment of a quality that permits a life of dignity and well-being, and he bears a solemn responsibility to protect and improve the environment for present and future generations. [...]"

The influence of the Stockholm Declaration is evident in the preamble of the Aarhus Convention, which explicitly mentions Principle 1 of the Stockholm Declaration and states that:

"Every person has the right to live in an environment adequate to his or her health and well-being, and the duty, both individually and in association with others, to protect and improve the environment for the benefit of present and future generations."

The Aarhus Convention has also endorsed "the right of every person of present and future generations to live in an environment adequate to his or her health and well-being", ${ }^{15}$ but it does not regulate a substantive right to a healthy environment. ${ }^{16}$ The Convention rather acknowledges the right of every individual to live in an adequate environment and that procedural rights serve as the means through which this human right should be achieved. ${ }^{17}$ In other words, the Aarhus Convention does not provide a substantive right to a healthy

${ }^{13}$ Rio Declaration on Environment and Development, Principle 10: "Environmental issues are best handled with participation of all concerned citizens, at the relevant level. At the national level, each individual shall have appropriate access to information concerning the environment that is held by public authorities, including information on hazardous materials and activities in their communities, and the opportunity to participate in decision-making processes. States shall facilitate and encourage public awareness and participation by making information widely available. Effective access to judicial and administrative proceedings, including redress and remedy, shall be provided."

${ }^{14}$ Declaration of the United Nations Conference on the Human Environment, (16 June 1972).

${ }^{15}$ Article 1, Aarhus Convention.

${ }^{16}$ M. Dellinger, 'Ten Years of the Aarhus Convention: how Procedural Democracy is Paving the Way for Substantive Change in National and International Environmental Law' 23(2) Colorado Journal of International Environmental Law and Policy, (2012), pp. 309-366, p. 21.

${ }^{17}$ For a discussion on the issue of the environment as a human right see: D. Shelton, 'Human Rights and the Environment: Substantive Rights', in M. Fitzmaurice, D. M. Ong and P. Merkouris (eds.), Research handbook on international environmental law, (Cheltenham, Northampton: Edward Elgar Publishing, 2010), pp. 265-283; D. Shelton, 'Human rights, environmental rights, and the right to environment' 28(1) Stanford Journal of International Law, (1991), pp. 103-138, A. Boyle, 'Human Rights or Environmental Rights? A Reassessment' 18(3) Fordham Environmental Law Review, (2007), pp. 471-511. 
environment, but it establishes a set of procedural rights that aim at realising a healthy environment.

As asserted by Sartoretti, "the AC prefers to defend the right to a healthy environment in its 'procedural' dimension, recognising that citizens have the right to be involved in decisions taken by institutions." 18 Boyle also acknowledges that "the Aarhus Convention is strictly procedural in content, limited to public participation in environmental decision-making, access to justice and information." ${ }^{19}$ Hey points out that "it is through these procedural rights that individuals and groups in society are able to invoke substantive environmental law before various national and regional (quasi-) judicial bodies." ${ }^{20}$ On the one hand, Mason sees this "indeterminate coupling of substantive and procedural rights" 21 as an inconsistency within the Aarhus framework which hinders the Convention's commitment to human rights. ${ }^{22}$ On the other hand, by examining the relationship between procedural and substantive rights, Cittadino concludes that "participatory requirements are functional to the realization of substantive rights". ${ }^{23}$ The non-recognition of an enforceable substantive right to a healthy environment can be seen as the Achilles' heel of the Aarhus Convention; ${ }^{24}$ however, the guarantee of procedural rights can help to realise the ultimate objective of the Convention: a healthy environment. ${ }^{25}$

${ }^{18}$ C. Sartoretti, 'The Aarhus Convention Between Protection of Human Rights and Protection of the Environment', in E. J. Lohse, M. Poto and G. Parola (eds.), Participatory rights in the environmental decision-making process and the implementation of the Aarhus Convention: a comparative perspective, (Berlin: Duncker \& Humblot, 2015), pp. 46-58, pp. 49-50.

${ }^{19}$ A. Boyle, op. cit. (2007), p. 477.

${ }^{20} \mathrm{E}$. Hey, 'The interaction between human rights and the environment in the European 'Aarhus space", Chapters, in A. Grear and L. J. Kotzé (eds.), Research Handbook on Human Rights and the Environment (Cheltenham, Edward Elgar Publishing, 2015), pp. 353-376, p. 374.

${ }^{21}$ M. Mason, 'Information disclosure and environmental rights: the Aarhus convention' 10(3) Global environmental politics, (2010), pp. 10-31, p. 11.

${ }^{22}$ M. Mason, op. cit. (2010), p. 26.

${ }^{23}$ F. Cittadino, 'Public Interest to Environmental Protection and Indigenous Peoples'rights: Procedural Rights to Participate and Substantive Guarantees', in E. J. Lohse, M. Poto and G. Parola (eds.), Participatory rights in the environmental decision-making process and the implementation of the Aarhus Convention: a comparative perspective, (Berlin: Duncker \& Humblot, 2015), pp. 76-90, p. 88. ${ }^{24}$ M. Poto, 'Strengths and Weaknesses of Environmental Participation Under the Aarhus Convention: What Lies Beyond Rhetorical Procedualisation?', in E. J. Lohse, M. Poto and G. Parola (eds.), Participatory rights in the environmental decision-making process and the implementation of the Aarhus Convention: a comparative perspective (Berlin: Duncker \& Humblot, 2015), pp. 93-104, p. 101.

${ }^{25}$ G. Parola, Environmental democracy at the global level rights and duties for a new citizenship, (London: Versita, 2013), p. 130. 
In this vein, the Aarhus Convention prescribes that the Parties shall guarantee the rights of access to information, public participation and access to justice in environmental matters. These are known as the three pillars of the Aarhus Convention. The three pillars are contained in Articles 4 and 5 (access to information), Articles 6, 7 and 8 (public participation in decision making) and Article 9 (access to justice).

The first pillar of the Aarhus Convention is dedicated to access to environmental information. There are two forms in which the public can have access to environmental information: upon request for information held by a public authority (passive form - Article 4) or when the information has to be made available promptly by a public authority (active form - Article 5). Exceptions to the right to access environmental information do apply and will be discussed in section 5.3.

For public participation, the second pillar of the Aarhus Convention establishes four regimes divided into three articles. Article 6 establishes that Parties shall guarantee the public participation of the public concerned in the decision making regarding specific activities listed in Annex I of the Convention, and they shall determine whether the same public participation requirements also apply to activities not listed in Annex I which may have a significant impact on the environment. Article 7 provides for the participation of the public selected by the public authority in the preparation of plans and programmes, and it refers to some paragraphs of Article 6 being applicable in this case. Distinctly, Article 7 prescribes weaker requirements in the preparation of policies. It requires that Parties only endeavour to provide for public participation but without any precise requirements for how and when public participation should be ensured. Article 8 provides for an even more loose regime by asking Parties to strive to promote public participation in the preparation of executive regulations and generally applicable legally binding normative instruments by public authorities.

In the event that the first two pillars are breached, the third pillar (Article 9) provides for access to justice in order to secure these rights. The first paragraph of Article 9 ensures that the public has access to a court, or another independent and impartial body established by law to protect their right guaranteed under Article 4 (information requests). The second paragraph of Article 9 states that members of the public concerned that have a sufficient interest or impairment of a right have access to review procedures relating to a breach of public participation requirements under Article 6 (decisions on specific activities). ${ }^{26}$ Furthermore, paragraph 3 of Article 9 requires that Parties ensure that members of the public

\footnotetext{
${ }^{26}$ Article 9(2) AC can also apply to "other relevant provisions" of the Convention if provided for under national law. Therefore, the Parties have the discretion to extend the review procedures prescribed in Article 9(2) AC to be applicable to other provisions of the Convention.
} 
have access to administrative or judicial procedures in case of any violation of national environmental law. ${ }^{27}$

\subsection{A regional convention with global relevance}

Although it is a UNECE regional convention, the Aarhus Convention has the potential to become a global convention. ${ }^{28}$ Article 19(3) of the Aarhus Convention states that, upon approval of the Meeting of the Parties (MoP), any UN Member State can accede to the Convention. In the 2010 Extraordinary Session of the Meeting of the Parties, the MoP "mandated the Working Group of the Parties to consider the procedure for decision-making concerning expressions of interest in accession to the Convention by non-UNECE States and on that basis to propose, if appropriate, a decision regarding the process of accession to the Convention for adoption at the fourth session of the Meeting of the Parties." 29

In 2011, during the Fourth session of the Meeting of the Parties, the MoP adopted a decision encouraging and setting out the procedural steps for the approval of accession by nonUNECE States. ${ }^{30}$ During the fifth Meeting of the Parties, it was suggested that the Convention should be amended to remove the provision requiring that the accession of non-ECE members must be approved by the MoP. ${ }^{31}$ The argument was that there was no similar requirement for non-ECE members that would like to access the Protocol on Parties to the Protocol on Pollutant Release and Transfer Registers, which is a legally binding international instrument for the regulation of pollution information. ${ }^{32}$ However, no decision was made on

${ }^{27}$ Article 9(3) AC will be discussed in connection with the enforcement of the second pillar of the Aarhus Convention, see section 5.3.

${ }^{28}$ E. Morgera, 'An Update on the Aarhus Convention and its Continued Global Relevance' 14(2) Review of European Community \& International Environmental Law, (2005), pp. 138-147, p. 138.

${ }^{29}$ European Commission, Aarhus Convention Implementation Report (2014a), p. 5.

${ }^{30}$ Decision IV/5 on accession to the Convention by non-United Nations Economic Commission for Europe Member States Adopted by the Meeting of Parties to the Convention on Access to Information, Public Participation in Decision-Making and Access to Justice in Environmental Matters at its fourth session (2011), p. 26-27.

31 "Representatives of Switzerland and the European ECO Forum suggested amending the text of the Convention to remove the current provision requiring approval by the Meeting of the Parties for such accessions, also noting that there was no such provision regarding approval for States outside the ECE region that wished to join the Protocol on PRTRs." Meeting of the Parties to the Convention on Access to Information, Public Participation in Decision-making and Access to Justice in Environmental Matters, Report of the fifth session of the Meeting of the Parties ECE/MP.PP/2014/2, (2014b), p. 11, para 37.

${ }^{32}$ Meeting of the Parties to the Convention on Access to Information, Public Participation in Decisionmaking and Access to Justice in Environmental Matters, Report of the fifth session of the Meeting of the Parties ECE/MP.PP/2014/2, (2014b), p. 11, para 37. "The objective of this Protocol is to enhance public access to information through the establishment of coherent, integrated, nationwide pollutant 
this matter. The topic was revisited in the sixth session of the MoP in 2017. A representative of the European ECO Forum suggested removing the requirement of approval for the accession of non-ECE countries by the MoP from the text of the Convention, via an amendment. ${ }^{33}$ The MoP only took note of the statement by the European ECO Forum representative ${ }^{34}$ and no further decision was taken on this topic. ${ }^{35}$

Viewed alongside this uncertainty, current developments suggest that it is unlikely that the Aarhus Convention will be ratified on a global scale. To date, all 47 Parties to the Convention are part of the UNECE region, ${ }^{36}$ but not all UNECE member states are Parties to the Aarhus Convention. This is the case for the Russian Federation, Canada and the United States, which are members of the ECE but have not signed the Aarhus Convention. ${ }^{37}$ As of yet, only three non-UNECE members have submitted official expressions to the secretariat (Cameroon in

release and transfer registers (PRTRs) in accordance with the provisions of this Protocol, which could facilitate public participation in environmental decision-making as well as contribute to the prevention and reduction of pollution of the environment." Article 1, Protocol on Pollutant Release and Transfer Registers to the Convention on Access to Information, Public Participation in Decision-Making and Access to Justice in Environmental Matters, Kiev, 21 May 2003, United Nations, Treaty Series, vol. 2626, p. 119. Doc. MP.PP/2003/12 (entered into force on 8 October 2009). (hereinafter Kiev Protocol) ${ }^{33}$ Meeting of the Parties to the Convention on Access to Information, Public Participation in DecisionMaking and Access to Justice in Environmental Matters, Report of the sixth session of the Meeting of the Parties (2017a), p.17, para 71.

${ }^{34}$ Meeting of the Parties to the Convention on Access to Information, Public Participation in DecisionMaking and Access to Justice in Environmental Matters, Report of the sixth session of the Meeting of the Parties (2017a), p. 17, para 73.

35 There is no further decision regarding the accession to the Convention by non-ECE members, as the report of the sixth session of the MoP containing the decisions adopted by the MoP shows. Meeting of the Parties to the Convention on Access to Information, Public Participation in Decision-Making and Access to Justice in Environmental Matters, Report of the sixth session of the Meeting of the Parties Addendum - Decisions adopted by the Meeting of the Parties ECE/MP.PP/2017/2/Add.1, (2017b).

${ }^{36}$ Chapter XXVII - Environment - 13. Convention on Access to Information, Public Participation in Decision-Making and Access to Justice in Environmental Matters, 26 June 2019, https://treaties.un.org/Pages/ViewDetails.aspx?src=TREATY\&mtdsg_no=XXVII-

$13 \&$ chapter $=27 \&$ lang $=$ en.

${ }^{37}$ V. Koester, 'The Convention on Access to Information, Public Participation in Decision-Making and Access to Justice in Environmental Matters (Aarhus Convention)', in G. Ulfstein, T. Marauhn and A. Zimmermann (eds.), Making Treaties Work, Human Rights, Environment and Arms Control, (Cambridge: Cambridge University Press, 2007), pp. 179-217. 
$2010^{38}$, Mongolia in $2011^{39}$ and Guinea-Bissau in $2017^{40}$ ), while Morocco communicated its "potential interest in acceding to the Convention" in $2014 .{ }^{41}$ In addition to these developments, at the time of writing, these countries had not yet acceded to the Convention.

Furthermore, the UN Economic Commission for Latin America and the Caribbean (ECLAC) adopted a regional treaty on access to environmental information, public participation and access to justice in environmental matters. ${ }^{42}$ It is apparent from this development that the more widespread codification and ratification of the rights contained in the Aarhus Convention are more likely to occur at the regional level, through the proliferation of similar treaties, rather than through a global ratification of the Convention itself. This development resembles the elaboration of parallel regional regimes to provide for the protection of human rights. The preference for this approach does not preclude the Convention from having a global significance; it has already inspired further developments in this area and will probably continue to do so. ${ }^{43}$ For instance, the Organization of America States (OAS) has recognised the Aarhus Convention as "a good example of a mechanism that formalizes the States Parties' commitments to the three access areas [information, participation and justice]". ${ }^{44}$ As the first group of states to draw up a binding convention on procedural environmental rights, the experience of the Parties to the Aarhus Convention is unique, and other countries can learn from their success as well as the obstacles they have faced in implementing the Convention.

\footnotetext{
${ }^{38}$ European Commission, Aarhus Convention Implementation Report, C(2017) 5129 final, (2014a), p. 5 .

${ }^{39}$ Meeting of the Parties to the Convention on Access to Information, Public Participation in DecisionMaking and Access to Justice in Environmental Matters, Report of the fourth session of the Meeting of the Parties (ECE/MP.PP/2011/2) (2011), 9, para 34.

${ }^{40}$ Meeting of the Parties to the Convention on Access to Information, Public Participation in DecisionMaking and Access to Justice in Environmental Matters, Report of the sixth session of the Meeting of the Parties (2017a), p. 16-17, para 70.

${ }^{41}$ Meeting of the Parties to the Convention on Access to Information Public Participation in DecisionMaking and Access to Justice in Environmental Matters, Report of the fifth session of the Meeting of the Parties (2014b), p. 11, para 37.

${ }^{42}$ Regional Agreement on Access to Information, Public Participation and Justice in Environmental Matters in Latin America and the Caribbean, Escazú on 4 March 2018 (not yet entered into force).

${ }^{43}$ U. Etemire, Law and Practice on Public Participation in Environmental Matters: The Nigerian Example in Transnational Comparative Perspective, (New York: Routledge, 2015), p. 13.

${ }^{44}$ Organization of American States, Inter-American Strategy for the Promotion of Public Participation in Decision-Making for Sustainable Development (2011), p. 24.
} 


\subsection{Shaping the meaning of the Aarhus Convention}

\subsubsection{The Compliance Committee's findings}

Certain provisions of the Aarhus Convention are worded in a general manner. Others, despite their precision, still confer a large margin of discretion on the Parties regarding how they can fulfil the relevant obligations. ${ }^{45}$ This means that further interpretations will be needed to clarify what is understood as a proper implementation of the Convention by the Parties. This interpretation is undertaken by domestic courts and also by the Aarhus Convention Compliance Committee (ACCC). The ACCC was created in the first Meeting of the Parties in $2002 .{ }^{46} \mathrm{It}$ is a board composed of nine members ${ }^{47}$ who are nominated by the Parties and/or environmental non-governmental organisations and elected by the MoP by consensus. ${ }^{48}$ The

${ }^{45}$ As observed by Mercadié: "To meet local needs and cover the wide range of possible situations, the
participation framework must be sufficiently flexible. Such flexibility appears to be taken into account by the Aarhus Convention. Firstly, because the wording of certain provisions is general (Article 7). Secondly, because the wording of the more normative provisions retains genuine flexibility (Article 6)." A. Mercadié, Application of the Aarhus Convention in the Integrated Coastal Zone Management (ICZM) Process (1999), p. 13. On the ambiguous nature of the text of the Aarhus Convention see Lee and Abbot: "Although access to information is the strongest, and perhaps least controversial, pillar of the Aarhus Convention, it is by no means completely straightforward. The relevant articles are ambiguous in places, leaving room for state (or EC) discretion, and its interaction with the range of existing provisions may be awkward." M. Lee and C. Abbot, 'The Usual Suspects? Public Participation Under the Aarhus Convention' 66(1) The Modern Law Review, (2003), pp. 80-108, p. 93.

Rose-Ackerman and Halpaap stated that the language of the Convention can be "sometimes vague and deferential to existing national laws." S. Rose-Ackerman and A. A. Halpaap, 'The Aarhus convention and the politics of process: the political economy of procedural environmental rights' Research in law and economics: a research annual, (2002), pp. 1-42, p. 4.

${ }^{46}$ The Meeting of the Parties is the main body of the Convention which meets every two years to ensure the review of compliance of the Convention. For all the tasks and powers held by the MoP, see Article 10 AC.

${ }^{47}$ Originally the Committee was composed of eight members, according to Meeting of the Parties to the Convention on Access to Information Public Participation in Decision-Making and Access to Justice in Environmental Matters, Report of the first Meeting of the Parties - Decision I/7 Review of Compliance (2002), Annex, section I.1. The number of members changed to nine from the third ordinary meeting of the Parties which took place in 2008. Meeting of the Parties to the Convention on Access to Information Public Participation in Decision-Making and Access to Justice in Environmental Matters, DECISION II/5 General Issues of Compliance (2005), Addendum, section 12.

${ }^{48}$ Failing consensus, the MoP shall elect the members by secret ballot. Meeting of the Parties to the Convention on Access to Information Public Participation in Decision-Making and Access to Justice in Environmental Matters, Report of the first Meeting of the Parties - Decision I/7 Review of Compliance (2002), Annex, section I.7. 
members act in their personal capacity. ${ }^{49}$ They make a solemn declaration that they will perform their functions impartially and conscientiously, ${ }^{50}$ which must also be signed in writing as requested by the Committee. ${ }^{51}$

The main role of the Committee is to examine, report and make recommendations to the MoP on issues related to Parties' compliance with the Convention. The MoP can then decide on the adoption of the recommendations and take suitable action. ${ }^{52}$

A request to review a Party's compliance can be initiated in five different ways: a) a submission from a Party regarding compliance by another Party ${ }^{53}$ b) a submission from a Party concerning its own compliance ${ }^{54}$ c) a referral by the secretariat to the Committee $; 5$

\footnotetext{
${ }^{49}$ Meeting of the Parties to the Convention on Access to Information Public Participation in DecisionMaking and Access to Justice in Environmental Matters, Report of the first Meeting of the Parties Decision I/7 Review of Compliance (2002), Annex, section I.11.

${ }^{50}$ Meeting of the Parties to the Convention on Access to Information Public Participation in Decision<aking and Access to Justice in Environmental Matters, Report of the first Meeting of the Parties Decision I/7 Review of Compliance (2002), Annex, section I.11.

${ }^{51}$ United Nations Economic Commission for Europe, 'Guide to the Aarhus Convention Compliance Committee' (Geneva: United Nations, 2017), p. 9.

${ }^{52}$ Meeting of the Parties to the Convention on Access to Information Public Participation in DecisionMaking and Access to Justice in Environmental Matters, Report of the first Meeting of the Parties Decision I/7 Review of Compliance (2002)., Annex, section III.13. J. Jendrośka, 'Aarhus Convention Compliance Committee: Origins, Status and Activities' 8(4) Journal for European Environmental \& Planning Law, (2011a), pp. 301-314, p. 304.

${ }^{53}$ Meeting of the Parties to the Convention on Access to Information Public Participation in DecisionMaking and Access to Justice in Environmental Matters, Report of the first Meeting of the Parties Decision I/7 Review of Compliance (2002), Annex, section IV.15.

${ }^{54}$ Meeting of the Parties to the Convention on Access to Information Public Participation in DecisionMaking and Access to Justice in Environmental Matters, Report of the first Meeting of the Parties Decision I/7 Review of Compliance (2002), Annex, section IV.16. According to Article 12 of the Aarhus Convention, the secretariat is the Executive Secretary of the Economic Commission for Europe (ECE). He or she is appointed by the Secretary-General of the United Nations. United Nations, Terms of Reference and Rules of Procedure of the Economic Commission for Europe (2009), para 17.

${ }^{55}$ Meeting of the Parties to the Convention on Access to Information Public Participation in DecisionMaking and Access to Justice in Environmental Matters, Report of the first Meeting of the Parties Decision I/7 Review of Compliance (2002), Annex, section V.17.
} 
d) a communication by members of the public concerning a Party's compliance,${ }^{56}$ or e) the Committee can start a compliance exam on its own initiative (proprio motu). ${ }^{57}$

The Aarhus Convention compliance mechanism is one of the few mechanisms in international environmental law that allows members of the public to address their concerns about a Party's compliance directly to a board of independent experts nominated to analyse the merits of the communication. ${ }^{58}$ On the one hand, this allows for public control in monitoring the implementation of the Convention; on the other hand, "the Compliance Committee cannot issue binding decisions, but rather may make recommendations either to the MoP, or, in certain circumstances, directly to individual Parties". ${ }^{59}$ Therefore, the power of the Committee is recommendatory and, consequently, the Meeting of the Parties has the power to consider whether or not to adopt its recommendations. ${ }^{60}$ As the highest authority of the Convention, the MoP, upon consideration of a report and any recommendations of the Committee, may take appropriate measures and accordingly: a) make recommendations and advice and assist Parties on the Convention's implementation; ${ }^{61}$ b) request the Party concerned to submit a strategy plan and to report on its implementation; ${ }^{62} \mathrm{c}$ ) recommend the Party concerned on specific measures raised by the member of the public; ${ }^{63} \mathrm{~d}$ ) declare non-

\footnotetext{
${ }^{56}$ Meeting of the Parties to the Convention on Access to Information Public Participation in DecisionMaking and Access to Justice in Environmental Matters, Report of the first Meeting of the Parties Decision I/7 Review of Compliance (2002), Annex, section VI.18.

57 "Guidance Document on the Aarhus Convention Compliance Mechanism." United Nation Economic Commission for Europe, www.unece.org/env/pp/compliance/CC_GuidanceDocument.doc. p. 1.

${ }^{58}$ United Nations Economic Commission for Europe, 'Guide to the Aarhus Convention Compliance Committee' (Geneva: United Nations, 2019), p. 6.

${ }^{59}$ United Nations Economic Commission for Europe, 'Guidance Document on the Aarhus Convention Compliance Mechanism' (Geneva: United Nations, 2010), p. 1.

${ }^{60}$ F. Marshall, 'Two Years in the Life: The Pioneering Aarhus Convention Compliance Committee 2004-2006’ 8(1) International Community Law Review, (2006), pp. 123-154, p. 133.

${ }^{61}$ Meeting of the Parties to the Convention on Access to Information Public Participation in DecisionMaking and Access to Justice in Environmental Matters, Report of the first Meeting of the Parties Decision I/7 Review of Compliance (2002), Annex, section XII.37(a) and (b).

${ }^{62}$ Meeting of the Parties to the Convention on Access to Information Public Participation in DecisionMaking and Access to Justice in Environmental Matters, Report of the first Meeting of the Parties Decision I/7 Review of Compliance (2002), Annex, section XII.37(c).

${ }^{63}$ Meeting of the Parties to the Convention on Access to Information Public Participation in Decisionmaking and Access to Justice in Environmental Matters, Report of the first Meeting of the Parties Decision I/7 Review of Compliance (2002), Annex, section XII.37(d).
} 
compliance $;{ }^{64}$ e) issue a caution; ${ }^{65}$ f) suspend a Party; ${ }^{66}$ or g) take "other non-confrontational, non-judicial and consultative measures". ${ }^{67}$

In the international realm, the relevance of the findings and recommendations of the Compliance Committee will discussed in section 3.5 in view of their importance for the interpretation of the Aarhus Convention. In the EU realm, even if it is not followed by the Court of Justice of the European Union (CJEU), Advocate General Jääskinen stated (in the context of the interpretation of EU law in light of the Aarhus Convention) that "reference should also be made to the position adopted by the Aarhus Convention Compliance Committee $[\ldots] " .68$

\subsubsection{The Aarhus Convention Implementation Guide}

The Aarhus Convention: An Implementation Guide was developed with the support of the Parties. ${ }^{69}$ By the time the Guide was published, the Second Meeting of the Signatories to the Convention noted that "it was hoped that the Guide would serve as a valuable tool to assist countries in implementing the Convention."70 This shows the support of the Parties in the

${ }^{64}$ Meeting of the Parties to the Convention on Access to Information Public Participation in Decision-
making and Access to Justice in Environmental Matters, Report of the first Meeting of the Parties Decision I/7 Review of Compliance (2002), Annex, section XII.37(e).

${ }^{65}$ Meeting of the Parties to the Convention on Access to Information Public Participation in Decisionmaking and Access to Justice in Environmental Matters, Report of the first Meeting of the Parties Decision I/7 Review of Compliance (2002), Annex, section XII.37(f).

${ }^{66}$ Meeting of the Parties to the Convention on Access to Information Public Participation in Decisionmaking and Access to Justice in Environmental Matters, Report of the first Meeting of the Parties Decision I/7 Review of Compliance (2002), Annex, section XII.37(g).

${ }^{67}$ Meeting of the Parties to the Convention on Access to Information Public Participation in Decisionmaking and Access to Justice in Environmental Matters, Report of the first Meeting of the Parties Decision I/7 Review of Compliance (2002), Annex, section XII.37(h). C. Pitea, op. cit. (2009), pp. 240241. S. Stec, 'Aarhus Environmental Rights' in Eastern Europe' 5 Yearbook of European environmental law, (2005), pp. 1-22, p. 18.

${ }^{68}$ AG Opinion in Joined Cases C-401/12 P to C-403/12 P Council of the European Union, European Parliament and European Commission v. Vereniging Milieudefensie and Stichting Stop Luchtverontreiniging Utrecht, 8 May 2014, ECLI:EU:C:2014:310, para 114. See also: A. Delgado Casteleiro, The Effects of International Dispute Settlement decisions in EU Law', in M. Cremona, A. Thies and R. A. Wessel (eds.), The European Union and international dispute settlement, (Oxford: Hart Publishing, 2017), pp. 302, p. 210.

${ }^{69}$ Meeting of the Signatories to the Convention on Access to Information, Public Participation in Decision-making and Access to Justice in Environmental Matters, Report on the first meeting (1999), para 40 (a).

70 "The Meeting was informed that the Implementation Guide on the Convention, produced as a collaborative project of the Regional Environmental Center for Central and Eastern Europe (REC), the Danish Environmental Protection Agency and ECE, had reached the point of publication. Advance 
elaboration and use of the Guide to aid in the interpretation and implementation of the Convention. The Implementation Guide has also been referred to in the findings and recommendations of the Aarhus Convention Compliance Committee. ${ }^{71}$ In view of these elements, and despite the non-binding status, the Implementation Guide can be considered nonetheless an important source. ${ }^{72}$

In the European realm, the CJEU stresses the non-legal character of the Guide, but it has also recognised its relevance for the interpretation of the Convention ${ }^{73}$ and referred to the Implementation Guide in its decisions. ${ }^{74}$ As stated by Advocate General Kokott, ${ }^{75}$ the Guide constitutes a source for the interpretation of the Aarhus Convention. However, the CJEU has also expressly disagreed with the Guide's interpretation. ${ }^{76}$

copies of the Guide, in English and in Russian, were distributed to participants. The foreword to the Guide had been contributed by the United Nations Secretary General, Mr. Kofi Annan. It was hoped that the Guide would serve as a valuable tool to assist countries in implementing the Convention." Meeting of the Signatories to the Convention on Access to Information, Public Participation in Decision-making and Access to Justice in Environmental Matters, Report on the second meeting (2000), para 43.

${ }^{71}$ Ms. Artmann concerning compliance by Czechia ECE/MP.PP/C.1/2017/3, 13 September 2016, para 99, and the Environmental Law Foundation concerning compliance by the United Kingdom of Great Britain and Northern Ireland ECE/MP.PP/C.1/2016/10, 17 June 2015, para 71 and 99.

${ }^{72}$ In this vein, Jassen reiterates that the Implementation Guide has no legal value and, regarding its relevance for interpretation, caution should be used: "Although this implementation guide has an enormous value for the interpretation and implementation of the Convention, one must keep in mind that it was drawn up by the NGOs, who were actively involved in the drafting process of the Convention. So, while the information in the Implementation Guide comes from a 'privileged source', it might also be coloured or perhaps even biased by the point of view of the NGOs. Yet, one should not underestimate its moral authority." K. Janssen, The availability of spatial and environmental data in the European Union at the crossroads between public and economic interests, (Austin: Wolters Kluwer, 2010), pp. 255, footnote 261.

73 Case C-182/10, Marie-Noëlle Solvay and Others v. Région Wallonne 16 February 2012, ECLI:EU:C:2012:82, para 27.

74 Case C-260/11, David Edwards and other v. Environment Agency, 11 April 2013, ECLI:EU:C:2013:221, para 34.

75 Opinion of Advocate General Kokott in Case C-266/09 Stichting Natuur en Milieu, Vereniging Milieudefensie, Vereniging Goede Waar \& Co. v. College voor de toelating van gewasbeschermingsmiddelen en biociden, 23 September 2010, ECLI:EU:C:2010:546, para 88.

${ }^{76}$ For instance, in Case C-204/09, Flachglas Torgau GmbH v. Federal Republic of Germany, 14 February 2012, ECLI:EU:C:2012:71, para 36. 


\subsubsection{The Court of Justice of the European Union}

In the European Union context, which is the focus of the next chapters of this thesis, the Court of Justice of the European Union (CJEU) interprets EU law to ensure that it is consistent in all Member States and that EU institutions comply with EU law. ${ }^{77}$ As the Aarhus Convention is part of EU law, the CJEU may be requested to interpret the Aarhus Convention when, among other things, it needs to rule on the EU secondary legislation which has transposed the Convention's obligations into EU law. The challenge of an EU measure can occur either through direct action under Article 263 TFEU or through the preliminary ruling procedure pursuant to Article 267 TFEU. ${ }^{78}$ In either case, the ruling of the CJEU will constitute a source of interpretation in the EU realm. The interpretation of the court will be analysed alongside the text while examining the implementation of the Aarhus Convention into EU law and especially while discussing the specifics of the case studies. The possible synergies between the interpretations of the Court and the Compliance Committee will be specifically highlighted.

\section{The Aarhus Convention and climate change}

The Aarhus Convention does not include the terms climate change or GHG emissions and this raises the question of whether and, if so, to what extent the climate change problem is part of the scope of the Convention or not. To answer this question, it is necessary to determine what the term environmental encompasses and whether climate change is part of its scope, since, as mentioned above, the Aarhus Convention covers access to environmental information and public participation in governmental environmental decision making.

To arrive at the determination of whether the Aarhus Convention captures the climate change problem, the word environmental needs to be interpreted. To do so, the Vienna Convention

\footnotetext{
77 Article 19, Consolidated Version of the Treaty on European Union, OJ C 326/13.

${ }^{78}$ Consolidated Version of the Treaty on the Functioning of the European Union, OJ C 326/47. See: C. Backes and M. Eliantonio, 'Access to court for environmental NGOs at European and national level: improvements and room for improvement since Maastricht?', in M. de Visser and A. P. van der Mei (eds.), The Treaty on European Union 1993-2013: Reflections from Maastricht (Cambridge, Antwerp, Portland: Intersentia, 2013), pp. 557-580, pp. 568-569. Although outside of the scope of this thesis, since it concerns actions taken at the Member State level, infringement proceedings may also offer an interpretation of the Aarhus Convention. According to Article 258 TFEU, the Commission has the right to initiate infringement proceedings against a Member State which failed to comply with its (environmental) obligations. The Commission may ultimately bring the non-compliant Member State before the CJEU. M. Eliantonio, 'The role of NGOs in environmental implementation conflicts: 'stuck in the middle' between infringement proceedings and preliminary rulings?' 40(6) Journal of European Integration, (2018), pp. 753-767, pp. 755-757.
} 
on the Law of the Treaties (VCLT) will be the primary point of reference. Articles 31 and 32 of the VCLT contain the rules of treaty interpretation. ${ }^{79}$

Article 31 of the VCLT lays down the general rules of interpretation, and Article 32 prescribes the supplementary means of interpretation. According to Article 32 of the VCLT, preparatory works and the circumstances of the conclusion of the treaty are to be used as a supplementary means of interpreting the Treaty. Although the preparatory work and the circumstances of the time of the adoption of the text of the Aarhus Convention will be presented first in this chapter, they will only be used to confirm the meaning resulting from the application of the general rule in Article 31 VCLT ${ }^{80}$ For the purpose of the analysis carried out in this chapter, not to follow the sequence provided in the VCLT articles does make sense since the contextualisation of the historical aspects can be presented in this manner in a more coherent way. Furthermore, starting the analysis with the historical circumstances leading up to the signing of the convention follows a chronological order that enables clearer results to be garnered from the interpretative exercise.

\subsection{Circumstances of drafting and conclusion of the Aarhus Convention}

The 1990s were a particularly active period for the discussion of environmental problems and the need to translate measures to tackle these problems into international agreements. Regarding the initiatives to combat climate change, the United Nations Framework Convention was open for signature in 1992 and entered into force in 1994, and the Kyoto Protocol was adopted in 1997. Despite this progress with regard to addressing climate change at the international level, there is no research on how this influenced the negotiations starting in 1996 and resulting in the Aarhus Convention. For this reason, the preparatory documents of the negotiation are analysed in the following section in order to determine if there is any indication that measures tackling climate change were meant to be encompassed by the Aarhus Convention.

\subsection{Climate (change) in the preparatory documents of the Aarhus Convention}

This section clarifies to what extent attention was paid to climate change during the preparation and negotiation of the Aarhus Convention, which started in 1996.

At the time of the negotiation of the Convention, there was an emerging recognition of the existence of climate change and the need to address this problem in the international community. Given the adoption of the UNFCCC in 1992, the problem of climate change was likely not out of sight during the preparation and negotiation of the Aarhus Convention.

\footnotetext{
${ }^{79}$ See Chapter II, section 1.2.

${ }^{80}$ Courts have also not followed the sequence of the articles, i.e. general rules (Article 31 ) in treaty interpretations as exemplified by R. K. Gardiner, op. cit. (2008), p. 41.
} 
Nevertheless, the final text of the Aarhus Convention does not contain any reference to climate or climate change. ${ }^{81}$

An analysis of the preparatory documents ${ }^{82}$ reveals that the inclusion of climate as one of the elements in the definition of environmental information was considered. ${ }^{83}$ The first draft of the Aarhus Convention ${ }^{84}$ included the word climate in the definition of environmental information, but this reference was removed from the definition that appears in the final version. ${ }^{85}$ The official documents provide little guidance as to the reason the word climate was omitted. In the third report on the negotiation of the Convention, two options were

\footnotetext{
${ }^{81}$ A former but shorter discussion on the coverage of climate change by the Aarhus Convention can be found in M. Peeters and S. Nóbrega, op. cit. (2014). This section builds on this article.

${ }^{82}$ An investigation of all official reports on the negotiation of the Convention was carried out to find out whether there was a discussion on climate change issues. The reports are available at: http://www.unece.org/env/pp/adwg.html.

83 'Delegations taking part in the discussion on the definition of 'environmental information' made proposals for its content. It was considered that the following elements should be covered by such a definition: human health and safety, bio-diversity, flora, fauna, soil, air, water, climate, natural resources, noise, radiation, land, protected landscapes, physical planning, land use, historic and cultural monuments or natural and cultural heritage and built structures, socio-economic conditions resulting from environmental change, biosphere, genetically modified organisms, outer space, waste, deep sea bed and chemicals." (emphasis added) Working Group for the preparation of a draft convention on access to environmental information and public participation in environmental decision-making, Report of the third session (1997d), p. 2.

${ }^{84}$ The first draft of the Convention "was produced prior to the first ad hoc working group meeting in Geneva in 1996.” E. Dannenmaier, “A European Commitment to Environmental Citizenship: Article 3.7 of the Aarhus Convention and Public Participation in International Forums' 18(1) Yearbook of International Environmental Law, (2008), pp. 32-64, p. 45.

${ }^{85}$ A definition of environmental information was contained in Article 1 (iii) of the Working Group for the preparation of a draft convention on access to environmental information and public participation in environmental decision-making, Draft elements for the Convention on Access to Environmental Information and Public Participation in Environmental Decision-making (1996), and read as follows: “"Environmental information' means any environmental information in written, visual, aural or database form in registers, reports and returns as well as computer records and other records kept otherwise than in a document. This information includes information on human health and safety, biodiversity, flora, fauna, soil, air, water, climate, natural resources, noise, radiation, land and historical monuments or other physical structures or the interaction among these factors; it also includes information on cultural heritage or socio-economic conditions resulting from alterations to those factors and on activities or measures adversely affecting, or likely to affect these factors and on activities or measures designed to protect these factors, including administrative measures and environmental management programmes as well as economic or financial analysis used in environmental decision-making" (emphasis added).
} 
proposed for the definition of environmental information (which at the time, was contained in Article 1). These were as follows: 86

"Option 1 (a) Elements of the environment such as biodiversity, flora, fauna [and other biological lifeforms], soil, atmosphere, air, water (including drinking-water), climate, natural resources, land, landscape, sites of natural or cultural interest [, built structures];

Option 2 (a) Elements of the environment, namely air, water, land and biological life." (emphasis added)

In the fourth report, the only amendment regarding this provision was the inclusion of the state of: ${ }^{87}$

"OPTION I (a) [The state of] elements of the environment such as biodiversity, flora, fauna [and other biological lifeforms], soil, atmosphere, air, water (including drinking water), climate, natural resources, land, landscape, sites of natural or cultural interest [, built structures];

OPTION II (a) [The state of] elements of the environment, namely air, water, land and biological life (biodiversity)."

Regarding these two options, the Environmental Citizens Organizations (ECO) ${ }^{88}$ stressed its preference for Option 1, since "elements such as climate change, the ozone layer, landscape, sites of natural or cultural interest and the built environment would not necessarily be covered by option $2 "{ }^{89}$ This demonstrates that, at least from the NGOs' perspective, climate changerelated information would have to be covered explicitly by the definition.

\footnotetext{
${ }^{86}$ Working Group for the preparation of a draft convention on access to environmental information and public participation in environmental decision-making, Report of the third session (1997d).

${ }^{87}$ Working Group for the preparation of a draft convention on access to environmental information and public participation in environmental decision-making, Report of the fourth session (1997b), p. 4.

${ }^{88} \mathrm{ECO}$ (which is referred to as Environmental NGOs Coalition) was a very active coalition of European NGOs and prepared a number of unofficial reports, showing the NGOs perspective on the matters discussed during the negotiation meetings. E. Dannenmaier, op. cit. (2008), pp. 41-42. Jeremy Wates was the chair of the Environmental Citizens Organizations (ECO) delegation and later became the first chair of the Secretariat and worked with the Secretariat until 2010.

${ }^{89}$ J. Wates, M. T. Nagy and S. Stec, ECO Report on the Fourth Negotiating Session and Preparatory Meetings (1997), p. 7.
} 
In the fifth report on the negotiations of the Convention, there was no discussion regarding this provision, and in the sixth report it appears that Option 1 was accepted with amendments, since the text was presented as follows: ${ }^{90}$

"(i) The state of elements of the environment, such as air and atmosphere, water, soil, land, landscape $1 /$ and natural sites, biological diversity and its components, and the interaction among these elements."

However, the term climate disappeared without further explanation. ${ }^{91}$

Apart from the suggestion to include the term climate in the definition of environmental information, the negotiation documents also reveal two other proposals which show that the climate change problem was not out of sight during the negotiations, at least for some actors involved in the negotiation process. The Czech Republic suggested that the reporting obligations in the provision related to the obligatory active dissemination of information by the government should include the Parties' contributions "to solving global environmental problems, such as climate change [...]". ${ }^{92}$ The NGOs coalition stated that a national system for pollutant release and transfer registers should incorporate a list of individual reportable substances which would include, among others, the substances "contributing to global warming [...]". ${ }^{93}$ However, these proposals were not adopted in the final text.

In conclusion, although the precise term climate change is not present in the final text of the Aarhus Convention, the analysis of the circumstances of the drafting and adoption of the Convention show that the climate change problem formed part of the discussions during the negotiation. However, remarkably, there is no explicit mention of the climate in the concluded text. This finding is a result of an examination of a supplementary source for interpreting the treaty and must be considered in view of the interpretation of the actual text and context of the Aarhus Convention, as will be carried out in the next section.

\footnotetext{
${ }^{90}$ Working Group for the preparation of a draft convention on access to environmental information and public participation in environmental decision-making, Report of the sixth session (1997c), p. 3.

${ }^{91}$ The other four reports do not deal with the content of this article. The only mention of this provision is in the report of the ninth session which states that Article 1 bis will be renumbered as Article 2 . Working Group for the preparation of a draft convention on access to environmental information and public participation in environmental decision-making, Report on the ninth session, p. 8.

${ }^{92}$ Working Group for the preparation of a draft convention on access to environmental information and public participation in environmental decision-making, Report of the fifth session (1997a), p. 6.

${ }^{93}$ Working Group for the preparation of a draft convention on access to environmental information and public participation in environmental decision-making, Report of the sixth session (1997c), p. 13.
} 


\subsection{Plain meaning of the text and context}

The analyses in this section uses the text and context of the Aarhus Convention to identify whether climate change is covered by the Convention.

The first VCLT rule of interpretation requires the interpreter to look for the plain or ordinary meaning of the words embodied in the treaty text. ${ }^{94}$ However, the word climate is not mentioned throughout the text of the Aarhus Convention, nor are definitions of environment or environmental matters provided.

In the absence of a term, as is the case for climate change in the Aarhus Convention, the interpreter may resort to the context of the treaty. The Aarhus Convention provides a definition of environmental information. The meaning given to environmental information acts as a guide when interpreting whether environmental issues are covered by the Convention, since it is from this definition that it becomes possible to interpret whether environmental issues, ${ }^{95}$ such as climate change, are covered by the Convention or not. Therefore, this analysis will proceed with a textual examination of the definition of environmental information contained in Article 2(3) of the Aarhus Convention.

\subsubsection{Interpretation of the term environmental information}

Environmental information is broadly defined in Article 2(3) AC as:

"any information in written, visual, aural, electronic or any other material form on:

(a) The state of elements of the environment, such as air and atmosphere, water, soil, land, landscape and natural sites, biological diversity and its components, including genetically modified organisms, and the interaction among these elements; (b) Factors, such as substances, energy, noise and radiation, and activities or measures, including administrative measures, environmental agreements, policies, legislation, plans and programmes, affecting or likely to affect the elements of the environment within the scope of subparagraph (a) above, and cost-benefit and other economic analyses and assumptions used in environmental decision-making; (c) The state of human health and safety, conditions of human life, cultural sites and built structures, inasmuch as they are or may be affected by the state of the elements of the environment or, through these elements"

This provision does not constitute an exhaustive list, but rather it provides an example of what environmental information may refer to. This means that Parties can include any other element in this provision, but it cannot narrow it down since the definition constitutes the

\footnotetext{
${ }^{94}$ A. Orakhelashvili, op. cit. (2008), p. 318.

95 J. Ebbesson, H. Gaugitsch, J. Jendrośka, F. Marshall and S. Stec, op. cit. (2014), p. 44. 
minimum requirements. ${ }^{96}$ While interpreting the provision, Parties should bear in mind that "the clear intention of the drafters, however, was to craft a definition that would be as broad in scope as possible". ${ }^{97}$ This broad interpretation of the definition of environmental was already recognised by the CJEU when the Court interpreted the definition of environmental information provided by Access to Information Directive, which mirrors the Aarhus Convention definition. ${ }^{98}$

\subsubsection{Climate change as part of the definition of environmental information}

As is clear from the aforementioned text, the word climate is not included in the definition of environmental information provided by the Convention. In light of this fact, this section will move to interpret the term environmental in the context of the whole provision in which this term in contained. In particular, the term atmosphere needs to be considered. As suggested by Koester "atmosphere is considerably broader than climate, and [that] information on climate change, taking into consideration the other elements contained in the provision on environmental information, was not needed". 99 Indeed, atmosphere is, by definition, broader than climate: the atmosphere comprises the layers of air around planet Earth. ${ }^{100}$ Weather is the condition of the atmosphere at a specific location and time, ${ }^{101}$ and the average weather of a certain area is the climate of a region. Therefore, the term

\footnotetext{
${ }^{96}$ J. Ebbesson, H. Gaugitsch, J. Jendrośka, F. Marshall and S. Stec, op. cit. (2014), p. 50.

${ }^{97}$ J. Ebbesson, H. Gaugitsch, J. Jendrośka, F. Marshall and S. Stec, op. cit. (2014), p. 50.

${ }^{98}$ The CJEU, while referring to Article 2(a) of previous Access to Environmental Information Directive (Directive 90/313), stated that: "It must be noted in the first place that Article 2(a) of the directive includes under 'information relating to the environment' any information on the state of the various aspects of the environment mentioned therein as well as on activities or measures which may adversely affect or protect those aspects, 'including administrative measures and environmental management programmes'. The wording of the provision makes it clear that the Community legislature intended to make that concept a broad one, embracing both information and activities relating to the state of those aspects." Case C-321/96, Wilhelm Mecklenburg v. Kreis Pinneberg - Der Landrat, 17 June 1998, ECLI:EU:C:1998:300, para 19.

${ }^{99}$ S. Nóbrega, Personal communication via email with the previous Chair to the Aarhus Convention Compliance Committee, Mr. Veit Koester (09 April 2013). [Access to Environmental Information].

${ }^{100}$ Intergovernmental Panel on Climate Change and S. E. Planton, 'Annex III: Glossary ', in M. Collins, R. Knutti, J. Arblaster, J. Dufresne, T. Fichefet, P. Friedlingstein, X. Gao, W. Gutowski, T. Johns and G. Krinner (eds.), Climate Change 2013: The Physical Science Basis. Contribution of Working Group I to the Fifth Assessment Report of the intergovernmental Panel on Climate Change (Cambridge, United Kingdom and New York, NY, USA: Cambridge University Press, 2013), pp. 1448, 1450.

101 "[...] this includes winds, clouds, precipitation, temperature, and relative humidity." J. H. Seinfeld and S. N. Pandis, 'Atmospheric chemistry and physics: from air pollution to climate change', Second Edition (Hoboken, New Jersey John Wiley \& Sons, 2006), p. 4.
} 
atmosphere encompasses climate. Since atmosphere is part of the definition of environmental, climate is consequently also part of the definition. ${ }^{102}$

Moreover, greenhouse gases "act as atmospheric thermal insulators"103 and one of the effects of global increases in the concentration of these gases in the atmosphere is the exacerbation of the greenhouse gas effect and the resulting climate change. ${ }^{104}$ Therefore, since climate change relates to the state of the atmosphere, and the atmosphere is included in what is considered environmental under the definition of environmental information in Article 2(3)(a) of the Aarhus Convention, climate change can be deemed to be part of what is considered environmental under the Convention.

Climate change could also be dealt within the context of Article 2(3)(b) of the Aarhus Convention, which is related to all factors (such factors being e.g. substances, energy, noise, and radiation) that affect or are likely to affect the elements of the environment. First, greenhouse gases such as carbon dioxide and methane ${ }^{105}$ are substances ${ }^{106}$ and can, therefore, be considered factors. Second, greenhouse gases are likely to affect the elements of the environment, since these gases have the potential to affect the state of the environment, particularly the atmosphere, as scientists have found that it is extremely likely that the increase in anthropogenic greenhouse gas emissions is the main cause for global warming in

${ }^{102}$ Replacing climate with the broader term atmosphere appears to justify the omission of the term when examined in isolation. However, when the definition is examined as a whole, one may wonder why air got a specific mention in the definition and climate did not. On the one hand, the inclusion of air, which could also be characterised as a narrower element of the atmosphere, suggests that the drafters of the Convention may not have considered that atmosphere would be interpreted as an umbrella term. On the other hand, perhaps the drafters understood air as being of particular importance as the substance that humans breathe and, for this reason, intended to emphasise the quality of the air in the layer of the atmosphere that is closest to the Earth's surface. In this sense, the explicit mention of air does not exclude that atmosphere also covers climate, even if it is not mentioned explicitly.

${ }^{103}$ J. H. Seinfeld and S. N. Pandis, op. cit. (2006), p. 2.

104 "The term of air pollution is often used in a misleading way. Actually, air pollution covers many phenomena which are driven by distinct processes and sometimes coupled: greenhouse effect due to the so-called greenhouse gases (e.g. carbon dioxide and methane) and the resulting climate change [...]" B. Sportisse, Fundamentals in air pollution: from processes to modelling: Springer Science \& Business Media, 2010), p. 9.

105 The Kyoto Protocol lists six greenhouses gases in its annex A: Carbon dioxide (C02), Methane (CH4), Nitrous oxide (N20), Hydrofluorocarbons (HFCs), Perfluorocarbons (PFCs), Sulphur hexafluoride (SF6).

${ }^{106}$ In scientific terms, a substance can be an element such as the oxygen $\left(\mathrm{O}_{2}\right)$ or a compound as the $\mathrm{CO}_{2}$. "A pure substance is something with a uniform and fixed composition at the nanoscopic level. As you will see, pure substances can be recognized by the unchanging nature of their properties. An element is a pure substance composed of only one kind of atom.” M. D. Joesten, J. L. Hogg and M. E. Castellion, 'The world of chemistry: essentials', Fourth Edition: Cengage Learning, 2007), p. 19. 
the mid-20 ${ }^{\text {th }}$ century. ${ }^{107}$ Therefore, greenhouse gases can be considered to be factors that affect or are likely to affect the atmosphere and, since climate change relates to the state of the atmosphere and greenhouse gases emissions affect the atmosphere, both climate change and greenhouse gases are included in what is considered environmental under the definition of environmental information in Article 2(3)(b) of the Aarhus Convention.

\subsection{Object and purpose}

Having concluded that the term environmental might be interpreted as encompassing climate change matters, the analysis now turns to examine whether such an interpretation is in line with the object and purpose of the Aarhus Convention. As clarified by Gardiner: "[I]n the Vienna rules, object and purpose function as a means of shedding light on the ordinary meaning rather than merely as an indicator of a general approach to be taken to treaty interpretation." 108

Article 1 of the Aarhus Convention, which is titled objective, states its object and purpose as follows:

"In order to contribute to the protection of the right of every person of present and future generations to live in an environment adequate to his or her health and wellbeing, each Party shall guarantee the rights of access to information, public participation in decision-making, and access to justice in environmental matters in accordance with the provisions of this Convention."

Since climate change issues, such as the threat of heatwaves ${ }^{109}$ and floods, ${ }^{110}$ are closely connected to the environmental conditions that affect human health and living conditions, the proposed interpretation the term environmental under the definition of environmental information (Article 2(3) AC) as including climate change matters is therefore in line with the objective of the Aarhus Convention of contributing to adequate living environments.

\subsection{Subsequent Agreement and Subsequent Practice}

The conclusion, reached by examining the meaning of the text, objective and purpose of the Convention, is that climate change is addressed by the Aarhus Convention. In order to give

\footnotetext{
${ }^{107}$ Intergovernmental Panel on Climate Change, op. cit. 2014b, p. 2 and 4. The term extremely likely is used throughout the report to express a level of confidence of between $95-100 \%$. Intergovernmental Panel on Climate Change, op. cit. 2014b, p. 2.

${ }^{108}$ R. K. Gardiner, op. cit. (2008), p. 190.

${ }^{109}$ Intergovernmental Panel on Climate Change, op. cit. 2014b, p. 2 and 4.

${ }^{110}$ Intergovernmental Panel on Climate Change, op. cit. 2014b, p. 2 and 4.
} 
more robustness to the argument, the analysis will continue with the examination of subsequent agreements or practice regarding the interpretation of the Aarhus Convention. ${ }^{11}$

Article 31(3)(a) of the VCLT refers to "any subsequent agreement between the Parties regarding the interpretation of the treaty or the application of its provision," while Article 31(3)(b) mentions "any subsequent practice in the application of the treaty which establishes the agreement of the parties regarding its interpretation". Although they are formulated as two different sources that can be taken into consideration for treaty interpretation, there is some overlap between the two provisions. As clearly noted by Orakhelashvili:

"There seems to be no clear-cut distinction between the concepts of subsequent agreement and subsequent practice, either in terms of the nature of the concepts or their place in terms of the structure of international law-making. For the purposes of treaty interpretation, there is hardly any substantial difference between these two elements, both of them referring to the agreement as to interpretation, except perhaps the fact that the former presumably refers to straightforward (express) agreement between the parties, while the latter seeks to infer such agreement from the practice of the application of the treaty." 112

These challenges in classifying a specific document under paragraphs a or b of Article 31(3) VCLT seem to permeate the discussion on how to classify the findings and recommendations of the Aarhus Convention Compliance Committee. ${ }^{113}$ These findings and recommendations are the instruments through which the Committee evaluates the application of the Convention by the Parties and interprets the Convention. There is no explicit provision in the decision on compliance mechanisms regarding the binding status of the findings and recommendations of the Compliance Committee. Koester understands that they can become binding if endorsed by the Meeting of the Parties. He further iterates that the endorsement by the Parties may mean "subsequent agreement between the parties regarding the interpretation of the treaty or the application of its provisions", according to Article 31(3)(a) of the Vienna Convention on the Law of the Treaties. ${ }^{114}$ Tanzi and Pitea (2011) classify the decisions of the Committee as subsequent practice for the purposes of Article 31(3)(b) VCLT in the following terms:

111 Also in view of the fact that there is no hierarchy in the elements of interpretation in Article 31 VCLT. R. K. Gardiner, 'Treaty interpretation', Second (USA: Oxford University Press, 2015), pp. 182183.

112 A. Orakhelashvili, op. cit. (2008), p. 355.

${ }^{113}$ For more information on the Committee, see section 2.3.1.

114 V. Koester, 'The Aarhus Convention Compliance Mechanism and Proceedings before its Compliance Committee', in C. Banner (ed.), The Aarhus Convention: A Guide for UK Lawyers, (Oxford: Bloomsbury Publishing, 2015), pp. 201-216, p. 205. See also Appendix 13 - Tabular Analysis of the Meeting of the Parties' Consideration of the Compliance Committee's Findings in 
"[...] any decision of the Committee, when it is backed by the MOP through adoption by consensus, may be considered as falling within the concept of 'subsequent practice' under the latter provision [Article 31(3)(b) VCLT]. This is particularly so when a given provision of the Convention has been consistently interpreted in the same way in different cases without objections by parties at the MOP." 115

Both authors agree that the Committee's findings and recommendations, once adopted by the MoP, have legal consequences on the interpretation of the Convention. Despite a possible disagreement on whether the decisions of the Committee fall within the concept of subsequent agreement or subsequent practice, the outcome is the same: the decisions of the Compliance Committee can be qualified as subsequent agreement or practice and can, therefore, be taken into consideration to interpret the meaning of its provisions. To date, all but one of the Committee's recommendations discussed during a MoP received the endorsement of the MoP. ${ }^{116}$ Furthermore, as noted by Banner, "the decisions [of the MoP] usually contain little if any additional reasoning over and above that given by the Compliance Committee." 117

Having established that the decisions of the ACCC can be taken into consideration to interpret the meaning of the provisions of the Aarhus Convention, the analysis turns to examine whether the ACCC has dealt with the definition of environmental information in view of climate change. The Compliance Committee has dealt with access to information within the context of different Communications. ${ }^{118}$ However, there are only two Communications which

Communications and referrals Concerning the Parties' Compliance in C. Banner, 'The Aarhus Convention: A Guide for UK Lawyers', (Oxford: Bloomsbury Publishing, 2015), pp. 327-330.

115 A. Tanzi and C. Pitea, 'The Interplay between EU law and International Law Procedures in Controlling Compliance with the Aarhus Convention by EU Member States', in M. Pallemaerts (ed.), The Aarhus Convention at Ten. Interactions and Tensions between Conventional International Law and EU Environmental Law, (Groningen: Europa Law Publishing, 2011), p. 380.

116 J. Jendrośka, op. cit. (2011a), p. 304. V. Koester, op. cit. (2015), p. 205. There is only one pending decision regarding the compliance by the European Union, which is planned to be discussed again in the next MoP in 2021. Meeting of the Parties to the Convention on Access to Information, Public Participation in Decision-making and Access to Justice in Environmental Matters, Report of the sixth session of the Meeting of the Parties ECE/MP.PP/2017/2 (2017a), p. 14-15.

${ }^{117}$ C. Banner, op. cit. (2015), p. 8.

${ }^{118}$ Among others, there were questions regarding whether environmental information encompasses: "a proposal to import and dispose of foreign radioactive waste" (Green Salvation (Kazakhstan) with regard to compliance by Kazakhstan UN Doc. ECE/MP.PP/C.1/2005/2/Add.1, 11 March 2005, pp. 2 and 4); "government decrees on land use and planning" (Communication by the Center for Regional Development/Transparency International Armenia, the Sakharov Armenian Human Rights Protection Center and the Armenian Botanical Society (Armenia) with regard to compliance by Armenia UN Doc. ECE/MP.PP/C.1/2006/2/Add.1, 10 May 2006, p.5); "EIA studies in their entirety, including specific methodologies of assessment and modelling techniques used in their preparation" (The non- 
deal with climate-related information, and both cases are related to renewable energy programmes. In Communication 54, the communicant alleged that insufficient or incorrect information was disseminated by the public authorities. ${ }^{119}$ For the analysis of the scope of the definition of environmental information, the allegation regarding the insufficient provision of information is relevant, since the findings of the Committee could have addressed what information should be disclosed. The Compliance Committee found that the "the Party concerned is obliged to ensure that each public authority possesses the environmental information which is relevant to its functions" but could not decide whether the Party concerned was not compliant because the allegation was not sufficiently substantiated. ${ }^{120}$ Therefore, no analysis of the scope of the definition was provided. In Communication 68, the communicant alleged that information regarding the $\mathrm{CO}_{2}$ emission savings calculations was imprecise. ${ }^{121}$ In its findings, the Committee reaffirmed the obligation of the Parties "to possess and update environmental information which is relevant for their functions"122 and added that "for public authorities engaged in decision-making regarding wind energy, this includes data arising from the application of different methods for calculating the $\mathrm{CO}_{2}$ reductions generated by wind energy projects, including data from actual measurements." 123 This finding brings clarification to the scope of environmental information regarding the information that the public authority needs to possess in the area of wind energy, i.e., the data from the measurement of $\mathrm{CO}_{2}$ reductions and therefore confirms

governmental organisation Alburnus Maior (Romania) with regard to compliance by Romenia UN Doc. ECE/MP.PP/2008/5/Add.7, 10 May 2006, p. 5); "finance contract" (The Albanian non-governmental organisation Civic Alliance for the Protection of the Bay of Vlora regarding compliance by the European Community UN Doc. ECE/MP.PP/C.1/2009/2/Add.1, 8 February 2011, pp. 5-6); and "contracts for rent of lands" (The non-governmental organisation Eco-TIRAS International Environmental Association of River Keepers regarding compliance by the Republic of Moldova UN Doc. ECE/MP.PP/C.1/2009/6/Add.3, 8 February 2011, p. 5). For more examples on what the definition of environemtal information includes, see E. Hey, 'Compliance Procedure: Aarhus Convention' Max Planck Encyclopedia of International Procedural Law [MPEiPro], (2019), para 24.

${ }^{119}$ Mr. Pat Swords concerning compliance by the European Union UN Doc. ECE/MP.PP/C.1/2012/12, 2 October 2012, para 88.

${ }^{120} \mathrm{Mr}$. Pat Swords concerning compliance by the European Union UN Doc. ECE/MP.PP/C.1/2012/12, para 90.

${ }^{121}$ Ms. Christine Metcalfe on behalf of the Avich and Kilchrenan Community Council concerning compliance by the European Union and the United Kingdom of Great Britain and Northern Ireland ECE/MP.PP/C.1/2014/5, 17 June 1998, para 51.

122 Ms. Christine Metcalfe on behalf of the Avich and Kilchrenan Community Council concerning compliance by the European Union and the United Kingdom of Great Britain and Northern Ireland ECE/MP.PP/C.1/2014/5, para 85.

${ }^{123}$ Ms. Christine Metcalfe on behalf of the Avich and Kilchrenan Community Council concerning compliance by the European Union and the United Kingdom of Great Britain and Northern Ireland ECE/MP.PP/C.1/2014/5, para 88. 
that climate-related information, particularly $\mathrm{CO}_{2}$ emissions, fall under the definition of environmental information.

\subsection{Interim conclusion}

The Aarhus Convention does not include the terms climate change or GHG emissions and this raises the question of whether, and, if so, to what extent, the climate change problem is part of the scope of the Convention. To answer this question, it was examined what the term environmental encompasses and whether climate change is part of its scope, since the Aarhus Convention covers access to environmental information and public participation in governmental environmental decision making. To carry out this research, in particular for the interpretation of the word environmental, the Vienna Convention on the Law of the Treaties (VCLT) was the primary point of reference. Articles 31 (general rules of interpretation) and 32 (the supplementary means of interpretation) of the VCLT contain the rules of treaty interpretation.

The analysis started with the historical circumstances leading up to the signing of the Convention, which is a supplementary means of interpretation. The circumstances of the conclusion and the preparatory work of the Aarhus Convention provided a nuanced perspective on how the climate change problem was part of the discussions: the preparatory works demonstrate an attempt to include the word climate and also that discussions took place regarding climate change, ${ }^{124}$ but they fail to provide a clear justification for the substitution of the first term for atmosphere, and nor for the exclusion of the term climate change.

The analysis continued with the general rules of interpretation as provided in Article 31 VCLT. Although there is no mention of the exact term climate or climate change in the text of the Convention, the definition of environmental information encompasses information on the condition of the atmosphere and consequently the climate (and climate change). Furthermore, greenhouse gases are substances and can, therefore, be considered factors that affect or are likely to affect the atmosphere, which is one of the elements listed in the definition. This interpretation is in line with the objective of the Convention, since climate change impacts may interfere with environmental conditions and affect the health and wellbeing of human beings. Hence, by examining the meaning of the text, objective and purpose of the Convention, it can be held that climate change matters are encompassed by the Aarhus Convention. The examination of subsequent agreements or practice regarding the interpretation of the Aarhus Convention could provide more elements to support this interpretation. The analysis showed that the decisions of the Aarhus Convention Compliance Committee fall within the meaning of subsequent agreement or subsequent practice

\footnotetext{
${ }^{124}$ See sections 3.1 and 3.2.
} 
according to Article 31(3)(a) and (b) VCLT. In this vein, these should be taken into consideration when interpreting the provisions of the Convention. Although the Aarhus Convention Compliance Committee has thus far dealt with only a few cases related to climate change matters, one case clearly demonstrates that climate change, and particularly $\mathrm{CO}_{2}$ emissions, have been regarded as part of the scope of the Convention. This corroborates the proposed interpretation according to which climate change falls within the scope of the term environmental, which is the closest to a definition of the environment under the Convention.

In sum, on the basis of the rules of interpretation provided in the VCLT, it is possible to conclude that climate change can be seen as being included in what is considered environmental under the definition of environmental information according to the Aarhus Convention. As previously ascertained, understanding the scope of environmental under the definition of environmental information is not only important for the provisions on access to environmental information, but it is also relevant for the other provisions of the Aarhus Convention, since, in the absence of a definition of the environment itself, it is from this definition that it becomes possible to interpret whether environmental issues are covered by the Aarhus Convention or not.

Based on the proposed interpretation, it is expected that, for instance, the following information held by public authorities falls within the definition of environmental information: the concentration of carbon dioxide in the atmosphere; the greenhouse gas emissions savings from the installation of renewable energy, such as wind power installations and solar panels; the amount of greenhouse gas emissions produced by different sectors such as agriculture, industry or transport. However, climate change is a broad term and whether any climate change-related case falls under the scope of the Convention has to be interpreted on a case-by-case basis.

\section{Access to environmental information under the Aarhus Convention and its implementation at the EU level}

\subsection{Introduction}

This section is dedicated to the first pillar of the Convention (access to environmental information), which is one of the two core rights examined in this thesis. The analysis contained in this section will explain the framework established in the Aarhus Convention and how this was implemented in the EU. This will help to understand how the right of access to environmental information has to be provided for individuals and ENGOs at the EU level. This examination, in turn, allows, in the case studies, to understand how this framework has to provide for rights to request environmental information in the field of EU climate change law. The third pillar, access to justice, will be examined only to the extent that it relates to the enforcement of the first pillar. 
One of the most important aspects of establishing the public's right of access to environmental information is deciding on the scope and content of that right. In particular, what information can be requested (ratione materiae), who the beneficiary of the right is and who is obliged to provide this information (ratione personae) are crucial. Therefore, this section will focus on the following definitions: (a) environmental information, (b) the public and (c) public authorities.

\subsubsection{The definition of environmental information}

The definition of environmental information provided by the Aarhus Convention in Article 2(3) of the Aarhus Convention was already explained in section 3.3.1.125 The definition is broad and includes a non-exhaustive list which is subject to interpretation by the Parties. However, such a definition sets the minimum standards and cannot be narrowed by the Parties.

Article 2(1)(d) of Regulation 1367/2006 (hereinafter: Aarhus Regulation), which closely follows the provisions of the Aarhus Convention, although the text is distributed across a greater number of paragraphs, provides that environmental information relates to any information in written, visual, aural, electronic, or any other material form on: (i) the state of the elements of the environment, such as air and atmosphere, water, soil, land etc.; (ii) factors, such as substances, energy, noise, radiation or waste, including radioactive waste, emissions, discharges and other releases into the environment, affecting or likely to affect the elements of the environment; (iii) measures; (iv) reports on the implementation of environmental legislation; (v) cost-benefit and economic analyses; and (vi) the state of human health and safety. Regarding climate-related information, what has been argued about the Aarhus Convention definition of environmental information applies equally to the Aarhus Regulation definition; therefore, this definition can also be regarded as encompassing climate-related information, such as the condition of the atmosphere and the concentration of greenhouse gases in the air, for the purpose of the Aarhus Regulation.

\subsubsection{The addressees of the right to environmental information: the public}

The definition of the public provided by the Aarhus Convention encompasses legal and natural persons and explicitly mentions associations, organisations and groups established in accordance with national legislation or practice. ${ }^{126}$ Under this definition, it is possible to identify three groups: (a) natural persons, (b) legal persons and (c) associations, organisations or groups. A natural person is a human being, while the concept of legal person "refers to an administratively, legislatively or judicially established entity with the capacity to enter

\footnotetext{
${ }^{125}$ Article 2(3), Aarhus Convention.

126 This wide definition applies to the provisions on access to environmental information which are discussed in section 5.2.
} 
into contracts on its own behalf, to sue and be sued, and to make decisions through agents, such as a partnership, corporation or foundation." 127 If an association, organisation or group has legal personality, it will fall under the definition, since it is a legal person. The emphasis on associations, organisations or groups, according to national legislation or practice as part of the public, suggests that associations, organisations or groups without legal personality may also be considered members of the public under these definitions. ${ }^{128}$ For instance, an $a d$ hoc organisation established to deal with water pollution in a specific municipality could be deemed part of the public if it fulfils the requirement of national legislation or practice. Such requirements must be in accordance with the objective of the Aarhus Convention to ensure broad access to environmental information. ${ }^{129}$

The Aarhus Regulation provides a definition of the public which mirrors the definition in the Convention. ${ }^{130}$ However, this definition is only used in the context of Article 4, which deals with the active form of access to environmental information, i.e. the collection and dissemination of information by public authorities without a request from the public. ${ }^{131}$

Concerning the passive form (which will be examined in section 4.2.1), Article 3 of the Aarhus Regulation provides that an applicant may request access to environmental information held by EU institutions or bodies. An applicant is defined by Article 2(1)(a) of the Aarhus Regulation as "any natural or legal person requesting environmental information". The difference between the definitions of an applicant under the Aarhus Regulation and the public under the Aarhus Conventions is that the latter explicitly includes associations, organisations or groups, in accordance with national legislation or practice. The absence of associations, organisations or groups, in accordance with national legislation or practice in the Aarhus Regulation indicates that the definition adopted at the EU level does not give special treatment to NGOs. This means that the EU's implementation of the provision limits its application to natural persons and organisations which are legal persons. Thus, the Regulation only permits associations with legal personality to request environmental information. Since the Aarhus Convention gives discretion to the Parties to define associations, groups and organisations in accordance with national legislation or practice, in the present case, EU legislation is permitted to establish such a requirement. Therefore, the Aarhus Regulation can be regarded as being in compliance with the Aarhus

\footnotetext{
${ }^{127}$ J. Ebbesson, H. Gaugitsch, J. Jendrośka, F. Marshall and S. Stec, op. cit. (2014), p. 46.

${ }_{128}$ J. Ebbesson, H. Gaugitsch, J. Jendrośka, F. Marshall and S. Stec, op. cit. (2014), p. 55.

${ }^{129}$ Article 1, Aarhus Convention. The CJEU already ruled that the establishment of a numeric criterion related to the members of an ENGO may be not acceptable when it is too restrictive. Case C-263/08, Djurgården-Lilla Värtans Miljöskyddsförening v. Stockholms kommun genom dess marknämnd, 15 October 2009, ECLI:EU:C:2009:631.

${ }^{130}$ Article 2(1)(b), Aarhus Regulation.

${ }^{131}$ See section 4.2.2.
} 
Convention since the latter does not impose an obligation on Parties to recognise Environmental Non-Governmental Organisations (ENGOs) without legal personality.

The question that arises, however, is whether the requirement of having legal personality, as required by the Aarhus Regulation, creates obstacles for the ENGOs established under the 28 different legal regimes of the Member States, should they seek to request environmental information at the EU level. The issue is very much linked to the question of standing before the CJEU.

Technically, standing of ENGOs before the European Courts is a different issue than the request for information from public authorities by ENGOs. However, at the EU level, the question of legal personality concerns both issues: ENGOs must have legal personality to request environmental information and to request an internal review, which is necessary under EU law to gain access to justice in case of an environmental law violation at the EU level. ${ }^{132}$ In the case of European Platform Against Windfarms (EPAW) v. European Commission, the Court of Justice discussed the question whether legal personality was necessary for the purpose of initiating an action against a decision that rejected the request made by the applicant for internal review. ${ }^{133}$ Despite the fact that this discussion was carried out for the purposes of assessing standing, it is, for the reason just mentioned, nevertheless relevant for the discussion of access to environmental information.

The EPAW case deals with the question of the legal personality of NGOs in the context of an action for annulment that originated from a denial of a request for internal review under the Aarhus Regulation. ${ }^{134}$ EPAW, the applicant, had initiated an action for annulment against the decision of the European Commission that rejected the request made by the applicant for internal review under Article 10 of Regulation 1367/2006 of the communication entitled 'Renewable Energy: a major player in the European energy market'. ${ }^{135}$ According to Article 263(4) TFEU, in order to be able to bring an action for annulment, the applicant should be a legal person. The Court stated that EPAW did not submit any constituting instrument or any other proof of its existence in law. ${ }^{136}$ EPAW recognised that it had no registration in any Member State of the European Union, but it argued that it was based primarily in Ireland, and this country does not require registration with the national authorities. Thus, EPAW

\footnotetext{
${ }^{132}$ Article 10, Aarhus Regulation.

133 The question of legal personality dealt with in Case T-168/13 was discussed in T. Moolenaar and S. Nóbrega, 'Access to justice: Environmental Non-Governmental Organisations according to the Aarhus Regulation' (2/2016) ELNI Review, (2016), pp. 76-84, pp. 79-81.

134 Case T-168/13, European Platform Against Windfarms (EPAW) v. European Commission, 18 March 2013, ECLI:EU:T:2014:47.

${ }^{135}$ Case T-168/13, European Platform Against Windfarms (EPAW) v. European Commission, para 5.

${ }^{136}$ Case T-168/13, European Platform Against Windfarms (EPAW) v. European Commission, para 11.
} 
claimed that "it must be recognised as having legal personality under Irish law". ${ }^{137}$ To support its argument, the organisation drew the attention of the Court to the fact that the Planning and Development Act 2000 entitles a private body or organisation that satisfies the following conditions to appeal to An Bord Pleanála, a quasi-judicial authority, against a decision on an application for development: "(i) the aims or objectives of which relate to the promotion of environmental protection, (ii) which has, during the period of 12 months preceding the making of the appeal, pursued those aims or objectives, and (iii) which satisfies such additional requirements (if any) as are prescribed under paragraph (e)" ${ }^{138}$ Under paragraph (e), the Minister could prescribe as an additional requirement "the possession of a specified legal personality and the possession of a constitution or rules". ${ }^{139}$ The Court acknowledged that such a possibility was not enforced by the Minister. ${ }^{140}$ However, the Court understood that such a right is limited to a specific field and is not capable of giving "general legal personality under Irish law", ${ }^{141}$ which would enable the organisation to bring an action before EU Courts on the basis of Article 263 (4) TFEU. ${ }^{142}$ In the absence of "constitutive instruments or of any other document relating to its constitutional structure and internal processes," it was not possible to prove its capability of acting as a responsible association in legal matters. ${ }^{143}$ In other words, in order to get standing before the EU courts, the organisation must be able to prove it has legal personality according to national law. ${ }^{144}$

The ruling of the Court does not shed light on the methods through which an organisation could possibly prove its constituency if the national law does not impose a registration requirement, as is permitted by the Aarhus Convention. Neither the Implementation Guide to the Aarhus Convention nor the case law of the Aarhus Convention Compliance Committee

${ }^{137}$ Case T-168/13, European Platform Against Windfarms (EPAW) v. European Commission, para 13. 138 Section $37(4)(d)$ of the Planning and Development Act 2000. Available at: http://www.lawreform.ie/_fileupload/Restatement/Second\%20Programme\%20of\%20Restatement/EN _ACT_2000_0030.PDF.

${ }^{139}$ Section 37(4)(e)(iii) of the Planning and Development Act 2000, as amended.

${ }^{140}$ Case T-168/13, European Platform Against Windfarms (EPAW) v. European Commission, para 15.

${ }^{141}$ Case T-168/13, European Platform Against Windfarms (EPAW) v. European Commission, para 17. 142 " [...] an applicant is a legal person if, at the latest by the expiry of the period prescribed for proceedings to be instituted, it has acquired legal personality in accordance with the law governing its constitution (see, by analogy, Case 50/84 Bensider and Others v Commission [1984] ECR 3991, paragraphs 7 and 8), or if it has been treated as an independent legal entity by the European Union institutions (Case T-161/94 Sinochem Heilongjiang v Council [1996] ECR II-695, paragraph 31, and Case T-170/94 Shanghai Bicycle v Council [1997] ECR II-1383, paragraph 26; see, with regard to professional staff associations, Case 175/73 Union syndicale - Amalgamated European Public Service Union and Others v Council [1974] ECR 917, paragraphs 11 to 13, and Case 18/74 General Union of Personnel of European Organisations v Commission [1974] ECR 933, paragraphs 7 to 9)." Case T168/13, European Platform Against Windfarms (EPAW) v. European Commission, para 23.

${ }^{143}$ Case T-168/13, European Platform Against Windfarms (EPAW) v. European Commission, para 25. ${ }^{144}$ There is no legal provision at the EU level for recognising legal personality. 
offer an explanation on this matter. In practice, at the EU level, this means that an ENGO, which is recognised in practice in a Member State, will not be able to request information at the EU level due to a lack of legal personality. A practical alternative to this problem would be to request environmental information as an individual (natural person), such as a person cooperating with the ENGO or a staff member, as this would remove the need to demonstrate legal constituency.

4.1.3. The authorities who are (and are not) subjected to the obligation to provide information

The Aarhus Convention's definition of public authorities includes all governmental authorities (national, regional and other levels); natural or legal persons with public administrative functions under national law; and those having public responsibilities or providing public services in relation to the environment. ${ }^{145}$ This detailed definition demonstrates a deliberate choice to accommodate private actors to perform environmentrelated public functions. ${ }^{146}$ Such private actors entrusted with, for instance, public responsibilities are then deemed to be a public authority according to the Aarhus Convention. ${ }^{147}$ This is extremely important in view of the measures adopted by the EU to tackle climate change by outsourcing public responsibility or functions to private actors. ${ }^{148}$ This development should not allow information on activities affecting the environment to be placed outside of the scope of procedural rights. ${ }^{149}$ In contrast, the Aarhus Regulation is applicable to "public institution, body, office or agency established by, or on the basis of, the Treaty". ${ }^{150}$ However, as rightly detailed in the preamble of the Aarhus Regulation, provisions of EU law should be consistent with that of the Aarhus Convention; ${ }^{151}$ therefore, a consistent

\footnotetext{
145 Article 2(2), Aarhus Convention.

146 J. Ebbesson, H. Gaugitsch, J. Jendrośka, F. Marshall and S. Stec, op. cit. (2014), p. 46.

${ }^{147}$ Article 2(2), Aarhus Convention.

${ }^{148}$ See for example the "issue of the European Commission's outsourcing of regulatory functions to private voluntary certification schemes [...]" J. Lin, op. cit. (2011), p. 43.

${ }^{149}$ In line with this, private entities that do not fall under the definition (i.e. which do not perform public administrative functions or provide public services) are under no obligation under the treaty. M. Mason, op. cit. (2010), p. 17. M. Mason, 'So Far but No Further? Transparency and Disclosure in the Aarhus Convention', in M. Mason and A. Gupta (eds.), Transparency in Global Environmental Governance: Critical Perspectives, (Cambridge, Massachusetts: MIT Press, 2014), pp. 83-106, p. 87.

${ }^{150}$ Article 2(1)(c) of the Aarhus Regulation reads: “'Community institution or body' means any public institution, body, office or agency established by, or on the basis of, the Treaty except when acting in a judicial or legislative capacity. However, the provisions under Title II shall apply to Community institutions or bodies acting in a legislative capacity".

${ }^{151}$ Recital 3, Preamble, Aarhus Regulation.
} 
interpretation with the Convention will allow for a definition which is at least as inclusive as the Convention. ${ }^{152}$

The Convention's definition of public authority excludes bodies or institutions acting in a judicial or legislative capacity ${ }^{153}$ and, consequently, they are not obliged to provide information under Article 4 of the Aarhus Convention. In comparison, the Aarhus Regulation also excludes from its scope "any public institution, body, office or agency established by, or on the basis of, the Treaty" when acting in a judicial or legislative capacity. ${ }^{154}$ However, according to Article 2(1)(c) of the Aarhus Regulation, which provides an exception to this general exclusion, the provisions on access to environmental information shall also be applicable to EU institutions and bodies acting in a legislative capacity, ${ }^{155}$ thereby expanding the scope of application of the right to access environmental information as provided by the Aarhus Convention.

\subsection{Forms of access to environmental information}

The Aarhus Convention prescribes two forms of acquiring environmental information from public authorities: the passive and the active. The passive form imposes the obligation on public authorities to disclose information upon the request of members of the public (Article 4), while the active form obliges public authorities to collect and disseminate information on their own initiative (Article 5). These provisions were implemented in relation to EU institutions and bodies in Articles 3, 4 and 8 of the Aarhus Regulation.

\footnotetext{
152 There is no case law interpreting the Aarhus Regulation on this matter.

153 Article 2(2), Aarhus Convention.

${ }^{154}$ Article 2(1)(c), Aarhus Regulation.

155 "In that regard, it is true that, as was noted by the General Court in paragraph 103 of the judgment under appeal, when the Commission prepares impact assessment documents, such as the documents at issue, it does not itself act in a legislative capacity. In addition, the impact assessment procedure takes place upstream of the legislative procedure sensu stricto, which does not formally begin until a legislative proposal is submitted by the Commission." Case C-57/16 P, ClientEarth v. European Commission, 4 September 2018, ECLI:EU:C:2018:660, para 86. For a discussion on the exemption provided by Article 2(2) of Directive 2003/4, see Case C-515/11, Deutsche Umwelthilfe eV v. Bundesrepublik Deutschland 18 July 2013, ECLI:EU:C:2013:523 in which the Court ruled that information regarding the preparation and adoption of normative regulations of a lower rank than a law shall be made available, at para 36; and Case C-204/09, Flachglas Torgau GmbH v. Federal Republic of Germany in which the Court decided that the legislative capacity exemption will apply only during "the period between the beginning and the end of the legislative procedure concerned", at para 76 . See also M. Peeters and S. Nóbrega, op. cit. (2014), pp. 359-360.
} 


\subsubsection{Passive access to environmental information}

Article 4 of the Aarhus Convention establishes the right of the public to obtain existing environmental information from public authorities upon request. This is commonly called passive access to environmental information, because the public authority remains inert until a member of the public exercises her or his right to request environmental information. In order to implement this provision, Parties are obliged to establish a system which allows a member of the public to request environmental information from a public authority. ${ }^{156}$ The Aarhus Convention prescribes that the requested environmental information must be disclosed within one month of the request being submitted. According to the Convention, this period can only be extended for one additional month in cases where it is justified by the volume and complexity of the request. ${ }^{157}$ Moreover, if the public authority imposes a fee to provide the requested environmental information, this fee should not exceed a reasonable amount. ${ }^{158}$ Article 4 of the Aarhus Convention thus establishes specific commitments: the provision of environmental information within a timeframe which can only be denied on the basis of very specific grounds. This framework clearly characterises an obligation of result, by prescribing a specific outcome, namely to provide environmental information upon the request of a member of the public and in accordance with the conditions of the Article. ${ }^{159}$ Article 4 of the Aarhus Convention has been implemented through Article 3 of the Aarhus Regulation.

Article 3 of the Aarhus Regulation stipulates that "Regulation (EC) No 1049/2001 shall apply to any request by an applicant for access to environmental information held by Community institutions and bodies". In other words, in relation to requests for environmental information, the Aarhus Regulation has to be read in combination with Regulation 1049/2001, which sets a general framework for access to documents at the EU level. According to Article 3 of Aarhus Regulation read in combination with Article 2 of Regulation 1049/2001, members of the public may request environmental information. Regulation 1049/2001 limits the right to request access to EU documents to EU citizens and any natural or legal person residing in or having its registered office in a Member State. ${ }^{160}$ The Aarhus Regulation extended the right to access environmental information to any member of the public "without discrimination as to citizenship, nationality or domicile and, in the case of a legal person, without

\footnotetext{
${ }^{156}$ Article 4(1), Aarhus Convention.

157 Article 4(2) of the Aarhus Convention reads: "The environmental information referred to in paragraph 1 above shall be made available as soon as possible and at the latest within one month after the request has been submitted, unless the volume and the complexity of the information justify an extension of this period up to two months after the request. The applicant shall be informed of any extension and of the reasons justifying it." (Emphasis added)

${ }^{158}$ Article 4(8), Aarhus Convention.

${ }^{159}$ For a discussion on obligations of effort and of result, see Chapter II, section 1.2.

${ }^{160}$ Article 2(2), Regulation 1049/2001.
} 
discrimination as to where it has its registered seat or an effective centre of its activities."161 As the Aarhus Regulation can be considered as a lex specialis vis-à-vis Regulation 1049/2001, the broader provision of the Aarhus Regulation prevails over that contained in Regulation 1049/2001 and, as a consequence, no violation of the Aarhus Convention can be detected at this instance.

The public authority concerned shall answer the request within 15 working days. This period can be extended by 15 working days in exceptional cases, such as when the application deals with a very large document or a very large number of documents. ${ }^{162}$ However, the conditions for extending the period to answer the request, i.e. volume and complexity of the requested information, are cumulative under the Aarhus Convention, while Regulation 1049/2001 allows for a deadline extension when only one of these two conditions is met, in this case, volume. ${ }^{163}$ The ACCC has emphasised that the volume of a request is not valid as a sole justification for a refusal and has offered a suggestion to the Parties on how to manage these situations:

\begin{abstract}
"Finally, information within the scope of article 4 should be provided regardless of its volume. In cases where the volume is large, the public authority has several practical options: it can provide such information in an electronic form or inform the applicant of the place where such information can be examined and facilitate such examination, or indicate the charge for supplying such information, in accordance with article 4, paragraph 8, of the Convention." 164 (Emphasis added)
\end{abstract}

As a consequence, the Aarhus Regulation read in combination with Regulation 1049/2201 allows for the refusal to provide environmental information under easier conditions than foreseen by the Aarhus Convention, which amounts to a violation of the Convention.

In regard to the timeframe, 30 working days $(2 \times 15$ days as allowed by Regulation $1049 / 2001$ ) usually amounts to six weeks, but it can be more depending on the number of holidays which will fall within that period. This means that the Aarhus Regulation requirement is somewhat stricter for the public authorities than that of the Aarhus Convention, which allows for two months. However, in practice, cases before the CJEU and

\footnotetext{
${ }^{161}$ Article 3, Aarhus Regulation corresponds to Article 3(9) AC.

162 Article 7(1) and (3), Regulation 1049/2001.

${ }^{163}$ J. J. Paradissis, 'The right to access environmental information: an analysis of UK law in the context of international, European, and comparative law', 2005, http://openaccess.city.ac.uk/8454/1/The_right_to_access_environmental_information_an_analysis_of_UK_law_in_the_context_of_international $\% 2 \mathrm{C}$ European $\% 2 \mathrm{C}$ and_comparative_la w.pdf, p. 118.

${ }^{164}$ Ukraine ACCC/C/2004/3 and ACCC/S/2004/1; ECE/MP.PP/C.1/2005/2/Add.3, 14 March 2005, para 33.
} 
the EU Ombudsman have shown that EU institutions have not respected this timeframe and, consequently, applicants have experienced long delays. ${ }^{165}$

Regarding the costs for producing and sending copies of environmental information, according to Regulation 1049/2001, the applicant may be charged for documents of more than 20 pages and but the charge should "not exceed the real cost of producing and sending the copies". ${ }^{166}$ The text of Regulation 1049/2001 could result in a breach of the Aarhus Convention if all of the costs passed on to the applicant would exceed a reasonable amount, as prescribed by Article 4(8) of the Aarhus Convention. Furthermore, Article 4(8) of the Aarhus Convention prescribes that "public authorities intending to make such a charge for supplying information shall make available to applicants a schedule of charges which may be levied, indicating the circumstances in which they may be levied or waived and when the supply of information is conditional on the advance payment of such a charge." Article 10(1) of Regulation 1049/2001 establishes the conditions for waiving the costs ("copies of less than 20 A4 pages and direct access in electronic form or through the register shall be free of charge") but there is no schedule of charges in Regulation 1049/2001. In addition, Article 7 of Commission Decision 2001/937 states that "if the volume of the documents requested exceeds twenty pages, the applicant may be charged a fee of EUR 0,10 per page plus carriage costs. The charges for other media shall be decided case by case but shall not exceed a reasonable amount." ${ }^{, 167}$ In the 2017 EU's implementation reports, the European Commission, on behalf of the EU, informed the Meeting of the Parties that requested information comprising "the EU institutions do not currently have a practice of charging for access to documents." 168 Therefore, in practice, it seems that costs impose no obstacle to accessing environmental information, since charges are not applied at the EU level, at least this was the case until 2017.

${ }^{165} \mathrm{~S}$. Wolf, 'Access to EU environmental information: EU compliance with Aarhus Convention' 14(4) ERA Forum, (2013), pp. 475-491, p. 487. On the delays by the European Commission to reply to requests, see for example: Case T-120/10, Client Earth and others v. Commission, 9 November 2011, ECLI:EU:T:2011:646, Case T-449/10, ClientEarth and others v. Commission, 9 November 2011, ECLI:EU:T:2011:647, Case T-168/13, European Platform Against Windfarms (EPAW) v. European Commission and Case T-111/11, ClientEarth v. Commission, 13 September 2013, ECLI:EU:T:2013:482. Decision of the European Ombudsman Closing His Inquiry into Complaint 339/2011/AN against the Commission (http://www.ombudsman.europa.eu/en/cases/decision.faces/en/11193/html.bookmark) and Decision of the European Ombudsman closing his inquiry into complaint 355/2007/(TN)FOR (http://www.ombudsman.europa.eu/cases/decision.faces/en/5515/html.bookmark). See also M. Peeters and S. Nóbrega, op. cit. (2014), pp. 361-362.

166 Article 10(1), Regulation 1049/2001.

${ }^{167}$ Commission Decision 2001/937/EC of 5 December 2001 amending its rules of procedure, OJ L $345 / 94$.

${ }^{168}$ European Commission, Aarhus Convention Implementation Report (2017a), p. 9. 


\subsubsection{Active access to environmental information}

The Convention provides an active right to information in Article 5, which means that in some circumstances, the public authority must provide environmental information on its own initiative. Article 5(1) creates an obligation to collect and disseminate environmental information which applies to the public authorities of the Parties. This Article also provides that the Parties have an obligation to achieve a specific result: in this case, the possession and dissemination of information. Therefore, Article 5(1) of the Aarhus Convention is also characterised as an obligation of result. ${ }^{169}$

Article 5(1)(a) of the Aarhus Convention imposes an obligation on the public authorities to possess and update environmental information relevant to their functions. One manner of collecting information from private actors is to impose self-monitoring obligations, including an obligation to keep a record of environmental data that must be periodically reported to the public authorities. ${ }^{170}$ Another potential approach is to request information as a compulsory condition of licensing and permitting procedures for their renewal by public authorities. An example of such a requirement at the moment of licensing is the publication of the Environmental Impact Assessment (EIA) in its entirety. ${ }^{171}$

Article 5(1)(b) of the Aarhus Convention requires that an informational system is established in order to ensure "an adequate flow of information to the public authorities about proposed and existing activities which may significantly affect the environment". ${ }^{172}$ The active dissemination of environmental information is strengthened by the Kiev Protocol on Pollutant Release and Transfer Registers (PRTR Protocol), which was adopted in 2003 and entered into force on 8 October 2009. ${ }^{173}$ The objective of PRTR Protocol is "to enhance public access to information through the establishment of coherent, integrated, nationwide pollutant release and transfer registers (PRTRs) in accordance with the provisions of this Protocol, which could facilitate public participation in environmental decision-making as well as contribute to the prevention and reduction of pollution of the environment."174 Furthermore, Article 5(1)(c) of the Aarhus Convention establishes that, in the event of any

\footnotetext{
${ }^{169}$ According to Article 5(1) AC, the public authority has the obligation to possess the environmental information. This information can also be requested by the member of the public under Article 4 AC. Therefore, there is a clear link between Article 5(1) AC and Article 4 AC that justifies the choice of concentrating on the first paragraph of Article 5.

${ }^{170}$ J. Ebbesson, H. Gaugitsch, J. Jendrośka, F. Marshall and S. Stec, op. cit. (2014), p. 98.

171 Alburnus Maior (concerning compliance by Romania ECE/MP.PP/2008/5/Add.7 16 April 2008, para 27.

${ }^{172}$ Article 5 (1) (b), Aarhus Convention.

${ }^{173} \mathrm{Kiev}$ Protocol, see footnote 30.

${ }^{174}$ Article 1, Kiev Protocol.
} 
imminent threat to human health or the environment, all relevant information shall be disseminated immediately and without delay to members of the public who may be affected.

The Aarhus Regulation implements Article 5(1)(a) of the Aarhus Convention by establishing that EU institutions "shall organise the environmental information which is relevant to their functions and which is held by them, with a view to its active and systematic dissemination to the public [...]". ${ }^{175}$ A distinction with the Aarhus Convention is that the Aarhus Regulation requires the EU institutions and bodies to organise the information already held by them, while the Aarhus Convention provides a clear obligation to possess environmental information.

Regarding Article 5(1)(b) of the Aarhus Convention, the Aarhus Regulation prescribes that EU institutions and bodies are also under an obligation to provide public access to a register of documents, in electronic form, and "references to documents shall be recorded in the register without delay". ${ }^{176}$ EU laws, and EU case law, among others, are made available via EurLex. ${ }^{177}$ Furthermore, the EU has established a specific register managed by the European Commission. The Commission register intends to complement the EurLex database and contains a number of different types of documents, such as communications from the Commission to other EU institutions; preparatory papers; agendas and minutes of Commission meetings; and staff working documents. ${ }^{178}$ However, some documents, such as initial drafts, may not be made available. ${ }^{179}$ The EU is also a Party to the PRTR Protocol and it has established the European Pollutant Release and Transfer

\footnotetext{
${ }^{175}$ Article 4(1), Aarhus Regulation.

176 Article 11 of Regulation 1049/2001 referred to by Article 4 of Regulation 1367/2006.

177 Available at: http://eur-lex.europa.eu/content/welcome/about.html.

178 According to the website of the Register of Commission Documents, these are the types of documents which the database contains: " $\mathrm{C} \quad$ Documents relating to official instruments for which the Commission has sole responsibility. Some are transmitted to the Council or Parliament for information; SEC Documents which cannot be classified in any of the other series; COM Proposed legislation and other Commission communications to the Council and/or the other institutions, and their preparatory papers. Commission documents for the other institutions (legislative proposals, communications, reports, etc.); SWD Commission staff working document; JOIN Commission and High Representative Joint Acts; OJ Agendas of Commission meetings PV Minutes of Commission meetings ETU References of studies entrusted by the Commission to external experts". European Commission. Help on document types, 19 June 2020, https://ec.europa.eu/transparency/regdoc/?fuseaction=helpcote.

${ }^{179}$ L. Krämer and A. Berthier, 'The Aarhus Convention: Implementation and compliance in EU law', 2014, p. 38.
} 
Register (E-PRTR), which provides environmental data from industrial installations in the EU Member States and in Iceland, Liechtenstein, Norway, Serbia, and Switzerland. ${ }^{180}$

The Aarhus Regulation also provides that, in the event of an imminent threat to human health, life or the environment, EU institutions and bodies shall, upon request of public authorities from Member States, work with those public authorities in order to enable the public authority to disseminate all relevant environmental information immediately and without delay to the public that might be affected. ${ }^{181}$ However, in contrast to what is prescribed in Article 5(1)(c) of the Aarhus Convention, EU institutions and bodies will act upon the request of Member States' public authorities, while the Aarhus Convention does not foresee a possibility for the obligation to disseminate information to be triggered by a request in these cases. Hence, the Aarhus Regulation can be regarded as being too restrictive to comply with requirements imposed by the Aarhus Convention.

Article 5 (1) (c) of the Aarhus Convention prescribes that, in the case of an imminent threat to human health or the environment, the public authority should disseminate the relevant information immediately and without delay. Article 8 of the Aarhus Regulation requires EU institutions and bodies only to act upon the request of public authorities of the Member States, and only the latter are under the obligation to disclose information immediately and without delay. ${ }^{182}$

\subsection{Grounds for refusal to provide public access to environmental information}

This section will discuss the grounds for a refusal to provide public access to environmental information as established in the Aarhus Convention and transposed at EU level. First, the Aarhus Convention exceptions to the right to have access to environmental information will be presented. Second, the implementation of these exceptions at the EU level will be discussed.

\footnotetext{
${ }^{180}$ Regulation (EC) No 166/2006 of the European Parliament and of the Council of 18 January 2006 concerning the establishment of a European Pollutant Release and Transfer Register and amending Council Directives 91/689/EEC and 96/61/EC, OJ L33/1. The European Pollutant Release and Transfer Register (E-PRTR) is available at: http://prtr.ec.europa.eu/\#/home.

${ }^{181}$ Article 8, Aarhus Regulation.

${ }^{182}$ However, EU documents "shall be recorded in the register without delay", according to Article 11(1) of Regulation 1049/2001.
} 


\subsubsection{Aarhus Convention}

According to Article 4 of the Aarhus Convention, public requests can only be refused on the basis of an exhaustive list of reasons. More precisely, refusal is permitted on formal (Article 4 (3)) or on substantive (Article 4(4)) grounds.

The Aarhus Convention stipulates that public authorities may refuse to provide information on the following formal grounds: when the public authority does not hold the environmental information; ${ }^{183}$ when the request is manifestly unreasonable or is formulated too generally; ${ }^{184}$ or when the request is for information which is still being prepared or is related to "internal communications of public authorities where such an exemption is provided for in national law or customary practice, taking into account the public interest served by disclosure." 185

Requests may also be refused on a substantive ground when the disclosure of the information would adversely affect the confidentiality of the proceedings of public authorities; ${ }^{186}$ the confidentiality of personal data and/or files relating to a natural person where that person has not consented to the disclosure of the information to the public; ${ }^{187}$ or the confidentiality of commercial and industrial information. ${ }^{188}$ Each of these grounds needs to be provided for under national law - which for the EU, as a Party to the Aarhus Convention, is EU legislation - and a ground for refusal will not be applicable if the requested information pertains to emissions that are relevant for the protection of the environment. ${ }^{189}$ Other substantive grounds are if the disclosure adversely affects international relations, national defence or public security; ${ }^{190}$ the course of justice; ${ }^{191}$ intellectual property rights; ${ }^{192}$ the interests of a third party who has supplied the information requested ${ }^{193}$ or; the environment to which the information relates. ${ }^{194}$ These substantive grounds are to be interpreted in a restrictive way, taking the public interest into account. ${ }^{195}$

\footnotetext{
${ }^{183}$ Article 4(3)(a), Aarhus Convention.

${ }^{184}$ Article 4(3)(b), Aarhus Convention.

${ }^{185}$ Article 4(3)(c), Aarhus Convention.

${ }^{186}$ Article 4(4)(a), Aarhus Convention.

${ }^{187}$ Article 4(4)(f), Aarhus Convention.

${ }^{188}$ Article 4(4)(d), Aarhus Convention.

${ }^{189}$ Article 4(4)(d), Aarhus Convention.

190 Article 4(4)(b), Aarhus Convention.

${ }^{191}$ Article 4(4)(c), Aarhus Convention.

192 Article 4(4)(e), Aarhus Convention.

${ }^{193}$ Article 4(4)(g), Aarhus Convention.

${ }^{194}$ Article 4(4)(h), Aarhus Convention.

${ }^{195}$ Article 4(4), last indent, Aarhus Convention.
} 


\subsubsection{EU's implementation}

With regard to the implementation of the grounds to refuse requests for access to environmental information, the Aarhus Regulation provides, as a starting point, that the exceptions contained in Regulation 1049/2001 will apply to requests for environmental information. However, the Aarhus Regulation has a system of derogations from the grounds of refusal contained in Regulation 1049/2001 in an effort to comply with the Aarhus Convention. It provides that the exceptions to the right to access environmental information regarding commercial interests and inspections and audits contained in Regulation $1049 / 2001$ do not apply to the request for environmental information related specifically to emissions into the environment. ${ }^{196}$ Furthermore, all other exceptions contained in Article 4 of Regulation 1049/2001 have to be interpreted in a restrictive way if the information requested relates to emissions into the environment. ${ }^{197}$ Even with this attempt to align the EU regime with the Aarhus Convention, the following incompatibilities are evident:

i) Military matters: the Aarhus Convention only provides for the possibility to refuse information if the disclosure would adversely affect national defence, ${ }^{198}$ while Regulation 1049/2001 broadens the exception by adding military matters. ${ }^{199}$ However, military matters do not always refer to defence matters. ${ }^{200}$ For instance, the renovation of a military airport or pollution due to military activities, including greenhouse gas emission during training operations, can be seen as military matters, but it is questionable whether all such operations can be considered defence matters and the information should therefore probably be disclosed on the basis of the Aarhus Convention. ${ }^{201}$

ii) Financial, monetary or economic policy of the Community or a Member State: Regulation 1049/2001 establishes in Article 4(1)(a) the non-disclosure of information, which would undermine the protection of the financial, monetary or

\footnotetext{
${ }^{196}$ Article 6(1) of the Aarhus Regulation reads: "1. As regards Article 4(2), first and third indents, of Regulation (EC) No 1049/2001, with the exception of investigations, in particular those concerning possible infringements of Community law, an overriding public interest in disclosure shall be deemed to exist where the information requested relates to emissions into the environment [...]."

${ }^{197}$ Article 6(1) of the Aarhus Regulation reads: "[...] As regards the other exceptions set out in Article 4 of Regulation (EC) No 1049/2001, the grounds for refusal shall be interpreted in a restrictive way, taking into account the public interest served by disclosure and whether the information requested relates to emissions into the environment."

198 Article 4(4)(b), Aarhus Convention.

${ }^{199}$ Article 4(1)(a), second indent, of Regulation 1049/2001.

${ }^{200}$ L. Krämer and A. Berthier, op. cit. 2014, p. 18.

${ }^{201}$ L. Krämer, 'The Aarhus Convention and the European Union', in C. Banner (ed.), The Aarhus Convention: a guide for UK lawyers, (Oxford: Hart Publishing, 2015), p. 18.
} 
economic policy of the Community or a Member State. However, the Aarhus Convention does not contain any similar provision.

iii) Commercial interest: Regulation 1049/2001 provides for non-disclosure of information that "would undermine the protection of commercial interests of a natural or legal person". ${ }^{202}$ Under the Aarhus Convention, public authorities may refuse the disclosure of information if the disclosure would adversely affect "the confidentiality of commercial and industrial information, where such confidentiality is provided by law in order to protect a legitimate economic interest". ${ }^{203}$ The Regulation broadens the Aarhus Convention exception in two aspects: 1) there is no requirement that the confidentiality is established by law; and 2) there is no qualification that the protection should concern a legitimate economic interest. Thus, this seems to allow a greater variety of interests that could be kept confidential.

iv) Legal advice: Regulation 1049/2001 provides for the refusal to disclose information if it would undermine the protection of legal advice. ${ }^{204}$ However, there is no corresponding provision in the Aarhus Convention.

v) Inspections, investigations and audits: Regulation 1049/2001 provides for non-disclosure of information that would undermine the protection of "the purpose of inspections, investigations and audits". ${ }^{205}$ The Aarhus Convention allows for the possibility of non-disclosure if the information would adversely affect "the ability of

\footnotetext{
202 Article 4(2), first indent, Regulation 1049/2001.

${ }^{203}$ Article 4(4)(d), Aarhus Convention. As mentioned above, according to Article 6(1) of the Aarhus Regulation, access to environmental information regarding commercial interests does not apply if the request for environmental information is related specifically to emissions into the environment. For all other types of environmental information, an overriding pubic interest is required by regulation 1049/2001. The requirement of having and overriding public interest (i.e. that the public interest should be considered more important than any other matter) may conflict with the Aarhus Convention which only requires to take into account the public interest. The ACCC already noted that in cases where the public interest is significant and the harm to the interests concerned is considered small, environmental information may still be deemed to be disclosed. In the words of the ACCC: "[...] The Committee wishes to point out that this exemption may not be read as meaning that public authorities are only required to release environmental information where no harm to the interests concerned is identified. Such a broad interpretation of the exemption would not be in compliance with article 4, paragraph 4 , of the Convention which requires interpreting exemptions in a restrictive way, taking into account the public interest served by disclosure. Thus, in situations where there is a significant public interest in disclosure of certain environmental information and a relatively small amount of harm to the interests involved, the Convention would require disclosure." (Emphasis added) The Albanian nongovernmental organisation Civic Alliance for the Protection of the Bay of Vlora regarding compliance by the European Community UN Doc. ECE/MP.PP/C.1/2009/2/Add.1, 8 February 2011, para. 30(c).

${ }^{204}$ Article 4(2), second indent, Regulation 1049/2001.

${ }^{205}$ Article 4(2), third indent, Regulation 1049/2001.
} 
a public authority to conduct an enquiry of a criminal or disciplinary nature". ${ }^{206}$ Therefore, the provision of Regulation 1049/2001 is much broader than that of the Aarhus Convention.

vi) Protection of decision making: Article 4(3) first part of Regulation $1049 / 2001$ provides that "access to a document, drawn up by an institution for internal use or received by an institution, which relates to a matter where the decision has not been taken by the institution, shall be refused if disclosure of the document would seriously undermine the institution's decision-making process, unless there is an overriding public interest in disclosure." Furthermore, the next part adds that "access to a document containing opinions for internal use as part of deliberations and preliminary consultations within the institution concerned shall be refused even after the decision has been taken if disclosure of the document would seriously undermine the institution's decision-making process, unless there is an overriding public interest in disclosure." The Aarhus Convention has no similar provision for the protection of the decision making of public authorities. Nonetheless, the reading of the other exceptions in the Convention may allow for a reading that allows for the compatibility of the Regulation with the Convention. According to the Aarhus Convention, public authorities may refuse the disclosure of environmental information "if the request concerns material in the course of completion or concerns internal communications of public authorities where such an exemption is provided for in national law or customary practice, taking into account the public interest served by disclosure". ${ }^{207}$ The Aarhus Convention also allows for the withholding of information if "the disclosure would adversely affect the confidentiality of proceedings of public authorities, where such confidentiality is provided for under national law". ${ }^{208}$ It could be concluded that the Regulation is compatible with the Convention.

Furthermore, the EU adopted the exceptions and additionally limited the discretion of the public authorities to decide whether to provide the requested environmental information, since Article 4(1) and (2) of Regulation 1049/2001 provides that "the institutions shall refuse access $[\ldots]$ ". This approach may not be compliant with the Aarhus Convention, as explained by Krämer and Berthier:

"Regulation 1049/2001 provides for "absolute" grounds for refusal. Article 4(1) and (2) provide that "the institutions shall refuse access...", whereas Article 4 of the Aarhus Convention states that "a request for environmental information may be refused if...". Where the Regulation sets out an obligation to refuse access, the Convention only provides the possibility of doing so. An official working for an EU

\footnotetext{
206 Article 4(4)(c), Aarhus Convention.

${ }^{207}$ Article 4(3)(c), Aarhus Convention.

${ }^{208}$ Article 4(4)(c), Aarhus Convention.
} 
institution is obliged to withhold a piece of information if it falls under the scope of an exception in Regulation 1049/2001 whereas she/he is offered a choice in deciding whether to disclose information despite the fact that an exception provided by the Aarhus Convention applies with regard to environmental information. As Regulation 1367/2006 refers to Article 4 of Regulation 1049/2001, the distinction between the obligation and the mere possibility to refuse to provide access is not correctly transposed and as a result, the quantity of information that is made publicly accessible is reduced." 209

As the comparative textual analysis reveals, there is no full compatibility between the provisions of the Aarhus Convention and Regulation 1049/2001 read in combination with Regulation 1367/2006. It is important to note that Article 4(3) and (4) of the Aarhus Convention provide an exhaustive list of exceptions and these are the only grounds on which a Party may allow public authorities to refuse a request for information. As clarified by the implementation guide to the Aarhus Convention, "[...] paragraphs 3 and 4 outline the only circumstances under which exceptions to the general rule apply." ${ }^{210}$ Consequently, national law - meaning EU law and in the present case Regulations 1049/2001 and 1367/2006 - may not exceed the limits set out in the Convention. The general rule is that information must be disclosed, ${ }^{211}$ and the optional regime of exceptions of the Convention set the ceiling for the discretion of the Parties. Nonetheless, the scope of the exceptions to access to environmental information provided at the EU level is broader than that which is allowed by the Aarhus Convention.

\subsection{Enforcing the right to access environmental information}

As explained in section 4.3, the right to access environmental information is not absolute and exceptions apply. However, if the request is ignored, wrongly refused or inadequately addressed, Article 9(1) of the Aarhus Convention provides for access to justice. According to this provision, the member of the public whose right of access to environmental information has been violated must have access to a review procedure before a court of law or another independent and impartial body established by law. The cost of seeking such a remedy must not be prohibitively expensive. ${ }^{212}$ Furthermore, when a Party provides for review by a court of law, the Party shall also ensure that the existence of an "expeditious procedure established by law that is free of charge or inexpensive for reconsideration by a public authority or review by an independent and impartial body other than a court of law." (Article 9(1) AC, emphasis added) This means that, according to the Aarhus Convention,

\footnotetext{
${ }^{209}$ L. Krämer and A. Berthier, op. cit. 2014, p. 18. The matter is still undecided, as there are no findings or recommendations of the ACCC or decision of the CJEU.

${ }^{210}$ J. Ebbesson, H. Gaugitsch, J. Jendrośka, F. Marshall and S. Stec, op. cit. (2014), p. 79.

${ }^{211}$ J. Ebbesson, H. Gaugitsch, J. Jendrośka, F. Marshall and S. Stec, op. cit. (2014), p. 86.

${ }^{212}$ Article 9(4), Aarhus Convention.
} 
Parties must ensure the presence of an administrative procedure before the applicant is able to access the court.

According to Regulation 1049/2001, applicants seeking reconsideration from an EU institution or body may submit a confirmatory application in case of a refusal or omission by the public authority. ${ }^{213}$ The confirmatory application - the term used in Regulation 1049/2001 to describe the act of the applicant asking the institution to reconsider the total or partial refusal of the request to disclose information - shall be answered within a maximum of 30 working days. ${ }^{214}$ The confirmatory application corresponds to the public authority's reconsideration prescribed by Article 9(1) of the Aarhus Convention, second subparagraph. The CJEU described the objective of these two stages as follows:

"With regard to Regulation No 1049/2001, it should be pointed out that Articles 7 and 8 of that regulation, by providing for a two-stage procedure, aim to achieve, first, the swift and straightforward processing of applications for access to documents of the institutions concerned and, second, as a priority, a friendly settlement of disputes which may arise. For cases in which such a dispute cannot be resolved by the parties, the abovementioned Article 8(1) provides two remedies, namely the institution of court proceedings or the lodging of a complaint with the Ombudsman.

That procedure, in so far as it provides for the making of the confirmatory application enables, in particular, the institution concerned to re-examine its position before taking a definitive refusal decision which could be the subject of an action before the courts of the Union. Such a procedure makes it possible to process initial applications more promptly and, consequently, more often than not to meet the applicant's expectations, while also enabling the institution to adopt a detailed position before definitively refusing access to the documents sought by the applicant, in particular where the applicant reiterates the request for disclosure of those documents notwithstanding a reasoned refusal by that institution." 215

In a case where a confirmatory decision entails the refusal of access to environmental information, in full or in part, or the institution or body does not reply within the prescribed timeframe, the applicant has the right to challenge the decision before the Court of Justice of the European Union ${ }^{216}$ or to make a complaint to the Ombudsman, pursuant to Article 8(3) of Regulation 1049/2001. The confirmatory decision is addressed to the applicant, and consequently, s/he will have access to review by a court under Article 263(4) TFEU.

\footnotetext{
${ }^{213}$ Article 7(2), Regulation 1049/2001.

${ }^{214}$ Article 8(1) and (3), Regulation 1049/2001.

215 Case C-362/08 P, Internationaler Hilfsfonds eV v. European Commission 26 January 2010, ECLI:EU:C:2010:40, para 53-54.

${ }^{216}$ First before the General Court and, in case of appeal, before the Court of Justice (Article 256 TFEU).
} 
Therefore, applicants will mostly face no standing problem while seeking judicial review before the General Court. ${ }^{217}$ However, it should be noted that a successful annulment action does not mean that the General Court will grant access to the requested documents, but only that the institution is under an obligation to re-examine its answer. ${ }^{218}$

On the basis of the analysis carried out above, it can be concluded that the provisions on access to justice regarding access to environmental information contained in Regulation 1049/2001 are in conformity with the requirements set out in the Aarhus Convention. ${ }^{219}$

However, one significant gap in the system can be identified in the fact that there is no provision to enforce the obligation of public authorities to disseminate information (active form), neither in the Aarhus Convention nor the Aarhus Regulation. Article 9(3) of the Aarhus Convention, which provides for redress in the case of a violation of national environmental law, may be of help to remedy this problem. ${ }^{220}$ This would be possible because the non-dissemination of environmental information amounts to a breach of Article 4 of the Aarhus Regulation. In turn, the violation of the Aarhus Regulation constitutes a breach of national environmental law for the purposes of Article 9(3) of the Aarhus Convention. However, at the EU level, this provision has not been fully implemented. ${ }^{221}$ This means that, in practice, a member of the public would not have access to justice in the case of a violation of the obligation to disseminate information. Furthermore, the CJEU, in a preliminary ruling, already denied direct effect to Article 9(3) of the Aarhus Convention. ${ }^{222}$ In sum, the application of the right in practice may still be problematic, as was highlighted by the Communication regarding the European Union's failure to comply with Article 9 (3) and (4) of the Aarhus Convention. ${ }^{223}$

\footnotetext{
${ }^{217}$ M. Pallemaerts, Compliance by the European Community with its obligations on access to justice as a party to the Aarhus Convention: an IIEP report for WWF-UK (2009), p. 32. See however the discussion regarding legal personality in section 4.1.2.

${ }^{218} \mathrm{H}$. Kranenborg and W. Voermans, Access to information in the European Union: a comparative analysis of EC and member state legislation, (Groningen: Europa Law Publishing, 2005), p. 36.

${ }^{219}$ L. Krämer and A. Berthier, op. cit. 2014, p. 71.

${ }^{220}$ Article 9(3) of the Aarhus Convention establishes that Parties shall ensure that the members of the public have access to administrative or judicial procedures to challenge acts and provisions which contravene provisions of its national law relating to the environment.

${ }^{221}$ M. Eliantonio, op. cit. (2018), pp. 759-762.

222 See Case C-240/09, Lesoochranárske zoskupenie VLK v. Ministerstvo životného prostredia Slovenskej republiky.

223 ClientEarth concerning compliance by the European Union (Part II), UN Doc. ECE/MP.PP/C.1/2017/7, 17 March 2017, para 123.
} 


\section{Public participation in environmental decision making under the Aarhus Convention and its implementation at the EU level}

\subsection{Introduction}

This section is dedicated to the second pillar of the Convention, which deals with public participation in governmental environmental decision making. This is one of the two core rights analysed in this thesis, the other being access to information. The analysis contained in this section will explain the framework established in the Aarhus Convention and how this was implemented in the EU. This enables an understanding of how the right to participate in governmental environmental decision making has to be provided for individuals and ENGOs at the EU level. It provides the bases for examining the public participation rights in the case studies following in the next chapters. The third pillar, access to justice, will be examined to the extent that it relates to the enforcement of public participation provisions.

\subsection{Types of public participation}

The Aarhus Convention approaches public participation in decision making in four different regimes laid down in three articles. ${ }^{224}$ The most detailed set of procedural rules relates to decisions on specific activities (Article 6). For plans, programmes and policies relating to the environment (Article 7) and the preparation of executive regulations and/or generally applicable legally binding normative instruments (Article 8), less detail is provided in terms of what the regime must entail. ${ }^{225}$

\subsubsection{Public participation in decisions on specific activities}

Article 6 of the Aarhus Convention deals with decisions that permit activities listed in Annex $\mathrm{I}^{226}$ or any other non-Annex I activity which may have a significant effect on the environment. ${ }^{227}$ According to this provision, the public concerned shall be informed early in the decision making procedure, and in an adequate and timely manner, of the details of the decision making process. ${ }^{228}$ The relevant information shall be made available at no cost to the public concerned. ${ }^{229}$ The public authority must take due account of the outcome of public

\footnotetext{
${ }^{224}$ Jendrośka, J., 2009, p. 499.

225 Jendrośka, J., 2014, p. 116.

${ }^{226}$ Article 6(1) (a), Aarhus Convention.

${ }^{227}$ Article 6(1) (b), Aarhus Convention.

${ }^{228}$ Article 6(2), Aarhus Convention.

${ }^{229}$ Article 6 (6), Aarhus Convention.
} 
participation $^{230}$ and inform the public promptly of the decision along with the reasons and considerations upon which it was based..$^{231}$

Public concerned is defined under Article 2(5) of the Aarhus Convention as "the public affected or likely to be affected by, or having an interest in, the environmental decisionmaking; non-governmental organizations promoting environmental protection and meeting any requirements under national law are considered to have an interest." The public concerned can be seen as a subgroup of the public, since only the members of the public who are affected or likely to be affected by, or having an interest in, the environmental decision making is considered the public concerned. Non-governmental organisations promoting environmental protection and meeting requirements under national law are deemed to have this interest and, therefore, fall under the scope of the definition of the public concerned. ${ }^{232}$ It is interesting to note that there was no differentiation between the public and the public concerned in the first draft of the Aarhus Convention. The first draft only contained the definition of the public, and the article related to public participation in environmental decision making, therefore, referred to the public. ${ }^{233}$ If this had been the final text, the potential number of persons entitled to participate would have been greater, since the definition of the public is broader than that of the public concerned.

Concerning implementation at the EU, in the European Commission's view, the first part of Article 6, which relates to activities listed in Annex I to the Convention (Article 6(1)(a)), did not need implementation at the EU level since the "decisions to authorise the listed activities are not taken at Community level, but by Member States, at local, regional or national level". ${ }^{234}$ Likewise, the Commission understood that Article 6(1)(b), which provides for public participation in decisions on other proposed activities "which may have a significant effect on the environment", is also not applicable at the EU level based on the following grounds:

\footnotetext{
${ }^{230}$ Article 6 (8), Aarhus Convention. Lee and Abbot state that the question on whether 'due account' may lead to an enhanced status for the outcome of the public participation is still open to debate. M. Lee and C. Abbot, op. cit. (2003), p. 97.

${ }^{231}$ Article 6 (9), Aarhus Convention.

${ }^{232}$ Article 2(5), Aarhus Convention.

${ }^{233}$ See Articles 1 and 5 of the Working Group for the preparation of a draft convention on access to environmental information and public participation in environmental decision-making, Draft elements for the Convention on Access to Environmental Information and Public Participation in Environmental Decision-making (1996).

${ }^{234}$ Proposal for a Regulation of the European Parliament and of the Council on the application of the provisions of the Århus Convention on Access to Information, Public Participation in Decision-making and Access to Justice in Environmental Matters to EC institutions and bodies, $\operatorname{COM}(2003) 622$ final C 96/22 (2004), p. 13.
} 
"Administrative decisions on the authorisation of chemicals, pesticides and biocides are, as a rule, taken at the level of Member States. Decisions taken at Community level, such as the establishment of lists of active substances or the classification of substances, are as such not aimed at as specific activities in the sense of Article 6. Regulation (EC) No 2037/2000 on ozone-depleting substances provides for administrative decisions at Community level. However, the decisions concerned do not have a significant effect on the environment, as they concern only the management of the different quota for the placing on the market or importation of such substances." ${ }^{235}$ (Emphasis added)

The question which however may be raised is whether the Commission was correct with regard to the inapplicability of Article 6(1)(b) of the Aarhus Convention at the EU level. In ACCC/C/2008/32, the communicant, ClientEarth, presented several examples to the Aarhus Convention Compliance Committee of decisions that are taken by the Commission which could fall under Article 6(1)(b), including authorisations to place on the market or the cultivation of genetically modified plants; decisions on active substances of biocidal products; and decisions on waiving the obligation for certain types of packaging from the requirement on concentration levels of heavy metals. ${ }^{236}$ This opinion clearly contradicts the point of view presented by the Commission. However, the ACCC did not provide a clear standpoint on the issue. It stated instead that:

"While the Committee does not rule out that some decisions, acts and omissions by the EU institutions - even if labelled "regulation"-may amount to some form of decision-making under articles 6-8 of the Convention, it will not carry out any examination on this issue." 237

Therefore, the ACCC did not clarify whether the decisions mentioned by the communicant would fall under the scope of the Article 6(1)(b) and would consequently also require implementation at the EU level.

5.2.2 Public participation concerning plans, programmes and policies relating to the environment

\footnotetext{
${ }^{235}$ Proposal for a Regulation of the European Parliament and of the Council on the application of the provisions of the Århus Convention on Access to Information, Public Participation in Decision-making and Access to Justice in Environmental Matters to EC institutions and bodies, $\operatorname{COM}(2003) 622$ final C 96/22 (2004), p. 13.

236 Reply from ClientEarth to the Aarhus Convention Compliance Committee's questions in Communication ACCC/C/2008/32, pp. 4-5.

237 ClientEarth concerning compliance by the European Union (Part I) UN ECE/MP.PP/C.1/2011/4/Add.1, 24 August 2011, para 72.
} 


\section{i. Aarhus Convention}

For plans and programmes, Article 7 provides legally binding language: "Each party shall make appropriate practical and/or other provisions for the public to participate during the preparation of plans and programmes relating to the environment". Furthermore, the requirements of Article 6(3), (4) and (8) apply, which means that reasonable timeframes need to be in place, that early participation must be ensured and that due account of the outcome of the public participation is taken. In relation to policies, the language is weaker, only establishing that Parties "to the extent appropriate [...] shall endeavour to provide opportunities for public participation". Thus, the obligation regarding policies established is only one of effort, while for plans and programmes, Article 7 creates an obligation of result. $^{238}$

While Article 6 of the Aarhus Convention focuses on decisions on specific activities, "where the underlying policy decisions have generally already been taken", ${ }^{239}$ Article 7 of the Aarhus Convention requires public participation during the preparation of plans, programmes and policies related to the environment. The Aarhus Convention does not specifically define plans and programmes. The Implementation Guide, however, uses as an example the definition contained in the Kiev Strategic Environmental Assessment Protocol. ${ }^{240}$ According to the protocol, plans and programmes mean the ones that are "required by legislative, regulatory or administrative provisions" and which are prepared and/or adopted "by an authority for adoption, through a formal procedure, by a parliament or a government". ${ }^{241}$ Article 7 of the Aarhus Convention also covers policies and, as with plans and programmes, it does not define policies. In a pure textual sense, policies can be considered as "a course or principle of action adopted or proposed by an organization or individual". ${ }^{242}$ According to the Implementation Guide, policies are subject to a different treatment compared to plans and programmes, because they are less concrete and they "require a more thorough and profound understanding of the legalities and political context of a particular place. Policy incorporates history and culture and entire legal frameworks that extend beyond the finite area in which they are developed." ${ }^{243}$ Apparently, a choice has been made in the Aarhus Convention to have a less stringent requirement for policies compared to plans and

\footnotetext{
${ }^{238}$ For a definition of obligation of result and obligation of effort see Chapter II, section 1.2.

${ }^{239}$ M. Lee and C. Abbot, op. cit. (2003), p. 100.

${ }^{240}$ UNECE Protocol on Strategic Environmental Assessment to the Convention on Environmental Impact Assessment in a Transboundary Context Kiev, 21 May 2003, United Nations, Treaty Series, vol. 2685, p. 140. Doc. ECE/MP.EIA/2003/2.C.N.951.2016 (entered into force on 8 October 2009).

${ }^{241}$ Article 2(5), Kiev SEA Protocol.

${ }^{242}$ A. Stevenson and M. Waite, Concise Oxford English Dictionary, (Oxford: Oxford University Press, 2011), p. 1110.

${ }^{243}$ J. Ebbesson, H. Gaugitsch, J. Jendrośka, F. Marshall and S. Stec, op. cit. (2014), p. 176.
} 
programmes. It may, however, not be easy to provide a clear distinction between, on the one hand, plans and programmes and, on the other hand, policies.

Unlike Article 6, which is directed towards the public concerned, Article 7 addresses the public. However, the public as used here is not the same as the public of the articles dealing with access to environmental information. In this case, the public will be determined by "the relevant public authority, taking into account the objective of the [Aarhus] Convention". ${ }^{244}$ This means that, as distinct from the public which is defined by the Convention in Article 2(4) and must be understood and implemented by the Parties accordingly, the public of Article 7 will be defined by the relevant public authorities. However, this should not be seen as an opportunity for the Parties to limit the scope of participation severely, since the public authority must take into account the objectives of the Aarhus Convention, which include the encouragement of widespread public participation. ${ }^{245}$

The reason for applying such a distinction regarding the addressees of the right to participate is not clear. Jendrośka suggests that the rationale behind this distinction could be to streamline public participation "in order to make it more effective". ${ }^{246}$ However, he does not give an explanation or example to clarify how introducing this distinction can make public participation more effective, particularly in light of the fact that the Convention already introduces a narrower concept of the public by providing a definition of the public concerned. The use of the term public concerned, where a more limited subset of applicants is considered desirable, would provide more certainty, as it is defined by the Convention, whereas public in Article 7 is left up to the discretion of the relevant public authorities. Furthermore, if the participation of the public, in general, was intended, then the use of the term the public, as defined in Article 2(4) of the Aarhus Convention, would allow for broader participation, as this term does not provide for any limitation.

\section{ii. EU's implementation}

The Aarhus Regulation provides for public participation only for plans and programmes but not for policies. Article 9 of the Aarhus Regulation states that institutions and bodies shall provide early and effective participation for the public, ${ }^{247}$ a time limit of at least eight weeks to receive comments and four-weeks' notice prior to meetings and hearings which can be

\footnotetext{
${ }^{244}$ Article 7, Aarhus Convention.

245 J. Jendrośka, 'Public Participation in Environmental Decision-Making: Interactions Between the Convention and EU Law and Other Key Legal Issues in its Implementation in the Light of the Opinions of the Aarhus Convention Compliance Committee', in M. Pallemaerts (ed.), The Aarhus Convention at ten: interactions and tensions between conventional international law and EU environmental law, (Groningen: Europa Law Publishing, 2011b), pp. 91-147, p. 129.

${ }^{246}$ J. Jendrośka, op. cit. (2011b), p. 129.

${ }^{247}$ Article 9(1), Regulation 1049/2001.
} 
reduced in urgent cases or when the public has already had the opportunity to comment, ${ }^{248}$ and due account of the outcome of the public participation should be taken. ${ }^{249}$ The Aarhus Regulation provides for a fixed timeframe, while the Aarhus Convention keeps the possibility of adjusting the time according to different phases and allowing sufficient time for informing the public and for ensuring effective participation during the environmental decision making. Therefore, if the fixed timeframe would hinder effective participation, then a violation of the Aarhus Convention would be at issue.

According to Article 9 of the Aarhus Regulation, in order to assess whether a document is a plan or programme some cumulative conditions apply: i.e. the measures need to be prepared or adopted by EU institutions or bodies and required by law or administrative provisions, and they need to contribute to achieving the objectives of the EU environmental policy. ${ }^{250}$ The explanatory memorandum of the Aarhus Regulation proposal refers to Commission $v$. Greece. ${ }^{251}$ In this document, the Commission, by relying on the Commission v. Greece case, states that the definition of plans and programmes encompasses all "sets of measures that, although not officially called 'plans' or 'programmes', in substance constitute an 'organised and co-ordinated system in order to reach certain objectives"”. ${ }^{252}$ Jendrośka ${ }^{253}$ argues that this judgment has to be seen in the specific regulatory context of the case and cannot be interpreted as determining "general criteria to be met by a document in order to be called 'plan'. ${ }^{254} \mathrm{He}$ explains that such an interpretation would lead to the undesirable situation where plans and programmes which do not provide an "organised and coordinated system" would be not obliged to be subject to public participation according to public participation rules for plans and programmes, despite the potential impact that it might have on the environment. ${ }^{255}$ However, he does not provide an example of such a situation. ${ }^{256}$ Krämer does

\footnotetext{
248 Article 9(4), Regulation 1049/2001.

${ }^{249}$ Article 9(5), Regulation 1049/2001.

${ }^{250}$ Article 2 (e), Aarhus Regulation. L. Krämer, op. cit. (2015), p. 90.

${ }^{251}$ Proposal for a Regulation of the European Parliament and of the Council on the application of the provisions of the Århus Convention on Access to Information, Public Participation in Decision-making and Access to Justice in Environmental Matters to EC institutions and bodies, COM(2003) 622 final C 96/22 (2004), 14.

${ }^{252}$ Ibid. Case C-387/97, Commission v. Greece, 04 July 2000, EU:C:2000:356.

${ }^{253} \mathrm{~J}$. Jendrośka, 'Public participation in the preparation of plans and programs: some reflections on the scope of obligations under Article 7 of the Aarhus Convention' 6(4) Journal for European Environmental \& Planning Law, (2009), pp. 495-515, p. 503.

${ }^{254}$ J. Jendrośka, op. cit. (2009), p. 503.

${ }^{255} \mathrm{Ibid}$. The author seems concerned that such a definition would hinder the possibility of analysing the decisions on a case basis approach.

256 There are two points of attention that need to be further explored. First, if the plan is required by law (and for the Aarhus Regulation a plan to be subject to Article 9 need to be required under legislative, regulatory or administrate provisions) then the absence of a plan which fulfils the required conditions already constitutes a breach of the relevant legislation. Second, if the plan is not required by law, should
} 
not ponder the possible further restrictive impacts of adopting such a definition and he, while referring to the same case, categorically states that "[It] is decisive that the paper constitutes an organised and coordinated system for reaching certain objectives." ${ }^{257}$ While acknowledging Jendrośka's concerns, this thesis will take the view that the plans and programmes which constitute an organised and coordinated system to reach certain objectives fall under Article 9 of the Aarhus Regulation.

While Article 7 of the Aarhus Convention also provides for public participation regarding policies, the Aarhus Regulation is silent concerning this legal provision. This can be explained by the fact that the point of departure for the proposal of the Aarhus Regulation was "limited to the legally binding requirements of the Århus Convention, i.e. Articles 6 and 7 , where the latter concerns public participation in the preparation of plans and programmes relating to the environment." ${ }^{258}$ However, albeit a weak one, Article 7 of the Aarhus Convention does contain an obligation of effort regarding policies. As a consequence, the EU remains under the obligation to endeavour to provide opportunities for public participation in the preparation of policies relating to the environment.

5.2.3 Public participation concerning executive regulation and/or generally applicable legally binding normative instruments

Article 8 of the Aarhus Convention requires Parties to strive "to promote effective public participation at an appropriate stage, and while options are still open, during the preparation by public authorities of executive regulations and other generally applicable legally binding rules that may have a significant effect on the environment." This provision has a broad scope, providing for public participation not only in the drafting of classic environmental measures, in areas such as pollution prevention and conservation of biodiversity, but also in the preparation of measures in areas that may have a significant effect on the environment,

these isolated measures not then be analysed in view of provisions that provide for public participation in specific activities or during the preparation of executive regulations and/or generally applicable legally binding normative instruments? The point is, if a document or normative intervention aims to present a system which organises and coordinates how a scheme or a policy is going to be implemented, then it would be easily seen as a plan. If not, then it "must be determined on a contextual basis, taking into account the legal effects of each decision." (Austria ACCC/C/2008/26, ECE/MP.PP/C.1/2009/6/Add.1, 8 February 2011, para 50).

${ }^{257}$ L. Krämer, Casebook on EU environmental law (Oxford, Portland: Hart Publishing, 2002), p. 364. L. Krämer, 'Mechanisms at EC level to hold the European Investment Bank accountable', 2006, http://old.bankwatch.org/right_to_appeal/background/eib_existing_mechanisms_kramer.pdf, p. 4 .

${ }^{258}$ Proposal for a Regulation of the European Parliament and of the Council on the application of the provisions of the Århus Convention on Access to Information, Public Participation in Decision-making and Access to Justice in Environmental Matters to EC institutions and bodies, p. 13. 
such as energy and transport. ${ }^{259}$ Despite its broad scope, the provision only requires Parties to strive to promote effective public participation. In fact, the draft of the provision was more ambitious, but "in the course of negotiations the requirement as originally proposed was diluted (despite strong opposition from Denmark, Norway and others)." 260 Consequently, Article 8 does not require Parties to achieve effective public participation, but it does create an obligation to make efforts to achieve it.

Article 8 confirms a general observation "that decisions at the highest levels have the least prescriptive requirements for public participation, even though they have the most farreaching effects". ${ }^{261}$ This shows that "the public participation pillar of the Convention is much more focused on decisions on specific activities than on strategic decisions." 262 As acknowledged by Jendrośka, "the Convention reflects the European tradition of granting the public broad information and participation rights during permitting procedures, which was motivated by the need to protect property rights, rather than the American concept of 'open government", 263

This specific approach, with an emphasis on greater involvement in local decision making, was referred to in the first edition of the Aarhus Convention Implementation Guide as the "ladder of participation". ${ }^{264}$ The second edition of the Implementation Guide does not include this reference. The change could be explained due to the influence of academic literature which does not believe that the Convention followed a specific public participation theory. For instance, Jendrośka, who suggested that the structure of the Convention's framework for

${ }^{259}$ M. Lee and C. Abbot, op. cit. (2003), p. 101, Proposal for a Regulation of the European Parliament and of the Council on the application of the provisions of the Århus Convention on Access to Information, Public Participation in Decision-making and Access to Justice in Environmental Matters to EC institutions and bodies, $\operatorname{COM(2003)~} 622$ final C 96/22 (2004).

${ }^{260} \mathrm{~K}$. Brady, 'New convention on access to information and public participation in environmental matters' 28(2) Environmental Policy and Law, (1998), pp. 69-76, p. 72.

${ }^{261}$ M. Ewing, A. Hough, M. Amajirionwu, Assessing Access to Information, Participation, and Justice in Environmental Decision-making in Ireland, Environmental Protection Agency,2008, p. 83, as cited in J. Jendrośka, op. cit. (2009), p. 501.

262 J. Jendrośka, op. cit. (2009), p. 501.

263 J. Jendrośka, op. cit. (2009), p. 501.

${ }^{264}$ The following text appeared in the first edition of the Aarhus Implementation Guide: "Many speak of a 'ladder' of participation, in which members of the public have the most power - even approaching direct democratic decision-making - with respect to local matters with no impact outside the community. As issues become more complex and involve more global issues and affect larger numbers of people, the role of individual members of the public diminishes and the role of politicians and public authorities that must bear responsibility for such decisions becomes greater. The involvement of the public can pass through various stages as one climbs up the ladder - from direct decision-making to administrative status, participation, consultation, to the right to be informed only." S. Stec, S. CaseyLefkowitz and J. Jendrośka, 'The Aarhus Convention: an implementation guide', 2000, p. 85. 
public participation is similar to the so-called ladder of public participation, ${ }^{265}$ later stated that it would be an "over-interpretation to suggest that the Convention is guided by a clear vision of public participation and provides a consistent and comprehensive legal framework reflecting any particular theory of public participation". ${ }^{266}$ The Convention is the result of the ambitions and compromises of the negotiating parties and, despite the discussion on whether it has a background theory for public participation, it does "provide a benchmark against which the entire framework or particular instances of its operation in practice can be assessed." 267

Since the European Commission understood Article 8 of the Aarhus Convention as not providing any legally binding requirement, ${ }^{268}$ there is no implementation of this provision at the EU level. Some scholars also argue that Article 8 is not of a legally binding nature ${ }^{269}$ and they perceive it as more of a guideline for public participation mechanisms. ${ }^{270}$ Nonetheless, the EU remains under the obligation to strive to promote public participation during the preparation of executive regulations and/or generally applicable legally binding normative instruments. 271

\subsection{Enforcing the right to public participation in environmental decision making}

According to Article 9(2) of the Aarhus Convention, members of the public concerned having a sufficient interest or maintaining the impairment of a right, where it is required under national law, shall have access to a review procedure before a court of law and/or another independent and impartial body established by law in order "to challenge the substantive and procedural legality of any decision, act or omission" subject to the provisions of Article 6 of the Aarhus Convention. ENGOs that meet national requirements are deemed to have sufficient interest and have rights capable of being impaired; therefore, they have access to justice under Article 9(2) of the Aarhus Convention. Thus, it is clear that the Convention

\footnotetext{
265 J. Jendrośka, 'Public Information and Participation in EC Environmental Law: Origins, Milestones and Trends', in R. Macrory (ed.), Reflections on 30 years of EU environmental law: a high level of protection?, 2006), p. 75.

${ }^{266}$ J. Jendrośka, op. cit. (2009), p. 498. J. Jendrośka, op. cit. (2011b), p. 98.

267 J. Jendrośka, op. cit. (2009), p. 498.

${ }^{268}$ Proposal for a Regulation of the European Parliament and of the Council on the application of the provisions of the Århus Convention on Access to Information, Public Participation in Decision-making and Access to Justice in Environmental Matters to EC institutions and bodies, COM(2003) 622 final C 96/22 (2004), p. 13.

${ }^{269}$ J. Jendrośka, op. cit. (2011b), p. 97.

${ }^{270} \mathrm{~B}$. Toth, 'Public participation and democracy in practice-Aarhus convention principles as democratic institution building in the developing world' 30(2) Journal of Land Resources \& Environmental Law, (2010), pp. 295-330, p. 303.

${ }^{271}$ Article 8 of the Aarhus Convention is further examined in section 4.4.3 of Chapter IV.
} 
requires the Parties to provide for access to justice in case of a breach of the provisions relating to public participation in decisions on specific activities (Article $6 \mathrm{AC}$ ).

A further question to be examined is whether Article 9(2) of the Aarhus Convention would also serve as a legal basis for access to justice in relation to plans and programmes. ${ }^{272} \mathrm{In}$ ACCC/C/2008/32, the communicant argued that, since the preparation of plans and programmes needs to follow the requirements of Article 6 (3), (4) and (8) of the Aarhus Convention, and Article 9(2) of the Aarhus Convention applies to "any decision, act and omission subject to the provisions of Article 6", the preparation of plans and programmes would also be subject to the review procedures provided by Article 9(2). ${ }^{273}$ Such an interpretation was not examined by the ACCC, since the Committee decided to "concentrate on the main allegation of the communicant, and examine the jurisprudence of the EU Courts on access to justice in environmental matters generally." 274

A further point to be considered is that Article 7 refers to the public which shall be identified by the relevant public authority, while Article 9(2) refers to the public concerned. A hypothetical result would be that, as the public identified by the public authority encompasses more participants than the public concerned, the member that had participated during the preparation of plans and programmes would not be able to rely on Article 9(2) of the Aarhus Convention, since the latter is addressed only to the public concerned. Conversely, a member of the public concerned which was not identified by the public authority during the decision making process could still rely on Article 9(2) of the Aarhus Convention.

Article 8 of the Aarhus Convention does not provide for a specific provision on access to justice in the case of a lack of participation in the elaboration of an executive regulation and/or generally applicable legally binding normative instruments. If a Party has adopted public participation requirements for executive regulations and/or generally applicable legally binding normative instruments in its national law, Article 9(3) of the Aarhus Convention may be used to guarantee access to justice, since a breach of the national legislation which implemented the provision would constitute a violation of national environmental law.

Regarding the EU's implementation, as discussed in section 5.2.1, in its proposal for the Aarhus Regulation, the Commission explained that Article 6 of the Aarhus Convention did

\footnotetext{
272 J. Jendrośka, op. cit. (2009), p. 500.

273 ClientEarth concerning compliance by the European Union (Part I) UN ECE/MP.PP/C.1/2011/4/Add.1, 24 August 2011, para 47.

274 ClientEarth concerning compliance by the European Union (Part I) UN ECE/MP.PP/C.1/2011/4/Add.1, para 63 and 72. Jendrośka also noted that this interpretation "requires careful consideration" but did not elaborate further on the topic since it was outside of the scope of his analysis. J. Jendrośka, op. cit. (2009), p. 500.
} 
not require implementation at the EU level. Consequently, there is no specific provision for access to justice in such cases. Concerning the participation rights to the elaboration of plans and programmes, the EU also understood that there is no legal obligation for the Parties under the Aarhus Convention to provide for access to justice, where there is a violation of the right to participation in the elaboration of plans and programmes relating to the environment. Since the EU opted only to implement those provisions which were considered to be legally binding, there is no provision on access to justice in case of a breach of Article 9 of the Aarhus Regulation, which focuses on public participation concerning plans and programmes relating to the environment at the EU level. However, the requirements of Article 6 (3), (4) and (8) of the Aarhus Convention apply to the preparation of plans and programmes. Therefore, there is an obligation for the EU to ensure the application of these public participation requirements and, according to Article 9(2) of the Aarhus Convention, guarantee access to justice in case of a breach.

Regarding the second part of Article 7 (policies) and Article 8 of the Aarhus Convention, as explained in sections 5.2.2 and 5.2.3, the EU has not transposed these provisions in the Aarhus Regulation, since they were considered not to be legally binding. Therefore, even in the case that the EU would have fully implemented Article 9(3) of the Aarhus Convention, it would still not be possible to base a claim on this provision since there is no implementation of Article 7 regarding policies and Article 8 concerning executive regulation and/or generally applicable legally binding normative instruments at the EU level, and, consequently, there would be no breach of national law that could trigger the application of Article 9(3) of the Aarhus Convention.

For these cases, Article 9(3) of the Aarhus Convention, which provides for redress in the case of a violation of national environmental law, may be of help to remedy this problem. This would be possible because the non-dissemination of environmental information could amount to a breach of Article 4 of the Aarhus Regulation. In turn, the violation of the Aarhus Regulation constitutes a breach of national environmental law for the purposes of Article 9(3) of the Aarhus Convention. However, at the EU level, this provision has not been implemented fully. ${ }^{275}$ This means that, in practice, a member of the public would not have access to justice in the case of a violation of the obligation to disseminate information. Furthermore, the CJEU, in a preliminary ruling, already denied direct effect for Article 9(3) of the Aarhus Convention. Therefore, there is hence no provision on access to justice, which focuses on public participation concerning executive regulation and/or generally applicable legally binding normative instruments at the EU level.

${ }^{275}$ M. Eliantonio, op. cit. (2018), pp. 759-762. 


\section{Conclusion}

This chapter had three main objectives: first, to investigate if the Aarhus Convention encompasses the climate change phenomenon; second, to introduce the rights of access to environmental information and to public participation, as foreseen by the Aarhus Convention; and third to examine the implementation of these rights at the EU level. The analysis disclosed the following.

\section{Climate Change under the scope of the Aarhus Convention}

Although there is no mention of the term climate change in the text of the Aarhus Convention, the interpretation of the definition of environmental information demonstrates that the term environmental encompasses the climate change phenomenon. By elaborating on what is encompassed by environmental, the definition provides insight into what is meant by the environment and which environmental issues are covered by the Convention. ${ }^{276}$ Therefore, since environment itself is not defined in the Convention, understanding the term environmental is not only important for the provisions on access to environmental information, but it is also important in interpreting other provisions of the Convention that refer to environment. Nonetheless, the limits of such an interpretation have not yet been tested by the CJEU and the ACCC.

\section{Access to environmental information}

Articles 4, 5 and 9(1) of the Aarhus Convention provide the framework for access to environmental information. In view of the clear and explicit commitments as to what has to be done by public authorities, the commitments contained in these provisions can be characterised as obligations of result. This means that the Parties have to achieve a specific result ensuring that their public authorities provide upon request (Article 4) and disseminate environmental information (Article 5).

Regarding the implementation of access to information at the EU level, it was shown that this has taken place via the Aarhus Regulation, which should be read in combination with Regulation 1049/2001 for the request of environmental information. Concerning access to environmental information, it was concluded that the provisions have mostly been transposed in a way which ensures compliance with the Aarhus Convention. However, regarding the implementation of the exceptions to the obligations to provide access to environmental information upon request, the analysis revealed that the EU requirements impose more limitations than those allowed by the Aarhus Convention. It is important to note that Articles 4(3) and (4) of the Aarhus Convention provide an exhaustive list of exceptions and they are the only grounds on which a Party may allow public authorities to refuse a request for

${ }^{276}$ J. Ebbesson, H. Gaugitsch, J. Jendrośka, F. Marshall and S. Stec, op. cit. (2014), p. 41. 
information. This means that the law of the Parties (in this case, the EU law provisions addressed to the EU institutions and bodies, in the present case) may not exceed the limits set out for exceptions in the Convention. In this regard, the EU is not compliant with the Aarhus Convention.

The Aarhus Convention provides for access to justice in cases of a violation of the right to receive information upon request. According to Regulation 1049/2001, at the EU level, applicants may seek a reconsideration from an EU institution with regard to a decision concerning a request for environmental information, which is followed by the possibility of instituting court proceedings. This shows the compliance of the EU with the Aarhus Convention requirements for access to justice to redress a violation of the right to access environmental information upon request.

Regarding the active form of this right, which is the obligation imposed on public authorities to disseminate information, the Aarhus Convention does not provide for similar specific provisions for access to justice in cases where public authorities do not disseminate environmental information. Article 9(3) of the Aarhus Convention, which provides for redress in the case of a violation of national environmental law, may be of help to remedy this problem, since the non-dissemination of environmental information may amount to a breach of Article 4 of the Aarhus Regulation. However, at the EU level, Article 9(3) of the Aarhus Convention has not been fully implemented in the EU. Furthermore, the Aarhus Regulation also does not provide a specific provision for access to justice in the case of a failure to disseminate environmental information.

\section{Public participation in environmental decision making}

Regarding public participation, there is no clear indication that the Convention followed a specific public participation theory. The Convention is the result of the aspirations and compromises of the negotiating parties and, despite the discussion on whether it has a background theory for public participation, it does provide a benchmark against which the legal framework of the Parties has to be assessed.

The obligations contained in Article 6 of the Aarhus Convention establishing public participation in decisions on specific activities can be generally characterised as an obligation of result. Nevertheless, the explanatory memorandum to the Aarhus Regulation's proposal clarifies that there are no measures related to specific activities which are taken at the EU level. ${ }^{277}$ As a consequence, the provision was not transposed. It was shown that this approach

\footnotetext{
${ }^{277}$ Proposal for a Regulation of the European Parliament and of the Council on the application of the provisions of the Århus Convention on Access to Information, Public Participation in Decision-making and Access to Justice in Environmental Matters to EC institutions and bodies, COM(2003) 622 final C 96/22 (2004), 13.
} 
is controversial, since some EU decisions may amount to a decision on specific activities within the scope of Article 6 of the Aarhus Convention.

Article 7 of the Aarhus Convention on public participation concerning plans, programmes and policies relating to the environment establishes two separate regimes for public participation. First, for plans and programmes, parts of Article 6 of the Aarhus Convention requirements apply to ensure participation during the development of plans and programmes. This first part is characterised by an obligation of result. Second, for policies, Parties are only required, to the extent appropriate, to endeavour to provide opportunities for public participation. This weak and imprecise formulation, which fails to explain the exact result to be achieved, makes the second part of Article 7 of the Aarhus Convention an obligation of effort. The Aarhus Regulation only provides for public participation concerning plans and programmes. This is due to the fact that the Aarhus Regulation is limited, according to its explanatory memorandum, to the "legally binding requirements" of the Aarhus Convention. ${ }^{278}$ This means that, since Article 6 was deemed not to apply at the EU level, only public participation concerning plans and programmes relating to the environment was implemented. However, it must be noted that, even if these are obligations of efforts, there remains an obligation for EU institutions and bodies to endeavour to provide opportunities for public participation during the preparation of policies.

Article 8 of the Aarhus Convention concerning public participation during the preparation of executive regulations and/or generally applicable legally binding normative instruments does not require parties to achieve effective public participation and it is also characterised as an obligation of effort. There is no implementation of Article 8 of the Aarhus Convention at the EU level since the European Commission understood that Article 8 does not provide any legally binding requirement. However, Article 8 creates an obligation to make efforts to achieve it, and this obligation applies to each of the EU institutions and bodies.

The Aarhus Convention also provides for access to justice in cases of a violation of the right to participate in decisions on specific activities which is foreseen in Article 6 of the Aarhus Convention. Since Article 6 was not implemented at the EU level, there is no specific provision for access to justice. Furthermore, neither the Aarhus Convention nor the Aarhus Regulation provide for a specific provision on access to justice in the case of a violation of the right to participate in the preparation of plans and programmes relating to the environment, let alone policies. It was argued that the preparation of plans and programmes would also be subject to the review procedures provided for by Article 9(2) of the Aarhus Convention, since the preparation of plans and programmes needs to follow the requirements

\footnotetext{
${ }^{278}$ Proposal for a Regulation of the European Parliament and of the Council on the application of the provisions of the Århus Convention on Access to Information, Public Participation in Decision-making and Access to Justice in Environmental Matters to EC institutions and bodies, $\operatorname{COM}(2003) 622$ final C 96/22 (2004), 13.
} 
of Article 6 (3), (4) and (8) of the Aarhus Convention. Moreover, Article 9(3) of the Aarhus Convention has the potential to fill this gap, since the non-participation in the preparation of plans and programmes may amount to a breach of Article 9 of the Aarhus Regulation.

In sum, this chapter disclosed that climate change falls within the scope of the Aarhus Convention and demonstrated that there are incompatibilities between EU law and the Aarhus Convention. The next chapters will investigate how the EU legal framework provides for access to information and public participation in the field of EU climate change law. 


\section{Chapter IV - The EU Emissions Trading System: Access to environmental information and public participation at the EU level}

\section{Introduction}

The European Union Emissions Trading System (EU ETS) is one of the measures adopted by the EU to tackle the climate change problem. The EU ETS covers approximately $45 \%$ of the EU's greenhouse gas emissions, and, according to the European Commission, it is the cornerstone of EU climate policy ${ }^{1}$ and the key tool to achieve the reduction of greenhouse gas emissions in a cost-effective manner. ${ }^{2}$ The EU ETS entered the EU legal order via the adoption of Directive 2003/87 (the EU ETS Directive), which establishes a scheme for greenhouse gas (GHG) emission allowance trading within the European Union. ${ }^{3}$ The EU ETS

\footnotetext{
${ }^{1}$ European Commission, 'The EU Emissions Trading System (EU ETS)', 2016, https://ec.europa.eu /clima/sites/clima/files/factsheet_ets_en.pdf, 10.2834/6083, p. 1. The Council has considered the EU ETS as the main instrument to achieve the EU 40\% reduction in greenhouse gas emissions by 2030. European Council, 2030 Climate and Energy Policy Framework, EUCO 169/14 (2014a), 2. Directive 2018/410 which amends the EU ETS Directive has replaced the word "scheme" with "system" (Article 1(2), Directive (EU) 2018/410 of the European Parliament and of the Council of 14 March 2018 amending Directive 2003/87/EC to enhance cost-effective emission reductions and low-carbon investments, and Decision (EU) 2015/1814, OJ L 76/3).

${ }^{2}$ European Commission - DG Climate. EU Emissions Trading System (EU ETS), 20 June 2020, https://ec.europa.eu/clima/policies/ets_en.

${ }^{3}$ Directive 2003/87/EC, consolidated version. Since the focus of this chapter is on the EU ETS until 2020, the consolidated version referred to in this chapter is the version of 30 of April of 2014 and not the most recent one dated 08 April 2018 which already includes the rules for the period after 2020.

The consolidated version of 30 of April of 2014 contains the following amendments: Directive 2004/101/EC of the European Parliament and of the Council of 27 October 2004 amending Directive 2003/87/EC establishing a scheme for greenhouse gas emission allowance trading within the Community, in respect of the Kyoto Protocol's project mechanisms, OJ L 338/18; Directive 2008/101/EC of the European Parliament and of the Council of 19 November 2008 amending Directive 2003/87/EC so as to include aviation activities in the scheme for greenhouse gas emission allowance trading within the Community, OJ L 8/3; Regulation (EC) No 219/2009 of the European Parliament and of the Council of 11 March 2009 adapting a number of instruments subject to the procedure referred to in Article 251 of the Treaty to Council Decision 1999/468/EC with regard to the regulatory procedure with scrutiny - Adaptation to the regulatory procedure with scrutiny - Part Two, OJ L 87/109; Directive 2009/29/EC of the European Parliament and of the Council of 23 April 2009 amending
} 
Directive was amended in 2009 by Directive 2009/29, which implemented more harmonised rules for the period from 2013 to $2020 .^{4}$

Despite the relevant role that the EU ETS has in EU climate policy, so far only a small number of scholars have discussed the interplay between procedural rights and the EU ETS Directive. ${ }^{5}$ In light of this knowledge gap regarding the current state of procedural rights under the EU ETS, this chapter seeks to determine to what extent rights, in terms of access to environmental information and participation in governmental environmental decision making, have to be provided to citizens and Environmental Non-Governmental Organisations (ENGOs). More precisely, this chapter will investigate how the EU legal framework provides for access to environmental information and for public participation in the context of acts adopted at the EU level under the auspices of the EU ETS Directive, as well as how compatible this framework is with the Aarhus Convention.

The chapter is structured as follows. Section 2 presents the gradual development of the legislative framework of the EU ETS. Section 3 introduces the legal framework for access to environmental information under the EU ETS at the EU level by discussing whether the Aarhus Regulation is applicable or not and by examining the provisions on access to information under the EU ETS Directive (section 3.2). This is followed by an investigation of the case law of the Court of Justice of the European Union (CJEU) concerning the problems surrounding access to EU ETS-related information upon request (section 3.3), and an analysis of the legal requirements for dissemination of information according to the EU ETS Directive and their compatibility with the Aarhus Convention (section 3.4). Section 4 offers an investigation of the legal framework for public participation under the EU ETS. First, the provisions which empower the European Commission to act will be analysed in view of the public participation requirements imposed by the EU ETS Directive (section 4.2). Second, the analysis will consider whether the Aarhus Regulation provides any obligation for public participation for the acts adopted by the Commission under the EU ETS (section 4.3). Third, it investigates whether the acts that may be adopted by the Commission fall under

Directive 2003/87/EC so as to improve and extend the greenhouse gas emission allowance trading scheme of the Community, OJ L 140/63; Decision No 1359/2013/EU of the European Parliament and of the Council of 17 December 2013 amending Directive 2003/87/EC clarifying provisions on the timing of auctions of greenhouse gas allowances Text with EEA relevance, OJ L 343/21; Regulation (EU) No 421/2014 of the European Parliament and of the Council of 16 April 2014 Amending Directive 2003/87/EC Establishing a Scheme for Greenhouse Gas Emission Allowance Trading within the Community, in View of the Implementation by 2020 of an International Agreement Applying a Single Global Market-Based Measure to International Aviation Emissions, OJ L 129/1; Treaty on the accession of the Republic of Croatia to the European Union, OJ L 112/10.

${ }^{4}$ See footnote 3 .

${ }^{5}$ The author would like to thank Marjan Peeters and Dyonisios Stivas for sharing their compilation on the EU ETS literature. See Chapter I, section 3.2.1 for an overview of the literature on this topic. 
one of the public participation regimes prescribed by the Aarhus Convention or not (section 4.4). Last, the compatibility of the public participation requirements under the EU ETS with the Aarhus Convention is analysed (section 4.5). Finally, section 5 concludes by delineating the legal barriers and the prospects regarding access to environmental information and public participation under the EU ETS.

\section{The EU ETS Directive}

The adoption of the EU ETS Directive, on 13 October 2003, marks the establishment of a scheme for greenhouse gas emission allowance trading within the European Union. ${ }^{6}$ The aim of this Directive, as explained in its own text, is "to promote reductions of greenhouse gas emissions in a cost-effective and economically efficient manner". ${ }^{7}$

The EU ETS is based on cap-and-trade, ${ }^{8}$ which means that emitters are allowed to trade emissions allowances within an overall limited level of emissions (cap). The system basically requires that operators covered by the system must have a permit issued by the competent national authority in order to be allowed to emit greenhouse gases. ${ }^{9}$ The Member State competent authority grants an authorisation to emit greenhouse gases only if the emitter is deemed capable of monitoring and reporting emissions. ${ }^{10}$ Each year the operators must surrender one EU Allowance (EUA) for each tonne of carbon emitted; ${ }^{11}$ in this way, they are

\footnotetext{
${ }^{6}$ Directive 2003/87/EC, consolidated version. See footnote 3 for the amendments included in this consolidated version.
}

${ }^{7}$ Article 1, Directive 2003/87/EC, consolidated version. The same text is still maintained in the consolidated version.

${ }^{8}$ E. Woerdman, 'The EU Greenhouse Gas Emissions Trading Scheme', in E. R. Woerdman, M.M.; Holwerda, M. (ed.), Essential EU Climate Law, (Cheltenham: Edward Elgar, 2015), p. 43.

${ }^{9}$ Articles 5, Directive 2003/87/EC, consolidated version. The aviation sector is not covered by the permit requirement. According to Article 3g, each aircraft operator shall "submit[s] to the competent authority in that Member State a monitoring plan setting out measures to monitor and report emissions and tonnekilometre data for the purpose of an application under Article $3 \mathrm{e}$ and that such plans are approved by the competent authority in accordance with the regulation referred to in Article 14".

${ }^{10}$ Article 6, Directive 2003/87/EC, consolidated version.

${ }^{11}$ Article 6(2)(e), Directive 2003/87/EC, consolidated version. Each allowance allows the emission of one tonne of carbon dioxide $\left(\mathrm{CO}_{2}\right)$, or the equivalent amount of two greenhouse gases: nitrous oxide $\left(\mathrm{N}_{2} \mathrm{O}\right)$ and perfluorocarbons (PFCs). Annex I, Directive 2003/87/EC, consolidated version. Although these gases are in a lower concentration in the atmosphere, the potential impact for climate change is much greater. European Environment Agency. Contribution of different greenhouse gases to the overall greenhouse gas concentration, 18 June 2020, http://www.eea.europa.eu/data-and-maps/daviz /contribution-of-the-different-ghgs-3\#tab-chart_3.

For example, reducing one tonne of $\mathrm{N}_{2} \mathrm{O}$ would be equivalent to reducing 298 tonness of $\mathrm{CO}_{2}$ emissions. "Each greenhouse gas has a different capacity to cause global warming, depending on its radiative properties, molecular weight and the length of time it remains in the atmosphere. The global warming 
obliged to surrender allowances equal to the total emissions they released in the year. ${ }^{12}$ Allowances are allocated to emitters, either free of charge ${ }^{13}$ or via auctions, ${ }^{14}$ and may be traded between allowance holders (any individual or legal person who has bought allowances), while anyone may buy allowances at auctions. ${ }^{15}$ If an operator does not surrender enough allowances to cover its emissions, the Member State must impose penalties. ${ }^{16}$

The EU ETS has gone through three phases. Phase I (2005-2007), the so-called "learning by doing" phase was a pilot period. ${ }^{17}$ This laid the groundwork for Phase II (2008-2012), where the system had to start functioning effectively in order to help the EU comply with the emissions reduction obligations according to the Kyoto Protocol. ${ }^{18}$ It left a great deal of policy space to Member States, putting them in charge of setting their own emissions levels (a national cap for the EU ETS emissions) and allocating their allowances through National Allocation Plans (NAPs). In Phase I, 95\% of the allowances had to be allocated free-ofcharge (grandfathering), ${ }^{19}$ while in Phase II $90 \%$ of the allowances still had to be grandfathered. ${ }^{20}$

potential (GWP) of each gas is defined in relation to a given weight of carbon dioxide for a set time period (for the purpose of the Kyoto Protocol a period of 100 years). GWPs are used to convert emissions of greenhouse gases to a relative measure (known as carbon dioxide equivalents: $\mathrm{CO}_{2}-$ equivalents). The weighting factors currently used are the following: carbon dioxide $=1$, methane $=25$, nitrous oxide $=298$, and sulphur hexafluoride $=22.800$, hydrofluorocarbons and perfluorocarbons comprise a large number of different gases that have different GWPs." Eurostat. Greenhouse gas emission statistics, 25 Jan, http://ec.europa.eu/eurostat/statisticsexplained/index.php/Greenhouse_gas_emission_statistics.

${ }^{12}$ Article 6(2)(e), Directive 2003/87/EC, consolidated version. The GHG allowances are the tradable rights of the EU ETS that may be traded among EU ETS installations and other actors. Each allowance allows operators to emit one tonne of carbon dioxide.

${ }^{13}$ Article 10a, 10b and 10c, Directive 2003/87/EC, consolidated version.

${ }^{14}$ Article 10, Directive 2003/87/EC, consolidated version.

${ }^{15}$ Article 19(2), Directive 2003/87/EC, consolidated version.

${ }^{16}$ Article 16, Directive 2003/87/EC, consolidated version.

17 European Commission. Phases 1 and 2 (2005-2012), 19 June 2020, http://ec.europa.eu/clima/policies/ets/pre2013/index_en.htm.

${ }^{18}$ Phase II coincided with the first commitment period of the Kyoto Protocol.

${ }^{19}$ Article 10, Directive 2003/87/EC of the European Parliament and of the Council of 13 October 2003 establishing a scheme for greenhouse gas emission allowance trading within the Community and amending Council Directive 96/61/EC, OJ L 275/32.

${ }^{20}$ Article 10, Directive 2003/87/EC, original version. K. Kulovesi, E. Morgera and M. Muñoz, 'Environmental integration and multifaceted international dimensions of EU law: unpacking the EU's 2009 Climate and Energy Package' 48(3) Common market law review, (2011), pp. 829-891, p. 853. 
The 2009 amendments to the EU ETS Directive introduced more harmonised rules to be applied in Phase III (2013-2020). ${ }^{21}$ In this phase, the system has an EU-wide cap, which means that there is a maximum amount of allowances that can be distributed across the EU and auctioning is the default method for allocating allowances. Phase III began with $20 \%$ of the allowances within the manufacturing industry sector being auctioned, with the goal of achieving $70 \%$ auctioning in 2020 and $100 \%$ auctioning in $2027 .{ }^{22}$ For the allowances that are still allocated for free, harmonised allocation rules also apply. The European Commission is empowered to determine, among the most important: (i) the quantity of emission allowances; ${ }^{23}$ (ii) the sectors and subsectors, which are part of the carbon leakage sector and may, therefore, get $100 \%$ free allocation of allowances, up to the sector's benchmark; ${ }^{24}$ (iii) the rules for the free allocation, ${ }^{25}$ and (iv) the rules for auctioning. ${ }^{26}$

\footnotetext{
${ }^{21}$ Recital 8, Preamble, Directive 2009/29/EC.

${ }^{22}$ Article 10(a)(11), Directive 2003/87/EC, consolidated version. For a better explanation on how the
} allowances will be allocated, see section 3.2.

${ }^{23}$ See for example Commission Decision 2010/384/EU of 9 July 2010 on the Community-wide quantity of allowances to be issued under the EU Emission Trading Scheme for 2013 (notified under document C(2010) 4658), OJ L 175/36.

${ }^{24}$ Commission Decision 2010/02/EU determining a list of sectors and subsectors which are deemed to be exposed to a significant risk of carbon leakage C(2009) 10251, OJ L 1/10.

${ }^{25}$ Decision Commission Decision 2011/278/EU of 27 April 2011 determining transitional Union-wide rules for harmonised free allocation of emission allowances pursuant to Article 10a of Directive 2003/87/EC of the European Parliament and of the Council, OJ L 130/1. Hereinafter the Benchmark Decision.

${ }^{26}$ Commission Regulation (EU) No 1031/2010 of 12 November 2010 on the timing, administration and other aspects of auctioning of greenhouse gas emission allowances pursuant to Directive 2003/87/EC of the European Parliament and of the Council establishing a scheme for greenhouse gas emission allowances trading within the Community, OJ L 302/1 (Auctioning Regulation). This chapter refers to the consolidated version of 27 of February 2014 which contains the following amendments: Commission Regulation (EU) No 1210/2011 of 23 November 2011 amending Regulation (EU) No $1031 / 2010$ in particular to determine the volume of greenhouse gas emission allowances to be auctioned prior to 2013, OJ L308/2; Commission Regulation (EU) No 784/2012 of 30 August 2012 amending Regulation (EU) No 1031/2010 to list an auction platform to be appointed by Germany and correcting Article 59(7) thereof, OJ L 234/4; Commission Regulation No 1042/2012 of 7 November 2012 amending Regulation (EU) No 1031/2010 to list an auction platform to be appointed by the United Kingdom, OJ L 310/9; Commission Regulation No 1143/2013 of 13 November 2013 amending Regulation (EU) No 1031/2010 on the timing, administration and other aspects of auctioning of greenhouse gas emission allowances pursuant to Directive 2003/87/EC of the European Parliament and of the Council establishing a scheme for greenhouse gas emission allowances trading within the Community in particular to list an auction platform to be appointed by Germany, OJ L 303/10; Commission Regulation No 176/2014 of 25 February 2014 amending Regulation (EU) No 1031/2010 in particular to determine the volumes of greenhouse gas emission allowances to be auctioned in 201320, OJ L 56/11. 


\section{Access to environmental information under the EU ETS}

\subsection{Introduction}

While the EU has adopted rules regarding access to environmental information (Directive 2003/4 and Regulation 1367/2006), the EU ETS Directive, ${ }^{27}$ which was adopted in 2003 and has been amended frequently since then, ${ }^{28}$ still contains articles that deal with access to environmental information. ${ }^{29}$ In order to understand the overall framework on access to EU ETS-related information, this section will take the following steps.

First, section 3.2 will identify whether the Aarhus Regulation, which is the general framework for access to environmental information at the EU level, is applicable for accessing EU ETS-related information followed by a discussion of three articles from the EU ETS Directive which form the regime for access to environmental information under the EU ETS namely, Articles 17, 15a and $19 .{ }^{30}$ Articles 17 and 15a deal specifically with access to information, while Article 19 focuses on the registries which disseminate key information about the functioning of the EU ETS. ${ }^{31}$ Second, using the case law of the Court of Justice of the European Union, section 3.3 will investigate the problems related to the right to request EU ETS-related information. Last, section 3.4 will discuss governmental obligations regarding the dissemination of EU ETS-related information.

\subsection{The legal framework for access to EU ETS-related information}

\footnotetext{
${ }^{27}$ Directive 2003/87/EC, consolidated version.

${ }^{28}$ See footnote 3 for the amendments until 2014. In addition to these amendments, other amendments have been brought about by Directive (EU) 2018/410.

${ }^{29}$ The term "information" has been mentioned 30 times in the text of the EU ETS Directive (including annexes).

${ }^{30}$ These articles do not make any distinction between stationary installations and the aviation sector, and they also do not apply a caveat to the application of a specific sector. Therefore, the articles on access to information are also applicable to the aviation sector.

${ }^{31}$ The other provisions related to access to environmental information scattered throughout the EU ETS Directive will not be analysed, as they do not concern EU institutions or bodies, and/or they do not address the public as defined by the Aarhus Convention. The exclusion of these provisions is justifiable since one of the aims of this chapter is to identify the legal framework for access to environmental information (within the definition of the Aarhus Convention under the EU ETS) at the EU level.

These provisions concentrate primarily on reporting obligations, which rest on the European Commission to report to the European Parliament and to the Council (see for instance Articles 10b(1) and 10(5), Directive 2003/87/EC, consolidated version) and on the Member States to publish information (Article 16(2), Directive 2003/87/EC, consolidated version) or to provide information to the Commission (Article 10c(1), Directive 2003/87/EC, consolidated version).
} 


\subsubsection{The EU ETS Directive and the Aarhus Regulation}

The preamble of the EU ETS Directive states the following:

"In order to ensure transparency, the public should have access to information relating to the allocation of allowances and to the results of monitoring of emissions, subject only to restrictions provided for in Directive 2003/4/EC of the European Parliament and of the Council of 28 January 2003 on public access to environmental information." 32

The preamble thus refers to Directive 2003/4 (the Access to Environmental Information Directive), ${ }^{33}$ which obliges Member States to implement the provisions on access to environmental information of the Aarhus Convention to their national legislation. However, as discussed in section 2, the 2009 amendments of the EU ETS Directive shifted the decision making in important aspects of the EU ETS from the national level to the EU level. Consequently, the applicable legal instrument for requesting information from the European Commission is Regulation 1367/2006 (the Aarhus Regulation) and not Directive 2003/4/EC. The fact that the Aarhus Regulation is not mentioned anywhere in the EU ETS Directive does not entail that the Aarhus Regulation is not applicable, since EU institutions and bodies are bound by this instrument. Furthermore, there is no explicit derogation in the EU ETS Directive from the Aarhus Regulation. Before discussing the Aarhus Regulation vis-à-vis the EU ETS Directive, the next section examines the specific EU ETS provisions on access to information.

\subsubsection{Article 17 of the EU ETS Directive}

The EU ETS Directive includes a specific provision on access to environmental information. Article 17 reads as follows:

"Decisions relating to the allocation of allowances, information on project activities in which a Member State participates or authorises private or public entities to participate, and the reports of emissions required under the greenhouse gas emissions permit and held by the competent authority, shall be made available to the public in accordance with Directive 2003/4/EC".

The EU ETS Directive was amended several times, but Article 17, which deals specifically with access to information, has been amended only once (in 2004) to accommodate the Kyoto Protocol's project mechanisms. ${ }^{34}$ After the 2009 amendments, Article 17 maintained

\footnotetext{
${ }^{32}$ Recital 13, Preamble, Directive 2003/87/EC, consolidated version.

33 Directive 2003/4/EC of 28 January 2003 on Public Access to Environmental Information and Repealing Council Directive 90/313/EEC, OJ L41/26.

${ }^{34}$ Amended by Directive 2004/101/EC.
} 
reference only to Directive 2003/4, thus giving the impression that the provision did not take into account the changes that had been brought about in Phase III of the EU ETS. These amendments could have included a reference to the Aarhus Regulation, which would have highlighted the new role of the Commission under the current phase of the EU ETS, particularly with regard to its decision making related to the allocation of allowances. Although Article 17 does not refer to the Aarhus Regulation, the latter applies to requests for environmental information when such information is held by the Commission, since EU institutions are bound by this instrument.

Despite this lack of fine-tuning, the examination of Article 17 remains relevant to understand how transparent the legislator intended the system to be, particularly with respect to the issue of the allocation of allowances.

Article 17 does not make clear whether it is applicable to the active dissemination of information by authorities and/or to requests for information. ${ }^{35}$ In the absence of more

${ }^{35}$ Neither the explanatory memorandum accompanying the Commission's proposal for the EU ETS Directive nor the legislative process brings clarification on whether Article 17 encompasses the active and passive form of access to environmental information. Proposal for a Directive of the European Parliament and of the Council establishing a scheme for greenhouse gas emission allowance trading within the Community and amending Council Directive 96/61/EC, COM/2001/0581 final - COD 2001/0245 (2001b).

The following documents of the legislative process were examined: 1) Opinion of the Committee of the Regions on the 'Proposal for a Directive of the European Parliament and of the Council establishing a scheme for greenhouse gas emission allowance trading within the Community and amending Council Directive 96/61/EC (2002/C 192/14), OJ C 192/59 (2002); 2) Opinion of the Economic and Social Committee on the Proposal for a Directive of the European Parliament and of the Council establishing a scheme for greenhouse gas emission allowance trading within the Community and amending Council Directive 96/61/EC (2002/C 221/08), OJ C 221/27 (2002); 3) European Parliament legislative resolution on the proposal for a European Parliament and Council directive establishing a scheme for greenhouse gas emission allowance trading within the Community and amending Council Directive 96/61/EC, COM(2001) 581 - C5-0578/2001 - 2001/ 0245(COD), Codecision procedure: first reading, OJ C 279 E/96 (2002); 4) Amended proposal for a Directive of the European Parliament and of the Council establishing a scheme for greenhouse gas emission allowance trading within the Community and amending Council Directive 96/61/EC, COM(2002) 680 final (2003a); 5) Common Position (EC) No 28/2003 adopted by the Council on 18 March 2003 with a view to adopting Directive 2003/. . .CE of the European Parliament and of the Council establishing a scheme for greenhouse gas emission allowance trading within the Community and amending Council Directive 96/61/EC (2003/C 125 E/05), OJ C 125 E/72 (2003); 6) Communication from the Commission to the European Parliament pursuant to the second subparagraph of Article 251(2) of the EC Treaty concerning the Common Position of the Council on the adoption of a Directive of the European Parliament and of the Council establishing a scheme for greenhouse gas emission allowance trading within the Community and amending Council Directive 96/61/EC, SEC/2003/0364 final - COD 2001/0245 (2003b); 7) European Parliament legislative resolution on the proposal for a European Parliament and Council Directive 
specific terminology, the provision is most likely applicable to both situations. Furthermore, as mentioned, the current version of Article 17 refers to Directive 2003/4, which governs passive and active access to environmental information. ${ }^{36}$ The original version of Article 17 referred to Articles 3(3) and (4) of Directive 2003/4 which regulate the right to request information. ${ }^{37}$ Such a reference could lead to the interpretation that Article 17 only governs the passive form (upon request) of access to information. However, the current version of Article 17 refers to Directive 2003/4 in general and the exceptions in Article 4(1) and (2) may also apply to the obligation to disseminate information, according to Article 7(5) of Directive 2003/4. In this vein, a possible interpretation is that Article 17 creates a double obligation for public authorities to disseminate environmental information and to disclose environmental information upon request.

Nonetheless, the material scope of the provision is limited by the second part of the Article, which refers to only three different kinds of information: (i) decisions relating to the allocation of allowances; (ii) information on project activities in which a Member State participates or authorises private or public entities to participate; and (iii) the reports of emissions required under the greenhouse gas emissions permit and held by the competent authority. Since the decision making for the allocation of allowances has shifted to the EU level, there is a need to analyse the possible meaning of Article 17 for acts concerning the allocation of allowances adopted at the EU level. ${ }^{38}$

At the time of the adoption of Article 17, as well as at the time of its only amendment in 2004, the allocation of allowances was made by Member States through the elaboration of National Allocation Plans. The provision most likely intended to address the allocation

establishing a scheme for greenhouse gas emission allowance trading within the Community and amending Council Directive 96/61/EC, 15792/1/2002 - C5-0135/2003 - 2001/0245(COD), Codecision procedure: second reading, OJ C 74 E/642 (2003); 8) Opinion of the Commission pursuant to Article 251 (2), third subparagraph, point (c) of the EC Treaty, on the European Parliament's amendments to the Council's common position regarding the proposal for a Directive of the European Parliament and of the Council establishing a scheme for greenhouse gas emission allowance trading within the Community and amending Council Directive 96/61/EC, COM(2003) 463 final (2003c).

${ }^{36}$ The text of the provision as it is presented in the consolidated version of 30 of April of 2014.

${ }^{37}$ The original text of Article 17 reads as follows: "Decisions relating to the allocation of allowances and the reports of emissions required under the greenhouse gas emissions permit and held by the competent authority shall be made available to the public by that authority subject to the restrictions laid down in Article 3(3) and Article 4 of Directive 2003/4/EC." The text was amended in 2004, see footnote 34 .

38 The two other kinds of information (information on project activities in which a Member State participates or authorises private or public entities to participate; and the reports of emissions required under the greenhouse gas emissions permit and held by the competent authority) will not be analysed because they are related to obligations that must be fulfilled at the Member State level and fall, therefore, outside of the scope of the present research which focuses on the EU level. 
decisions taken at the Member State level and to fine-tune the obligation under the EU ETS with the Access to Environmental Information Directive. With the empowerment of the Commission to take decisions on the allocation of allowances in Directive 2009/29, one may wonder what the shift of the decision making to the EU level may mean for the interpretation of Article 17.

However, the fact that the obligation under Article 17 was created before the empowerment of the Commission and was linked to the Access to Environmental Information Directive, it is likely to refer to decisions that Member States still have to make in the allocation process. ${ }^{39}$ Nonetheless, the potential limitation of Article 17 to Member States does not exempt the Commission from disclosing its acts on the allocation of allowances, since the TFEU and the Aarhus Regulation are applicable. Yet, this does show that the current provision does not reflect the shift in the decision making from the Member State level to the EU level.

\subsubsection{Article 15a of the EU ETS Directive}

As concluded above, Article 17 of the EU ETS Directive was not fine-tuned to reflect the empowerment of the European Commission brought about by the 2009 amendments, but these amendments did introduce Article 15a which explicitly refers to the Commission, as follows:

"Member States and the Commission shall ensure that all decisions and reports relating to the quantity and allocation of allowances and to the monitoring, reporting and verification of emissions are immediately disclosed in an orderly manner ensuring non-discriminatory access.

Information covered by professional secrecy may not be disclosed to any other person or authority except by virtue of the applicable laws, regulations or administrative provisions."

Article 15a, first indent, states that not only Member States, but also the Commission, "shall ensure that all decisions and reports relating to the quantity and allocation of allowances and to the monitoring, reporting and verification of emissions are immediately disclosed in an orderly manner ensuring non-discriminatory access". ${ }^{40}$ The use of the term immediately disclosed addressed to the Member States and the Commission reads as if the information is to be disclosed to the public as soon as the competent authority possesses the information. This is especially so because the term immediately disclosed is not followed by the term upon

\footnotetext{
${ }^{39}$ Article 11, Directive 2003/87/EC, consolidated version.

${ }^{40}$ Artticle 15a, Directive 2003/87/EC, consolidated version.
} 
request, and therefore it confers an active character on the provision: the obligation of the public authority to disseminate information.

Content-wise, there is an overlap in the type of information that is covered by Articles 17 and $15 \mathrm{a} .{ }^{41}$ Both provisions refer to decisions on the allocation of allowances but with the difference that Article 15a prescribes the obligation on the Member States and the Commission to provide information, while Article 17 only mentions the Members States. Also, both provisions require the Member States to make reports of emissions available to the public. Article 17 specifies that the reports are those required under the greenhouse gas emissions permit, while Article 15a goes a step further and not only requires Member States but also the Commission to disclose not only reports but also decisions immediately relating to the monitoring, reporting and verification of emissions. The reference to the Commission and the inclusion of the quantity of allowances suggests that Article 15a acknowledges, at least regarding the calculation of the number of allowances, the role of the European Commission in determining an EU-wide cap. Another feature that seems to corroborate the argument that Article 15a reflects, partially, the new role of the Commission in the third phase of the EU ETS is that Article 15a neither refers to Directive 2003/4 nor the Aarhus Regulation, while Article 17 refers to Directive 2003/4. Furthermore, despite the fact that Article 15a does not refer explicitly to information on project activities, as does Article 17, it can also be interpreted as including this kind of information when it refers to the quantity of allowances, since installations can use international credits towards fulfilling part of their obligations under the EU ETS. ${ }^{42}$

A major distinction between Articles 17 and 15a is that Article 15a pays special attention to the disclosure of information covered by professional secrecy, an aspect that is not present in Article 17. The second indent of Article 15a states that information protected by professional secrecy - a term that is not defined by the EU ETS Directive - may only be disclosed to third parties in accordance with "applicable laws, regulations or administrative provisions." In this vein, it is possible to argue that the provision implicitly refers to the Environmental Information Directive and the Aarhus Regulation as applicable laws.

\footnotetext{
${ }^{41}$ Opinion of Advocate General Kokott in Joined Cases C-191/14, C-192/14, C-295/14, C-389/14 and C-391/14 to C-393/14, Borealis Polyolefine GmbH and others v. Bundesminister für Land- und Forstwirtschaft, Umwelt und Wasserwirtschaft and others, 12 November 2015, ECLI:EU:C:2015:754, para 145.

${ }^{42}$ Article 11a, Directive 2003/87/EC, consolidated version.
} 
Furthermore, as in Article 17, Article 15a limits the kind of information that should be disclosed. Therefore, Article 15a is not capable of covering all aspects regarding access to information under the EU ETS. ${ }^{43}$

\subsubsection{Article 19 of the EU ETS Directive}

Article 19 of the EU ETS Directive deals with the creation and maintenance of a registry for accounting allowances issued under the EU ETS, as follows:

"1. Allowances issued from 1 January 2012 onwards shall be held in the Community registry for the execution of processes pertaining to the maintenance of the holding accounts opened in the Member State and the allocation, surrender and cancellation of allowances under the Commission Regulation referred to in paragraph 3.

Each Member State shall be able to fulfil the execution of authorised operations under the UNFCCC or the Kyoto Protocol.

2. Any person may hold allowances. The registry shall be accessible to the public and shall contain separate accounts to record the allowances held by each person to whom and from whom allowances are issued or transferred.

3. In order to implement this Directive, the Commission shall adopt a Regulation for a standardised and secured system of registries in the form of standardised electronic databases containing common data elements to track the issue, holding, transfer and cancellation of allowances, to provide for public access and confidentiality as appropriate and to ensure that there are no transfers which are incompatible with the obligations resulting from the Kyoto Protocol. That Regulation shall also include provisions concerning the use and identification of CERs and ERUs in the Community scheme and the monitoring of the level of such use. That measure, designed to amend non-essential elements of this Directive by supplementing it, shall be adopted in accordance with the regulatory procedure with scrutiny referred to in Article 23(3).

4. The Regulation referred to in paragraph 3 shall contain appropriate modalities for the Community registry to undertake transactions and other operations to implement arrangements referred to in Article 25(1b). That Regulation shall also include processes for the change and incident management for the Community registry with regard to issues in paragraph 1 of this Article. It shall contain appropriate modalities for the Community registry to ensure that initiatives of the Member States pertaining

\footnotetext{
${ }^{43}$ Moreover, some elements mentioned in Article 15a concern information that the Commission would usually not possess, such as information related to the verification of emissions.
} 
to efficiency improvement, administrative cost management and quality control measures are possible." 44

The original version of paragraph 1 stipulated that the Member States should establish and maintain a registry in order to ensure the proper transactions of allowances. ${ }^{45}$ The European Commission, in accordance with Article 19(3) of the EU ETS Directive, adopted Regulation $2216 / 2004$ for a standardised and secured system of registries. ${ }^{46}$ The EU system of registries has been in place since January 2005 with the role of providing a standardised and secure system of electronic registries, which tracks the issuance, holding, transfer, and cancellation of all allowances issued under the EU ETS.

The 2009 amendments brought changes to Article 19 of the EU ETS Directive, which stipulates that emission allowances issued from 1 January 2012 onwards must be held in a single Union Registry on accounts managed by the Member States. ${ }^{47}$

In 2013, Commission Regulation 389/2013 established a centralised Union Registry, ${ }^{48}$ which has replaced Member States' national registries, and it currently covers all 31 countries participating in the EU ETS. The Union Registry is related to the European Union Transaction Log (EUTL), which is managed by a central administrator designated by the European Commission. ${ }^{49}$ The European Union Transaction Log is a virtual database that "automatically checks, records, and authorises all transactions that take place between

\footnotetext{
${ }^{44}$ Article 19, Directive 2003/87/EC, consolidated version.

${ }^{45}$ Article 19(1), Directive 2003/87/EC, original version. Article 19(1) of the EU ETS Directive before the 2009 amendments read: " 1 . Member States shall provide for the establishment and maintenance of a registry in order to ensure the accurate accounting of the issue, holding, transfer and cancellation of allowances. Member States may maintain their registries in a consolidated system, together with one or more other Member States." (Article 19(1), Directive 2003/87/EC, original version).

${ }^{46}$ Commission Regulation (EC) No 2216/2004 of 21 December 2004 for a standardised and secured system of registries pursuant to Directive 2003/87/EC of the European Parliament and of the Council and Decision No 280/2004/EC of the European Parliament and of the CouncilText with EEA relevance, OJ L 386/1.

${ }^{47}$ After the 2009 amendments, Article 19 reads: "1. Allowances issued from 1 January 2012 onwards shall be held in the Community registry for the execution of processes pertaining to the maintenance of the holding accounts opened in the Member State and the allocation, surrender and cancellation of allowances under the Commission Regulation referred to in paragraph 3.

Each Member State shall be able to fulfil the execution of authorised operations under the UNFCCC or the Kyoto Protocol."

${ }^{48}$ Commission Regulation (EU) No 389/2013 of 2 May 2013 establishing a Union Registry pursuant to Directive 2003/87/EC of the European Parliament and of the Council, Decisions No 280/2004/EC and No 406/2009/EC of the European Parliament and of the Council and repealing Commission Regulations (EU) No 920/2010 and No 1193/2011, OJ L 122/1. Article 19(3) of the EU ETS Directive empowers the European Commission to adopt a regulation.

${ }^{49}$ Article 20(1), Directive 2003/87/EC, consolidated version.
} 
accounts in the Union Registry. This verification ensures that any transfer of allowances from one account to another is consistent with EU ETS rules."50

Paragraph 2 of Article 19 of the EU ETS Directive states that:

"Any person may hold allowances. The registry shall be accessible to the public and shall contain separate accounts to record the allowances held by each person to whom and from whom allowances are issued or transferred."

Through the use of the words accessible to the public, it seems that there is an obligation for the central administrator to actively make the information available to the public. However, because the sentence that establishes the obligation comes just after the statement "Any person may hold allowances", the accessibility to the public seems to be established in view of giving access to the public to participate in the system and hold allowances. However, the paragraph does not clarify whether accessibility would include access to all accounts, which would entail access to information on the number of emissions allowances transferred and acquired by holders, the dates of the transactions, and the names of the holders, among others. Furthermore, there is no timeframe for when the information should be made accessible.

Paragraph 3 of Article 19 of the EU ETS Directive brings more clarity on which kind of information the registry needs to contain:

"In order to implement this Directive, the Commission shall adopt a Regulation for a standardised and secured system of registries in the form of standardised electronic databases containing common data elements to track the issue, holding, transfer and cancellation of allowances, to provide for public access and confidentiality as appropriate and to ensure that there are no transfers which are incompatible with the obligations resulting from the Kyoto Protocol. That Regulation shall also include provisions concerning the use and identification of CERs and ERUs in the Community scheme and the monitoring of the level of such use. That measure, designed to amend non-essential elements of this Directive by supplementing it, shall be adopted in accordance with the regulatory procedure with scrutiny referred to in Article 23(3)."

Paragraph 3 seems to create a special regime for the Union Registry apart from the general regime set by Article 17. This is because, while Article 17 in principle governs access to information under the EU ETS, Article 19 says that the registry shall provide for "public access and confidentiality as appropriate". Therefore, according to the Article, it will be the further regulatory instrument, in this case, a regulation adopted by the Commission, that will determine which kind and when the information should be made available. ${ }^{51}$ Of course, this

50 European Commission Climate Action, Union Registry, 19 June 2020, https://etsregistry.webgate.ec.europa.eu/euregistry/EU/index.xhtml.

${ }^{51}$ The regulations adopted by the Commission are discussed in section 3.3.1, iii. 
determination has to be carried out in accordance with the limits prescribed by the EU treaties and international agreements.

\subsection{Passive Access to EU ETS-related information}

Having examined the general regime for access to information under the EU ETS Directive contained in Articles 15a, 17 and 19, using the case law, this section will investigate the problems concerning the right to request EU ETS-related information. First, it delves into the boundaries of the definition of environmental information (section 3.3.1), and, second, into the limits of application of the grounds for refusal of environmental information (section 3.2.2) in the context of the EU ETS.

3.3.1. Definition of environmental information: the extent to which EU ETS-related information is environmental information

i. Access to data for the calculation of the Cross-Sectoral Correction Factor

The free allocation of allowances is based on ex-ante benchmarks, which have to be determined by the Commission on the basis of "the average performance of the $10 \%$ of installations in a sector or subsector in the Community [now the EU] that are most efficient in the years 2007-2008." 52 This means that installations with low carbon emissions are favoured in free allocation because they have the most efficient installations. ${ }^{53}$

The Commission adopted a decision establishing the benchmark criteria (the Benchmark Decision) ${ }^{54}$ According to Article 15(1) and (2) of this Benchmark Decision, all Member States elaborated the so-called national implementation measures (NIMs), which contain a preliminary calculation of the number of free allowances to be allocated to each installation in their territory, which they must notify to the Commission. ${ }^{55}$ Following the submission of the NIMs for the third period (EU ETS Phase III), the Commission evaluated the data provided by the Member States, to check if all installations were included and if the harmonised allocation rules were applied correctly. The Commission calculated the maximum amount of free allocation according to Article 10a(5) of the EU ETS Directive, and the "preliminary allocation through the NIMs exceeded the maximum amount of allowances available in 2013." 56 Therefore, as provided for in Article 10a(5) of the ETS

\footnotetext{
${ }^{52}$ Article 10a (2), Directive 2003/87/EC, consolidated version.

${ }^{53}$ E. Woerdman, op. cit. (2015), p. 57.

${ }^{54}$ Commission Decision 2011/278/EU, see footnote 25.

${ }^{55}$ Article 11, Directive 2003/87/EC, consolidated version.

56 European Commission. Free allocation, 19 June 2020, https://ec.europa.eu/clima/policies/ets/allowances_en.
} 
Directive, the Commission had to apply a Cross-Sectoral Correction Factor (CSCF) to reduce the total number of allowances for free allocation. ${ }^{57}$

Consequently, in September 2013, the Commission adopted a decision establishing the first Cross-Sectoral Correction Factor. ${ }^{58}$ Some operators challenged the Commission decision since they believed that the CSCF was calculated wrongly, which would imply a too-low allocation of free allowances. ${ }^{59}$ In Joined Cases C-191/14, C-192/14, C-295/14, C-389/14, and C-391/14 to C-393/14, the Court of Justice answered preliminary questions posed by courts from Austria, the Netherlands and Italy as to whether the Commission calculated the number of free allowances to be allocated to installations correctly in the period after $2013 .{ }^{60}$

In particular, Article 10a(5) of the EU ETS Directive establishes how to determine the maximum amount of allowances that will be allocated for free. However, there was a divergence in the interpretations of Article 10a(5)(b) of the EU ETS Directive due to different translations of the provision. As explained by the Court:

"[...] the different language versions are not consistent with one another. Whereas the French version of subparagraph (b) of Article 10a(5) of Directive 2003/87 refers to 'emissions ... which are only included in the Community scheme from 2013 onwards', other language versions, such as the Spanish, Danish, German, English,

\footnotetext{
${ }^{57}$ A uniform Cross-Sectoral Correction Factor (CSCF) is applied to ensure the annual free allocation remains within this limit and consequently within the overall EU ETS cap. The CSCF, which is determined in accordance with Article 15(3) of the Benchmarking Decision, is the factor that adjusts the difference between the sum of free allocations elaborated by Member States and calculation of the maximum amount that can be allocated for free in accordance with Article 10a(5) of the EU ETS Directive. In other words, the CSCF is the result of a comparison between the bottom-up sum of preliminary free allocations and the top-down calculation of the maximum amount that can be handed out for free and it is set out in Annex II of Decision 2013/448/EU. Although the calculations by the Member States are based on the Benchmarking Decision, the difference is due to fact that installations could choose for different periods for the production of data (2005-2008 and 2009-2010) and also for the increase in the number of sectors and subsectors in the list of sector and subsectors deemed to be in risk of carbon leakage. (Questions and Answers on the cross-sectoral correction factor (CSCF), 19 June 2020, https://www.karlsruhe.ihk.de/blueprint/servlet/resource/blob/2470276/810edae144345f4716c95 6c99715080e/faq-data.pdf, p. 5)

${ }^{58}$ Commission Decision (EU) No 2013/448/EU concerning national implementation measures for the transitional free allocation of greenhouse gas emission allowances in accordance with Article 11(3) of Directive 2003/87/EC of the European Parliament and of the Council, OJ L 240/27.

${ }^{59}$ Opinion of Advocate General Kokott in Joined Cases C-191/14, C-192/14, C-295/14, C-389/14 and C-391/14 to C-393/14, Borealis Polyolefine GmbH and others v. Bundesminister für Land- und Forstwirtschaft, Umwelt und Wasserwirtschaft and others, para 24.

60 Joined Cases C-191/14, C-192/14, C-295/14, C-389/14 and C-391/14 to C-393/14, Borealis Polyolefine $\mathrm{GmbH}$ and others v. Bundesminister für Land- und Forstwirtschaft, Umwelt und Wasserwirtschaft and others, 28 April 2016, ECLI:EU:C:2016:311, para 87.
} 
Italian, Netherlands, Polish, Portuguese, Romanian, Slovene and Swedish language versions, refer to 'emissions from installations ... which are only included in the Community scheme from 2013 onwards'." ${ }^{61}$ (emphasis added)

To solve this question, the Court argued that, when there is a divergence among the language versions, the provision must be interpreted in accordance with the context and purpose of the legal rules into which the provision is inserted. ${ }^{62}$ In this case, the Court looked to the purpose of the directive and its subsequent amendments and concluded that "[...] when establishing the maximum annual amount of allowances, the Commission was required, in accordance with subparagraph (b) of Article 10a(5) of Directive 2003/87, to take account only of the emissions from the installations included in the Community system from 2013 onwards." 63 (Emphasis added)

Since the Commission took emissions of installations that were covered by the EU ETS before 2013 into account, ${ }^{64}$ the court concluded that this calculation was based on erroneous

61 Joined Cases C-191/14, C-192/14, C-295/14, C-389/14, and C-391/14 to C-393/14, Borealis Polyolefine $\mathrm{GmbH}$ and others v. Bundesminister für Land- und Forstwirtschaft, Umwelt und Wasserwirtschaft and others, para 89.

62 Joined Cases C-191/14, C-192/14, C-295/14, C-389/14, and C-391/14 to C-393/14, Borealis Polyolefine $\mathrm{GmbH}$ and others v. Bundesminister für Land- und Forstwirtschaft, Umwelt und Wasserwirtschaft and others, para 90.

63 Joined Cases C-191/14, C-192/14, C-295/14, C-389/14, and C-391/14 to C-393/14, Borealis Polyolefine $\mathrm{GmbH}$ and others v. Bundesminister für Land- und Forstwirtschaft, Umwelt und Wasserwirtschaft and others, para 94.

${ }^{64}$ The conclusion by the Court that there is an obligation to include only installations subject to the scheme for the first time from 2013 onwards leaves the question unanswered as to what happens to the emissions from installations that were already part of the scheme and cover activities that are subject to the scheme from 2013 onwards. (Opinion of Advocate General Kokott in Joined Cases C-191/14, C192/14, C-295/14, C-389/14, and C-391/14 to C-393/14, Borealis Polyolefine GmbH and others v. Bundesminister für Land- und Forstwirtschaft, Umwelt und Wasserwirtschaft and others, para 104). Advocate General Kokott explains that the EU ETS Directive (Article 10a(5)(b) and Article 9a(2) Directive 2003/87/EC, as amended) does not provide a clear answer to this question (Opinion of Advocate General Kokott in Joined Cases C-191/14, C-192/14, C-295/14, C-389/14, and C-391/14 to C-393/14, Borealis Polyolefine GmbH and others v. Bundesminister für Land- und Forstwirtschaft, Umwelt und Wasserwirtschaft and others, para 105), and that the Commission "was under no obligation to redress the asymmetry in the implementing rules". (Opinion of Advocate General Kokott in Joined Cases C-191/14, C-192/14, C-295/14, C-389/14, and C-391/14 to C-393/14, Borealis Polyolefine $\mathrm{GmbH}$ and others v. Bundesminister für Land- und Forstwirtschaft, Umwelt und Wasserwirtschaft and others, para 108) 
data which led to the allocation of more free allowances than was permitted by Article $10 \mathrm{a}(5)(\mathrm{b})$ of the EU ETS Directive. ${ }^{65}$ The Court then ruled that the decision was invalid. ${ }^{66}$

This ruling is important for the purpose of defining the scope of the right of access to environmental information under the EU ETS because, by the time the CSCF was adopted, the Commission stated that "the value of the CSCF is the result of mathematical calculations based on verified Member State data." ${ }^{67}$ Indeed, the calculation is the result of a mathematical calculation stipulated by Article 15(3) of the Benchmark Decision. ${ }^{68}$ However, the Dutch Council of State (Raad van State) pointed out that the decision does not contain the data to replicate such a calculation. ${ }^{69}$ Furthermore, the Italian Court (Tribunale Amministrativo Regionale per il Lazio) considered that the statement of reasons for the decision on the CSCF was inadequate, since the reasons did not contain information on the actual data used by the Commission. ${ }^{70}$ The questions referred by the Dutch Council of State and the Italian Court thus related to whether a sufficient statement of reasons for the determination of the CSFC was provided. However, these questions were not further discussed by the Court. ${ }^{71}$ The Court shied away from them on the grounds that there was no need to answer other questions, since the answer to the previous questions already invalidated the CSCF. ${ }^{72}$ The Advocate General

65 Joined Cases C-191/14, C-192/14, C-295/14, C-389/14, and C-391/14 to C-393/14, Borealis Polyolefine $\mathrm{GmbH}$ and others v. Bundesminister für Land- und Forstwirtschaft, Umwelt und Wasserwirtschaft and others, para 95.

66 Joined Cases C-191/14, C-192/14, C-295/14, C-389/14, and C-391/14 to C-393/14, Borealis Polyolefine $\mathrm{GmbH}$ and others v. Bundesminister für Land- und Forstwirtschaft, Umwelt und Wasserwirtschaft and others, para 99.

${ }^{67}$ European Commission. Questions and Answers on the cross-sectoral correction factor (CSCF), 19 June 2020, https://www.karlsruhe.ihk.de/blueprint/servlet/resource/blob/2470276/810edae144345 f4716c956c99715080e/faq-data.pdf. p. 5.

${ }^{68}$ Commission Decision 2011/278/EU, see footnote 25.

${ }^{69}$ Joined Cases C-191/14, C-192/14, C-295/14, C-389/14, and C-391/14 to C-393/14, Borealis Polyolefine $\mathrm{GmbH}$ and others v. Bundesminister für Land- und Forstwirtschaft, Umwelt und Wasserwirtschaft and others, para 28.

70 Joined Cases C-191/14, C-192/14, C-295/14, C-389/14, and C-391/14 to C-393/14, Borealis Polyolefine $\mathrm{GmbH}$ and others v. Bundesminister für Land- und Forstwirtschaft, Umwelt und Wasserwirtschaft and others, para 28.

71 Joined Cases C-191/14, C-192/14, C-295/14, C-389/14, and C-391/14 to C-393/14, Borealis Polyolefine $\mathrm{GmbH}$ and others v. Bundesminister für Land- und Forstwirtschaft, Umwelt und Wasserwirtschaft and others, para 28. Fifth and sixth questions referred by the Raad van State and third question by the Tribunale Amministrativo Regionale. Joined Cases C-191/14, C-192/14, C-295/14, C389/14, and C-391/14 to C-393/14, Borealis Polyolefine GmbH and others v. Bundesminister für Landund Forstwirtschaft, Umwelt und Wasserwirtschaft and others, para 29 and 37, respectively.

72 Joined Cases C-191/14, C-192/14, C-295/14, C-389/14, and C-391/14 to C-393/14, Borealis Polyolefine $\mathrm{GmbH}$ and others v. Bundesminister für Land- und Forstwirtschaft, Umwelt und Wasserwirtschaft and others, para 100. Joined Cases C-191/14, C-192/14, C-295/14, C-389/14, and C- 
Kokott, on the other hand, explored the issue of the availability of the data to the public to calculate the CSCF by the Commission.

The Advocate General started by mentioning that the decision determining the CSCF does explain how the factor was calculated. ${ }^{73}$ However, she continued, this decision does not contain all the data used by the Commission to calculate the correction factor. For example, it is not clear which installations the Commission considered electricity generators, ${ }^{74}$ and only by accessing the NIMs could a member of the public be aware of the preliminary total annual amount for the free allocation. ${ }^{75}$ The NIMs are recorded in the Union Registry. Although any individual can sign on to the Union Register by creating an account with a username and password, ${ }^{76}$ information about the NIMs is not available when one logs into the Union Registry website. ${ }^{77}$ To collect the data needed to calculate this information, it would be necessary to log in to the page of the registry of each of the 31 countries which are Parties to the EU ETS, and this registration has a financial cost. ${ }^{78}$

Almost two months after the decision was adopted, ${ }^{79}$ DG Climate Action released a document which attempts to provide further information on the calculation of the CSCF ${ }^{80}$ For instance, it states that electricity generators are, in accordance with Article 3(u) of the EU ETS Directive, "installations that, on or after 1 January 2005, have produced electricity for sale to

391/14 to C-393/14, Borealis Polyolefine GmbH and others v. Bundesminister für Land- und Forstwirtschaft, Umwelt und Wasserwirtschaft and others, para 100.

${ }^{73}$ Recital 25, Preamble, Commission Decision (EU) No 2013/448/EU.

${ }^{74}$ Opinion of Advocate General Kokott in Joined Cases C-191/14, C-192/14, C-295/14, C-389/14, and C-391/14 to C-393/14, Borealis Polyolefine GmbH and others v. Bundesminister für Land- und Forstwirtschaft, Umwelt und Wasserwirtschaft and others, Opinion in Joined Cases C-191/14, C192/14, C-295/14, C-389/14, and C-391/14 to C-393/14, para 137.

${ }^{75}$ Opinion of Advocate General Kokott in Joined Cases C-191/14, C-192/14, C-295/14, C-389/14, and C-391/14 to C-393/14, Borealis Polyolefine GmbH and others v. Bundesminister für Land- und Forstwirtschaft, Umwelt und Wasserwirtschaft and others, para 139.

76 European Commission. Union Registry, 19 June 2020, https://etsregistry.webgate.ec.europa.eu/euregistry/EU/index.xhtml.

77 European Commission. Union Registry, 19 June 2020, https://etsregistry.webgate.ec.europa.eu/euregistry/EU/index.xhtml. The only documents available are the Kyoto Protocol Public Reports. (European Commission. Kyoto Protocol Public Reports, 19 June 2020, https://ets-registry.webgate.ec.europa.eu/euregistry/EU/index.xhtml.)

${ }^{78}$ For the fees charged by Member States for the accounts in the Union registry, see: European Commission. Union Registry - Phase 3 (2013-2020), 20 June 2020, https://ec.europa.eu/clima/policies/ets/registry_en\#tab-0-1.

${ }^{79}$ The decision is from 09 September 2013 and the explanatory document is from 22 October 2013.

${ }^{80}$ The document can be found here:

https://ec.europa.eu/clima/sites/clima/files/ets/allowances/docs/cross_sectoral_correction_factor_en.p df 
third parties and in which no activity listed in Annex $\mathrm{I}$ is carried out other than the 'combustion of fuels"', but the list of such installations is not provided. The lack of available information means, in the Advocate General's view, that members of the public cannot identify precisely whether the Commission used the correct method and data according to the EU ETS Directive and the Benchmark Decision. ${ }^{81}$ Advocate General Kokott pointed out that, even if the data were not available in the text of the Decision, the Commission could have made it possible to access the raw data and refer to such availability in the statement of reasons. ${ }^{82}$ The court did not rule on this matter, and, therefore, there is not yet a judicial decision on the need to provide access to all relevant data used for the calculation in the decision making for the allocation of allowances. This is despite the command of Article 15a of the EU ETS Directive that the Commission shall disclose all decisions and reports related to the quantity and allocation of allowances immediately.

ii. Request for a document on the allocation of free allowances submitted by a Member State

The Saint-Gobain Glass Deutschland GmbH v. European Commission Case is also related to the Union-wide rules for the harmonised free allocation of emission allowances. ${ }^{83}$ In this case, Saint-Gobain Glass Deutschland, a company which operates installations falling under the EU ETS, had requested a document (an excel table) communicated by Germany to the European Commission. This document contained information related to the estimation made by German authorities of free emission allowances to be allocated the industries falling under the EU ETS in the German territory. ${ }^{84}$ The communication of the German authorities was made in accordance with the Benchmark Decision. ${ }^{85}$ This provision refers to Article 11(1) of the EU ETS Directive, which states that Member States shall publish and submit to the European Commission the list of installations covered by the EU ETS in its territory, and also the number of allowances to be allocated for free. Since Saint-Gobain Glass Deutschland

\footnotetext{
${ }^{81}$ Opinion of Advocate General Kokott in Joined Cases C-191/14, C-192/14, C-295/14, C-389/14, and C-391/14 to C-393/14, Borealis Polyolefine GmbH and others v. Bundesminister für Land- und Forstwirtschaft, Umwelt und Wasserwirtschaft and others, para 133.

${ }^{82}$ Opinion of Advocate General Kokott in Joined Cases C-191/14, C-192/14, C-295/14, C-389/14, and C-391/14 to C-393/14, Borealis Polyolefine GmbH and others v. Bundesminister für Land- und Forstwirtschaft, Umwelt und Wasserwirtschaft and others, para 140.

${ }^{83}$ Case T-476/12, Saint-Gobain Glass Deutschland GmbH v. European Commission, 11 December 2014, ECLI:EU:T:2014:1059.

84 Case C-60/15 P, Saint-Gobain Glass Deutschland v. Commission, 13 July 2017, ECLI:EU:C:2017:540, para 17. (Please note that, although discussing the case before the General Court, reference regarding the facts of the case refers to the appeal, since it was translated into English. M. Hillebrandt and L. Leppävirta, 'On the Administration of Pollution: How Much "Space to Think" May the EU Claim?’ 8(4) European Journal of Risk Regulation, (2017), pp. 791-797, p. 791.

${ }^{85}$ Commission Decision 2011/278/EU.
} 
did not receive a reply within the timeframe established by Regulation 1049/2001, it initiated an action for annulment of the Commission's implied refusal to grant the applicant access to the information. ${ }^{86}$

Regarding the interpretation of the definition of environmental information, the General Court understood that the requested information constituted environmental information within the definition of the Aarhus Regulation. ${ }^{87}$ The General Court explained that the requested information is closely related to GHG emissions and that the information concerns the state of elements of the environment, such as air and the atmosphere, within the meaning of Article 2(1)(d)(iii) of the Aarhus Regulation. The General Court added that the aim of the measure to protect the environment is confirmed by the preamble of the EU ETS Directive, which shows that the EU ETS was established in order to reduce GHG emissions in the atmosphere and stabilise the concentrations of that gas at a level, which prevents any dangerous anthropogenic interference with the atmosphere climate system. ${ }^{88}$ There was a consensus among the Parties on the fact that the document falls under the definition of environmental information of the Aarhus Regulation (Article 2(1)(d)(iii)) and this was not a point challenged in the appeal. ${ }^{89}$ The case illustrates that industries also make use of the access to environmental information right, and that they had to appeal in order to get access the requested information..$^{90}$

iii. Request for data related to the transfer of allowances under national registry

In Ville de Lyon v. Caisse des dépôts et consignations, the city of Lyon requested the administrator of the French national registry of greenhouse gas emission allowances to provide information on the number of greenhouse gas emission allowances sold by the operators of 209 urban heating sites in 2005, the dates of the transactions and the names of the those transferring and acquiring the emissions allowances. ${ }^{91}$

\footnotetext{
${ }^{86}$ Case C-60/15 P, Saint-Gobain Glass Deutschland v. Commission, para 29.

${ }^{87}$ Case T-476/12, Saint-Gobain Glass Deutschland GmbH v. European Commission, para 61.

${ }^{88}$ Recitals 3 and 5, Directive 2003/87/EC, consolidated version. Case T-476/12, Saint-Gobain Glass Deutschland GmbH v. European Commission, para 60.

${ }^{89}$ Opinion of Advocate General Szpunar in Case C-60/15 P Saint-Gobain Glass Deutschland v. Commission, 23 September 2010, EU:C:2016:778, para 86. M. Hillebrandt and L. Leppävirta, op. cit. (2017), p. 792. The appeal concerned the interpretation of Article 4(3) (first subparagraph) of Regulation No 1049/2001 according to Article 6(1) (second sentence) of Regulation No 1367/2006.

${ }^{90}$ The ground for a refusal to provide the requested information will be discussed in section 3.3.2.i.

91 Case C-524/09, Ville de Lyon v. Caisse des dépôts et consignations, 22 December 2010, ECLI:EU:C:2010:822, para 29 and 41. See: M. Peeters and S. Nóbrega, op. cit. (2014), pp. 358-359. H. von Holleben, 'Judgment of the General Court of the EU on Access to Information Under Substance Law: Case T-545/11, Judgment of 08 October 2013’ 4(4) European Journal of Risk Regulation, (2013), pp. 565-578, pp. 569-570.
} 
Advocate General Kokott examined whether the information requested constitutes environmental information within the meaning of Article 2 of Directive 2003/4. She considered that information on emission allowance transactions qualifies as environmental information within the meaning of Article 2(1)(b) of Directive 2003/4 as "factors, ... such as emissions ..., affecting or likely to affect the elements of the environment". ${ }^{2}$

The Court took a different approach, in contrast to the AG's opinion, by not focusing on the definition of environmental information. The Court acknowledged that the EU legislature has adopted access to information requirements in the EU ETS Directive, but it did not intend to "make the reporting of all information or data" under the EU ETS subject to the Access to Environmental Information Directive..$^{93}$ The Court understood that the requested information does not fall under Article 17 of the EU ETS Directive, which provides that decisions relating to the allocation of allowances shall be made available to the public in accordance with the Access to Environmental Information Directive. In fact, according to the Court, such trading data information falls under the scope of Article 19 of the EU ETS Directive and Regulation 2216/2004. ${ }^{94}$ Article 19, which deals with registries, does not refer to Directive 2003/4, but rather it states that the Commission shall adopt a regulation which, among other subject matters, provides for "public access and confidentially as appropriate". ${ }^{95}$ At the time of the judgment, this was Regulation 2216/2004. ${ }^{96}$ The Court favoured the application of the special provision ${ }^{97}$ of the EU ETS Directive (Article 19) and ruled that the information should be available after a five-year period has passed, in accordance with the Regulation 2216/2004, ${ }^{98}$ allowing, therefore, a specific provision to outweigh Article 17, which is governed by Directive 2003/4. Nonetheless, the judgment lacked an analysis as to whether such a

\footnotetext{
${ }^{92}$ Case C-524/09, Ville de Lyon v. Caisse des dépôts et consignations, para 33 and 42.

${ }^{93}$ Case C-524/09, Ville de Lyon v. Caisse des dépôts et consignations, para 38.

${ }^{94}$ Case C-524/09, Ville de Lyon v. Caisse des dépôts et consignations, para 39.

${ }^{95}$ Article 19(3), Directive 2003/87/EC, original version.

96 Commission Regulation (EC) No 2216/2004. This regulation was repealed by Commission Regulation (EC) No 920/2010 of 7 October 2010 for a standardised and secured system of registries pursuant to Directive 2003/87/EC of the European Parliament and of the Council and Decision No 280/2004/EC of the European Parliament and of the Council, OJ L 270/1 subsequently repealed by Commission Regulation (EU) No 389/2013.

${ }^{97}$ The Court also favoured the application of special provisions in other cases. See Case C-552/07 Commune de Sausheim v. Azelvandre, 17 February 2009, ECLI:EU:C:2009:96, para 55, in which the Court favoured the application of Article 25(4) of Directive 2001/18 of the European Parliament and of Council on the deliberate release into the environment of genetically modified organisms, OJ. L 106/1, instead of the general rule of Directive 2003/4. P. Oliver, 'Access to Information and to Justice in EU Environmental Law: The Aarhus Convention’ 36 Fordham International Law Journal, (2013), pp. 1423-1470, p. 1439.

${ }^{98}$ Commission Regulation (EC) No 2216/2004.
} 
categorisation of trading data (within a special category that is not governed by the Directive 2003/4) complies with the Aarhus Convention.

Although this case does not deal with environmental information held by an EU institution or body, and the application of the Aarhus Regulation is therefore not triggered if a request for trading data information would be addressed to the Central Administrator of the Union Registry, based on the same line of reasoning and expecting the case law would follow a consistent approach, it is likely that the outcome of the case would be the same. In case C$556 / 14 \mathrm{P}$, the Court of Justice dealt with the refusal by the Commission of a request from an operator for information on alleged stolen allowances. ${ }^{99}$ The request for information addressed to the Commission was handled by the Director-General of DG Climate Action in the capacity of Central Administrator of the EU Transaction Log. ${ }^{100}$ The Central Administrator is the person designated by the Commission to operate and maintain the Union transaction log. ${ }^{101}$ The Court, as in the Ville de Lyon Case, ruled that the information was governed by Regulation No 2216/2004 which was adopted pursuant to Article 19(3) of the EU ETS Directive. ${ }^{102}$ Whether the general regime of Article 17 of the EU ETS Directive would apply was not considered in this judgment. Again, the Court considered the nondisclosure of information lawful by favouring the application of the special regime established by Article 19 without pondering whether such an approach is compatible with the regime for access to environmental information under the Aarhus Convention. ${ }^{103}$ In conclusion, the outcome would be the same if the request would be addressed to the

99 Case C-556/14 P, Holcim (Romania) SA v. European Commission 7 April 2016, ECLI:EU:C:2016:207.

${ }^{100}$ Case C-556/14 P, Holcim (Romania) SA v. European Commission, para 24.

${ }^{101}$ Article 20(1), Directive 2003/87/EC, consolidated version. At the time of the ruling the definition could be found in Article 2(h), Commission Regulation (EC) No 2216/2004. At the time of writing, this regulation had been repealed and the definition of Central Administrator is based on Article 3(2) of Commission Regulation (EU) No 389/2013.

102 Case C-556/14 P, Holcim (Romania) SA v. European Commission, para 46.

${ }^{103}$ If the Court had considered the application of Article 17, the first step would have been to consider whether the Aarhus regulation is applicable to the Central Administrator or not. The Aarhus Regulation applies to Union institutions or bodies, which is a narrower definition than public authorities in the Aarhus Convention (Chapter III, section 4.1.3, of this thesis). Based on the facts of case C-556/14P, the Director-General of DG Climate Action was acting as the Central Administrator, since the DirectorGeneral of DG Climate Action is a member of an EU institution, the Aarhus Regulation would be applicable. In a hypothetical case where the Central Administrator would be not be a member of an EU institution or body, the Court could still consider that the Aarhus Regulation would be applicable, since the person was designated by the Commission and the information is ultimately held by it. The second step would be to analyse whether the requested information is environmental information or not. If the answer is affirmative, the final step would be to considerer if the information could be kept confidential based on the grounds for refusal established in the Aarhus Regulation. 
Commission: non-immediate disclosure of the requested information. However, if the same request for information would be made under the 2013 amended regulation, in which the rules for the disclosure of information had different requirements for the time for releasing the information. At the time of the Ville de Lyon Case and Case 556/14P, information had to be released only after a five-year period had elapsed. ${ }^{104}$ A request for information under the current regulation would require the information to be released earlier, three years after the transaction was concluded. ${ }^{105}$ This difference in the time to release the information reveals that, for EU ETS-related information, such as information about transactions related to allowances, the Commission has the discretion to decide for how long information should be kept out of public sight. ${ }^{106}$

\subsubsection{Grounds for refusal}

i. Non-disclosure of information which relates to ongoing decision making

The Saint-Gobain case also sheds light on the grounds for refusal relied upon by the Commission when refusing the disclosure of the document (an excel table) communicated by the German authorities to the Commission. ${ }^{107}$ This document contains information related to the estimation made by Germany regarding emission allowances allocated for free to the industries falling under the EU ETS in the German territory. ${ }^{108}$ At the time of the request, the Commission had not taken the decision on the final number of allowances that could be allocated free of charge. For this reason, the General Court held that the disclosure of this information could undermine the ongoing decision making process. ${ }^{109}$

To reach this conclusion, the General Court interpreted the first subparagraph of Article 4(3) of Regulation 1049/2001 in conjunction with Article 6(1) (second sentence) of the Aarhus Regulation. Article 3 of the Aarhus Regulation stipulates that requests for access to environmental information held by EU institutions or bodies are to be dealt with within the framework of Regulation 1049/2001. This regulation provides for exceptions to the disclosure of information in Article 4. Among these exceptions is 4(3) of Regulation

\footnotetext{
${ }^{104}$ Annex XIV, para 12, Commission Regulation (EC) No 2216/2004.

${ }^{105}$ Annex XIV, para 4, Commission Regulation (EU) No 389/2013.

106 The Commission operates under the control of the Member States and, hence, its discretion is limited.

107 This case was already introduced in section 3.3.1.ii.

${ }^{108}$ Case C-60/15 P, Saint-Gobain Glass Deutschland v. Commission, para 17. Please note that, although the case before the General Court is discussed, references regarding the facts of the case come from the appeal case, since only the latter has been translated into English. M. Hillebrandt and L. Leppävirta, op. cit. (2017), p. 791.

${ }^{109}$ Case C-60/15 P, Saint-Gobain Glass Deutschland v. Commission, para 39.
} 
1049/2001, which allows the refusal of the information where a decision has not been taken by the concerned institution. However, according to Article 6(1) of the Aarhus Regulation, this exception must be interpreted in a "restrictive way, taking into account the public interest and whether the information requested related to emission into the environment". When interpreting this provision and specifically the concept of public interest, the General Court stated that Saint-Gobain Glass Deutschland was pursuing particular interests with the disclosure of this information to correct any mistakes in the information provided by the German authorities to the Commission. ${ }^{110}$ Thus, no public interest could be identified in its request. ${ }^{11}$ The General Court, therefore, considered the exception applicable, and the nondisclosure of information was deemed lawful. ${ }^{112}$

In order for the exception to be applicable, allowing the non-disclosure of information which could undermine the decision making, two conditions need to be present: (i) the existence of public interest and (ii) the fact that the information is related to emissions into the environment. In his opinion, Advocate General Szpunar stated that the Commission's decision denying the information requested by Saint-Gobain "fails to specify whether or not the information requested relates to emissions into the environment and fails to take into account the public interest served by disclosure."113 AG Szpunar also noticed that the right of access to information is guaranteed to any natural or legal person without the need to state any interest. ${ }^{114}$ Therefore, the fact that the applicant is an operator covered by the EU ETS and is a recipient of the free allowances should not be relevant to whether there is public interest in the disclosure. In fact, access to environmental information allows members of the public to become aware of relevant information regarding the protection of the environment and subsequently voice their concerns. ${ }^{115}$ Furthermore, if a member of the public, being a beneficiary of the system or not, identifies an error in data submitted by a Member State, it could potentially help the Commission to fulfil its obligation under the EU ETS properly. ${ }^{116}$ However, as noticed by the Court of Justice, although the Aarhus Regulation mentions the need to provide effective opportunities for public participation in environmental decision making, the Regulation does not require examination or reaction to public concerns regarding

\footnotetext{
${ }^{110}$ Case T-476/12, Saint-Gobain Glass Deutschland GmbH v. European Commission, para 103. The judgment of this case is only available in German and French.

${ }^{111}$ Case T-476/12, Saint-Gobain Glass Deutschland GmbH v. European Commission, para 101.

${ }^{112}$ Case T-476/12, Saint-Gobain Glass Deutschland GmbH v. European Commission, para 111.

113 Opinion of Advocate General Szpunar in Case C-60/15 P Saint-Gobain Glass Deutschland v. Commission, para 89.

114 Opinion of Advocate General Szpunar in Case C-60/15 P Saint-Gobain Glass Deutschland v. Commission, para 91.

115 Opinion of Advocate General Szpunar in Case C-60/15 P Saint-Gobain Glass Deutschland v. Commission, para 90.

116 Opinion of Advocate General Szpunar in Case C-60/15 P Saint-Gobain Glass Deutschland v. Commission, para 90.
} 
the disclosure of documents. ${ }^{117}$ Therefore, it is difficult to see how the disclosure of information could delay the Commission's administrative procedures. ${ }^{118}$

On a side note, it would be interesting to see whether the General Court would have achieved the same conclusion regarding public interest in the context of the ground of refusal as regulated by Article 6(1) of the Aarhus Regulation, if the request was made by an environmental NGO or an individual. However, it is difficult to predict the outcome, since the concept of public interest remains a "ghost concept". ${ }^{119}$

In its judgment of the appeal, the Court of Justice did not focus on the two aforementioned conditions. Rather, it focused on the distinction between decision making and administrative procedures. ${ }^{120}$ The Court of Justice found that the General Court did not interpret the first subparagraph of Article 4(3) of Regulation 1049/2001 in conjunction with the second sentence of Article 6(1) of the Aarhus Regulation correctly, which requires a strict interpretation of the exception for enabling the non-disclosure of information which could undermine the decision making process. ${ }^{121}$ The judgment established that there is a distinction between decision making itself and the entire administrative procedure, which led to the decision. ${ }^{122}$ In this case, the information sent by the German authorities to the Commission is part of the administrative procedure, and it is distinct from the Commission's decision making process itself, which was the process to achieve the decision. ${ }^{123}$ Therefore, under a narrow interpretation, as required by the second sentence of Article 6(1) of the Aarhus Regulation, on the exception which allows for the non-disclosure of information which could undermine decision making process, ${ }^{124}$ the information should be disclosed.

The Court of Justice also affirmed that "the mere reference to a risk of negative repercussions linked to access to internal documents and the possibility that interested parties may influence

\footnotetext{
${ }^{117}$ Case C-60/15 P, Saint-Gobain Glass Deutschland v. Commission, para 84.

${ }^{118}$ Case C-60/15 P, Saint-Gobain Glass Deutschland v. Commission, para 84.

119 'However, the concept of 'public interest', which offers a perspective from which to assess and resolve the tension between confidentiality and public access and ultimately to ensure the right of the public to participate, has remained a ghost concept. This makes it difficult to anticipate how individual decisions will be taken, and what, in fact, will count as a 'public interest' for the purposes of the act of balancing." E. Korkea-Aho and P. Leino, 'Who owns the information held by EU agencies? Weed killers, commercially sensitive information and transparent and participatory governance' 54(4) Common Market Law Review, (2017), pp. 1059-1091, p. 1068.

${ }^{120}$ Case C-60/15 P, Saint-Gobain Glass Deutschland v. Commission, para 76. R. Moules, 'Significant EU Environmental Cases: 2017’ 30(1) Journal of Environmental Law, (2018), pp. 157-167, p. 158.

${ }^{121}$ Case C-60/15 P, Saint-Gobain Glass Deutschland v. Commission, para 86. R. Moules, op. cit. (2018), p. 158.

${ }^{122}$ Case C-60/15 P, Saint-Gobain Glass Deutschland v. Commission, para 76.

${ }^{123}$ R. Moules, op. cit. (2018), p. 158.

${ }^{124}$ Article 4(3), first subparagraph, Regulation 1049/2001.
} 
the procedure do not suffice to prove that disclosure of those documents would seriously undermine the decision-making process of the institution concerned." ${ }^{125}$ As a consequence of this ruling, the exception, which allows for non-disclosure which could undermine the decision making process, should be interpreted as only applying to the decision making and not to the administrative procedure which precedes it. Furthermore, the Saint-Gobain case shows that the supposed threat to the decision making process is not sufficient to justify the non-disclosure of the information. ${ }^{126}$

ii. Confidentiality of commercial and industrial information

a) Ville de Lyon Case

a.1) The opinion of the Advocate General and Judgment of the Court of Justice

The Ville de Lyon Case is not only relevant for understanding what is covered by the definition of environmental information, ${ }^{127}$ but also for the interpretation of the limits of the grounds for refusal related to commercial information. In this case, Advocate General Kokott answered the question of whether information on allowance trading data qualifies as information on emissions into the environment within the meaning of Article 4 of Directive 2003/4 against which the "confidentiality of commercial and industrial information" exception cannot be invoked. ${ }^{128}$ The Advocate General reached the conclusion that the information being sought did not qualify as information on emissions into the environment, since the trading of emission allowances takes place before substances are released. ${ }^{129}$ Indeed, under the EU ETS, if a private or legal person has bought allowances, there is a choice to bank, sell or use them to covering emissions that have already been released in the environment. ${ }^{130}$

Since Advocate General Kokott reached the conclusion that information on allowance trading data does not qualify as information on emissions into the environment, she then explained that the confidentiality of commercial and industrial information exception applies in this

${ }^{125}$ Case C-60/15 P, Saint-Gobain Glass Deutschland v. Commission, para 83.

126 Case C-60/15 P, Saint-Gobain Glass Deutschland v. Commission, para 83. R. Moules, op. cit. (2018), p. 158. Saint-Gobain Glass Deutschland could also have requested the information directly from the German authorities and see whether its request would be denied. Such approach could potentially result in the disclosure of the information.

${ }^{127}$ See section 3.3.1.iii.

${ }^{128}$ Artcile 4(4)(d), Access to Environmental Information Directive.

${ }^{129}$ Opinion of the Advocate General Kokott in Case C-524/09, Ville de Lyon v. Caisse des dépôts et consignations, 14 October 2010, EU:C:2010:613, ECLI:EU:C:2010:613, para 74.

${ }^{130}$ Private or legal persons can even decide not to use or cancel allowances. See for an example footnote 155. 
case. ${ }^{131}$ Therefore, there is a presumption of confidentiality interests within the meaning of Regulation on the Registry, ${ }^{132}$ and an overriding public interest had to be present in order to disclose the information. ${ }^{133}$ Advocate General Kokott concludes that, since the reference for a preliminary ruling failed to show overriding public interest, the confidentiality interests prevail and the information shall not be disclosed. ${ }^{134}$

Presupposing that the information would be requested at the EU level - the question would be addressed to the Central Administrator of EU Transaction Log - would the AG reach the same conclusion? Assuming that the Advocate General will consider that Central Administrator as being appointed by the Commission will also be subject to the Aarhus Regulation, ${ }^{135}$ the analysis would follow the same line of reasoning: the information is not related to emissions into the environment. In this circumstance, the Aarhus Regulation also requires that the public interest has to be weighed against the interest served by the refusal, 136 but the Advocate General did not find that the questions referred by the national court indicated any overriding public interest served by the disclosure of the requested information. ${ }^{137}$ Therefore, the Advocate General would likely reach the same conclusion, if the information would be requested from the Central Administrator: non-disclosure of the requested information.

The Court of Justice does not deal with the ground for refusal related to commercial information, since it deemed that the requested information falls under the special regime of Article 19 of the EU ETS Directive. Consequently, the Court did not test whether the information requested was emissions into the environment. After this test, the Court could have achieved the same conclusion (lawful rejection of the request), but it would have provided a greater level of clarification on the interpretation of the Aarhus Convention. ${ }^{138}$ Further clarification into the question of what constitutes emissions into the environment can

\footnotetext{
${ }^{131}$ Article 4(2)(d), Access to Environmental Information Directive.

${ }^{132}$ Commission Regulation 2216/2004 adopted according to Article 19 of the EU ETS Directive on the regulation of the registry, which contains trading information data. See section 3.2.4.

133 Opinion of Advocate General Kokott in Case C-524/09, Ville de Lyon v. Caisse des dépôts et consignations, para 84 .

134 Opinion of Advocate General Kokott in Case C-524/09, Ville de Lyon v. Caisse des dépôts et consignations, para 85 .

135 The answer on whether the Central Administrator is covered by the Aarhus Regulation is not clear due to the narrow definition of Union institutions and bodies contained in the Aarhus Regulation. See Chapter III, section 4.1.3.

${ }^{136}$ Article 6(1), Aarhus Regulation.

${ }^{137}$ Article 6(1), Aarhus Regulation. Opinion of Advocate General Kokott in case C-524/09, Ville de Lyon v. Caisse des dépôts et consignations, para 84.

${ }^{138}$ Peeters and Nóbrega have already pointed out that the Court could have provided more clarification on the interpretation of the Aarhus Convention. M. Peeters and S. Nóbrega, op. cit. (2014), p. 359.
} 
be found in another case to be discussed below which, despite not dealing with the EU ETS emissions, discusses the definition of emissions into the environment.

a.2) Are greenhouse emission allowances 'emissions into the environment'?

The Court revisited the question regarding the concept of emissions into the environment in European Commission v. Stichting Greenpeace Nederland. ${ }^{139}$ The case deals with a request for information by NGOs regarding the authorisation of glyphosate. The European Commission rejected the request for access to information on the basis of the exception in the Aarhus Regulation that allows for the protection of commercial interests (Article 6(1)). However, the same provision provides for an absolute obligation for disclosure if the information relates to emissions into the environment. The court ruled that emissions into the environment encompass actual and potential emissions, but not hypothetical ones. ${ }^{140}$ The court clarified:

"Although the placing on the market of a product or substance is not sufficient in general for it to be concluded that that product or substance will necessarily be released into the environment and that information concerning the product or substance relates to 'emissions into the environment', the situation is different as regards a product such as a plant protection product, and the substances which that product contains, which, in the course of normal use, are intended to be released into the environment by virtue of their very function. In that case, foreseeable emissions, under normal or realistic conditions of use, from the product in question, or from the substances which that product contains, into the environment are not hypothetical and are covered by the concept of 'emissions into the environment' within the meaning of the first sentence of Article 6(1) of Regulation No 1367/2006." $" 141$ (emphasis added)

The Court also set aside the Commission's argument that emissions must relate to emissions originating from installations such as factories and power stations. ${ }^{142}$ This line of argumentation also seems to be present in the Aarhus Convention Implementation Guide.

\footnotetext{
${ }^{139}$ Case C-673/13 P European Commission v. Stichting Greenpeace Nederland and other, 23 November 2016, ECLI:EU:C:2016:889.

${ }^{140}$ Case C-673/13 P European Commission v. Stichting Greenpeace Nederland and other, para 71. See also V. A. Buonsante and A. Friel, 'What is Information Relating to Emissions into the Environment?' 8(2) European Journal of Risk Regulation, (2017), pp. 453-460, p. 457.

${ }^{141}$ Case C-673/13 P European Commission v. Stichting Greenpeace Nederland and other, para 75. The same was stated in case Case C-442/14, Bayer CropScience SA-NV and other v. College voor de toelating van gewasbeschermingsmiddelen en biociden, 23 November 2016, ECLI:EU:C:2016:890, para 78.

${ }^{142}$ Case C-673/13 P European Commission v. Stichting Greenpeace Nederland and other, para 40.
} 
Considering the lack of a definition of the term emissions under the Aarhus Convention, the Guide suggests, in the context of Article 4(4)(d) of the Aarhus Convention (confidentiality of commercial and industrial information exception), to use the definition of the Industrial Emissions Directive, ${ }^{143}$ which defines an emission as "direct or indirect release of substances, vibrations, heat or noise from individual or diffuse sources in the installation into air, water or land". ${ }^{144}$ However, the Court ruled that neither the Aarhus Regulation nor the Aarhus Convention contains elements to support the view that emissions into the environment are limited to emissions originating from specific industrial installations such as factories and power stations. $^{145}$

By analogy, under normal conditions, the EU ETS allowances are intended to be released into the environment (i.e., using allowances to compensate for the emissions of installations). In exceptional cases, for instance when the holder does not make use of allowances or when the holder buys with the intention of removing the allowances from the market, ${ }^{146}$ then the allowance will not be translated into emissions into the environment. However, GHG emission allowances, by the nature of their function, are intended to be released into the environment. Although the case European Commission v. Stichting Greenpeace Nederland deals with pesticide emissions and not with greenhouse gas emissions, it does clarify the concept of emissions into the environment which can be applied to the discussion of the release of any kind of emissions into the environment. However, such an interpretation still needs to be tested by the European courts with respect to emissions in the context of the EU ETS.

Another aspect that still needs clarification by the courts is whether the difference in terminology in the transposition of Article 4(4)(d) of the Aarhus Convention into EU law is in compliance with the Convention. ${ }^{147}$ While the Aarhus Convention establishes that the

${ }^{143}$ J. Ebbesson, H. Gaugitsch, J. Jendrośka, F. Marshall and S. Stec, op. cit. (2014), p. 88.

${ }^{144}$ Article 3(4), Directive 2010/75/EU of the European Parliament and of the Council of 24 November 2010 on industrial emissions (integrated pollution prevention and control), OJ L 334/17.

145 Case C-673/13 P European Commission v. Stichting Greenpeace Nederland and other, para 60 and 61.

${ }^{146}$ See for instance the Carbonkiller which is an initiative of WISE (World Information Service on Energy) through which individuals can buy allowances that are removed from the market and cannot be used by the industries. This is done with the intention of increasing the price of the allowances which will, as a consequence, stimulate industries to search for more efficient technologies due to the high prices of the allowances.

147 According to Article 4(4)(d) of the Aarhus Convention, in order for commercial and industrial information be considered confidential, it must fulfil three requirements: (i) the confidentiality of the information must be expressly protected by national law; (ii) the confidentiality shall protect a "legitimate economic interest"; and (iii) the information must not concern "emissions which are relevant for the protection of the environment". In Ville de Lyon Case, the information was considered confidential under Commission Regulation 2216/2004 and it can be possibly interpreted as a legitimate 
exception applies if the information is on emissions which is relevant for the protection of the environment, the Aarhus Regulation ${ }^{148}$ and Directive 2003/4 ${ }^{149}$ refer to information on emissions into the environment. Because of this terminology, AG Kokott understood in the Ville de Lyon Case that greenhouse gas emission allowances could not be considered emissions into the environment since they are not yet released into the environment. Therefore, AG Kokott considered that only actual emissions could be considered emissions into the environment. Even without discussing the possible incompatibility between the different terminology in the transposition of Article 4(4)(d) of the Aarhus Convention into EU law, the court ruled that emissions into the environment encompass actual and potential emissions, ${ }^{150}$ therefore giving a much more inclusive interpretation to what encompasses emissions into the environment.

For the specific grounds for refusal to protect commercial and industrial information, Article 4(4)(d) of the Aarhus Convention states that any emission which would be relevant for the protection of the environment should be disclosed. This is broader than the Aarhus Regulation and Directive 2003/4 which refer to information on emissions into the environment. ${ }^{151}$ By not referring to emissions into the environment, the text of the Aarhus Convention does not leave space for the discussion on whether the emission needs to have actually been released into the environment or not. In fact, any emission which would be relevant for the protection of the environment should be disclosed. This would also include information on greenhouse gas emission allowances, since they may affect the environment. It is true that the holder of these allowances may never use them, and the emissions would therefore not be released into the environment. ${ }^{152}$ However, these allowances still have the potential to impact the environment if used to compensate emissions. In particular, if the allowances are granted for free, it is expected that these allowances will be released into the environment, since the installation will use up all the allowances received for free before buying allowances to fulfil their obligations under the EU ETS.

economic interest since competitors could gain a commercial advantage based on the trading data information. Therefore, the first two requirements are fulfilled. See, Ebbesson, J., Gaugitsch, H., Jendrośka, J., Marshall, F. and Stec, S., 2014, pp. 87-88.

${ }^{148}$ Article 6(1), Aarhus Regulation.

${ }^{149}$ Article 4(2) last paragraph, Directive 2003/4.

${ }^{150}$ Case C-673/13 P European Commission v. Stichting Greenpeace Nederland and other, para 71. See also V. A. Buonsante and A. Friel, op. cit. (2017), p. 457.

${ }^{151}$ Article 4(2) last paragraph, Access to Environmental Information Directive. Article 6(1), Aarhus Regulation.

It is interesting to note that, while the Aarhus Convention allows for non-disclosure of information in order to protect commercial and industrial information, the Aarhus Regulation read in combination with Regulation 1049/2001 foresees non-disclosure of information only to protect commercial interests.

${ }^{152}$ P. Oliver, op. cit. (2013), p. 1439. 
In the Cross-Sectoral Correction Factor (CSCF) case, the raw data for the calculation of the CSCF was not made available to the public and the Commission even refused a request for access to the data. ${ }^{153}$ In doing so, the Commission relied on the argument that the data contained business secrets. ${ }^{154}$ The question that may arise is whether this data can be treated confidentially and whether this ground for refusal is applicable to this situation.

Article 15a of the EU ETS Directive provides that the Commission shall disclose all decisions and reports relating to the quantity and allocation of allowances. In its second paragraph, it allows for the protection of information covered by professional secrecy in accordance with applicable laws, regulations and administrative provisions. In this case, the Aarhus Regulation is applicable, even if Article 15a did not directly refer to it. According to Article 6(1) of the Aarhus Regulation, information related to emissions into the environment should be disclosed, even if the information concerns the commercial interests of a legal person by virtue of the existence of an overriding public interest in the disclosure. ${ }^{155}$ This means that, if the information is related to emissions into the environment, which seems to be the case for most or all of the information at stake in this case since the data concerned emissions already released by the installations (verified emissions), then the data should be disclosed. As pointed out by Advocate General Kokott, during the proceedings it was not possible to conclude whether the data could be treated confidentially. ${ }^{156}$ However, in order to rely on the exception for confidentiality in relation to commercial interests, the Commission should have conducted an analysis of the data to make a distinction between those that are related to emissions into the environment and those that are not, and subsequently releasing all of the former.

As mentioned in section 3.3.1.iii, the Court of Justice did not delve into the application of the exception or the protection of business or trade secrets, as the Court looked directly at

\footnotetext{
${ }^{153}$ Opinion of Advocate General Kokott in Joined Cases C-191/14, C-192/14, C-295/14, C-389/14, and C-391/14 to C-393/14, Borealis Polyolefine GmbH and others v. Bundesminister für Land- und Forstwirtschaft, Umwelt und Wasserwirtschaft and others, para 141.

${ }^{154}$ The Commission is supported by Germany in this argumentation; see Opinion of Advocate General Kokott in Joined Cases C-191/14, C-192/14, C-295/14, C-389/14, and C-391/14 to C-393/14, Borealis Polyolefine $\mathrm{GmbH}$ and others v. Bundesminister für Land- und Forstwirtschaft, Umwelt und Wasserwirtschaft and others, para 142.

155 Looking at the Aarhus Convention, Article 4(4)(d) prescribes that commercial and industrial information may be kept confidential in order to protect an economic interest, but this protection is overturned when the information is related to emissions into the environment.

${ }^{156}$ Opinion of Advocate General Kokott in Joined Cases C-191/14, C-192/14, C-295/14, C-389/14, and C-391/14 to C-393/14, Borealis Polyolefine GmbH and others v. Bundesminister für Land- und Forstwirtschaft, Umwelt und Wasserwirtschaft and others, para 150.
} 
whether the Commission calculated the correction factor correctly. Since the Court found that the calculation was based on incorrect data (due to a divergent interpretation of which installations should be taken into account to determine the maximum annual amount of allowances), ${ }^{157}$ the Court ruled that the decision was invalid. ${ }^{158}$ Due to the invalidity of the decision, the Commission adopted a new CSCF. ${ }^{159}$ Again, the Commission only published the data after the decision was undertaken. ${ }^{160}$ Moreover, once again this publication was not accompanied by the raw data that could allow for the replication of the calculation.

This case demonstrates that even decisions which do not require the exercise of discretion by the Commission may still be subject to error. The different translations and consequent interpretations of the text of the Directive, and the asymmetry in the implementation rules, demonstrate the complexity of the system. ${ }^{161}$ Nevertheless, groups, such as specialised NGOs and researchers having access to information, can provide technical arguments which may

157 Joined Cases C-191/14, C-192/14, C-295/14, C-389/14, and C-391/14 to C-393/14, Borealis Polyolefine $\mathrm{GmbH}$ and others v. Bundesminister für Land- und Forstwirtschaft, Umwelt und Wasserwirtschaft and others, para 87.

158 Joined Cases C-191/14, C-192/14, C-295/14, C-389/14, and C-391/14 to C-393/14, Borealis Polyolefine $\mathrm{GmbH}$ and others v. Bundesminister für Land- und Forstwirtschaft, Umwelt und Wasserwirtschaft and others, para 99.

${ }^{159}$ Commission Decision (EU) No 2017/126 of 24 January 2017 amending Decision 2013/448/EU as regards the establishment of a uniform cross-sectoral correction factor in accordance with Article 10a of Directive 2003/87/EC of the European Parliament and of the Council, OJ L 19/93.

160 The decision was adopted on 25 January 2017 and the aggregated data was published in February 2017. Publication of aggregated production data used to determine free allocations under the EU ETS $\begin{array}{lll}\text { for the 2013-2020: } & \text { period }\end{array}$ https://ec.europa.eu/clima/sites/clima/files/euets_product_benchmarks_en.pdf.

${ }^{161}$ M. Peeters, 'HvJ EU van 28 april 2016 in de gevoegde zaken C 191/14, C 192/14, C 295/14, C 389/14 en C 391/14 tot en met C 393/14, ECLI:EU:C:2016:311' 44(6) Tijdschrift Milieu \& Recht, (2017), pp. 537-540, paragraph 2. The original text in Dutch reads as follows: "Het is niet gemakkelijk de casus te begrijpen: het administratief-technische pakket aan juridische criteria voor gratis toedeling is zeer moeilijk te doorgronden. Bij een dergelijke hoge mate van complexiteit van regulering wordt de transparantie van de bestuurlijke besluitvorming, en daarmee ook de democratische en rechterlijke controle op deze besluitvorming, kwetsbaar. Immers, een voorwaarde voor adequate controle op besluitvorming is dat de gronden voor de besluitvorming bekend en begrijpelijk zijn. Bij heel complexe criteria - zoals overduidelijk het geval is bij de gratis toewijzing van broeikasgasemissierechten - zal het alleen voor specialisten nog inzichtelijk zijn of de juiste informatie gebruikt is, en of de juiste gevolgtrekking heeft plaatsgevonden. Bovendien speelt in EU verband vaak de taalkwestie een rol: ook in onderhavige zaak bestond verwarring over de uitleg van criteria vanwege discrepantie in verschillende taalversies (paragraaf 89 en verder). Daarnaast zit er een ingewikkelde asymmetrie in het geregelde systeem van toewijzingscriteria (zie daarover paragraaf 78). Door de AG wordt zelfs geopperd dat dit probleem wellicht over het hoofd is gezien door de wetgever (zie met name paragrafen 76-79 en de paragrafen 107-108 van de conclusie: er ontbreken 'duidelijke uitlatingen van de wetgever' en er is geen verplichting voor de Commissie de asymmetrie op te heffen).” 
help to arrive at a correct decision. Furthermore, in light of the Aarhus Convention, independent of the complexity of the information, what matters is whether a ground for an exception to disclosure could be granted to keep information confidential. When dealing with emissions into the environment, the regime is even stricter, and the analysis of whether the information should be disclosed has to take into account that, in these cases, the ground for refusal (i.e. protection of commercial and industrial information) is not applicable. In the CSCF Case, the court did not deal precisely with this question, because the main issue concerned the proper calculation of the correction factor. However, if a member of the public would make a request for the raw data used by the Commission, the limits of the application of the exception would have to be clarified.

\subsection{Dissemination of EU ETS-related information}

Article 19 of the EU ETS Directive provides that the Union Registry shall contain separate accounts to record the transactions related to allowances and it needs to be accessible to the public. Therefore, it is important to see what is made available and what possible legal problems can emanate from the implementation of this obligation.

The EU ETS information related to the allocation and transactions related to allowances is scattered among three web pages: the Union Registry webpage that is part of the EU ETS website, ${ }^{162}$ the Union Registry website ${ }^{163}$ and European Union Transaction Log website. ${ }^{164}$

On the Union Registry webpage, which is part of the European Commission website, information is made available regarding compliance data, i.e., the name of the installations and the respective number of allowances surrounded by each installation, the number of verified emissions per installation, and the exchange of international credits under the EU ETS. ${ }^{165}$ Complementing this information, the EU Transaction Log also provides information on the allocation of allowances, i.e., the distribution per country of the surrendered and free allocated emissions per country. ${ }^{166}$ Interestingly, the Union Registry website only makes the reports on the Kyoto Protocol available. ${ }^{167}$ Although any individual can sign in to the Union

162 European Commission. Union Registry - Phase 3 (2013-2020), 19 June 2020, https://ec.europa.eu/clima/policies/ets/registry_en\#tab-0-1.

163 European Commission. Union Registry, 20 June 2020, https://etsregistry.webgate.ec.europa.eu/euregistry/EU/index.xhtml.

164 European Commission-Directorate-General Climate Action. European Union Emissions Transaction log, 18 June 2020, https://ec.europa.eu/clima/ets/napMgt.do.

165 European Commission. Union Registry - Phase 3 (2013-2020), 19 June 2020, https://ec.europa.eu/clima/policies/ets/registry_en\#tab-0-1.

166 European Commission-Directorate-General Climate Action. European Union Emissions Transaction log, 18 June 2020, https://ec.europa.eu/clima/ets/napMgt.do.

${ }^{167}$ The Kyoto Protocol Reports are reports on the transactions related to international credits for the purpose of meeting the EU's obligations as a Party to the Kyoto Protocol and under Article 10 of 
Register by creating an account with a username and password, ${ }^{168}$ the only information available is on the reports on the Kyoto Protocol and a tab for accounts become visible. This evidences that the "accessible to the public" referred in Article 19(2) probably refers to access to enable any member of the public to create an account to hold and trade allowances, but it does not provide for ample access to EU ETS-related information.

Article 19(3) of the EU ETS Directive requires that information on Certified Emission Reductions (CERs) and Emission Reduction Units (ERUs) must also be made available on the Union Registry. Until 2013, it was possible to trace the number of allowances originating from international offset credits (CERs and ERUs) that were used by operators to cover their emissions. ${ }^{169}$ However, in 2014 the Commission published the information on compliance data and verified emissions for 2013 without the data on international credits exchanged. ${ }^{170}$ After public complaints from civil society groups, the Commission released another document with the volume and type of offsets surrendered. ${ }^{171}$ However, unlike in previous years, the names of the companies did not appear in the document. The Commission explained the absence of the information as follows:

"Companies can exchange CERs and ERUs for allowances up to their individual entitlement limits set in the registry. In contrast with phase two, no information is available on the number of CERs and ERUs used for compliance. Since in phase 3 CERs and ERUs are no longer directly surrendered but exchanged for allowances, it is impossible to trace how many CERs and ERUs were used in a particular compliance year." 172 (Emphasis added)

The Commission Regulation on the Union Registry explained that fungible credits (i.e., units that are interchangeable) were necessary in order to have a well-functioning system. ${ }^{173}$ It may

\footnotetext{
Regulation 525/2013 of the European Parliament and of the Council of 21 May 2013 on a mechanism for monitoring and reporting greenhouse gas emissions and for reporting other information at national and Union level relevant to climate change and repealing Decision No 280/2004/EC, OJ L 165/13.

168 European Commission. Union Registry, 20 June 2020, https://etsregistry.webgate.ec.europa.eu/euregistry/EU/index.xhtml.

${ }^{169} \mathrm{CERs}$ are credits issued for emission reductions from CDM project activities, while EURs are issued for JI projects.

${ }^{170}$ Ember. Transparency in the EU Emissions Trading Scheme has been unnecessarily reduced. Available at: https://ember-climate.org/2014/05/16/transparency-issues-compound-problems-with-eucarbon-market/.

171 Ember. Transparency issues compound problems with EU carbon market. Available at: https://ember-climate.org/2014/05/16/transparency-issues-compound-problems-with-eu-carbonmarket/.

${ }^{172}$ European Commission. "Number of international credits exchanged totals 132.8 million". Available at: http://ec.europa.eu/clima/news/articles/news_2014050201_en.htm.

${ }^{173}$ Recital 8, Preamble, Commission Regulation (EU) No 389/2013.
} 
occur that transactions recorded in the system need to be undone (reversal of transactions), because there was an unintentional or erroneous transaction. ${ }^{174}$ Furthermore, in the case of theft, there will be a claim to restore the stolen credits. In all of these situations, the fungibility of the allowances means that the allowance holder may claim the same amount of allowances, but not the specific allowances. ${ }^{175}$

Since the above-mentioned situation deals with information at the EU level, the Aarhus Regulation will also apply. Article 4(2)(e) of the Aarhus Regulation states that, among others, registries shall include "data or summaries of data derived from the monitoring of activities affecting, or likely to affect, the environment". Considering that the international credits used in the system are used to compensate emissions that have an impact on the environment, combined with the potential impact that the projects from which these credits originated may have in the hosting countries, it can be considered an activity affecting or likely to affect the environment. ${ }^{176}$ In this vein, there is an obligation for the registry to make the information about the use of international credits in the EU ETS available, according to Article 4(2)(e) of the Aarhus Regulation. The fact that the information is not available on the Union Registry website but rather in the website of the DG Climate action about the Union Registry does not constitute a barrier to fulfilling the obligation prescribed under the Aarhus Convention, because the ultimate result, which is to make the information available to the public, is fulfilled. However, the issue regarding the disclosure of the names of the installations that have used international credits to compensate their emissions is not clarified by this provision. It could be argued that, by disclosing the number of credits used in the system and the projects from which the credits originated would be enough to fulfil the obligation under the Aarhus Regulation. However, it can also be argued that the use of credits is part of data that affects the environment and, therefore, should also be disseminated. These arguments have not yet been considered by the Court of Justice.

The need to harmonise the system in order to guarantee the free circulation of carbon credits among EU ETS installations seems to have come at the expense of public access to information. Since the names of the companies which use the international credits cannot be known due to the fungibility of the allowances and international credits, NGOs claimed that the restriction on information on CERS and ERUS will have an impact on the behaviour of

\footnotetext{
${ }^{174}$ Article 70, Commission Regulation (EU) No 389/2013.

175 European Commission. General Questions and Answers on Registries (05/2013), 19 June 2020, https://ec.europa.eu/clima/policies/ets/registry_en\#tab-0-2.

${ }^{176}$ Regarding claims of negative impacts of CDM projects, see: R. Spalding-Fecher, A. N. Achanta, P. Erickson, E. Haites, M. Lazarus, N. Pahuja, N. Pandey, S. Seres and R. Tewari, Assessing the impact of the clean development mechanism - Report commissioned by the High Level Panel on the CDM policy Dialogue (2012), 47- 49.
} 
companies. ${ }^{177}$ Companies that purchase credits from responsible projects could use this kind of information to differentiate themselves towards consumers, but with this change, the differentiation becomes harder.

\subsection{Interim conclusion}

The general regime for access to environmental information under the EU ETS can be found within Articles 17, 15a, and 19 of the EU ETS Directive. Articles 17 and 15a deal specifically with access to information, while Article 19 focuses on the registries, which contain key information about the functioning of the EU ETS.

The analysis carried out in section 3.2 showed that, despite the fact that Article 17 of the EU ETS Directive does not reflect the shift of decision making from the national level to the EU level, the Aarhus Regulation applies to information requests addressed to the Commission, since EU institutions are bound, in any case, by the Aarhus Regulation. Furthermore, it was also identified that Article 17 of the EU ETS Directive obliges public authorities to either disseminate environmental information and to disclose it upon request.

Secondly, section 3.2 concluded that the second part of Article 15a of the EU ETS Directive implicitly refers to these Directive 2003/4 as well as to the Aarhus Regulation when it makes reference to "applicable laws, regulations or administrative provisions". ${ }^{178}$

Finally, section 3.2 showed that Article 19 establishes a provision on the dissemination of information that also involves the European Commission. However, the extent to which this provision allows for access to information is not clear from the wording of the provision.

The limited scope of Article 15a and 17 cannot cover all the possible requests for information under the EU ETS. To examine the definition of environmental information and the limits of the grounds for the disclosure of environmental information further, an investigation of the case law was carried out in section 3.3.

Concerning the definition of environmental information, the case law dealt with information regarding data used for the calculation the CSCF, information on the allocation of free allowances by a Member State and trading data. Regarding the calculation of the CSCF, the opinion of the Advocate General showed that the raw data needed to replicate the calculation should be made available to the public. Unfortunately, the CJEU did not delve specifically into this question in its judgment. In the Saint-Gobain Glass Deutschland case, the Court

177 Ember. Transparency issues compound problems with EU carbon market, 19 June 2020, https://ember-climate.org/2014/05/16/transparency-issues-compound-problems-with-eu-carbonmarket/.

${ }^{178}$ Article 15a deals with professional secrecy, an aspect which is not present in Article 17 of the EU ETS Directive. 
tackled the information concerning the allocation of free allowances and confirmed that the list of installations covered by the EU ETS and also the number of allowances allocated for free by a Member State constitute environmental information within the definition of the Aarhus Regulation. The opinion of the Advocate General in the Ville de Lyon case further demonstrated that trading data constitutes environmental information, although this issue did not receive particular attention in the judgment. These cases reveal that a significant amount of EU ETS-related information falls within the definition of environmental information, although, in the Saint-Gobain Glass Deutschland case and in the Ville de Lyon case, such an interpretation still needs confirmation from the Court of Justice of the European Union.

Regarding the grounds for refusal, the case law showed that these grounds have to be interpreted in a restrictive way. On the topic of applying the exception for refusal in case of information in that could undermine the decision making process, the CJEU made a distinction in the Saint-Gobain case between decision making itself and the entire administrative procedure, which leads to a decision. It concluded that all information that is part of the administrative procedure should be disclosed. Concerning, secondly, the application of the exception for the protection of the confidentiality of commercial and industrial information, the Ville de Lyon and CFCS cases, despite not dealing directly with this exception, allowed for the possibility to explore its application, since the public authority relied on this ground to refuse access to the environmental information. The analysis in this chapter showed that the application of this exception, when dealing with emissions into the environment, is even stricter, and the analysis of whether the information should be disclosed has to take into consideration that, in these cases, the ground for refusal (i.e. protection of commercial and industrial information) is not applicable. Furthermore, the discussion on what constitutes emissions into the environment in view of the EU ETS suggests that there is a need for an interpretation of the Aarhus Convention in light of the new developments to combat climate change, such as emissions trading. At the time of the adoption of the Aarhus Convention, emissions trading was still a concept that needed further practical development, and it can be assumed that the broad term emissions was related to the actual release of substances from installations within more classic command-and-control instruments. With the advent of a market-based instrument, such as emissions trading, there is a need for further interpretation in view of the potential release of substances and the creation of new concepts such as greenhouse gas emission allowances.

Regarding, finally, the active dissemination of information by the Commission, which was discussed in section 3.4, the Union Registry is the main tool used to make information available to the public, according to Article 19 of the EU ETS Directive. However, in reality, the EU ETS information related to the allocation and transaction of allowances is scattered among three web pages. The fact that the EU ETS Directive empowers the Commission to adopt a regulation, which provides for public access and confidentiality as appropriate, results in a possibility of tailoring how and when the information is available. The compatibility of 
the exercise of this discretion - as the change in the way the information about international credits or the time transaction-related information is released to the public - with the Aarhus Convention has yet to be tested by the European courts.

Furthermore, the analysis in section 3.4 makes it possible to identify that there is no registry available to the public that would provide information on the number and nature of requests to access EU ETS-related information. This is an indication of the limitations on access to environmental information rights in the EU. A readily available registry with a compilation of all requests would not only help the members of the public to get information, but it would also avoid the situation in which civil servants have to answer the same questions repeatedly. These examples demonstrate that there is still much room for a further and more ambitious interpretation of the Aarhus Convention with regard to disclosing environmental information under the EU ETS.

\section{Public Participation in the decision making of the EU ETS}

\subsection{Introduction}

This section will undertake a systematic analysis of the provisions which empower the European Commission to act under the EU ETS Directive at the EU level in view of public participation requirements mandated by the Aarhus Convention and the Aarhus Regulation. First, the provisions which empower the European Commission to act are mapped. Concomitantly, it will be identified whether the provisions, on the basis of which the acts may be adopted at the EU level, require public participation or not. Second, the analysis will consider if the Aarhus Regulation provides any obligation for public participation for acts adopted by the Commission under the EU ETS. Third, this section will study if these decisions fall within the scope of the second pillar of the Aarhus Convention and, if they do, which legal requirements the Commission needs to fulfil in order to comply with the requirements of the Aarhus Convention. Fourth, the current EU legal framework is contrasted to the legal requirements found in the previous section to test its compatibility with the Aarhus Convention.

\subsection{Public participation under the EU ETS Directive at the EU level}

In contrast to access to information, the EU ETS Directive does not provide any specific provision on public participation that applies to all provisions of the Directive. Moreover, none of the amendments to the EU ETS Directive, thus far, were aimed at implementing public participation in the decision making process. ${ }^{179}$

\footnotetext{
${ }^{179}$ For the amendments to the EU ETS Directive, see footnote 3.
} 
In order to identify the current legal framework for public participation at the EU level, a mapping of the core acts (prescribed by the EU ETS Directive) to be taken at the EU level must, therefore, be carried out to identify what is the legal procedure through which these acts may be adopted and whether the procedure imposes public participation requirements.

With respect to the acts that will be analysed, it is important to note that, in the third phase of the EU ETS, the EU ETS Directive empowers the European Commission to regulate the cap, the allowance allocation rules and the harmonised rules regarding monitoring and verification. The implementation of the monitoring and verification provisions falls under the competence of the Member States. This section will thus focus on public participation in the setting of the cap and allocation of allowances, with monitoring and verification only analysed in view of the harmonised rules established at the EU level.

\subsubsection{Cap}

The EU ETS emissions cap is related to the EU commitments under the Kyoto Protocol to reduce its emissions by $8 \%$ in the first commitment period (2008-2012) and $20 \%$ in the second commitment period (2012-2020). ${ }^{180}$

In Phase I, the learning by doing phase from 2005-2007, and in Phase II, running from 20082012, the Member States were in charge of stipulating the overall amount of allowances needed ${ }^{181}$ that is, they could set their own national cap through National Action Plans (NAPs). For the purpose of this chapter, the most relevant aspect is that the NAPs were subject to public participation at the Member State level. The NAPs had to be based on "objective and transparent criteria, including those listed in Annex III, taking due account of comments from the public" and had to be notified to the Commission. ${ }^{182}$ The Commission had the power to reject each NAP, in whole or in part. ${ }^{183}$

Phase III began in 2013 and ran until 2020. NAPs no longer exist, and the amended EU ETS Directive provides for an EU-wide cap on emissions based on the allowances allocated in 2008-2012. This means that, since 2013, there is an EU-wide cap that will be reduced "in a linear manner" by $1.74 \%{ }^{184}$ in order to achieve a general reduction of $21 \%$ below the 2005 emissions levels by $2020 .^{185}$

The establishment of the EU-wide cap may be affected by the entrance and withdrawal of sectors and subsectors in the system and the use of international credits that may be used to

\footnotetext{
180 Article 1, Doha Amendment.

181 A more detailed explanation of these phases is provided in section 2 .

182 Article 9(1), Directive 2003/87/EC, original version.

183 Article 9(3), Directive 2003/87/EC, original version.

${ }^{184}$ Article 9, Directive 2003/87/EC, consolidated version.

185 Recital 14, Preamble, Directive 2009/29/EC.
} 
offset the greenhouse gas emissions. Therefore, the acts adopted by the Commission in this realm will also be analysed.

\section{i. $\quad$ EU-wide Cap}

Article 9 of the EU ETS Directive prescribes how the cap shall be established by the Commission. The cap for emissions from stationary installations is established, according to Article 9 of the EU ETS Directive, by the decision of the European Commission acting alone. The decision is thus taken solely by the College of Commissioners which is based on the principle of collegiality. ${ }^{186}$ This means that the College of Commissioners - which is composed of 28 members - is seen as one body responsible collectively for the decisions taken. $^{187}$

It should be noted that the question of whether the implementing power of the Commission should be subject to control by the Member States is determined by the EU legislator. ${ }^{188}$ The Regulation on Committee Procedure states that the mechanisms for control will "apply where a legally binding Union act [...] identifies the need for uniform conditions of implementation and requires that the adoption of implementing acts by the Commission be subject to the control of Member States." ${ }^{189}$ In the case of Article 9 of the EU ETS Directive, the Council and the Parliament, when adopting the Directive, did not require Member State control and the Commission can thus adopt the implementing decisions on the cap without a committee procedure. ${ }^{190}$ The absence of a requirement for Member State control could be due to the fact that Article 9 prescribes precisely how the cap should be determined: "based on the total quantities of allowances issued or to be issued by the Member States in accordance with the Commission Decisions on their national allocation plans for the period from 2008 to

186 Article 9, Directive 2003/87/EC, consolidated version. On the Principle of collegiality see N. Nugent, W. E. Paterson and V. Wright, The European Commission, (Houndmills, Basingstoke, Hampshire: Palgrave, 2001), pp. 91-93.

187 European Commission, Rules of Procedure of the European Commission C(2000) 3614, OJ L 308/26 (2000).

${ }^{188}$ Legal Service of the Council of the European Union, Application of Articles 290 (delegated acts) and 291 (implementing acts) TFEU (2011), p. 11.

${ }^{189}$ Regulation (EU) No 182/2011 of the European Parliament and of the Council of 16 February 2011 laying down the rules and general principles concerning mechanisms for control by Member States of the Commission's exercise of implementing powers, OJ L 55/13.

${ }^{190}$ First Commission decision determining the Cap for 2013: Commission Decision 2010/384/EU. Second Commission decision determining the Cap for 2013 was adopted: Commission Decision 2010/634/EU of 22 October 2010 adjusting the Union-wide quantity of allowances to be issued under the Union Scheme for 2013 and repealing Decision 2010/384/EU (notified under document C(2010) 7180), OJ L 279/34. After the adoption of the first decision, additional information was made available and the first decision had to be repealed and replaced (Recital 2, Preamble, Commission Decision 2010/634/EU) 
2012", ${ }^{191}$ leaving no space for the exercise of discretion by the Commission on how to calculate the cap.

While the legislator did not find it necessary to provide for Member State control, Article 9 of the EU ETS Directive also does not foresee any public participation requirement for the adoption of the decision on the cap.

\section{ii. Opt-in and opt-out of the EU ETS}

Member States may take further measures to include additional activities or types of gases (called opt-in) in the EU ETS, but these inclusions are subject to the approval of the European Commission. ${ }^{192}$ In the period from 2008 to 2012, Article 24 of the EU ETS Directive served as the legal basis for five Commission decisions regarding the inclusion of nitrous oxide $\left(\mathrm{N}_{2} \mathrm{O}\right)$ emissions associated with the production of nitric acid. The requests, which were approved by the Commission, were made by Austria, ${ }^{193}$ Italy, ${ }^{194}$ Latvia, ${ }^{195}$ the Netherlands, ${ }^{196}$ and the United Kingdom. ${ }^{197}$ Since 2013, the $\mathrm{N}_{2} \mathrm{O}$ emissions associated with the production of nitric acid are covered by the EU ETS. ${ }^{198}$

The five decisions related to $\mathrm{N}_{2} \mathrm{O}$ emissions are implementing decisions which were adopted by the Commission following the regulatory procedure with scrutiny according to Article $5 \mathrm{a}$ of Council Decision 1999/468/EC, which prescribes how the implementing powers conferred

\footnotetext{
${ }^{191}$ Article 9, Directive 2003/87/EC, consolidated version.

192 Article 24, Directive 2003/87/EC, consolidated version.

${ }^{193}$ Décision de la Commission concernant l'inclusion unilatérale par l'Autriche de gaz à effet de serre et d'activités supplémentaires dans le système communautaire en application de l'article 24 de la directive 2003/87/CE du Parlement européen et du Conseil (C(2009)9849/F1)2009.

${ }^{194}$ Décision de la Commission concernant l'inclusion unilatérale, par l'Italie, de gaz à effet de serre et d'activités supplémentaires dans le système d'échange de quotas d'émission de gaz à effet de serre dans l'Union en application de l'article 24 de la directive 2003/87/CE du Parlement européen et du Conseil Commission (C(2012)497/1).

${ }^{195}$ Commission Decision concerning the unilateral inclusion of additional installations by the Republic of Latvia in the Community emission allowance trading scheme pursuant to Article 24 of Directive 2003/87/EC of the European Parliament and of the Council (C(2009)3032/F1).

${ }^{196}$ Commission Decision of 17.12.2008 concerning the unilateral inclusion of additional greenhouse gases and activities by the Netherlands in the Community emissions trading scheme pursuant to Article 24 of Directive 2003/87/EC of the European Parliament and of the Council (C(2008) 7867), OJ L $175 / 36$.

${ }^{197}$ Commission Decision of 6.6.2011 concerning the unilateral inclusion of additional greenhouse gases and activities by the United Kingdom in the scheme for greenhouse gas emission allowance trading within the Union pursuant to Article 24 of Directive 2003/87/EC of the European Parliament and of the Council (C(2011)3798).

${ }^{198}$ Article 1(30) and Annex I, Directive 2009/29/EC.
} 
on the European Commission shall be exercised. ${ }^{199}$ Comitology, which is the procedure through which the Commission exercises its implementing powers with the assistance of committees composed by the Member States representatives, ${ }^{200}$ does not foresee the participation of the public and the Member States participate only through their representative on the committee. Likewise, Article 24 of the EU ETS Directive does not require any public participation.

Member States may also exclude small installations (called opt-out) which are subject to measures that achieve equivalent emissions reductions. ${ }^{201}$ In this case, there is no need for explicit approval from the Commission: i.e. if the Commission does not object, the exclusion is deemed approved. ${ }^{202}$ Germany, the United Kingdom, France, Spain, Croatia, Slovenia, and Italy have all excluded installations with low emissions from the EU ETS. ${ }^{203}$ The Commission has a period of three months to object to the Member State's decision. Article 27 of the EU ETS Directive does not clarify how this objection of the Commission is to be expressed in legal terms but the provision, per se, does not provide any requirement for public participation (only consultation with the operator by the Member State is prescribed). It should be noted that public participation may take place at the Member State level regarding the national decision if prescribed by national law, but this would not exclude the possibility of public participation taking place at the EU level, which could, for instance, have been provided for in the EU ETS Directive.

iii. Restrictions on the use of international credits

Under the Kyoto Protocol, there are two mechanisms which generate international credits, namely: the Clean Development Mechanism (CDM) and the Joint Implementation (JI). ${ }^{204}$

${ }^{199}$ Council Decision 1999/468/EC of 28 June 1999 laying down the procedures for the exercise of implementing powers conferred on the Commission, OJ L 184/23.

${ }^{200}$ P. Ponzano, 'The Reform of Comitology and Delegated Acts: An Executive's View', in C. F. Bergström and D. Ritleng (eds.), Rulemaking by the European Commission: The New System for Delegation of Powers, (Oxford: Oxford University Press, 2016), pp. 37- 54, p. 37.

${ }^{201}$ Article 27, Directive 2003/87/EC, consolidated version.

${ }^{202}$ Article 27(2), Directive 2003/87/EC, consolidated version.

${ }^{203}$ Recital 2, Preamble, Commission Implementing Decision 2013/634/EU of 31 October 2013 on the adjustments to Member States' annual emission allocations for the period from 2013 to 2020 pursuant to Decision No 406/2009/EC of the European Parliament and of the Council, OJ L 292/19 provided the information about the Member States that excluded installations with low emissions from the EU ETS. It can be that other Member States will take similar measures and therefore it remains important for the present discussion to examine which legal instrument the Commission may use to intervene and whether the decision making allows for public participation.

204 According to Article 12(2) of the Kyoto Protocol: "The purpose of the clean development mechanism shall be to assist Parties not included in Annex I in achieving sustainable development and in contributing to the ultimate objective of the Convention, and to assist Parties included in Annex I in 
The use of such project-based credits is allowed under the EU ETS until $2020^{205}$ but their use is subject to quantitative ${ }^{206}$ and qualitative restrictions. ${ }^{207}$ The use of CDM and JI credits are limited to $11 \%$ of the operator allocation in the $2008-2012$ period, and to $4.5 \%$ of their verified emission in the 2013-2020 period for newcomers. ${ }^{208}$ The EU ETS Directive has blocked the use of credits originating from nuclear energy products, afforestation or reforestation activities, ${ }^{209}$ and it has established that, from 2013 onwards, the use of credits from new CDM projects is limited to projects located in Least Developed Countries (LDCs). ${ }^{210}$ In the third period, the Commission may also adopt restrictions on the use of specific credits (qualitative restriction). ${ }^{211}$ The Commission has used this possibility to block the use of credits from projects involving the destruction of industrial gases. ${ }^{212}$ The

achieving compliance with their quantified emission limitation and reduction commitments under Article 3." Article 12(2), Kyoto Protocol.

The mechanism known as "joint implementation" is defined under Article 6 of the Kyoto Protocol. It allows an Annex B Party to use emission reduction units (ERUs) from projects in another Annex B Party to achieve its target.

Article 6 of the Paris Agreement establishes a mitigation mechanism which will replace the CDM and JI after 2020.

${ }^{205}$ Article 11a(4), Directive 2003/87/EC, consolidated version.

${ }^{206}$ Article 11a(9), Directive 2003/87/EC, consolidated version. The existing power conferred on the Commission by Article 11a(9) of the EU ETS Directive has been revoked for the period after 2020. Recital 27 and Article 1(18), Directive (EU) 2018/410.

${ }^{207}$ Article 11a(8), Directive 2003/87/EC, consolidated version. The existing power conferred on the Commission by Article 11a(8) of the EU ETS Directive has been revoked for the period after 2020 . Recital 27 and Article 1(18), Directive (EU) 2018/410.

208 The limitation already established in Article 11a(8) of the EU ETS Directive and further detailed in Article 1 (2), Comission Regulation (EU) No 1123/2013 of 8 November 2013 on determining international credit entitlements pursuant to Directive 2003/87/EC of the European Parliament and of the Council, OJ L 299/32.

${ }^{209}$ Article 1 (2), Directive 2004/101/EC.

${ }^{210}$ Article 11a(4), Directive 2003/87/EC, consolidated version.

211 Article 11a(9), Directive 2003/87/EC, consolidated version. This amendment was introduced through Article 1(13), Directive 2009/29/EC.

${ }^{212}$ Commission Regulation (EU) No 550/2011 of 7 June 2011 on determining, pursuant to Directive 2003/87/EC of the European Parliament and of the Council, certain restrictions applicable to the use of international credits from projects involving industrial gases, OJ L 149/1. 
Commission has also adopted a decision to avoid the double counting ${ }^{213}$ of greenhouse gas emission reductions. ${ }^{214}$

In sum the Commission has adopted three acts: (i) a Commission Regulation on quantitative restrictions; (ii) a Commission Regulation on the prohibition of the use of credits from projects involving the destruction of industrial gases and (iii) a Commission Decision on rules to avoid double counting. These measures were adopted via the comitology procedure, which, as already explained, does not foresee public participation. ${ }^{215}$ Likewise, the provisions of the EU ETS Directive (Articles 11a(8), 11a(9) and 11b(7)) on which these acts were based do not contain public participation requirements for the adoption of these acts.

\subsubsection{Allocation of allowances}

As described in the introduction on the EU ETS Directive (section 2), the first two phases of the EU ETS were primarily based on free allocation, and Member States could define how the emissions allowances would be allocated to their industries. ${ }^{216}$ For Phase III, which is the first phase of the centralised regime, auctioning is the default method of allocating allowances

\footnotetext{
213 "Double counting occurs when a single GHG emission reduction or removal, achieved through a mechanism issuing units, is counted more than once towards attaining mitigation pledges or financial pledges for the purpose of mitigating climate change." L. Schneider, A. Kollmuss and M. Lazarus, 'Addressing the risk of double counting emission reductions under the UNFCCC' 131(4) Climatic Change, (2015), pp. 473-486, p. 474.

214 The legal basis for the adoption of the act is Article 11b(7), Directive 2003/87/EC, consolidated version. The decision to avoid the double counting of greenhouse gas emission reductions Commission Decision 2006/780/EC of 13 November 2006 on avoiding double counting of greenhouse gas emission reductions under the Community emissions trading scheme for project activities under the Kyoto Protocol pursuant to Directive 2003/87/EC of the European Parliament and of the Council, OJ L 316/12. ${ }^{215}$ According to the EU ETS Directive, the acts based on Articles 11a(8), 11a(9), in the present case the two Regulations, should follow the regulatory procedure with scrutiny in accordance with Articles $5 \mathrm{a}(1)$ to (4) and 7, Council Decision of 28 June 1999 laying down the procedures for the exercise of implementing powers conferred on the Commission (1999/468/EC), OJ L 184/23. While the acts adopted under and 11b(7) EU ETS Directive, in this case the Commission decision on the avoidance of double counting, should follow the regulatory procedure with scrutiny in accordance with Articles 5a(1) to (4) and Article 7, Council Decision 1999/468/EC. This decision was repealed by Regulation (EU) No 182/2011. However, the effects of Article 5a of Decision 1999/468/EC was provisionally maintained to allow the transition of existing basic acts which refer to this Article (see Recital 21 of Regulation (EU) No 182/2011), such as is the case of the EU ETS Directive.

${ }^{216}$ Article 11, Directive 2003/87/EC, original version.
} 
within the EU ETS. ${ }^{217}$ However, this default method is subject to many exceptions that full auctioning is not expected to occur until $2027 .^{218}$

The power sector has been subject to full auctioning since 2013. ${ }^{219}$ However, eight Member States benefit from a transitional period of free allocation for power generators in order to help modernise their electricity production. ${ }^{220}$

Within the manufacturing sector, the transition to auctioning is taking shape gradually. The manufacturing industry started receiving $80 \%$ of its allowances free-of-charge in 2013, but this decreases progressively each year to $30 \%$ in 2020 with a target of no free allocation by $2027 . .^{221}$

In the aviation sector, only $15 \%$ of aviation allowances will be auctioned until $2020 . .^{222}$ The aviation sector was only incorporated into the EU ETS in 2009 through an amendment to the EU ETS Directive that, among other changes, introduced a chapter dedicated to the aviation sector. $^{223}$ Airlines can use any allowances for compliance purposes, ${ }^{224}$ but stationary installations cannot use aviation allowances. ${ }^{225}$ Only emissions from flights within the European Economic Area are covered by the EU ETS. ${ }^{226}$

\footnotetext{
${ }^{217}$ Article 10 (1), Directive 2003/87/EC, consolidated version.

218 The rules on free allocation might change if an international agreement is reached, Article 10(a)(1) of Directive 2003/87/EC, consolidated version.

${ }^{219}$ Article 10a (1), Directive 2003/87/EC, consolidated version.

${ }^{220}$ The countries that derogates from the full auctioning in the power section are: Hungary, Poland, Bulgaria, Czech Republic, Romania, Cyprus, Estonia, and Lithuania.

${ }^{221}$ Article 10(a)(11), Directive 2003/87/EC, consolidated version.

${ }^{222}$ Article 3d(2), Directive 2003/87/EC, consolidated version.

${ }^{223}$ Thus, one might wonder if such provisions would also produce implications for procedural rights. For the sake of clarification, the EU ETS Directive does not include any special rules regarding access to environmental information and public participation for the aviation sector. Therefore, the analysis in this chapter also applies to the aviation sector.
}

${ }^{224}$ Article 12(2a), Directive 2003/87/EC, consolidated version.

${ }^{225}$ Article 12(3), Directive 2003/87/EC, consolidated version. This is because the aviation sector is not covered by the Kyoto Protocol and, therefore, its emissions were not calculated within the targets of the Protocol. A. Anger and J. Köhler, 'Including aviation emissions in the EU ETS: Much ado about nothing? A review' 17(1) Transport Policy, (2010), pp. 38-46, p. 39.

226 The original idea was to apply the EU ETS to emissions from flights from, to and within the European Economic Area, see Directive 2008/101/EC. However, the EU limited the scope of the EU ETS to flights within the European Economic Area until 2016 while waiting for the development of a global measure by the International Civil Aviation Organization (Article 1 (1), Regulation (EU) No 421/2014.) Due to the adoption of a resolution by the 2016 International Civil Aviation Organization Assembly on the global measure, the EU decided to maintain the application of the EU ETS limited to flights within the European Economic Area from 2017 to 2023 (see Article 1(6)(b)(i), Regulation (EU) 
Hence, under the third phase of the EU ETS, operators either receive allowances for free or buy them. These allowances can then be traded as needed. The rules for the allocation of allowances (stationary and aviation) are determined in the EU ETS Directive and further developed through the adoption of acts by the Commission. The next sections explain the rules for the allocation of allowances highlighting whether these decisions were taken allowing for public participation or not.

\section{i. Auctioning}

In the third phase of the EU ETS, all the allowances which are not allocated for free shall be auctioned. ${ }^{227}$ According to Article 10(4) of the EU ETS Directive, the Commission adopted a regulation on the timing, administration and other aspects of the auctioning of greenhouse gas emission allowances through comitology, which does not foresee any public participation. ${ }^{228}$ This regulation has been amended several times but none of these amendments introduced public participation requirements. ${ }^{229}$

\section{ii. Free allocation}

The free allocation of allowances is based on ex-ante benchmarks, which have to be determined based on "the average performance of the $10 \%$ of installations in a sector or subsector in the Community [now the EU] that are most efficient in the years 2007-2008".230 This means that installations with low-carbon emissions are favoured. ${ }^{231}$ The total amount of free allowances received by each installation is determined based on such emission benchmarks. The Commission adopted a decision establishing the benchmark criteria. ${ }^{232}$ Article 10a(1) EU ETS on which this decision was based does not prescribe the Commission to carry out a public participation procedure but only requires the Commission to consult the relevant stakeholders. However, the provision does not offer a further explanation of how

2017/2392 of the European Parliament and of the Council of 13 December 2017 amending Directive 2003/87/EC to continue current limitations of scope for aviation activities and to prepare to implement a global market-based measure from 2021, OJ L 350/7). See E. Woerdman, op. cit. (2015), pp. 54-55.

${ }^{227}$ Article 10(1), Directive 2003/87/EC, consolidated version.

${ }^{228}$ Commission Regulation (EU) No 1031/2010.

229 Comission Regulation (EU) No 1210/2011. Commission Regulation (EU) No 784/2012.; Commission Regulation No 1042/2012. Commission Regulation No 1143/2013. Commission Regulation No 176/2014. Commission Regulation (EU) 2017/1902 of 18 October 2017 amending Commission Regulation (EU) No 1031/2010 to align the auctioning of allowances with Decision (EU) 2015/1814 of the European Parliament and of the Council and to list an auction platform to be appointed by the United Kingdom, OJ L 269/13.

${ }^{230}$ Article 10a (2), Directive 2003/87/EC, consolidated version.

${ }^{231}$ E. Woerdman, op. cit. (2015), p. 57.

${ }^{232}$ Commission Decision 2011/278/EU. 
these relevant stakeholders are to be selected. The Commission carried out five stakeholders meetings, but it was not clear which stakeholders participated. ${ }^{233}$

To ensure the annual free allocation remains within the overall EU ETS cap, a uniform crosssectoral correction factor (CSCF) is applied. ${ }^{234}$ Article 10a(5) of the EU ETS Directive, which prescribes the application of a CSCF, does not require any public participation. As discussed in relation to the EU-wide cap (Article 9(a) EU ETS Directive), it could be argued that the legislator felt that no public scrutiny would be necessary, since no discretion is given to the Commission on the calculation of the maximum annual amount of allowances, and the CSFC is just a factor to ensure that the total is within this limit. In this vein, the instruction on the calculation provided in the EU ETS Directive would not require any exercise of discretion.

iii. Carbon Leakage

The term carbon leakage refers to the risk that emission-intensive production will move to a jurisdiction that does not regulate carbon emissions. ${ }^{235}$ To avoid this potential problem, sectors and subsectors deemed to be at a significant risk of carbon leakage will continue, until 2020 , to receive $100 \%$ free allocation of allowances, up to the sector's benchmark. ${ }^{236}$

\footnotetext{
${ }^{233}$ European Commission, Impact Assessment of the Commission Decision on determining transitional Union-wide rules for harmonised free allocation pursuant to Article 10a of Directive 2003/87/EC, C(2011) 2772 final (2011b), p. 7.

${ }^{234}$ For an explanation on the CSCF see section 3.4.1.i.

235 "This [carbon leakage] might happen if in a specific country or regional organization the government wants to introduce carbon policies, while other important countries in the rest of the world hesitate to do so.” M. Peeters, op. cit. (2008), p. 27. In order to support her argument, Peeters refers to E. Woerdman, S. Clò and A. Arcuri, 'European emissions trading and the polluter-pays principle: assessing grandfathering and over-allocation', in M. Faure and M. Peeters (eds.), Climate Change and European Emission Trading, (Cheltenham: Edward Elgar, 2008), pp. 128-150.

"Abatement activities of the industrialized countries might result in a movement of the GHG emissions into the regions with no restrictions. This effect has been called leakage."

S. V. Paltsev, 'The Kyoto Protocol: Regional and Sectoral Contributions to the Carbon Leakage' 22(4) The Energy Journal, (2001), pp. 53-79, p. 54.

"Carbon leakage can be defined as the ratio of emissions increase from a specific sector outside the country (as a result of a policy affecting that sector in the country) over the emission reductions in the sector (again, as a result of the environmental policy).” J. Reinaud, Issues behind CompetItIveness and Carbon Leakage: Focus on Heavy Industry (2008), 3.

"In the EU-ETS context, carbon leakage is defined as an increase in emissions outside the region as the result of the policy to cap emission in the EU. It is measured by the ratio of emissions increase outside the EU (as a result of the EU-ETS) over the emissions reductions in the EU (again, as a result of the EU-ETS)." J. Reinaud, Issues behind CompetItIveness and Carbon Leakage: Focus on Heavy Industry (2008), 56.

${ }^{236}$ Article 10(a)(12), Directive 2003/87/EC, consolidated version.
} 
Article 10a(13) of the EU ETS Directive prescribes that the Commission shall consult with Member States, the sectors or subsectors concerned and other relevant stakeholders to determine the list of sectors and subsectors which are exposed to a significant risk of carbon leakage. ${ }^{237}$ However, concerning the free allocation of allowances, the provision does not offer a further explanation on how the relevant stakeholders are to be selected. The Commission adopted the carbon leakage list in 2009 (for the 2010-2014 period), ${ }^{238}$ which was amended in 2011, $2392012^{240}$ and 2013. ${ }^{241}$ A second list was adopted in 2014 (for the 2015-2020 period). ${ }^{242}$ Both lists were subject to open public consultations, which are open to the general public and are online-based, ${ }^{243}$ and the Commission received input from companies, NGOs, individuals, and researchers. ${ }^{244}$

${ }^{237}$ Article 10a(13) reads: "By 31 December 2009 and every five years thereafter, after discussion in the European Council, the Commission shall determine a list of the sectors or subsectors referred to in paragraph 12 on the basis of the criteria referred to in paragraphs 14 to 17.

Every year the Commission may, at its own initiative or at the request of a Member State, add a sector or subsector to the list referred to in the first subparagraph if it can be demonstrated, in an analytical report, that this sector or subsector satisfies the criteria in paragraphs 14 to 17 , following a change that has a substantial impact on the sector's or subsector's activities.

For the purpose of implementing this Article, the Commission shall consult the Member States, the sectors or subsectors concerned and other relevant stakeholders.

Those measures, designed to amend non-essential elements of this Directive by supplementing it, shall be adopted in accordance with the regulatory procedure with scrutiny referred to in Article 23(3)." (Emphasis added), Article 10a(13), Directive 2003/87, consolidated version.

${ }^{238}$ Commission Decision 2010/02/EU.

${ }^{239}$ Commission Decision 2011/745/EU amending Decisions 2010/2/EU and 2011/278/EU as regards the sectors and subsectors which are deemed to be exposed to a significant risk of carbon leakage C(2011) 8017, OJ L 299/9.

${ }^{240}$ Commission Decision 2012/498/EU amending Decisions 2010/2/EU and 2011/278/EU as regards the sectors and subsectors which are deemed to be exposed to a significant risk of carbon leakage C(2012) 5715, OJ L 241/52.

${ }^{241}$ Commission Decision 2014/9 amending Decisions 2010/2/EU and 2011/278/EU as regards the sectors and subsectors which are deemed to be exposed to a significant risk of carbon leakage $\mathrm{C}(2013)$ 9186, OJ L 9/9.

${ }^{242}$ Commission Decision 2014/746/EU of 27 October 2014 determining, pursuant to Directive 2003/87/EC of the European Parliament and of the Council, a list of sectors and subsectors which are deemed to be exposed to a significant risk of carbon leakage, for the period 2015 to $2019 \mathrm{C}(2014) 7809$, OJ L 308/114.

${ }^{243}$ A. Bunea, 'Designing stakeholder consultations: Reinforcing or alleviating bias in the European Union system of governance?' 56(1) European Journal of Political Research, (2017), pp. 46-69, p. 52. Public consultation at the EU level is discussed further in section 4.5.2.

${ }^{244}$ Four stakeholder meetings on the subject of carbon leakage were held in 2008 and 2009. https://ec.europa.eu/clima/sites/clima/files/ets/allowances/leakage/docs/sec_2009_1710_en.pdf. 
iv. Option for transitional free allocation

Eight Member States - Bulgaria ${ }^{245}$ Cyprus,${ }^{246}$ the Czech Republic, ${ }^{247}$ Estonia, ${ }^{248}$ Hungary, ${ }^{249}$ Lithuania, ${ }^{250}$ Poland, ${ }^{251}$ and Romania ${ }^{252}$ - have applied for a derogation of the obligation to auction all allowances for the energy sector. ${ }^{253}$ All applications were approved by the Commission and, as a result, these Member States are allowed to give a "decreasing number of free allowances to existing power plants for a transitional period until 2019". 254 Two other Member States, Latvia and Malta, could also have applied for this derogation, but they did

Consultation on methodology for Commission Decision determining the list of sectors and subsectors deemed to be exposed to a significant risk of carbon leakage, for the period 2015-2019 from 06 June 2013 to 30 August 2013.

http://ec.europa.eu/clima/consultations/articles/0021_en.

${ }^{245}$ Commission Decision of 6.7.2012 concerning the application pursuant to Article 10c (5) of Directive 2003/87/EC of the European Parliament and of the Council to give transitional free allocation for the modernisation of electricity generation notified by Bulgaria (C(2012) 4560 final).

${ }^{246}$ Commission Decision of 23.5.2012 concerning the application pursuant to Article 10c (5) of Directive 2003/87/EC of the European Parliament and of the Council to give transitional free allocation for the modernisation of electricity generation notified by Cyprus (C(2012) 3260 final).

${ }^{247}$ Commission Decision of 6.7.2012 concerning the application pursuant to Article 10c (5) of Directive 2003/87/EC of the European Parliament and of the Council to give transitional free allocation for the modernisation of electricity generation notified by the Czech Republic (C(2012) 4576 final).

${ }^{248}$ Commission Decision of 23.5.2012 concerning the application pursuant to Article 10c (5) of Directive 2003/87/EC of the European Parliament and of the Council to give transitional free allocation for the modernisation of electricity generation notified by Estonia (C(2012) 3271 final).

${ }^{249}$ Commission Decision of 30.11.2012 concerning the application pursuant to Article 10c (5) of Directive 2003/87/EC of the European Parliament and of the Council to give transitional free allocation for the modernisation of electricity generation notified by Hungary (C(2012) 8675 final).

${ }^{250}$ Commission Decision of 23.5.2012 concerning the application pursuant to Article 10c (5) of Directive 2003/87/EC of the European Parliament and of the Council to give transitional free allocation for the modernisation of electricity generation notified by Lithuania (C(2012) 3237 final).

${ }^{251}$ Commission Decision of 13.7.2012 concerning the application pursuant to Article 10c (5) of Directive 2003/87/EC of the European Parliament and of the Council to give transitional free allocation for the modernisation of electricity generation notified by Poland (C(2012) 4609 final).

${ }^{252}$ Commission Decision of 6.7.2012 concerning the application pursuant to Article 10c (5) of Directive 2003/87/EC of the European Parliament and of the Council to give transitional free allocation for the modernisation of electricity generation notified by Romania (C(2012) 4564 final).

${ }^{253}$ Article 10c, Directive 2003/87/EC, consolidated version.

254 European Commission. Transitional free allocation to electricity generators, 19 June 2020, https://ec.europa.eu/clima/policies/ets/allowances/electricity_en. European Commission. Transitional free allocation to electricity generators, 19 June 2020, https://ec.europa.eu/clima/policies/ets/allowances/electricity_en. 
not do so. ${ }^{255}$ These decisions, like those regarding the cap, are taken solely by the Commission, and Article 10c(6) EU ETS Directive does not foresee any public participation.

\subsubsection{Monitoring and verification}

While monitoring and verification are tasks to be carried out at the Member State level, the EU ETS Directive has empowered the Commission ${ }^{256}$ to adopt regulations harmonising the monitoring and reporting of emissions, ${ }^{257}$ and standards for verification and accreditation. ${ }^{258}$ These legal bases for the adoption of these regulations do not prescribe public participation requirements, ${ }^{259}$ and these two regulations were adopted via comitology, which, as already explained, does not foresee public participation.

\subsection{The Aarhus Regulation and the EU ETS Directive}

Even though the EU ETS Directive does not refer to the Aarhus Regulation, which provides for the application of the Aarhus Convention to European institutions and bodies, European institutions and bodies still have to comply with the Regulation. ${ }^{260}$

The Aarhus Convention has been partially implemented at the EU level via the Aarhus Regulation, with public participation requirements only applicable in relation to plans and programmes. ${ }^{261}$ Therefore, the acts adopted by the Commission under the EU ETS Directive would only be subject to public participation requirements, as prescribed by the Aarhus

255 European Commission. Transitional free allocation to electricity generators, 19 June 2020, https://ec.europa.eu/clima/policies/ets/allowances/electricity_en.

${ }^{256}$ Articles 14(1) and 15, Directive 2003/87/EC, consolidated version.

${ }^{257}$ Article 14(1), Directive 2003/87/EC, consolidated version. Commission Regulation 601/2012 on the monitoring and reporting of greenhouse gas emissions pursuant to Directive 2003/87/EC of the European Parliament and of the Council, OJ L 181/30. Commission Regulation 601/2012 repealed Commission Decision 2007/589/EC of 18 July 2007 establishing guidelines for the monitoring and reporting of greenhouse gas emissions pursuant to Directive 2003/87/EC of the European Parliament and of the Council (notified under document number C(2007) 3416), OJ L 229/1. However, its effects were maintained for the first two trading periods. Article 76(2), Commission Regulation 601/2012.

${ }^{258}$ Article 15, Directive 2003/87/EC, consolidated version. Commission Regulation 600/2012 on the verification of greenhouse gas emission reports and tonne-kilometre reports and the accreditation of verifiers pursuant to Directive 2003/87/EC of the European Parliament and of the Council, OJ L 181/1. ${ }^{259}$ The three decisions establishing the guidelines for monitoring and reporting for the first two trading periods were decisions taken by the commission without the control of the Member States. These guidelines were adopted in the form of a Commission Decision (these decisions contained the guidelines), and since decisions are binding in their entirety according to Article 288, these guidelines are, therefore, binding.

${ }^{260}$ Article 288, TFEU.

${ }^{261}$ Article 9, Aarhus Regulation. 
Regulation, if the act would fall under the definition of plans and programmes. ${ }^{262}$ As explained in Chapter III, plans and programmes under the Aarhus Regulation encompass 'measures that, although not officially called 'plans' or 'programmes', in substance constitute an "organised and co-ordinated system in order to reach certain objectives"". ${ }^{263}$ The acts adopted by the Commission in the EU ETS context and described above do not seem to constitute plans and programmes, since they are clearly binding provisions setting rules, for instance, for auctioning and benchmarking, and are hence, in this respect, to be distinguished from plans and programmes. Therefore, the Aarhus Regulation does not impose any obligation regarding public participation for the acts described in the previous section.

Of course, the lack of proper implementation does not limit the legal effects of the Convention, which has been ratified by the European Union, since the obligation remains under international public law in accordance with Article 216(2) TFEU. In this vein, the Court of Justice has ranked the Aarhus Convention as higher than other secondary EU legislation, such as the Aarhus Regulation. ${ }^{264}$ In view of this obligation, the acts adopted under the EU ETS Directive must be examined in light of the provisions for public participation in the Aarhus Convention. The question that follows is whether, even in the absence of provisions under the Aarhus Regulation, there is still an obligation under the Aarhus Convention for the Commission to provide for public participation in the decision making process under the EU ETS. This question is extremely relevant for two reasons: (i) if the answer is yes, it means that the Aarhus Convention has been implemented incorrectly; (ii) if the answer is no, it means that the Aarhus Convention does not cover all environmental issues, especially market-based instruments. The next section will delve into these questions.

4.4. Public participation under the EU ETS: an analysis of the compatibility with the Aarhus Convention

The participatory rights of the Aarhus Convention are laid down in Articles 6 (specific activities), 7 (plans, programmes and policies) and 8 (executive regulations and/or generally applicable binding normative instruments). ${ }^{265} \mathrm{EU}$ acts, despite their official title - for instance decision and regulation - may be considered measures which fall under Articles 6,

\footnotetext{
${ }^{262}$ For further explanation on the Aarhus Regulation see Chapter III.

${ }^{263}$ Case C-387/97, Commission v. Greece. For a discussion on the scope of the definition of plans and programmes, see Chapter III, section 5.2.2.

${ }^{264}$ Joined Cases C-401/12 P to 403/12 P, Council of the European Union, European Parliament and European Commission v. Vereniging Milieudefensie and Stichting Stop Luchtverontreiniging Utrecht 13 January 2015, ECLI:EU:C:2015:4, para 52. See also L. Krämer, 'Procedural Environmental Rights: Principle X in Theory and Practice', in J. Jendroska and M. Bar (eds.), The Aarhus Convention at Ten. Interactions and Tensions between Conventional International Law and EU Environmental Law, (Cambridge, Antwerp, Portland: Intersentia, 2017), p. 124.

${ }^{265}$ For an analysis of these provisions, see Chapter III of this thesis.
} 
7 or 8 of the Aarhus Convention. ${ }^{266}$ In order to identify the correct legal basis for public participation under the Aarhus Convention, it is important to define the nature of the decisions of the acts adopted by the Commission under the auspices of the EU ETS Directive. ${ }^{267}$ The following sections will analyse if the acts mentioned in section 4.2 and taken by the Commission under the EU ETS Directive fall under one of the aforementioned articles of the Aarhus Convention.

4.4.1. Public Participation in Decisions on Specific Activities (Article 6 of the Aarhus Convention)

Article 6 of the Aarhus Convention prescribes public participation in specific activities. ${ }^{268}$ Regarding the applicability of Article 6 of the Aarhus Convention, the Compliance Committee to the Aarhus Convention decided that: "The extent to which the provisions of article 6 apply [..] depends inter alia on the extent to which the [decisions] can be considered 'decisions on specific activities', that is, decisions that effectively pave the way for specific activities to take place." 269 (Emphasis added) Moreover, the Implementation Guide states that the decision making under Article 6 results in directions only to those involved in the particular matter before the authority (such as permit, authorisation or any other required administrative procedure). ${ }^{270}$

To test whether the decisions adopted by the Commission under the EU ETS Directive fall under Article 6 of the Aarhus Convention, three steps are needed. First, it is necessary to

\footnotetext{
${ }^{266}$ The ACCC "does not rule out that some decisions, acts and omissions by the EU institutions - even if labelled 'regulation' - may amount to some form of decision-making under articles 6-8 of the Convention." ClientEarth concerning compliance by the European Union (Part I) UN ECE/MP.PP/C.1/2011/4/Add.1, para 72.

${ }^{267}$ J. Jendrośka, op. cit. (2009), p. 504.

${ }^{268}$ The title of Article 6 refers to decisions on specific activities, while alineas $a$ and $b$ refer to decisions on proposed activities. Despite the difference in terminology, it seems that the terms specific activities and proposed activities have the same function: to define which kind of activities the article is referring to. However, neither proposed activities nor specific activities are terms defined in the Aarhus Convention. The Implementation Guide to the Aarhus Convention suggests as a source of inspiration the definition for the term proposed activity contained in the Espoo Convention: "any activity or any major change to an activity subject to a decision of a competent authority in accordance with an applicable national procedure". Article 1(v), Convention on Environmental Impact Assessment in a Transboundary Context, Espoo, Finland, 25 February 1991, United Nations Treaty Series, vol. 1989, p. 309, entrered into force on 10 September 1997. J. Ebbesson, H. Gaugitsch, J. Jendrośka, F. Marshall and S. Stec, op. cit. (2014), p. 131.

${ }^{269}$ Communication by the Center for Regional Development/Transparency International Armenia, the Sakharov Armenian Human Rights Protection Center and the Armenian Botanical Society (Armenia) with regard to compliance by Armenia UN Doc. ECE/MP.PP/C.1/2006/2/Add.1 para 28.

${ }^{270}$ J. Ebbesson, H. Gaugitsch, J. Jendrośka, F. Marshall and S. Stec, op. cit. (2014), p. 182.
} 
examine whether the acts are proposed activities. Following the definition of the Espoo Convention, the purpose of the acts adopted by the Commission under the EU ETS Directive is not allowing an activity, which is subject to a specific procedure, to start functioning but rather to maintain the activities in an already established system, the EU ETS. Second, these acts do not pave the way for the participants of the EU ETS to exercise their activities. In fact, the process of allowing an activity, which is subject to a specific procedure, happens at the Member State level through the permit procedure. Third, the result of the decision making of the Commission is equally applicable to all EU ETS participants under similar conditions. Therefore, the acts adopted under the EU ETS Directive and mapped out in section 4.2 do not fall under Article 6 of the Aarhus Convention and, as a result, there is no obligation to ensure public participation for the adoption these acts, which can be derived from Article 6 of the Aarhus Convention.

4.4.2. Public Participation concerning plans, programmes and policies relating to the environment (Article 7 of the Aarhus Convention)

Regarding the application of Article 7 of the Aarhus Convention, it has already been established that the acts adopted by the Commission under the EU ETS Directive do not constitute a plan or programme according to the Aarhus Regulation (see section 4.3). However, it still remains to be seen if they could be considered plans and programmes in accordance with the Aarhus Convention.

The Aarhus Convention does not specifically define plans and programmes. The Implementation Guide, however, uses as an example the definition contained in the Kiev Strategic Environmental Assessment Protocol. ${ }^{271}$ According to the protocol, plans and programmes mean acts that are "required by legislative, regulatory or administrative provisions" and which are prepared and/or adopted "by an authority for adoption, through a formal procedure, by a parliament or a government". ${ }^{272}$ This definition explains some requirements for being covered by the definition, i.e. who should produce ${ }^{273}$ and via which procedure, but it does not exactly define what plans and programmes are.

${ }^{271}$ Protocol on Pollutant Release and Transfer Registers to the Convention on Access to Information, Public Participation in Decision-Making and Access to Justice in Environmental Matters, Kiev, 21 May 2003, United Nations, Treaty Series, vol. 2626, p. 119. Doc. MP.PP/2003/12 (entered into force on 8 October 2009), (hereinafter Kiev Protocol),

272 Article 2(5), Kiev SEA Protocol.

${ }^{273}$ In some cases, the decision making is carried out in a multi-level government structure, such as the application for the transitional free allocation for the modernisation of electricity generation, which requires the elaboration by a Member State, while the application needs approval by the Commission (Article 10c(6) EU ETS Directive). The Czech NGO Environmental Law Service challenged the national plan of the Czech Republic before the ACCC on the grounds of a breach of the public participation requirements by the Czech goverment and the Commission, because both were considered 
The Implementation Guide to the Aarhus Convention acknowledges that plans and programmes "have common-sense and sometimes legal meanings throughout the ECE region". ${ }^{274}$ Taking the definition at the EU level, mentioned in section 4.3, it can be concluded that the Aarhus Convention does not provide a broader definition of plans and programmes than the Aarhus Regulation. In this vein, the Commission measures taken under the EU ETS also cannot be considered a plan or programme under the Aarhus Convention. ${ }^{275}$

Even after determining that the Commission measures taken under the EU ETS cannot be considered as plans and programmes, also under the Aarhus Convention, it is still necessary to investigate whether these acts could be considered policies. Article 7 of the Aarhus Convention also covers policies, and as with plans and programmes, the Aarhus Convention does not define policies. Policies can be considered as "a course or principle of action adopted or proposed by an organization or individual". ${ }^{276}$ According to the Implementation Guide, policies receive a different treatment than plans and programmes, because they are less concrete and they "require a more thorough and profound understanding of the legalities and political context of a particular place. Policy incorporates history and culture and entire legal frameworks that extend beyond the finite area in which they are developed." ${ }^{277}$ In this vein, the acts adopted by the Commission under the EU ETS Directive do provide for concrete standards. The acts of the Commission have to be taken either without discretion (as with the cap) or set specific binding rules (as with allocation and auctioning of allowances). Consequently, the acts also do not fall under Article 7 of the Aarhus Convention.

4.4.3. Public Participation during the Preparation of Executive Regulations and/or Generally Applicable Legally Binding Normative Instruments (Article 8 of the Aarhus Convention)

Article 8 of the Aarhus Convention is titled "Public participation during the preparation of executive regulations and/or generally applicable legally binding normative instruments", and it states that public participation shall be ensured "during the preparation by public authorities of executive regulations and other generally applicable legally binding rules that may have a significant effect on the environment." (Emphasis added) Thus, to understand if

\footnotetext{
responsible for preparation of plan (Environmental Law Service (Ekologiský právní servis) concerning compliance by the Czech Republic UN Doc. ECE/MP.PP/C.1/2014/9, 20 December 2013, However, the ACCC only dealt with the compliance with the Aarhus Convention by the Czech Republic, thereby excluding the European Union from the scope of its decision, because it considered the Czech Replubic the only Party concerned.

${ }^{274}$ J. Ebbesson, H. Gaugitsch, J. Jendrośka, F. Marshall and S. Stec, op. cit. (2014), p. 173.

${ }^{275}$ Article 7, Aarhus Convention. For further discussion, see section 5.2.2 of Chapter III.

${ }^{276}$ A. Stevenson and M. Waite, Concise Oxford English Dictionary, (Oxford: Oxford University Press, 2011), p. 1110.

277 J. Ebbesson, H. Gaugitsch, J. Jendrośka, F. Marshall and S. Stec, op. cit. (2014), p. 176.
} 
the acts adopted under the EU ETS Directive are covered by Article 8 of the Aarhus Convention, it is necessary to understand what are executive regulations and generally applicable legally binding rules that may have a significant effect on the environment.

With regard to executive regulations, this term could be understood, in some legal systems, as "only immediately executable rules." 278 Article 8 of the Aarhus Convention also prescribes participation in the decision making of generally applicable legally binding rules that is used interchangeably with generally applicable legally binding normative instruments (in the title), which does not bring much clarity on the exact meaning of these terms. The Implementation Guide explains that "such generally applicable legally binding rules include decrees, regulations, ordinances, instructions, normative orders, norms and rules." 279 The scope seems very broad and has the potential to cover all the regulatory activities of public authorities, ${ }^{280}$ which are not acting in a legislative or judiciary capacity. ${ }^{281}$ Although the public authorities acting in a legislative capacity are exempted from the obligation to provide public participation, the obligation remains regarding the preparatory acts until the time the act is handed over to the legislative body. ${ }^{282}$

Another condition for the applicability of Article 8 of the Aarhus Convention is that the executive regulation and the legally binding rules may have a significant effect on the environment. The conditional may means that the possibility of a significant effect triggers the obligation under Article 8 of the Aarhus Convention. ${ }^{283}$ The term significant effect is not defined by the convention and Parties have to decide its precise meaning, taking the objectives of the Convention into account. While testing the significance of an effect on the environment, the Parties should do so objectively and in a way that does not avoid public participation. ${ }^{284}$ Having established the scope of Article 8 of the Aarhus Convention, the remainder of this section will test whether the Commission acts adopted under the EU ETS Directive may be encompassed by this provision.

\footnotetext{
278 J. Ebbesson, H. Gaugitsch, J. Jendrośka, F. Marshall and S. Stec, op. cit. (2014), p. 182.

${ }^{279}$ J. Ebbesson, H. Gaugitsch, J. Jendrośka, F. Marshall and S. Stec, op. cit. (2014), p. 182.

${ }^{280}$ A. Berthier and L. Krämer, 'The Aahrus Convention: Implementation and Compliance in EU Law': ClientEarth, 2014), p. 48.

${ }^{281}$ Article 2(2), Aarhus Convention.

${ }^{282}$ L. Lavrysen, 'An introduction to the Aarhus Convention', 2009, pp. 4-5.

283 J. Ebbesson, H. Gaugitsch, J. Jendrośka, F. Marshall and S. Stec, op. cit. (2014), p. 132. Please note that the Implementation Guide, while discussing the term significant effect on the environment under Article $8 \mathrm{AC}$, refers to the commentaries to this term regarding Article 6(1) AC. This is the reason why the references regarding this term cite the pages of the Implementation Guide discussing significant effect on the environment under Article 6(1) AC.

${ }^{284}$ J. Ebbesson, H. Gaugitsch, J. Jendrośka, F. Marshall and S. Stec, op. cit. (2014), p. 132.
} 
i. Executive regulations and other generally applicable legally binding normative instruments

It seems that the aim of Article 8 of the Aarhus Convention is to cover all the legally binding acts of a general scope of the executive branch that are not legislative acts. Therefore, in order to test whether the Commission acts adopted under the EU ETS Directive may be encompassed by Article 8 of the Aarhus Convention, it is necessary to verify whether the acts adopted emanate from the executive branch and whether they are generally applicable legally binding instruments.

As highlighted by Barnard and Peers (2014), the executive task of the Commission to adopt delegated acts or implementing measures "can be compared to the powers that are delegated to the executive and to civil servants in the Member States by acts of parliament in order to implement legislation (often known as 'delegated legislation', although that term is not used as regards the EU measures)." 285 According to the TFEU, legislative acts are legal acts adopted by legislative procedures prescribed in the EU treaties (Article 289 TFEU). Regarding, non-legislative acts (acts that do not follow these legislative procedures), the TFEU provides for two categories: delegated (Article 290 TFEU) and implementing acts (Article 291 TFEU), although the clear distinction between these categories remains to be determined. ${ }^{286}$ The new delegated acts are in fact the old comitology regulatory procedure with scrutiny, ${ }^{287}$ and therefore some provisions of the EU ETS Directive which currently foresee the use of the regulatory procedure with scrutiny will have to be aligned with the new system contained in Article 290 TFEU. ${ }^{288}$ This does not change the current analysis, since these future acts would still be a "non-legislative act of general application" (Article 290 TFEU), and the Commission will, therefore, not be acting in a legislative capacity. ${ }^{289}$ Some

${ }^{285}$ C. Barnard and S. Peers, European union law, (Oxford: Oxford University Press, 2014), p. 46.

${ }^{286}$ D. Chalmers, G. Davies and G. Monti, 'European Union law: cases and materials', 2010, Cambridge Books Online http://dx.doi.org/10.1017/CBO9780511841408, pp. 100-101. Kieran Bradley, 'Rulemaking by the European Commission: The New System for Delegation of Powers', in C. F. Bergström and D. Ritleng (eds.), Rulemaking by the European Commission: The New System for Delegation of Powers: Oxford University Press, 2016), p. 78.

${ }^{287}$ Legal Service of the Council of the European Union, Application of Articles 290 (delegated acts) and 291 (implementing acts) TFEU (2011), 4.

${ }^{288}$ Some examples of acts adopted by the Commission under the EU ETS via the regulatory procedure with scrutiny: regulation on international credit entitlement, decision on the benchmark criteria for the free allocation of allowances, decisions on the lists list of sectors and subsectors deemed to be at a significant risk of carbon leakage. The 2018 amendment to the EU ETS Directive already replaced Article 23 and the amended version provides for the adoption of delegated acts. Article 1, Directive (EU) 2018/410.

${ }^{289}$ M. Pallemaerts, 'Access to Environmental Justice at EU Level : has the "Aarhus Regulation" improved the Situation?', in M. Pallemaerts (ed.), The Aarhus Convention at ten: interactions and 
authors consider that the delegated acts are a transfer or extension of legislative power and therefore quasi-legislative, rather than mere implementing acts. ${ }^{290}$ Regardless of the discussion on the nature of delegated and implementing acts, these acts are an emanation of the executive power with general application and should be considered as falling under Article 8 of the Aarhus Convention.

There is still a category of non-legislative acts that are not categorised by the TFEU. ${ }^{291}$ Among those are the acts adopted by the Commission that are of an executive nature, but they do not intend to establish uniform conditions for implementation, as prescribed in Article 291 TFEU. For instance, the decisions adopted by the Commission on the cap are taken by the Commission without the assistance of a Committee (no comitology procedure) and have general application.

All the acts adopted by the Commission discussed in this chapter are acts of general application, because their addressees are not determined or determinable. ${ }^{292}$ Now that it has been established that the acts of the Commission adopted under the EU ETS Directive fall under the scope of executive regulations and/or generally applicable binding rules, the next step is to identify whether these acts may have a significant effect on the environment, and thus to determine whether the requirements of Article 8 of the Aarhus Convention are applicable.

ii. Significant effect on the environment

a) The criteria for determining significant effect on the environment

The Convention does not define what significant effect on the environment means and does not clarify whether significant effects comprise positive and negative effects. The Implementation Guide also does not define significant effect on the environment and suggests that some guidance on how to interpret the term in other contexts can be found in the Espoo

tensions between conventional international law and EU environmental law, (Groningen/Amsterdam: Europa Law Publishing, 2011), p. 279.

${ }^{290}$ See: P. P. Craig, 'Delegated acts, implementing acts and the new Comitology Regulation' 36(5) European Law Review, (2011), pp. 671-687, p. 672; H. Hofmann and A. Türk, Legal challenges in EU administrative law: towards an integrated administration, (Cheltenham: Edward Elgar Publishing, 2009), p. 108.

${ }^{291}$ P. Craig and G. De Búrca, EU law: text, cases, and materials, Fifth Edition (Oxford: Oxford University Press, 2011), p. 118.

${ }^{292}$ These non-legislative acts took the form of a regulation or decision. Regulations and decisions are among the legal instruments available to the European institutions to exercise the Union's competences, according to Article 288 TFEU. How they are adopted defines whether they are a legislative act or not. 
Convention. ${ }^{293}$ Paragraph 1 of Appendix III of the Espoo Convention guides the Parties to identify criteria to determine significant adverse impact, as follows:

"In considering proposed activities to which Article 2, paragraph 5, applies, the concerned Parties may consider whether the activity is likely to have a significant adverse transboundary impact in particular by virtue of one or more of the following criteria:

(a) Size: proposed activities which are large for the type of activity;

(b) Location: proposed activities which are located in or close to an area of special environmental sensitivity or importance (such as wetlands designated under the Ramsar Convention, national parks, nature reserves, sites of special scientific interest, or sites of archaeological, cultural or historical importance); also, proposed activities in locations where the characteristics of proposed development would be likely to have significant effects on the population;

(c) Effects: proposed activities with particularly complex and potentially adverse effects, including those giving rise to serious effects on humans or on valued species or organisms, those which threaten the existing or potential use of an affected area and those causing additional loading which cannot be sustained by the carrying capacity of the environment." ${ }^{294}$ (emphasis added)

From the reading of the provision, three criteria can be identified: size, location and effects. There are two problems with this source of inspiration for the purpose of using them to determine the meaning of significant effect on the environment under Article 8 of the Aarhus Convention: (i) these criteria are used to measure the significance of the effect of projectbased activities, or as called in Article 6 of the Aarhus Convention and the Espoo Convention proposed activities, (ii) the Espoo Convention already determined that these criteria are to identify adverse impact, while Article 8 of the Aarhus Convention does not make a distinction between positive and negative effects. Therefore, for the analysis of Article 8 of the Aarhus Convention, the criteria for measurement (size, location and effects) has to be reinterpreted to considerer whether the Commission's acts adopted under the EU ETS Directive may have a significant effect on the environment.

b) Size and location

\footnotetext{
${ }^{293}$ J. Ebbesson, H. Gaugitsch, J. Jendrośka, F. Marshall and S. Stec, op. cit. (2014), p. 132.

294 Appendix III, Convention on Environmental Impact Assessment in a Transboundary Context, Espoo, Finland, 25 February 1991, United Nations Treaty Series, vol. 1989, p. 309 (entrered into force on 10 September 1997).
} 
Most of the acts adopted by the Commission under the EU ETS cover all installations of the scheme (size) and the territory of, at least, 28 countries (location). Even those that are addressed to a specific Member State, such as the allocation of free allowances for the modernisation of the electricity sector, cover a matter of a considerable size (gases and installations) and location (entire country). Therefore, by considering the geographical area and size of the EU ETS, the acts adopted by the Commission under the EU ETS would fulfil the first two measurement criteria for identifying whether these acts may have a significant effect on the environment.

Regarding the last criterion for determining significant effect on the environment, the effects, it is necessary to evaluate individually whether the acts adopted by the Commission under the EU ETS have an effect on the environment.

c) Effects on the environment

Since Article 8 of the Aarhus Convention does not specify which kind of effects should be considered, it can be argued that both positive and negative effects should be part of the evaluation of whether a measure has effect on the environment. Even measures adopted with the objective of the protection of the environment can also have a negative impact on the environment. For instance, a measure to reduce GHGs emissions, such as wind power, may cause a disturbance to routes of migratory birds or affect the breeding success of certain species. ${ }^{295}$ Therefore, the effects of the acts adopted by the Commission under the EU ETS, either positive or negative, will be analysed as part of the assessment of the effects on the environment.

\section{c.1) Cap}

Looking at the acts adopted by the European Commission under auspices of the EU ETS, those related to the cap concern the determination of the EU-wide cap, opt-in and opt-out and the use of international credits. The cap expresses in the number of emission allowances the overall volume that can be emitted by the sectors and subsectors that are covered by the EU ETS. ${ }^{296}$ This is a crucial element to achieve the objective of reducing GHGs, and ultimately protecting the environment. Mistakes on the calculation of the cap mean that this overall goal is undermined. Hence, the setting of the cap clearly has an effect on the environment.

Regarding the opt-in of activities or gases, it means that more installations and gases will be covered by the scheme. This produces a positive effect on the environment, since more

\footnotetext{
${ }^{295}$ M. W. Tingley, 'Effects of offshore wind farms on birds: Cuisinarts of the sky or just tilting at windmills?', 2003.

${ }^{296}$ European Commission, op. cit. 2016, p. p. 2.
} 
emissions will be controlled and reduced by the scheme. The opt-out of installations are subject to the condition that the excluded installations are subject to equivalent measures as they were part of the EU ETS, and this condition could lead to the interpretation that there would not have been any effect on the environment. However, this depends on the content of the decisions on opt-out, so the decision can clearly have an impact on the environment and public participation could focus on the question on whether the measures are indeed equivalent to the EU ETS.

The use of international credits may interfere with the cap and the credits can be created on the expenses of the environmental protection of the hosting countries. In this vein, the use of these credits has the potential of affecting the functioning of the EU ETS and, consequently, the protection of the environment and, at the same time, the environment of the hosting country.

In sum, decisions on the cap, including opt-in and opt-out, may have a significant effect on the environment.

\section{c.2) Allocation of Allowances}

The Commission's acts concerning the allocation of allowances are related to auctioning, free allocation of allowances, the carbon leakage sector, and the option for transitional free allocation. Regarding the auctioning, the Commission's act is related to the timing and administration of the auctions. At first sight, it could be said that no direct effect on the environment is foreseeable. However, a reliable auctioning system ensures that there is no fraud and that the auctioning of allowances really reflects the number of allowances that should be put on the market in accordance with the established cap. A wrong amount of allowances available for auction would have a negative effect on the environment, since the cap would not be respected.

The benchmark criteria, which is used to allocate allowances for free, can, if it sets a strong benchmark in accordance with the EU ETS Directive, in the mid- to long-term, lead producers to strive to become more efficient and avoid extra production costs. Therefore, it amounts to a positive effect on the environment, since more efficient installations mean fewer emissions.

The Cross-Sectoral Correction Factor (CSCF) guarantees that the number of allowances allocated for free is done in accordance with the limits established in the EU ETS. The CSCF entails a positive effect on the environment, since it guarantees that operators will not receive more free allowances than is prescribed. However, if the CSCF is calculated wrongly, even if the cap remains the same, more allowances will be allocated for free. It may discourage the operators from reducing emissions, since they do not have to buy allowances to compensate for their emissions. It may also slow down the process to move to cleaner 
technologies, since they can still profit without changing their current behaviour. These potential outcomes in case of a wrong calculation of the CSCF are clearly potentially negative effects on the environment.

For the carbon leakage sectors and subsectors, the same reasoning can be applied as for the CSCF. Since allowances will be allocated for free, the same phenomenon of slowing down the transition to cleaner technologies may happen. Therefore, also, in this case, a potentially negative effect on the environment can be foreseen.

Regarding the option for transitional free allocation, although the cap remains the same, and bearing in mind that it is a measure to encourage installations to use cleaner technologies, more allowances allocated for free may discourage the operators to reduce emissions. Similarly, in this case, it can be argued that the acts adopted by the Commission regarding transitional free allocation may have an effect on the environment. Therefore, acts adopted by the Commission to manage the allocation of allowances may have a significant effect on the environment.

\section{c.3) Monitoring, reporting and verification}

Monitoring, reporting and verification (MRV) are essential to ensure compliance and therefore guarantee that the reduction of emissions is being achieved. Therefore, it is the MRV that indicates whether the system is functioning properly. In this vein, a proper MRV is necessary in order not to validate a defective system, which could bring negative effects to the environment. At the same time, a strong MRV ensures that the system is achieving its objectives, which include the reduction of emissions entailing a positive effect on the environment.

In sum, it can be argued that all the aforementioned acts, considering their size, location and potential effects on the environment, have a significant effect on the environment. Therefore, Article 8 of the Aarhus Convention applies to the acts adopted by the Commission under the EU ETS and the final step is to identify whether the Commission has fulfilled its public participation obligation with respect to the measures adopted under the EU ETS Directive.

4.5. The extent to which the European Commission complies with Article 8 of the Aarhus Convention requirements

Having established that the acts adopted by the European Commission under the EU ETS fall under the scope of Article 8 of the Aarhus Convention, it remains to be investigated to what extent the European Commission complies with the requirements stemming from Article 8.

In order to comply with Article 8 of the Aarhus Convention, Parties shall make efforts to promote timely and effective participation. To accomplish this objective, Parties should 
guarantee that a proper timeframe for effective public participation is fixed, that the draft rules are made available to the public, that the public has the opportunity to comment, and that the result is taken into account as far as possible. Therefore, Parties are required to take concrete measures towards the achievement of Article 8 requirements. The assessment of compliance with the provision will be based on the steps taken towards the achievement of these goals and not on specific results. ${ }^{297}$ Here it is also interesting to note that Article 8, in contrast to Article 6 of the Aarhus Convention, does not refer to the public concerned. It rather says that the public should be given participation opportunities. As explained by Kramer and Berthier (2014) "this is due to the fact that executive regulations are of general application and therefore concern everybody." 298 In this vein, the public under Article 8 of the Aarhus Convention can be connected to the definition of the public under Article 2(4) of the Aarhus Convention.

Hence, the next step is to analyse whether, the EU, as a Party to the Aarhus Convention, has strived to promote public participation during the preparation by the Commission of the acts adopted under the EU ETS Directive as identified in section 4.2. In this vein, the next section first examines the legal obligation to provide for public participation contained in the EU ETS Directive. Second, the analysis will move to examine the consultation requirements applicable at the EU level and contained in the 2002 Communication, ${ }^{299}$ which was applicable at the time the acts adopted by the Commission identified in section 4.2 were adopted, and in the Better Regulation Package, ${ }^{300}$ applicable at the time of writing. The rationale for this analysis is grounded in the close connection between the concepts of participation and consultation. In what is known as Arnstein's "ladder", public participation ranges from non-participation to the full engagement of citizens that can even culminate in citizens' control. ${ }^{301}$ The consultation is therefore seen as one step on the overall ladder of

${ }^{297}$ J. Ebbesson, H. Gaugitsch, J. Jendrośka, F. Marshall and S. Stec, op. cit. (2014), p. 181.

298 A. Berthier and L. Krämer, op. cit. (2014), p. 48.

299 European Commission, Communication from the Commission Towards a reinforced culture of consultation and dialogue-General principles and minimum standards for consultation of interested parties by the Commission, $\operatorname{COM}(2002) 704$ final (2002).

300 Communication from the Commission to the European Parliament, the Council, the European Economic and Social Committee and the Committee of the Regions Better regulation for better results - An EU agenda, $\operatorname{COM(2015)~} 215$ final (2014c). This 2015 Communication was accompanied by the Commission Staff Working Document Better Regulation Guidelines (European Commission, Commission Staff Working Document - Better Regulation Guidelines, SWD(2015) 111 final (2015b). which has been updated in 2017 (European Commission, Commission Staff Working Document Better Regulation Guidelines, SWD(2017) 350 (2017c).

${ }^{301}$ S. R. Arnstein, 'A ladder of citizen participation' 35(4) Journal of the American Institute of planners, (1969), pp. 216-224, p. 217. 
public participation, the latter being a much broader concept. ${ }^{302}$ In this vein, consultations do not automatically imply public participation, and a further analysis of the legal framework for consultations at the EU level is needed to identify whether the stakeholders' consultations could fulfil the obligations under Article 8 of the Aarhus Convention. Finally, the section analyses whether the current legal framework can fulfil the obligations contained in Article 8 of the Aarhus Convention.

4.5.1. Legal Framework for public participation for acts adopted under the EU ETS Directive

Neither the EU ETS Directive (see section 4.2) nor the Aarhus Regulation (see section 4.3) requires public participation for all the acts taken by the Commission under the EU ETS Directive. Therefore, the EU ETS Directive does not explicitly implement Article 8 of the Aarhus Convention. Nevertheless, the EU ETS Directive contains provisions to consult stakeholders. This is the case in respect of: (i) the decisions on free allocation of allowances and benchmark pursuant to Article 10a(1) and (2) of the EU ETS Directive which requires consultation with relevant stakeholders, including the sectors and subsectors concerned; and (ii) the definition of the list of the sectors and subsectors deemed to be in risk of carbon leakage according to Article 10a(13) which requires consultation with Member States, the sectors and subsectors and other relevant stakeholders. ${ }^{303}$ In these cases, the Commission was under a legal obligation to conduct a consultation. For all other decisions, there was no obligation for consultation deriving directly from the EU ETS Directive.

The question is whether the obligation to consult stakeholders contained in Articles 10a(1) and (13) could amount to public participation as prescribed by Article 8 of the Aarhus Convention . To what extent these provisions can amount to public participation as prescribed by the Aarhus Convention will be the subject matter of the following analysis.

\subsubsection{Consultation at the EU level}

At the EU level, the European Commission can conduct consultations which are mandatory according to secondary legislation or the Commission may act suo motu. Such consultation may be closed or open. ${ }^{304}$ In the first type, the Commission approaches the specific

\footnotetext{
302 'Inviting citizens' opinions, like informing them, can be a legitimate step toward their full participation. But if consulting them is not combined with other modes of participation, this rung of the ladder is still a sham since it offers no assurance that citizen concerns and ideas will be taken into account.” S. R. Arnstein, op. cit. (1969), p. 219.

${ }^{303}$ However, some provisions refer to different terminology, for instance: Article 10b requires consultation with all relevant social partners, Article 16 consultation with the authorities, and Article 27 consultation with the operator.

${ }^{304}$ C. Marxsen, 'Open Stakeholder Consultations at the European Level-Voice of the Citizens?' 21(2) European Law Journal, (2015), pp. 257-280, p. 261.
} 
stakeholders that are considered to contribute their opinion or concern on the topic of the decision making. ${ }^{305}$ The open consultations are instead open to the general public and are online-based. ${ }^{306}$ Any citizen, NGO, business association, public authority, or private company may submit its considerations on a proposed subject that is open for consultation online. ${ }^{307}$ The two types of consultation can be (and often are) used together. ${ }^{308}$

Although the EU already conducted consultations in earlier periods, this practice was only formalised with the "White Paper on European Governance", ${ }^{309}$ which was followed by a "Communication from the Commission Towards a reinforced culture of consultation and dialogue - General principles and minimum standards for consultation of interested parties by the Commission" (hereafter the 2002 Communication). ${ }^{310}$ The rules and principles guiding the EU consultations have been "reviewed as part of reforming the EU Better Regulation policy." 311

According to the 2002 Communication, which set out how the Commission should conduct the consultation, the Commission should conduct public consultation "on major policy initiatives", ${ }^{312}$ with the Commission deciding what qualifies as a major policy initiative. This means that in practice the decision whether or not to hold consultation was still with the Commission in the end and, in the absence of an obligation in secondary legislation, was at its discretion. Therefore, the Commission could still decide to conduct consultations even when the general principles and minimum standards of the 2002 Communication do not apply. Despite having discretion on whether to hold a consultation, the Commission could also decide on which type of consultation it would conduct. ${ }^{313}$ Regarding who has access to the consultation process, if a consultation was open, the general public had access to it, but if the consultation is closed only the identified target group could participate. The definition of the target groups was to be made in accordance with the criteria set out in the

\footnotetext{
${ }^{305}$ A. Bunea and R. Thomson, 'Consultations with interest groups and the empowerment of executives: Evidence from the European Union’ 28(4) Governance, (2015), pp. 517-531, p. 520.

${ }^{306}$ A. Bunea, op. cit. (2017), p. 52.

${ }^{307}$ A. Bunea and R. Thomson, op. cit. (2015), p. 520.

${ }^{308}$ A. Bunea and R. Thomson, op. cit. (2015), p. 520.

309 A. Bunea, op. cit. (2017), p. 47. European Commission, European Governance: a White Paper, $\operatorname{COM}(2001) 428$ final (2001a).

${ }^{310}$ European Commission, 2002 Communication (2002).

${ }^{311}$ A. Bunea, op. cit. (2017), p. 47.

312 European Commission, 2002 Communication (2002), p. 15.

313 A. Bunea and R. Thomson, op. cit. (2015), p. 520. European Commission, 2002 Communication (2002), p. 11.
} 
Communication. ${ }^{314}$ However, these criteria, although calling for equitable and adequate coverage of the affected parties, still left much discretion on how to select the target group. ${ }^{315}$

In 2015 the Commission issued the "Better regulation for better results - An EU agenda" Communication, ${ }^{316}$ which builds upon the 2002 Communication and was itself subject to consultation. ${ }^{317}$ This 2015 Communication was accompanied by the Commission Staff Working Document Better Regulation Guidelines, ${ }^{318}$ which was updated in 2017. ${ }^{319}$ Despite the fact that the Commission retains the discretion to decide whether to hold public consultations, the 2015 Communication prescribes that stakeholders should be able to provide feedback on the draft of implementing and delegated acts, which are the categories of the Commission's acts under analysis in this chapter. ${ }^{320}$

\subsubsection{Compliance with Article 8 of the Aarhus Convention}

i. Could a soft law instrument fulfil the obligations under Article 8 of the Aarhus Convention?

Article 8 of the Aarhus Convention requires Parties to strive to promote effective public participation, but it does not make clear how. Since the obligation contained in Article 8 of the Aarhus Convention is an obligation of effort, the determination of compliance is based on the steps taken towards the achievement of these goals. ${ }^{321}$ The EU has no hard law instruments (in the form of secondary legislation) to regulate the public participation for acts adopted by the Commission under the EU ETS Directive. Instead, at the EU level, the matter is regulated through soft law instruments (communication and guidelines). This raises the question of whether the 2002 Communication, the 2015 and 2017 guidelines, and the accompanying toolboxes of the latter two could fulfil the requirements of Article 8 of the Aarhus Convention.

Article 3(1) of the Aarhus Convention requires Parties to have a transparent and consistent framework, but it does not limit the type of instruments to achieve this. In fact, to achieve a transparent and consistent framework, Parties shall take the necessary legislative, regulatory and other measures. What exactly other measures means is not defined by the Convention.

\footnotetext{
${ }^{314}$ European Commission, 2002 Communication (2002), p. 19-20.

315 European Commission, 2002 Communication (2002), p. 19-20.

${ }^{316}$ European Commission, Better regulation for better results - An EU agenda (2014c).

${ }^{317}$ A. Bunea, op. cit. (2017), p. 47 and 52.

318 European Commission, Commission Staff Working Document - Better Regulation Guidelines, SWD(2015) 111 final (2015b).

${ }^{319}$ European Commission, 2017 Staff Working Document (2017c).

${ }^{320}$ European Commission, Better regulation for better results - An EU agenda (2014c), p. 5.

${ }^{321}$ J. Ebbesson, H. Gaugitsch, J. Jendrośka, F. Marshall and S. Stec, op. cit. (2014), p. 181.
} 
The Implementation Guide suggests that "possible 'other measures' might include strategies, codes of conduct and good practice recommendations." 322 In this vein, communications and guidelines can be used to achieve a transparent and consistent framework. Therefore, the fact that the EU has used soft law to establish its public participation requirements at the EU level is in compliance with Article 8 of the Aarhus Convention.

It is also important to note that the Commission has expressed an evolving position regarding the binding nature of the requirements for public participation. In its 2002 Communication, it made it very apparent that there was no intention to establish a legally binding approach. In the words of the Commission:

"[...] The Commission remains convinced that a legally-binding approach to consultation is to be avoided, for two reasons: First, a clear dividing line must be drawn between consultations launched on the Commission's own initiative prior to the adoption of a proposal, and the subsequent formalised and compulsory decision making process according to the Treaties. Second, a situation must be avoided in which a Commission proposal could be challenged in the Court on the grounds of alleged lack of consultation of interested parties. Such an over-legalistic approach would be incompatible with the need for timely delivery of policy, and with the expectations of the citizens that the European Institutions should deliver on substance rather than concentrating on procedures. $" 323$

However, in the 2017 Guidelines, the Commission made a move towards the recognition of the legal implications of the instrument: "Such guidance may contain interpretation of EU law, which, according to the case-law of the Court of Justice of the European Union, may legally bind the Commission." 324 This reflects an understanding, already expressed in academic literature, that "soft law can create legal obligations for the enacting European institution, and the Courts require the institution to comply with such instruments." ${ }^{325}$ If this

\footnotetext{
${ }^{322}$ J. Ebbesson, H. Gaugitsch, J. Jendrośka, F. Marshall and S. Stec, op. cit. (2014), p. 60.

${ }^{323}$ European Commission, 2002 Communication (2002), p. 10.

${ }^{324}$ European Commission, 2017 Staff Working Document (2017c), p. 43.

${ }^{325}$ O. Stefan, 'European Union Soft Law: New Developments Concerning the Divide Between Legally Binding Force and Legal Effects' 75(5) The Modern Law Review, (2012), pp. 879-893, p. 882. Eliantonio and Stefan explain that "the courts have acknowledged binding legal effects to soft law in limited circumstances: where soft law is construed as introducing a new obligation, where a soft law measure states the way in which an EU institution intends to exercise its discretion, or, as far as Member States are concerned, where the soft law measure at stake has been produced in cooperation with the Member States." (M. Eliantonio and O. Stefan, 'Soft Law Before the European Courts: Discovering a 'common pattern'?' 37 Yearbook of European Law, (2018), pp. 457-469, p. 462.). For further discussion on the legal effects of soft law instruments see F. Terpan, 'Soft Law in the European UnionThe Changing Nature of EU Law’ 21(1) European Law Journal, (2015), pp. 68-96,
} 
trend is upheld, soft law clearly contributes to achieving compliance with Article 8 of the Aarhus Convention. The concern is that the Commission can amend soft law unilaterally, but it cannot amend a piece of secondary legislation, such as the EU ETS, which could potentially include public participation requirements.

Having determined that the use of soft law to establish public participation requirements at the EU level, as such, is in compliance with Article 8 of the Aarhus Convention, the question that follows is whether the EU consultation framework could fulfil the public participation requirements of Article 8 of the Aarhus Convention.

ii. 2002 Communication

The 2002 Communication gave discretion to the Commission on whether or not to hold consultations and which type of consultations to conduct. Regarding whether or not to hold consultations, Article 8 of the Aarhus Convention does not foresee such discretion. In order for the Party, in this case, the EU, to comply with Article 8 of the Aarhus Convention, concrete steps towards achieving the requirements need to be taken. In this vein, the lack of certainty (given the Commission's discretion) that these consultations would be carried out can be considered in violation of Article 8 of the Aarhus Convention.

Even considering that the 2002 Communication allowed for a margin of discretion that is not foreseen in Article 8 of the Aarhus Convention, it is still relevant to consider whether a consultation conducted according to the 2002 Communication fulfilled the requirements mandated by Article 8. When the Commission has an obligation under the EU ETS Directive to conduct consultations (and therefore no discretion), such an analysis allows it to be identified whether the consultation requirements comply with Article 8 of the Aarhus Convention or not. According to the 2002 Communication, the consultation should take place early in the decision making process, ${ }^{326}$ clear and comprehensible information should be available, ${ }^{327}$ the consultation should be carried out within a reasonable timeframe, ${ }^{328}$ the results should be published, and there is an obligation to show how the input was taken into consideration. ${ }^{329}$ The open consultations, as described by the communication, could fulfil the minimum standards set by the Aarhus Convention, since the consultation was open to the public, the Commission had the obligation to notify the public of the consultation properly,

See Case T-7/89, Hercules Chemicals v. Commission 17 December 1991, ECLI:EU:T:1991:75, para 53, in which the General Court decided that the Commission had a duty to comply with the rules it imposed on itself in the Twelfth Competition Report. The Court of Justice confirmed this judgment in the appeal, see Case C-51/92, Hercules Chemicals v. Commission, 8 July 1999, ECLI:EU:C:1999:357.

${ }^{326}$ European Commission, 2002 Communication (2002), p. 18.

${ }^{327}$ European Commission, 2002 Communication (2002), p. 19.

${ }^{328}$ European Commission, 2002 Communication (2002), p. 21.

${ }^{329}$ European Commission, 2002 Communication (2002), p. 22. 
while it was still possible to intervene, and there was a timeline and the outcome had been taken into consideration. Therefore, an open consultation that followed the 2002 Communication Guidelines fulfilled the requirements mandated by Article 8 .

In the closed consultations, even if sufficient time was provided, the drafts of the acts were made available, and the feedback was taken into due account, the requirements mandate by Article 8 were not fulfilled since this provision requires the public to be consulted and not only target stakeholders. Article 8, unlike Article 7 of the Aarhus Convention, does not provide for any discretion for the public authorities to identify the members of the public who should participate in the decision making process. ${ }^{330}$ Therefore, the simple fact that the Commission consulted target groups instead of the public amounted to a breach of Article 8 of the Aarhus Convention. In this vein, only open consultations that followed the 2002 Communication Guidelines could fulfil the Article 8 requirements. However, as already mentioned, the mere fact that the Commission had discretion on whether to conduct the consultation (even if in practice it would always consult) was already in itself a breach of Article 8 of the Aarhus Convention.

iii. 2015 and 2017 Better Regulation Guidelines

The Better Regulation Guidelines is the current instrument that details the procedures for consultations at the EU level. The first version of the guidelines is from $2015^{331}$ and the second version is from 2017. ${ }^{332}$ The guidelines are Commission staff working documents that have been accompanied by a toolbox that contains additional guidance to users in the application of Better Regulation Guidelines. Both versions will be examined in order to check whether the changes introduced by the 2017 version of the guidelines indicate a move towards more public participation.

The 2015 guidelines stated that "the opportunity to provide feedback on delegated acts will apply with a limited number of exceptions." ${ }^{333}$ For implementing acts, while the 2002 Communication excluded acts adopted under the comitology procedure, the 2015 Guidelines provided that "the opportunity to provide feedback must be considered for acts adopted under committee control" (emphasis added). ${ }^{334}$ "However, several categories of exemptions apply

\footnotetext{
${ }^{330}$ Article 7 AC reads: "The public which may participate shall be identified by the relevant public authority, taking into account the objectives of this Convention."

${ }^{331}$ European Commission, Commission Staff Working Document - Better Regulation Guidelines, SWD(2015) 111 final (2015b).

332 European Commission, 2017 Staff Working Document (2017c).

333 European Commission, Commission Staff Working Document - Better Regulation Guidelines, SWD(2015) 111 final (2015b), p. 67.

${ }^{334}$ European Commission, Commission Staff Working Document - Better Regulation Guidelines, SWD(2015) 111 final (2015b), p. 67.
} 
and due to the varied nature of implementing acts the final decision should be made on a case-by-case basis." 335 Therefore, it was still left up to the Commission to decide whether the acts adopted by the Commission through the use of the comitology procedure would fall under one of the exceptions and not be subject to public participation. Here it is interesting to note that the term feedback is used in the 2015 Guidelines. However, while referring to the exceptions, the guidelines say that "the Commission will not consult on draft of delegated and implementing acts" and provides a list of exceptions to the four-week public consultation requirement. ${ }^{336}$ Such a statement suggests that the guidelines used the terms feedback and public consultation interchangeably.

As mentioned above, the 2015 Guidelines were updated in 2017. The 2017 text of the accompanying toolbox clarifies that "collecting feedback under the feedback mechanisms differs from collecting in put under consultation", ${ }^{337}$ and add that "the collection of feedback offers an opportunity for stakeholders to express general views on a specific document [...] not based on specific questions or consultation background documents." 338 Furthermore, the four-week feedback on the draft of delegated, implementing acts and regulatory procedure with scrutiny is the default, ${ }^{339}$ and the exceptions for not publishing the drafts should be interpreted restrictively. ${ }^{340}$ Regarding who can participate in this feedback opportunity, the text sometimes refers to stakeholder feedback. The term stakeholder seems to be used in a broad sense. The toolbox accompanying the text of the 2017 Guidelines explains that the aim of the feedback on drafts is to give "the public at large the possibility to react on actual draft act", ${ }^{341}$ and that citizens and stakeholders can provide feedback. ${ }^{342}$ Even when the closed or public stakeholder consultation has taken place, they do not replace the opportunity for feedback. ${ }^{343}$ This shows that, although using sometimes the term stakeholders, the guidelines

\footnotetext{
335 European Commission, Commission Staff Working Document - Better Regulation Guidelines, SWD(2015) 111 final (2015b), p. 67.

${ }^{336}$ European Commission, Better regulation for better results - An EU agenda (2014c), p. 67.

${ }^{337}$ European Commission, Better Regulation "Toolbox" which complements the Better Regulation Guidelines presented in SWD(2017) 350 (2017b), p. 437.

338 European Commission, Better Regulation "Toolbox" which complements the Better Regulation Guidelines presented in SWD(2017) 350 (2017b), p. 437.

339 European Commission, Better Regulation "Toolbox" which complements the Better Regulation Guidelines presented in SWD(2017) 350 (2017b), p. 444.

${ }^{340}$ European Commission, Better Regulation "Toolbox" which complements the Better Regulation Guidelines presented in SWD(2017) 350 (2017b), p. 443-444.

${ }^{341}$ European Commission, Better Regulation "Toolbox" which complements the Better Regulation Guidelines presented in SWD(2017) 350 (2017b), p. 444.

342 European Commission, Better Regulation "Toolbox" which complements the Better Regulation Guidelines presented in SWD(2017) 350 (2017b), p. 437.

${ }^{343}$ European Commission, Better Regulation "Toolbox" which complements the Better Regulation Guidelines presented in SWD(2017) 350 (2017b), p. 444.
} 
aim to reach the public at large. This is a feature in compliance with Article 8 of the Aarhus Convention, which prescribes participation of the public.

Furthermore, the rules contained in the 2017 Guidelines and its accompanying toolbox could fulfil the minimum standards set by Article 8 of the Aarhus Convention, namely "(a) Timeframes sufficient for effective participation should be fixed; (b) Draft rules should be published or otherwise made publicly available; and (c) The public should be given the opportunity to comment, directly or through representative consultative bodies." Furthermore, "the result of the public participation shall be taken into account as far as possible." $" 344$ According to the 2017 Guidelines, the consultation is open to stakeholders, a term that seems to embed the same meaning as the public; the timeframe of four weeks is fixed; the drafts of the acts are published; ${ }^{345}$ the stakeholders have the opportunity to comment; and the Commission has to explain how the feedback was taken into account. ${ }^{346}$

However, there are two points of concern that amount to non-compliance with Article 8 of the Aarhus Convention. First, Article 8 does not provide for any exception to the rule that the drafts should be subject to public participation, while the 2017 Better Regulation Guidelines provide for the application of exceptions. Second, the four-week timeframe is applicable to all kinds of acts independent of the complexity of the act, while Article 8 of the Aarhus Convention requests that the timeframe should be sufficient for effective participation. Probably, the reasoning behind the four-week timeframe for feedback is that issues that are more complex are subject to impact assessments, which require public consultation. ${ }^{347}$ Despite the fact that such an issue could only be solved on a case-by-case basis, what can be concluded is that the text of the 2017 Guidelines does not allow for flexibility in relation to the timeframe, which may amount to insufficient time for effective participation for all drafts.

In sum, the fact that the provisions of the EU ETS Directive refer to consultation with stakeholders does not necessarily amount to compatibility with Article 8of the Aarhus Convention. Only the cases where the EU ETS prescribes consultation and an open consultation is conducted, then the Article 8 requirements are fulfilled.

Even for the cases under the EU ETS Directive, where there is no obligation for the Commission to conduct consultation, the 2017 Guidelines provides for stakeholders' feedback on the draft of implementing and delegated acts, which encompasses all the acts adopted by the Commission discussed in this chapter. This could amount to compliance with

\footnotetext{
${ }^{344}$ Article 8, Aarhus Convention.

345 European Commission, Better Regulation "Toolbox" which complements the Better Regulation Guidelines presented in SWD(2017) 350 (2017b), p. 441-442.

${ }^{346}$ European Commission, Better Regulation "Toolbox" which complements the Better Regulation Guidelines presented in SWD(2017) 350 (2017b), p. 441-443.

${ }^{347}$ European Commission, 2017 Staff Working Document (2017c), p. 8 and 16.
} 
Article 8 of the Aarhus Convention. However, Article 8 does not provide for any exception to the rule that the drafts should be subject to public participation, and it requires that the timeframe should be sufficient for effective participation, while the Better Regulation Guidelines provides for the application of exceptions and no flexibility regarding the timeframe.

\subsection{Interim conclusion}

The analysis carried out in section 4.2 has shown that the EU ETS Directive does not have a general provision on public participation, which applies to all provisions of the Directive. Section 4.2 also investigated whether public participation requirements could be derived from specific provisions under the EU ETS Directive which serve as a legal basis for the adoption of the Commission's acts. The investigation revealed that public participation is not required for the adoption of most acts. The only exception are the acts regulating the free allocation of allowances and the carbon leakage sector for which the EU ETS Directive prescribes the consultation of stakeholders. However, the provisions do not provide a further explanation on how the relevant stakeholders are to be selected.

Having examined the specific provisions of the EU ETS Directive, section 4.3 explored whether the Aarhus Regulation imposes a general obligation regarding public participation for the acts described in section 4.2. The Aarhus Regulation only requires public participation requirements for plans and programmes. ${ }^{348}$ It was concluded that the acts adopted by the Commission in the EU ETS context and described in section 4.2 do not constitute plans and programmes, since they are clearly binding provisions setting rules, for instance, for auctioning and benchmarking, and are hence, in this respect, to be distinguished from plans and programmes. Therefore, the Aarhus Regulation does not impose any obligation regarding public participation for the acts described in the previous section.

In the absence of public participation provisions under the Aarhus Regulation that would be applicable to the acts described in section 4.2, section 4.4 investigated whether there is still an obligation under the Aarhus Convention for the Commission to provide for public participation in the decision making process under the EU ETS. The analysis carried out in section 4.4 demonstrated that the acts described in section 4.2 qualify as "executive regulations and other generally applicable legally binding normative instruments", because they are acts of general application as their addressees are not determined or determinable. ${ }^{349}$ Furthermore, considering their size, location and potential effects on the environment, they have a significant effect on the environment. Therefore, they fall under the scope of

\footnotetext{
${ }^{348}$ Article 9, Aarhus Regulation.

349 These non-legislative acts took the form of a regulation or decision. Regulations and decisions are among the legal instruments available to the European institutions to exercise the Union's competences, according to Article 288 TFEU. How they are adopted defines whether they are a legislative act or not.
} 
application of Article 8 of the Aarhus Convention and, as a consequence, there is a legal obligation for the Commission to strive to promote public participation.

Having established that Article 8 of the Aarhus Convention applies, section 4.5 showed that consultation is seen as one-step of the overall ladder of public participation, but that consultations are not the same as public participation. Therefore, section 4.5 analysed whether the legal framework for stakeholders' consultations at the EU level could fulfil the obligations under Article 8 of the Aarhus Convention. Consequently, the consultation requirements applicable at the EU level (and contained in the 2002 Communication, which was applicable at the time the acts adopted by the Commission identified in section 4.2 were adopted, and in the Better Regulation Package, ${ }^{350}$ applicable at the time of writing) were examined.

Although consultation is not the same as public participation, section 4.5 argued that, where the EU ETS Directive requires consultation and an open consultation is conducted, then the requirements mandated by Article 8 would be fulfilled. For all the other situations, the 2002 Communication cannot fulfil Article 8 requirements. This is due to the fact the 2002 Communication gives discretion to the Commission on whether or not to hold consultations and which type of consultations to conduct. Regarding whether or not to hold consultations, Article 8 of the Aarhus Convention does not foresee such discretion.

Under the current legal framework, the 2017 Better Regulation Guidelines provide for stakeholders' feedback on the drafting of implementing and delegated acts. This could amount to compliance with Article 8 of the Aarhus Convention when implementing and delegated acts are adopted, which encompasses most of the acts adopted by the Commission discussed in this chapter. However, the 2017 Better Regulation Guidelines cannot ensure compliance with Article 8 of the Aarhus Convention regarding the acts adopted by the Commission acting alone, since these acts are not covered. Moreover, in contrast with Article 8 of the Aarhus Convention, the Better Regulation Guidelines provide for the application of exceptions and no flexibility regarding the timeframe. Therefore, the guidelines, per se, cannot guarantee that the EU fully complies with Article 8 of the Aarhus Convention.

\footnotetext{
${ }^{350}$ European Commission, Better regulation for better results - An EU agenda (2014c). This 2015 Communication was accompanied by the Commission Staff Working Document Better Regulation Guidelines, European Commission, Commission Staff Working Document - Better Regulation Guidelines, SWD(2015) 111 final (2015b), which was updated in 2017, European Commission, 2017 Staff Working Document (2017c).
} 


\section{Conclusion}

This chapter explored the access to EU ETS-related information and public participation in the acts adopted by the Commission under the EU ETS Directive.

Section 2 showed that Phase III of the EU ETS is based on more harmonised rules which have empowered the European Commission to determine key elements of the EU ETS, among the most important: (i) the quantity of emission allowances; (ii) the sectors and subsectors, which are part of the carbon leakage sector and may, therefore, get $100 \%$ free allocation of allowances, up to the sector's benchmark; (iii) the rules for the free allocation; and (iv) the rules for auctioning.

Having established the importance of the Commission's decision making for the functioning of the EU ETS, section 3 investigated access to information under the EU ETS Directive. Section 3 first identified that the general regime for access to environmental information under the EU ETS can be found within Articles 17, 15a, and 19 of the EU ETS Directive. The analysis carried out in section 3.2 showed that the scope of Article 15a and 17 is limited and, consequently, cannot cover all the possible requests for information under the EU ETS. To examine the definition of environmental information and the limits of the ground for disclosure of environmental information further, an investigation of the case law was carried out in section 3.3. Concerning the definition of environmental information, the case law dealt with information regarding data used for the calculation of the CSCF, information on the allocation of free allowances by a Member State and trading data. These cases reveal that a great number of EU ETS-related information falls within the definition of environmental information, although, in two of these cases, such an interpretation still needs to be confirmed by the Court of Justice of the European Union. Regarding the grounds for refusal, the case law showed that these grounds have to be interpreted in a restrictive way. For the EU ETS, it was argued that there is a need for further interpretation: at the time of the adoption of the Aarhus Convention, emissions trading was still a concept that needed further practical development, and it can be assumed that the broad term emissions was related to the actual release of substances from installations within more classic command-and-control instruments. With the advent of a market-based instrument such as emissions trading, there is a need for further interpretation in view of the potential release of substances and the creation of new concepts such as greenhouse gas emission allowances.

Regarding the active dissemination of information by the Commission, section 3.4 showed that the EU ETS Directive empowers the Commission to adopt a regulation which provides for public access and confidentiality as appropriate, allowing for the possibility to tailor how and when the information is available. The compatibility of the exercise of this discretion with the Aarhus Convention has yet to be tested by the European courts. 
With regard to public participation, the analysis carried out in section 4.2 showed that the EU ETS Directive does not provide a general provision on this matter which would apply to all decisions to be taken under this Directive. Furthermore, section 4.2 revealed that public participation is not required for the adoption of most acts. The exception to this are acts regulating the free allocation of allowances and the carbon leakage sector for which the EU ETS Directive prescribes the consultation of stakeholders. However, the provisions do not provide a further explanation of how the relevant stakeholders are to be selected. Having examined the specific provisions of the EU ETS Directive, section 4.3 concluded that the Aarhus Regulation does not impose any obligation regarding public participation for the acts described in the previous section 4.2.

In the absence of a general obligation regarding public participation for the acts described in section 4.2, section 4.4 investigated whether there is still an obligation under the Aarhus Convention for the Commission to provide for public participation in the decision making process under the EU ETS. The analysis carried out in section 4.4 demonstrated that the acts described in section 4.2 qualify as "executive regulations and other generally applicable legally binding normative instruments", because they are acts of general application as their addressees are not determined or determinable. ${ }^{351}$ Furthermore, considering their size, location and potential effects on the environment, they have a significant effect on the environment. Therefore, they fall under the scope of application of Article 8 of the Aarhus Convention and, as a consequence, there is a legal obligation for the Commission to strive to promote public participation.

Having established that Article 8 of the Aarhus Convention applies, the final step was to identify whether the Commission has fulfilled its public participation obligation with respect to the measures adopted under the EU ETS Directive. Consultations do not automatically imply public participation, and therefore a further analysis of the legal framework for consultations at the EU level was needed to identify whether the stakeholders' consultations could fulfil the obligations under Article 8 of the Aarhus Convention. Section 4.5 argued that, under the current legal framework, even for the cases under the EU ETS Directive where there is no obligation for the Commission to conduct consultations, the 2017 Better Regulation Guidelines provide for stakeholders' feedback on the draft of implementing and delegated acts, which encompasses most of the acts adopted by the Commission discussed in this chapter. This could amount to compliance with Article 8 of the Aarhus Convention when implementing and delegated acts are adopted. However, the acts adopted by the Commission acting alone would not be covered and, therefore, no compliance with Article 8 of the Aarhus Convention could be achieved. Moreover, Article 8 does not provide for any exception to the

\footnotetext{
351 These non-legislative acts took the form of a regulation or decision. Regulations and decisions are among the legal instruments available to the European institutions to exercise the Union's competences, according to Article 288 TFEU. How they are adopted defines whether they are a legislative act or not.
} 
rule that the drafts should be subject to public participation, and it requires that the timeframe should be sufficient for effective participation, while the Better Regulation Guidelines provide for the application of exceptions and no flexibility regarding the timeframe. Therefore, the guidelines, per se, cannot guarantee that the EU fully complies with Article 8 of the Aarhus Convention.

On a more positive note, the chapter identified that, according to the 2017 Better Regulation Guidelines, the default is that all the delegated and implemented acts are now subject to public feedback. Moreover, the Commission made a move towards the recognition of the legal implications of the 2017 Guidelines by recognising that the guidelines may legally bind the Commission. ${ }^{352}$

In light of the conclusions reached in this chapter, it can be argued that public participation under the EU ETS could be strengthened if the EU ETS Directive contained a specific provision on public participation. Since the centralisation of major decisions at the EU level, the Commission has assumed a more prominent role, but neither the EU ETS Directive nor the Aarhus Regulation guarantee public participation in the acts the Commission has to adopt. A specific approach under the EU ETS Directive regulating, precisely, public participation for the acts the Commission has to adopt would bring the adoption of these acts into line with the Convention's requirements. It should be noted that this recommendation could lead to a fragmentation of EU environmental legislation. A less fragmented approach would consist of a proper implementation of the Aarhus Convention at the EU level, by making an amendment to the Aarhus Regulation. However, it remains to be seen whether a common provision would be suitable for all the different provisions in EU environmental law.

${ }^{352}$ European Commission, 2017 Staff Working Document (2017c), p. 43. 


\section{Chapter V - Certification of Biofuels: Access to environmental information and public participation at the EU Level}

\section{Introduction}

The Renewable Energy Directive (RED) was adopted in 2009 and contains the legally enforceable target for Member States to achieve $20 \%$ of renewable energy consumption in the European Union (EU) by 2020. ${ }^{1}$ Member States must also ensure that at least $10 \%$ of their transport fuels come from renewable sources by this deadline. ${ }^{2}$ In order to achieve this target, the RED incentivises the use of biofuels and bioliquids by Member States. ${ }^{3}$

However, this push towards biofuels has been controversial because it is still uncertain to what extent they contribute to reducing greenhouse gas emissions and the possible land-use

\footnotetext{
${ }^{1}$ Article 3(1), Renewable Energy Directive, consolidated version. (hereafter referred to as Directive 2009/28/EC or RED). Since the focus of this chapter is on the renewable energy targets until 2020, the consolidated version referred to in this chapter is the version of 05 October 2015 and not the recast dated from 21 December 2018, which already includes the rules for the period after 2020.

The consolidated version of 05 October 2015 contains the following amendments: Council Directive 2013/18/EU of 13 May 2013 adapting Directive 2009/28/EC of the European Parliament and of the Council on the promotion of the use of energy from renewable sources, by reason of the accession of the Republic of Croatia, OJ L 158/230; and Directive (EU) 2015/1513 of the European Parliament and of the Council of 9 September 2015 amending Directive 98/70/EC relating to the quality of petrol and diesel fuels and amending Directive 2009/28/EC on the promotion of the use of energy from renewable sources, OJ L 239/1.

${ }^{2}$ Article 3(4), Renewable Energy Directive, consolidated version.

${ }^{3}$ Recital 69, Preamble, Renewable Energy Directive, consolidated version. For after 2020, the European Commission did not propose new targets for renewable energy in the transport sector. Consequently, the demand for biofuels may be reduced. (Communication from the Commission to the European Parliament, the Council, the European Economic and Social Committee and the Committee of the Regions - A policy framework for climate and energy in the period from 2020 to 2030, SWD(2014) 15 final / SWD(2014) 16 final, p. 6 (section 2.2)). The targets for 2021 and beyond are established in the recast of the Renewable Energy Directive: Directive (EU) 2018/2001 of the European Parliament and of the Council of 11 December 2018 on the promotion of the use of energy from renewable sources (recast), OJ L 328/82.
} 
change related to the cultivation of crops for biofuels. ${ }^{4}$ In an attempt to address some of these sustainability issues, the EU set out sustainability criteria in Article 17 of the RED and only the biofuels that fulfil these criteria can count towards national renewable energy targets. According to the sustainability criteria, biofuels shall achieve greenhouse gas savings of at least $60 \%$ in comparison to fossil fuels and shall not be made from raw material obtained from land with a high biodiversity value (such as primary forests or highly biodiverse grasslands) or from land with high carbon stock (such as wetlands or forests). ${ }^{5}$ Companies may choose from three methods in order to show that their biofuels comply with the sustainability criteria: ${ }^{6}$ (i) national systems; (ii) voluntary schemes; and (iii) international agreements. ${ }^{7}$ Article 18(4) empowers the European Commission to recognise voluntary national or international schemes as capable of checking for compliance with the EU's biofuels sustainability criteria. ${ }^{8}$ It means that these voluntary schemes will verify that biofuel production did not take place on land with high biodiversity or with high carbon stock and that the production of biofuels leads to a sufficient level of greenhouse gas emissions savings.

The recognition process conducted by the European Commission has so far not been analysed from a procedural rights perspective. Although biofuels, and especially the process of recognition of the voluntary schemes, which aim to guarantee that biofuels meet the sustainability criteria, have already been discussed substantially, an analysis in view of the Aarhus Convention requirements is still lacking. ${ }^{9}$ This chapter, therefore, assesses the regime ${ }^{4}$ J. Lin, op. cit. (2011), p. 44. S. Romppanen, op. cit. (2012a), pp. 173-174. S. Romppanen, 'Regulating
Better Biofuels for the European Union' 21(3) European Energy \& Environmental Law Review, (2012b), pp. 123-141, pp. 124-126.

${ }^{5}$ Article 17(2), Renewable Energy Directive, consolidated version. The 60\% greenhouse gas emissions requirement for biofuels and bioliquids produced in installations starting operations after 5 October 2015. For the installations that were in operation on or before 5 October 2015, biofuels and bioliquids shall achieve a greenhouse gas emission saving of at least 35\% until 31 December 2017 and at least $50 \%$ from 1 January 2018.

${ }^{6}$ According to Article 18(7) of the Renewable Energy Directive, no further proof maybe requested by a Member State if the proof of compliance has been made in accordance with Article 18(4) of this directive. Also, confirming that Article 18 of the Renewable Energy Directive gives economic operators the possibility to choose among the three methods to show Member State compliance with the sustainability criteria, see S. Romppanen, op. cit. (2012a), p. 178.

${ }^{7}$ Article 18 (4), Renewable Energy Directive, consolidated version.

${ }^{8}$ All the discussions in this chapter also apply to bioliquids. There are no adopted binding criteria for the sustainability of solid and gaseous biomass for electricity, heating and cooling for the period studied in this thesis (up to 2020). However, the Commission made a recommendation to Member States for developing their own national schemes. T. Yue, op. cit. (2016), p. 114.

${ }^{9}$ Some authors have discussed the question of the transparency of the voluntary schemes, but there is no mention of the Aarhus Convention. See S. Romppanen, op. cit. (2012a), p. 175; J. Lin, op. cit. (2011), p. 56; Paiement, P., 'Transnational delegation, accountability and the administrative governance of biofuel standards', in S. Wood, R. Schmidt, K. Abbott, B. Eberlein and E. Meidinge (eds.), 
of access to biofuel-related information and public participation in decision making of the recognition of biofuels voluntary schemes at the EU level in view of the Aarhus Convention requirements.

The chapter is structured as follows. Section 2 introduces the sustainability criteria, explains the recognition process of biofuels voluntary schemes at the EU level, identifies the actors involved in the recognition process and provides a critical analysis of the RED requirement of having an adequate standard of transparency in this process. Section 3 discusses the legal framework for access to information related to biofuels in view of the literature and the relevant case law and tests its compatibility with the Aarhus Convention. Section 4 examines the legal framework for public participation in biofuels voluntary schemes and certification of biofuels decision making and tests its compatibility with the Aarhus Convention. Section 5 concludes by highlighting the legal problems uncovered by this research and pointing at possible solutions.

\section{The sustainability criteria}

\subsection{Introduction}

Article 17 RED lays down the sustainability criteria for biofuels. ${ }^{10}$ Paragraphs 2 to 6 establish the criteria that must be fulfilled before the biofuels can be counted towards the renewable energy target. There are also social and economic aspects among the sustainability criteria for which the Commission has obligations to report to the European Parliament and the Council, but they are not part of the mandatory sustainability criteria. ${ }^{11}$

The mandatory sustainability criteria determine that (i) greenhouse gas emission saving from biofuels and bioliquids produced by installations that started operating after 5 October 2015 shall be at least $60 \% ;^{12}$ (ii) biofuels "shall not be made from raw material obtained from land with high biodiversity value"; 13 (iii) biofuels "shall not be made from raw material obtained

Transnational business governance interactions: Enhancing regulatory capacity, ratcheting up standards and empowering marginalized Actors (Cheltenham: Edward Elgar Publishing, 2019), pp. 227-252, pp. 234-236.

${ }^{10}$ The sustainability criteria also apply to bioliquids, see Recital 67, Preamble, Directive 2009/28/EC of the European Parliament and of the Council of 23 April 2009 on the promotion of the use of energy from renewable sources and amending and subsequently repealing Directives 2001/77/EC and 2003/39, OJ L140/16.

${ }^{11}$ Article 17(7), Renewable Energy Directive.

12 Article 17(2), Renewable Energy Directive, consolidated version. For installations that were in operation on or before 5 October 2015 the greenhouse gas emission saving criteria for biofuels and bioliquids is of at least 35\% until 31 December 2017 and at least 50\% from 1 January 2018.

${ }^{13}$ Article 17(3), Renewable Energy Directive, consolidated version. 
from land with high carbon stock"; ${ }^{14}$ (iv) "shall not be made from raw material obtained from land that was peatland in January 2008"; and (v) certain agro-environmental practices must be applied in the EU biofuel's cultivation. ${ }^{15}$ Only the biofuels that fulfil these conditions can be used to achieve the national renewable energy targets. It means that biofuels that do not meet the sustainable criteria of the Directive may be commercialised, but they cannot be counted to fulfil national renewable energy targets. ${ }^{16}$ In order to use biofuels, which can be counted to fulfil the national targets, Member States are obliged to require economic operators to prove that the biofuels and bioliquids concerned comply with the sustainability criteria. ${ }^{17}$ As already stated in section 1 , in order to prove compliance with the sustainability criteria, economic operators may choose among three methods: a) national systems; ${ }^{18}$ b) voluntary schemes recognised by the European Commission; ${ }^{19}$ and c) bilateral or multilateral agreements. $^{20}$

Of the three options, voluntary schemes have been considered the most important compliance mechanism, as they are applicable EU-wide. ${ }^{21}$ By November 2019, there are 14 active voluntary schemes recognised by the European Commission. ${ }^{22}$ The recognition of voluntary schemes is the focus of the present study, since this is the only method developed so far, at the EU level, to recognise biofuels as sustainable. Bilateral and multilateral agreements could have been part of the scope of this study, since they may be concluded by the EU. However, at the time of writing no such agreements had been concluded. ${ }^{23}$

\footnotetext{
${ }^{14}$ Article 17(4), Renewable Energy Directive, consolidated version.

${ }^{15}$ Article 17(6), Renewable Energy Directive.

${ }^{16}$ Article 17(1), Renewable Energy Directive. S. Romppanen, op. cit. (2012a), p. 176. M. Peeters,
} 'Instrument mix or instrument mess? The administrative complexity of the EU legislative package for climate change', in M. Peeters and R. Uylenburg (eds.), EU Environmental Legislation: Legal Perspectives on Regulatory Strategies, (Cheltenham: Edward Elgar, 2014), pp. 173-192, p. 179.

${ }^{17}$ Article 18(1), Renewable Energy Directive.

${ }^{18}$ Article 18(3), Renewable Energy Directive.

${ }^{19}$ Article 18(4) second subparagraph, and Article 18(7) Renewable Energy Directive.

${ }^{20}$ Article 18(4) first subparagraph and Article 18(7), Renewable Energy Directive.

${ }^{21}$ European Commission, Report from the Commission to the European Parliament, the Council, the European Economic and Social Committee and the Comittee of the Regions, SWD(2015) 117 final (2015d), p. 15.

22 European Commission. Voluntary schemes, 19 June 2020, https://ec.europa.eu/energy/en/topics/renewable-energy/biofuels/voluntary-schemes. See Annex with the name of the voluntary schemes and date of recognition. The European Commission has recognised more schemes over the years, but some of them did not request a new recognition after the decision has expired.

23 “" [...] bilateral agreements, there are as yet none in place or recognized by the Commission. Brazil and the USA have shown interest in developing such an agreement for the purpose of compliance with 
Regarding the non-mandatory sustainability criteria, the RED prescribes that the Commission shall report every two years to the European Parliament and the Council on national measures taken regarding the greenhouse gas savings, biodiversity, carbon stock criteria, as well as soil, water and air protection in the countries which are a significant source of biofuels or of raw materials for biofuels consumed within the EU. ${ }^{24}$ In addition to this, there are further reporting obligations regarding soil, water and air protection, and also on socio-economic sustainability aspects. ${ }^{25}$ The European Commission may propose action to correct the sustainability criteria if there is evidence of negative impact of biofuels on the environment and on economic and social aspects, especially if "evidence shows that biofuel production has a significant impact on food prices". ${ }^{26}$

2.2. The voluntary schemes to demonstrate compliance of biofuels with the sustainability criteria

sustainability criteria of biofuels, but nothing has been recognized or established to date". C. Hamelinck, M. Koper, L. Janeiro, C. Klessmann, R. Kuwahata, C. Nabe, M. Doering, M. Cuijpers, A. van den Bos, M. Spoettle, S. Alberici, M. Ragwitz, S. Steinhilber, J. Nysten, D. Fouquet, G. Resch, L. Liebmann, A. Ortner, C. Panzer, F. Johnson, O. Olsen, J. Godar, L. Karlberg, and G. Fischer, Renewable energy progress and biofuels sustainability (2014), p. 193.

${ }^{24}$ Article 17(7), Renewable Energy Directive.

25 Article 17(7), Renewable Energy Directive. According to Article 17(7) RED, the European Commission shall also report to the European Parliament and the Council on soil, water and air protection, and as well on socio-economic sustainability aspects, such as the availability of foodstuffs at affordable prices, and the respect of land-use rights related, and the status of ratification by concerned countries of the Conventions on labour rights agreed under the International Labour Organisation (The RED lists the following labour right conventions: Convention concerning Forced or Compulsory Labour (No 29), Convention concerning Freedom of Association and Protection of the Right to Organise (No 87), Convention concerning the Application of the Principles of the Right to Organise and to Bargain Collectively (No 98), Convention concerning Equal Remuneration of Men and Women Workers for Work of Equal Value (No 100), Convention concerning the Abolition of Forced Labour (No 105), Convention concerning Discrimination in Respect of Employment and Occupation (No 111), Convention concerning Minimum Age for Admission to Employment (No 138), Convention concerning the Prohibition and Immediate Action for the Elimination of the Worst Forms of Child Labour (No 182)), as well as the Cartagena Protocol on Biosafety and the Convention on International Trade in Endangered Species of Wild Fauna and Flora.

${ }^{26}$ Article 17(7), last indent, Renewable Energy Directive. The RED Directive does not define what a corrective action is. Different methods could be considered to correct a negative social impact caused by an increased demand for biofuels, depending on who it shall be addressed it could be a decision, a regulation or an amendment to the RED. For a discussion on the methods, see: E. Maitre and J. Meissner Pritchard, 'Reporting obligations under the Renewable Energy Directive and the Fuel Quality Directive' Legal Briefing ClientEarth, (2011), pp. i-20, p. 13. 
At the time of writing, voluntary schemes are the only method used at EU level to show compliance with the sustainability criteria contained in the RED. Recital 79 of the preamble of the RED explains the objective and importance of these voluntary schemes:

"It is in the interests of the Community to encourage [...] voluntary international or
national schemes that set standards for the production of sustainable biofuels and
bioliquids, and that certify that the production of biofuels and bioliquids meets those
standards. For that reason, provision should be made for such [...] schemes to be
recognised as providing reliable evidence and data, provided that they meet adequate
standards of reliability, transparency and independent auditing." (Emphasis
added)

Article 18 RED authorises the Commission to decide on the approval of voluntary schemes and describes the procedure for the adoption of a decision which recognises the voluntary schemes:

"4. [...] The Commission may decide that voluntary national or international schemes setting standards for the production of biomass products contain accurate data for the purposes of Article 17(2), and/or demonstrate that consignments of biofuel or bioliquid comply with the sustainability criteria set out in Article 17(3), (4) and (5), and/or that no materials have been intentionally modified or discarded so that the consignment or part thereof would fall under Annex IX. $[\ldots]$;

5. The Commission shall adopt decisions under paragraph 4 only if the agreement or scheme in question meets adequate standards of reliability, transparency and independent auditing. In the case of schemes to measure greenhouse gas emission saving, such schemes shall also comply with the methodological requirements in Annex V[...].

6. Decisions under paragraph 4 of this Article shall be adopted in accordance with the examination procedure referred to in Article 25(3). Such decisions shall be valid for a period of no more than five years." (Emphasis added).

In an attempt to provide more clarity on this recognition process, in June 2010, the Commission published Communication 160/01, which explains the requirements, the assessment and the recognition process undertaken by the European Commission to recognise voluntary schemes. ${ }^{27}$

\footnotetext{
${ }^{27}$ Communication from the Commission on voluntary schemes and default values in the EU biofuels and bioliquids sustainability scheme, 2010/C 160/01, OJ C 160/1 (2010b). The European Commission has also published Communication from the Commission on the practical implementation of the EU
} 
Within the European Commission, the Directorate-General for Energy (DG ENER) leads the recognition procedure of voluntary schemes. ${ }^{28}$ It assesses the voluntary schemes with the help of an evaluator/contractor, which analyses the technical aspects of schemes. ${ }^{29}$ The selection of the contractor is made through calls for tenders. ${ }^{30}$ The selected evaluator/contractor will assess the application and consider if there is a need to adjust the scheme in order to comply fully with the sustainability criteria. If there is a need for adjustments, the evaluator, on behalf of the Commission, will give the applicant the opportunity to find solutions. ${ }^{31}$ When the assessment indicates that a scheme meets the sustainability criteria, Communication 160/01 prescribes that the Commission shall "initiate the process leading to the adoption of a Commission decision". ${ }^{32}$ The first step taken by the DG ENER is "an inter-service consultation with other Directorates-General for their coapproval". ${ }^{33}$ After the technical assessment has been approved by the Directorates-General, the DG ENER starts the process leading to the adoption of the Commission decision via comitology, ${ }^{34}$ which involves the Committee on the Sustainability of Biofuels and Bioliquids. ${ }^{35}$ The Committee votes and then DG ENER makes its recommendation to the European Commission regarding the adoption of an implementing decision recognising the scheme. ${ }^{36}$ The decision is valid for five years. ${ }^{37}$ If, during the validity of the decision, the operator of the voluntary scheme wants to implement changes, it may do so upon notification

biofuels and bioliquids sustainability scheme and on counting rules for biofuels, 2010/C 160/02, OJ C 160/8 (2010a).

${ }^{28}$ T. Vogelpohl and D. Perbandt, 'Biofuel sustainability certifications in the EU: democratically legitimate and socio-environmentally effective?', in M. Vogt (ed.), Sustainability certification schemes in the agricultural and natural resource sectors: outcomes for society and the environment, (Abingdon, Oxon: Routledge, 2019), pp. 179-198.

${ }^{29}$ S. Ugarte, J. van Dam, S. Spijkers and M. Gaebler, op. cit. (2013), p. 7.

${ }^{30}$ See for an example a selection that took place in March/April 2015. European Commission, Contract notice: Assessment of voluntary schemes and agreements used for sustainability claims (2015/S 060104704) OJ/S S60 (2015c).

${ }^{31}$ S. Ugarte, J. van Dam, S. Spijkers and M. Gaebler, op. cit. (2013), p. 7.

${ }^{32}$ Communication from the Commission on voluntary schemes and default values in the EU biofuels and bioliquids sustainability scheme, 2010/C 160/01, OJ C 160/1 (2010b), section 2.1.

${ }^{33}$ S. Ugarte, J. van Dam, S. Spijkers, and M. Gaebler, op. cit. (2013), p. 7.

34 "The term 'comitology' is shorthand for the way the Commission exercises the implementing powers conferred on it by the EU legislator, with the assistance of committees of representatives from the EU Member States." European Commission. Comitology Register - Frequently Asked Questions, 19 June 2020, http://ec.europa.eu/transparency/regcomitology/index.cfm?do=FAQ.FAQ.

35 The Committee on the Sustainability of Biofuels and Bioliquids was established by Article 25(2), Renewable Energy Directive.

${ }^{36}$ The decision is adopted in accordance with the advisory procedure Article 18(6), Renewable Energy Directive.

${ }^{37}$ Article 18(6), Renewable Energy Directive. 
to the Commission. If such an amendment affects the basis of the initial scheme that was approved, then DG ENER will undertake a new assessment. ${ }^{38}$

In case the scheme does not meet the sustainability criteria, the Communication only mentions that the applicant will be informed, and it does not make clear through which instrument the applicants will be informed. ${ }^{39}$ In fact, there is no formal decision taken by the Commission. ${ }^{40}$

The flowchart below depicts the recognition process of the biofuels voluntary schemes combining the information from the RED, the Communication 160/01 and the literature:

\footnotetext{
${ }^{38}$ European Commission, Communication from the Commission on voluntary schemes and default values in the EU biofuels and bioliquids sustainability scheme, 2010/C 160/01, OJ C 160/1 (2010b), Section 1, last indent and Section 2.1.

39 "If the assessment indicates that a scheme does not meet the requirements, the Commission will inform the submitting organisation accordingly". Communication from the Commission on voluntary schemes and default values in the EU biofuels and bioliquids sustainability scheme, 2010/C 160/01, OJ C 160/1 (2010b), Section 2.1.

40 "The Commission cannot adopt a Decision to refuse recognition for a scheme which is not able to demonstrate compliance with the sustainability criteria. Therefore, even if an assessment is carried out to refuse recognition for a scheme, there are no formal documents which can be shared." Personal communication via Europe Direct Contact Centre (12 April 2017). [Biofuels voluntary schemes - first answer]. Nevertheless, the message informing the organisation that the scheme will not be recognised may be challenged, since it implies a non-recognition decision. If the submitting organisation disagrees with the Commission's non-recognition, it may start an action for annulment under Article 263 TFEU, since the implied decision is addressed to the submitting organisation itself. It would also be possible for Non-Governmental Organisations (NGOs) to request an internal review, which is part of the EU's attempt to implement access to justice in case of an environmental law violation at the EU level. Article 10, Aarhus Regulation. For an explanation of the internal review, see Chapter III, section 5.1.
} 


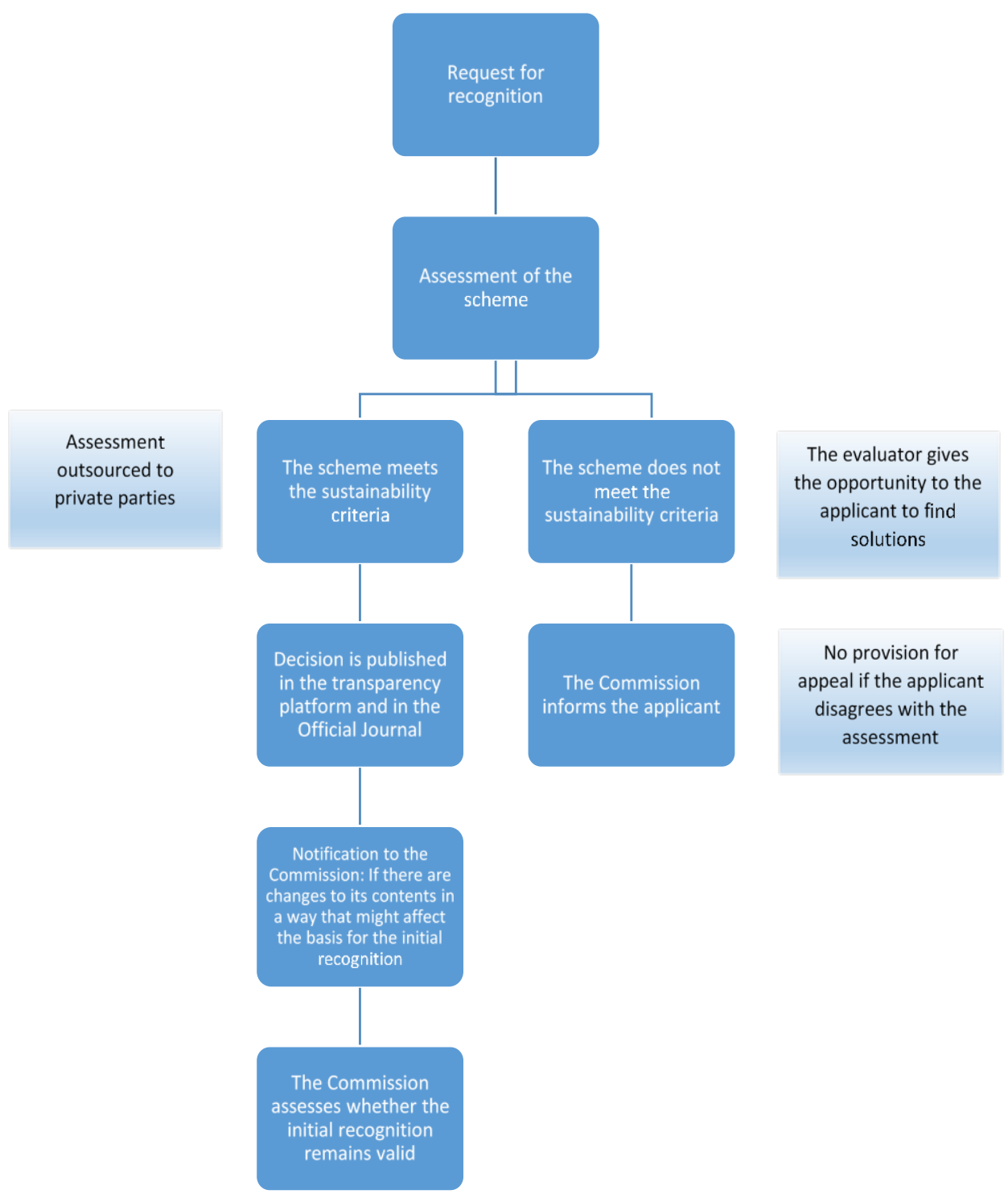

Figure 02: Recognition of the biofuels voluntary schemes ${ }^{41}$

${ }^{41}$ Flowchart developed by the author. 


\subsection{Identifying the actors involved in the recognition process}

Based on the recognition process of the voluntary schemes presented above, it is possible to identify the participation of public and private actors. First, the Commission is responsible for recognising the voluntary schemes. Second, the evaluator/contractor analyses the technical aspects of the schemes on the basis of a mandate received by the Commission. Third, the recognised voluntary scheme certifies the biofuels as sustainable and that it is operated by a private party. Besides the Commission, the evaluator/contractor and the private party operating the recognised voluntary scheme, the public is a potential actor. Members of the public, such as Environmental Non-Governmental Organisations (ENGOs), may request information from the aforementioned actors about the recognition and certification of biofuels and may also attempt to participate in the decision making process. Therefore, all of these actors play or may play an important role in access to biofuel-related information and public participation in the recognition of voluntary schemes.

\subsection{The requirement of an adequate standard of transparency for the recognition of voluntary schemes}

As stated above in section 2.2, Article 18(5) RED prescribes that voluntary schemes are only recognised if they meet an adequate standard of transparency. Transparency may encapsulate a broad meaning, which does not only refer to access to information but also the availability and accessibility of the information, and the ability of the public to be informed about governmental decision making. ${ }^{42}$ But transparency standards conventionally refer to public access to information held by the public authorities as well as information about governmental decision making. ${ }^{43}$ This chapter will deal with transparency to the extent that it relates to the right to access information. The focus is therefore on access to information and the required standard of transparency will be explored so as to understand whether it provides requirements for access to information.

Transparency is not the only criterion that the Commission has to respect in its decision making regarding the voluntary schemes. Article 18(5) RED states that the recognition of voluntary schemes shall be granted by the Commission only if the schemes meet "adequate standards of reliability, transparency and independent auditing". These are vague criteria and the Commission has given guidance in Communication 160/01 on what is to be understood by adequate standards of independent and reliable auditing. ${ }^{44}$ However, this communication

\footnotetext{
${ }^{42}$ H. Kilmartin and E. Mendelson, 'Transparency and Public Participation in the Rulemaking Process' Paper 238 Faculty Scholarship, (2008), pp. 924-972, p. 926.

${ }^{43}$ C. Coglianese, H. Kilmartin and E. Mendelson, Transparency and Public Participation in the Rulemaking Process: A Nonpartisan Presidential Transition Task Force Report (2008), p. V.

${ }^{44}$ Communication from the Commission on voluntary schemes and default values in the EU biofuels and bioliquids sustainability scheme, 2010/C 160/01, OJ C 160/1 (2010b), Section 2.2.2.
} 
does not give any guidance on what can be understood as an adequate standard of transparency. This lack of guidance may lead to different levels of transparency among the approved schemes. ${ }^{45}$ As shown by a study from the Dutch Ministry of Economic Affairs "there is a variation in assurance requirements between systems for those points where the EU-RED lacks guidance or provides room for interpretation". ${ }^{46}$ An example of this variation is the fact that not all voluntary schemes provide the summary reports of the audit assessments for the evidence related to the activities the voluntary schemes claim to be able to perform on their websites. ${ }^{47}$

All Commission decisions recognising schemes before the 2015 amendment to the RED found that the schemes met "adequate standards of reliability, transparency and independent auditing." ${ }^{48}$ The question that follows is how transparency standards have been evaluated if there are no assessment criteria for such standards. The assessment reports on which the Commission decisions are based also do not provide clarification regarding transparency. ${ }^{49}$ Consequently, it can be stated that the assessment procedure "does not produce necessary information on the standards against which the voluntary certification schemes are assessed and selected". 50

After the amendment brought by Directive 2015/1513 to the RED, this situation has improved. For the voluntary schemes that have been and will be recognised after the amendment, the Commission has prepared a new recognition template that includes a section

\footnotetext{
${ }^{45}$ In fact, the only reference to the term "transparency" in Communication (2010/C 160/01) is to the "transparency platform".

${ }^{46}$ J. Van Dam, S. Ugarte and S. van Iersel, Selecting a biomass certification system-a benchmark on level of assurance, costs and benefits, https://jvdconsultancy.com/wpcontent/uploads/2019/11/Selecting-a-biomass-certific-ation-system---a-benchmark-on-level-ofassurance-costs-and-benefits-March-2012-.pdf (2012), p. 12. This study compares eight recognised schemes. On the different degree of transparency among the schemes, see also: I. Schlamann, B. Wieler, M. Fleckenstein, J. Walther-Thoß, N. Haase and L. Mathe, 'Searching for Sustainability: Comparative Analysis of Certification Schemes for Biomass used for the Production of Biofuels', (Düsseldorf: WWF Deutschland, 2013).

${ }^{47}$ J. Van Dam, S. Ugarte and S. van Iersel, Selecting a biomass certification system-a benchmark on level of assurance, costs and benefits, https://jvdconsultancy.com/wpcontent/uploads/2019/11/Selecting-a-biomass-certific-ation-system---a-benchmark-on-level-ofassurance-costs-and-benefits-March-2012-.pdf (2012), pp. 23-24. For an overview of the all voluntary schemes see: https://ec.europa.eu/energy/en/topics/renewable-energy/biofuels/voluntary-schemes 48 This conclusion has been reached by examining all the Commission's decisions.

49 The assessment reports may be found here: https://ec.europa.eu/energy/en/topics/renewableenergy/biofuels/voluntary-schemes. Expired decisions will be not available on this website but are on file with the author.

${ }^{50}$ S. Romppanen, op. cit. (2012a), p. 182.
} 
on the transparency of the schemes. ${ }^{51}$ A similar section was not present in the templates used for the recognition of the schemes before the amendment. ${ }^{52}$ The section on transparency states that "voluntary schemes should make available information that is relevant for the operation of the system or for transparency purposes." 53 Furthermore, the section lists which information, in particular, should be published: the list of economic operators that are or have been recognised under the scheme; information on the withdrawal or suspension of certificates; the latest version of scheme documents; the auditing certification bodies; publication of contact details for the scheme; and the names of the voluntary schemes from which the applicant scheme accepts certified material. ${ }^{54}$

Furthermore, pursuant to Directive 2015/1513, there is an obligation for the voluntary schemes to report to the Commission on many different aspects of the operation of the schemes. Regarding access to information and public participation, the schemes have to report on "transparency, particularly in relation to the accessibility of the scheme, the availability of translations in the applicable languages of the countries and regions from which raw materials originate, the accessibility of a list of certified operators and relevant certificates, and the accessibility of auditor reports" 55 and also the "stakeholder involvement, particularly as regards the consultation of indigenous and local communities prior to decision making during the drafting and reviewing of the scheme as well as during audits and the response to their contributions". ${ }^{56}$ The Commission has to analyse these reports, reviewing the operation of recognised voluntary schemes and identifying best practices and report to the Council and the Parliament. ${ }^{57}$ This is a novelty, since there was no provision in the RED

${ }^{51}$ European Commission, Assessment Protocol Template (2015a), Section 6.13. The protocol is from November 2015 (European Court of Auditors, The EU system for the certification of sustainable biofuels (2016), p. 54).

${ }^{52}$ All the schemes will have to be subject to a new decision after five years, which is the validity of any Commission decision recognising schemes according to Article 18(6), Renewable Energy Directive, consolidated version. It means that eventually all schemes will be approved in accordance with the new template.

${ }^{53}$ European Commission, Assessment Protocol Template (2015a), Section 6.13.

${ }^{54}$ European Court of Auditors, The EU system for the certification of sustainable biofuels (2016), p. 54. For instance, voluntary schemes may certify biofuels as being sustainable for which biomass certified by another voluntary scheme has been used. In this case, the applicant scheme should publish the names of the schemes from which it has accepted certified material.

${ }^{55}$ Article 18(6)(c), Renewable Energy Directive, consolidated version.

${ }^{56}$ Article 18(6)(d), Renewable Energy Directive, consolidated version.

${ }^{57}$ Article 18(6), Renewable Energy Directive, consolidated version. According to Article 18(6), third block, last sentence, the report shall be based on the best information available, including following consultations with stakeholders, and on practical experience in the application of the schemes. Therefore, the provision requires the Commission to base the report also on information generated during stakeholders' consultations, but the provision does not explicitly require the Commission to conduct consultations for the elaboration of the report. 
explaining how the Commission would monitor the voluntary schemes. This report should contain a vast list of areas, among others, transparency in relation to the accessibility of the scheme and stakeholder involvement. However, these are only reporting obligations.

Furthermore, for standards of independent auditing, the Commission may, based on a risk analysis or on these reports, set new standards and require all voluntary schemes to apply those standards. ${ }^{58}$ The Commission may repeal the decision to recognise the voluntary scheme, which does not comply with the new standards of independent auditing within a prescribed timeframe. ${ }^{59}$ Interestingly, the standard of transparency and reliability did not receive the same treatment.

\subsection{Interim Conclusion}

Despite the fact that all Commission decisions recognising voluntary schemes before the 2015 amendment to the RED affirm that adequate standards of reliability, transparency and independent auditing have been met, the analysis carried out in this section found that neither the RED defines this standard, nor the assessment reports, on which the Commission decisions for recognising these schemes were based, provided clarification regarding the transparency standards that have been employed when recognising the voluntary schemes. ${ }^{60}$ Therefore, the established legal framework and the subsequent decisions did not contain information on the transparency standards against which the voluntary certification schemes are assessed and approved. ${ }^{61}$ The amendment about brought by Directive 2015/1513 has improved this situation. As a consequence of this amendment, the RED currently includes more requirements regarding transparency on the recognition of voluntary schemes and an obligation for the Commission to prepare the report on the revision of the operation of the voluntary schemes. ${ }^{62}$ For the voluntary schemes that have been and will be recognised after the amendment, the Commission has prepared a new recognition assessment template that includes a section on the transparency of the schemes. ${ }^{63}$ A similar section was not present in the templates used for the recognition of the schemes before the amendment. ${ }^{64}$ This section on transparency from the Commission's template requires the voluntary schemes to make

\footnotetext{
${ }^{58}$ Article 18 (5), Renewable Energy Directive, consolidated version.

${ }^{59}$ Article 18 (5), Renewable Energy Directive, consolidated version.

${ }^{60}$ The assessment reports may be found here: https://ec.europa.eu/energy/en/topics/renewableenergy/biofuels/voluntary-schemes.

${ }^{61}$ S. Romppanen, op. cit. (2012a), p. 182.

${ }^{62}$ Article 18 (6), Renewable Energy Directive, consolidated version.

${ }^{63}$ European Commission, Assessment Protocol Template (2015a), Section 6.13.

${ }^{64}$ All the schemes will have to be subject to a new decision after five years, which is the validity of any Commission decision recognising schemes according to Article 18(6), Renewable Energy Directive, consolidated version. It means that, in the end, all schemes are expected to be approved in accordance with the new template.
} 
information on their actions performed and operations available,${ }^{65}$ such as the latest version of scheme documents and the list of economic operators that are recognised under the scheme.

\section{Access to biofuel-related information}

\subsection{Introduction}

There is no general provision on access to information in the RED that would apply to all situations under the Renewable Energy Directive. In this vein, in order to understand the framework applicable in the case of the recognition of the voluntary schemes, it is necessary to look at the relationship of the RED with the Aarhus Regulation and the specific provisions governing the recognition process.

First, this section analyses the legal framework for access to biofuel-related information and identifies the current and potential legal problems. Second, it explores whether biofuelrelated information can be considered environmental information and whether the actors involved in the recognition process can be considered to fall under the definition of public authority. Third, it discusses whether there exists a legal obligation for the European Commission, the evaluator/contractor who helps on the assessment procedure, and the recognised schemes to disseminate and disclose information upon request. Finally, it examines the legal problems related to requesting biofuel-related information through the lens of relevant case law.

\subsection{The RED and the Aarhus Regulation}

Recital 90 of the preamble of the RED states that its implementation should reflect, where relevant, the provisions of the Aarhus Convention, in particular as implemented through the Directive on Access to Environmental Information, which is applicable in case information is requested from national authorities. ${ }^{66}$ However, there is no specific reference in the RED covering access to information at the EU level. Nevertheless, there is no doubt that, in the case of information held by the European Commission, Regulation 1367/2006 (the Aarhus Regulation), which implemented the provisions of the Aarhus Convention for the European institutions, will apply. However, the fact that the RED only mentions the Directive on Access to Environmental Information shows the missed opportunity of fine-tuning the provisions on access to environmental information.

\footnotetext{
${ }^{65}$ European Commission, Assessment Protocol Template (2015a), Section 6.13.

${ }^{66}$ Directive 2003/4, see footnote 33 of Chapter IV.
} 


\subsection{Setting the scene for access to environmental information}

According to the Aarhus Convention and the Aarhus Regulation, rights and obligations regarding access to environmental information can only be exercised if the requested information falls under the definition of environmental information and if this information is requested from or disseminated by public authorities. Therefore, this section examines whether information on biofuels is environmental information and whether the information is held by a public authority.

\subsubsection{The definition of environmental information: Biofuel-related information}

Article 2(1)(d) (i) and (ii) of the Aarhus Regulation mirroring Article 2(3) of the Aarhus Convention provides that “"environmental information' means any information in written, visual, aural, electronic or any other material form on: (i) the state of the elements of the environment, such as air and atmosphere, water, soil, land etc.; and (ii) factors, such as substances, energy, noise, radiation or waste, including radioactive waste, emissions, discharges and other releases into the environment, affecting or likely to affect the elements of the environment[...]".

According to this definition, information on energy, affecting or likely to affect the environment, should be considered environmental information. Biofuels are a source of energy derived from biomass. However, to fall under the definition of environmental information, information on energy also needs to affect or be likely to affect the elements of the environment. A concern about the potential impact of biofuels on the environment (in this case land and atmosphere) is that an increase in biofuels consumption will change the use of the land from the production of local crops to the production of feedstock for biofuels. This change in the use of the land could increase deforestation and lead to extra carbon emissions due to more intensive agricultural use of uncultivated lands. ${ }^{67}$ This phenomenon is known as Indirect Land Use Change (ILUC).

A 2015 study commissioned by the European Commission to evaluate the impact of land use change for biofuels consumed in the EU pointed out that "the total land use change caused by the EU 2020 biofuel mandate is 8.8 Mha (million hectares), of which 8 Mha is new cropland and the remaining $0.8 \mathrm{Mha}$ consists of short rotation plantations on existing cropland. From the 8.8 Mha, 2.9 Mha of conversion takes place in Europe by less land abandonment and 2.1 Mha of land is converted in Southeast Asia under pressure from oil

\footnotetext{
${ }^{67}$ J. Lin, op. cit. (2011), p. 47. H. Valin, D. Peters, M. van den Berg, S. Frank, P. Havlik, N. Forsell, C. Hamelinck, J. Pirker, A. Mosnier, J. Balkovič, E. Schmid, M. Dürauer, and F. di Fulvio, The land use change impact of biofuels consumed in the EU: Quantification of area and greenhouse gas impacts, https://ec.europa.eu/energy/sites/ener/files/documents/Final\%20Report_GLOBIOM_publication.pdf (2015), p. IV.
} 
palm plantation expansion, half of which occurs at the expense of tropical forest and peatland." 68 These results show that the production of biofuels may have an impact on deforestation in response to the increased demand for biofuels. This is only one example of the potentially negative environmental effects of biofuel production ${ }^{69}$ and it is important to bear in mind that there might be different effects depending on the feedstocks used for this production. ${ }^{70}$ In this vein, it is possible to conclude that, in principle, biofuel-related information is environmental information in accordance with the definition of the Aarhus Regulation and the Aarhus Convention (although the qualification needs to be made for every specific request).

3.3.2. The definition of public authority: Commission, evaluator/contractor and recognised voluntary schemes

Having established that biofuel-related information can in principle be qualified as environmental information in accordance with the definition of the Aarhus Regulation and the Aarhus Convention, it is now necessary to examine whether the information is held by a public authority.

Regarding voluntary schemes, there are two levels where the information is held: (i) information held by the European Commission and the evaluator/contractor to assess the voluntary schemes, and (ii) information held by the operator of voluntary schemes for the certification of biofuels. The question that follows (and which is discussed in this section) is whether a legal obligation exists for the Commission, the private operators and operator of voluntary schemes to disseminate and disclose upon request the information held for the purposes of certification and recognition process. Such a question is important, because the duty to provide information is imposed only on public authorities. ${ }^{71}$

The Commission, the evaluator/contractor and the operator of voluntary schemes for the certification of biofuels will only have an obligation to disclose information in case they can be considered public authorities. Article 2(1)(c) of Regulation 1367/2006 defines an EU

\footnotetext{
${ }^{68}$ H. Valin, D. Peters, M. van den Berg, S. Frank, P. Havlik, N. Forsell, C. Hamelinck, J. Pirker, A. Mosnier, J. Balkovič, E. Schmid, M. Dürauer, and F. di Fulvio, The land use change impact of biofuels consumed in the EU: Quantification of area and greenhouse gas impacts, https://ec.europa.eu/energy/sites/ener/files/documents/Final\%20Report_GLOBIOM_publication.pdf (2015), p. IX.

${ }^{69}$ Another example is that using biofuels is a combustion process that releases pollutants into the air.

${ }^{70}$ H. Valin, D. Peters, M. van den Berg, S. Frank, P. Havlik, N. Forsell, C. Hamelinck, J. Pirker, A. Mosnier, J. Balkovič, E. Schmid, M. Dürauer, and F. di Fulvio, The land use change impact of biofuels consumed in the EU: Quantification of area and greenhouse gas impacts, https://ec.europa.eu/energy/sites/ener/files/documents/Final\%20Report_GLOBIOM_publication.pdf (2015), p. IX.

${ }^{71}$ Recital 9, Preamble and Articles 4 and 5, Aarhus Convention.
} 
institution or body as "any public institution, body, office or agency established by, or on the basis of, the Treaty except when acting in a judicial or legislative capacity". Under this definition, only the Commission is considered a public authority.

The Aarhus Convention, however, in Article 2(2), contains a much broader definition of public authority, as it defines as follows:

“(a) Government at national, regional and other level;

(b) Natural or legal persons performing public administrative functions under national law, including specific duties, activities or services in relation to the environment;

(c) Any other natural or legal persons having public responsibilities or functions, or providing public services, in relation to the environment, under the control of a body or person falling within subparagraphs (a) or (b) above;

(d) The institutions of any regional economic integration organization referred to in article 17 which is a Party to this Convention." (Emphasis added)

It is clear that the European Commission falls under alinea $d$. However, it seems that the European Commission also falls under alinea $a$, since the definition is broad enough to encompass institutions from all governmental levels. Therefore, there is no doubt that the European Commission is a public authority in accordance with the Aarhus Convention's definition.

The EU chose not to implement paragraphs $\mathrm{b}$ and $\mathrm{c}$ of the Aarhus Convention in the Aarhus Regulation. Furthermore, the RED does not establish any duty for the evaluator/contractor, and activities by the latter fall directly under the responsibility of the Commission. As far as the activities by the contractor to fulfil the Commission's task prescribed by the RED are concerned, it may be assumed that information can be asked for through the Commission.

For the classification of evaluators/contractors and the recognised schemes, more explanation is needed in order to conclude whether they can be classified as a public authority in light of the Aarhus Convention. The Implementation Guide clarifies that:

"The first key difference between subparagraph (c) and (b) is the source of authority of the person performing public functions or providing public services. It can be distinguished from subparagraph (b) in that the bodies addressed derive their 


\section{authority not from national legislation, but indirectly through their control by those defined in subparagraphs (a) and (b).,"72}

The evaluators/contractors are contracted by the Commission to assess the applications by the operators of voluntary schemes. Therefore, they cannot fall under alinea $b$, since evaluators/contractor derive their tasks from the Commission and not directly from national law (in this case EU law). To fall under alinea $c$, the following requirements need to be fulfilled: i) be a natural or legal person; ii) having public responsibilities or functions, or providing public services, in relation to the environment; and iii) be under control of a body or person falling within alineas $a$ or $b$. First, the evaluators/contractors are private actors who perform supervisory functions (analyses of the technical aspects of schemes) on the basis of a mandate of the European Commission. Second, the technical assessments made by evaluators/contractors are related to the environment, since they evaluate whether the schemes have the tools to demonstrate that biofuels comply with the sustainability criteria. Third, the European Commission is covered by alinea $a$ and has the power - by means of the contract - to exercise control over the evaluators/contractors. A narrow interpretation could lead to the understanding that the evaluators/contractors could not fall under alinea $c$, since the European Commission, which exercises the control, would only fall under alinea $d$, which is not included under the definition in $c$. Under this narrow interpretation, since alinea $c$ refers only to $a$ and $b$, the European Commission as an institution of a regional economic integration organisation would not be a body that could fulfil the condition required under alinea $c$. However, this interpretation would not align with the aim of the Aarhus Convention to provide for access to environmental information. ${ }^{73}$ Moreover, the inclusion of alinea $d$ is a way of broadening the definition rather than narrowing it. By refuting such a narrow interpretation and including the Commission under the definition of alinea a, the evaluators/contractors qualify as public authorities under the Article 2(2)(c) of the Aarhus Convention.

Regarding the question whether the operators of the voluntary schemes can also be qualified as a public authority according to the Aarhus Convention, the following analysis applies. The Renewable Energy Directive confers the power on the Commission to recognise the biofuels voluntary schemes. ${ }^{74}$ The recognised voluntary schemes can then certify biofuels according to the sustainability criteria established in the RED. The Commission derives the authority from the RED, and the biofuels voluntary schemes, in turn, derive their authority from the Commission. Even if the RED establishes the sustainability criteria and allows for the existence of the voluntary schemes, the source of authority emanates indirectly from the RED and directly from the Commission. In the Fish Legal case, the CJEU confirmed that the

\footnotetext{
72 J. Ebbesson, H. Gaugitsch, J. Jendrośka, F. Marshall and S. Stec, op. cit. (2014), p. 47.

${ }^{73}$ Article 1, Aarhus Convention.

${ }^{74}$ Article 18(5), Renewable Energy Directive, consolidated version.
} 
source of authority should come from national legislation in order for natural and legal persons to fall within the category of public authorities under alinea $b .{ }^{75}$ In this vein, the voluntary schemes do not fall under alinea $b$. Alinea $c$ remains to be analysed. As mentioned above, according to alinea $c$, three conditions need to fulfilled: the natural or legal persons have public responsibilities or functions, or provide public services; these public responsibilities or functions, or public services are related to the environment; and the persons are under the control of a body or person falling within subparagraphs (a) or (b).

First, the voluntary schemes are private actors, which perform public tasks (certification of biofuels). The Commission is empowered by the RED to recognise voluntary schemes, which certify biofuels in accordance with the sustainability criteria. ${ }^{76}$ Second, the assessment of the biofuels to certify them as compatible with the sustainability criteria made by the voluntary schemes are related to the environment, since they certify the biofuels that will count towards the renewable energy target. Third, the European Commission, which may be regarded as a person falling under alinea $a$, exercises control over the voluntary schemes.

Even while the schemes conduct the certification process by themselves, the schemes are under the control of the Commission for the following reasons: the Commission can repeal the decisions recognising the schemes $;{ }^{77}$ the Commission may change the requirements for the recognition of the schemes $;^{78}$ the recognised schemes have to report to the Commission regarding its activities (auditing, non-compliance, transparency, stakeholder involvement...). ${ }^{79}$ Consequently, voluntary schemes operated by private actors and recognised by the Commission fall under Article 2(2)(c) of the Aarhus Convention.

After classifying evaluators/contractors and voluntary schemes as public authorities under Article 2(2)(c) of the Aarhus Convention, a last remark needs to be made. The Court held that natural or legal persons falling under similar provisions only have to disclose information that is related to the public environmental service provided. ${ }^{80}$ This conclusion relates to the

\footnotetext{
${ }^{75}$ Note that in this case the Court interpreted Article 2(2) of Directive 2003/4/EC but, since the text is very similar to the text of the Aarhus Convention under examination in this section, the reasoning employed by the Court can be applied to the discussion of the classification of recognised voluntary schemes as public authorities. Case C-279/12, Fish Legal and Emily v. Information Commissioner, United Utilities Water plc, Yorkshire Water Services Ltd, Southern Water Services Ltd, 19 December 2013, ECLI:EU:C:2013:853, para 48.

${ }^{76}$ J. Lin, op. cit. (2011), p. 65.

77 Article 18 (5), Renewable Energy Directive, consolidated version.

78 Article 18 (5), Renewable Energy Directive, consolidated version.

${ }^{79}$ Article 18 (6), Renewable Energy Directive, consolidated version.

${ }^{80}$ Note that in this case the Court interpreted Article 2(2) of Directive 2003/4/EC but since the text is very similar to the text of the Aarhus Convention under examination in this section, the reasoning employed by the Court can be applied to the discussion of the classification of recognised voluntary
} 
fact that the public function of the private entity is limited to the public responsibilities and functions exercised or public services offered. All the other activities will be considered private activities outside the scope of the Aarhus Convention. In practice, the distinction between the activities that derive from private or public functions may, however, be blurred and it may, therefore, be complex to distinguish which environmental information should be disclosed.

\subsection{The dissemination of biofuel-related information}

Having established that biofuel-related information is environmental information and assuming that the Commission, the evaluator/contractor and the recognised schemes fall under the definition of public authorities for the purposes of the Aarhus Convention, this section and the following one focus on the two sides of the right to access environmental information: active (this section 3.4) and passive (section 3.5).

This section will concentrate on the active side by investigating whether there is a legal obligation incumbent upon the European Commission, the evaluator/contractor and the recognised schemes by virtue of the RED, the Aarhus Regulation and the Aarhus Convention to disseminate biofuels related information.

3.4.1. Limited dissemination of biofuel-related information: recognition of voluntary schemes

The decisions taken by the Commission and the documents presented by the applicants for the recognition of voluntary schemes are made available on the transparency platform created according to Article 24 RED. ${ }^{81}$ This EU transparency platform is a website which comprises renewable energy-related information. ${ }^{82}$ However, such documents are only made available after the decisions on the recognition of the schemes have been taken. There is no register in the transparency platform of the application for recognition of biofuels voluntary schemes. In other words, by checking the transparency platform, it is not possible to know how many requests are (at a certain moment) in the pipeline and what the content of these requests is. This means that the public will most likely not know when a procedure for considering a request is taking place, which clearly limits the possibility of the public to request information. Since the Commission takes the decisions on the recognition of voluntary schemes through comitology, the draft decisions are made publicly available in the

\footnotetext{
schemes as public authorities. Case C-279/12, Fish Legal and Emily v. Information Commissioner, United Utilities Water plc, Yorkshire Water Services Ltd, Southern Water Services Ltd, para 83.

${ }^{81}$ Communication from the Commission on voluntary schemes and default values in the EU biofuels and bioliquids sustainability scheme, 2010/C 160/01, OJ C 160/1 (2010b), Section 1.

${ }^{82}$ European Commission. Renewable energy: Moving towards a low carbon economy, 19 June 2020, https://ec.europa.eu/energy/en/topics/renewable-energy.
} 
Comitology Register. ${ }^{83}$ Following the 2017 Better Regulation Guidelines that provide for the four-week feedback on the draft of implementing acts, ${ }^{84}$ in 2017 , for the first time, the Commission gave the opportunity for feedback during the recognition of a biofuels voluntary scheme, ${ }^{85}$ but the Commission did not receive any feedback. ${ }^{86}$ However, these drafts were not accompanied by the documents on which the Commission based its decision. ${ }^{87}$ The question that follows is whether there is a legal obligation for the Commission to disseminate information during the entire recognition process. With regard to this, the following analysis can be provided.

Article 4 of Regulation 1367/2006 requires the EU institutions to disseminate environmental information that is "relevant to their functions and which is held by them". Since it has been already established that biofuel-related information is environmental information, this article is applicable to the Commission. Article 4(2) of the Aarhus Regulation also requires that the databases or register shall include, among others, "authorisation with significant impact on the environment" or "risk assessments concerning environmental elements".

Interestingly, neither Article 4 of the Aarhus Regulation nor Article 5 of the Aarhus Convention (which deals with active dissemination of environmental information) contains requirements regarding the timeframe to make information available. ${ }^{88}$ It means that the fact that the information on the recognition of voluntary schemes is made available only after the decision was taken seems to be in compliance with the Aarhus Regulation and the Aarhus Convention. Despite this, the lack of information since the very beginning of the recognition of voluntary schemes has drawn the attention of an ENGO, which has called for transparency in this process. More precisely, the ENGO recommends that "schemes submitted for recognition are published on the transparency register as soon as their application is received". 89

83 European Commission. Comitology Register - Frequently Asked Questions, 19 June 2020, http://ec.europa.eu/transparency/regcomitology/index.cfm?do=FAQ.FAQ.

${ }^{84}$ Better Regulation "Toolbox" which complements the Better Regulation Guidelines presented in $\operatorname{SWD}(2017) 350$ (2017b), p. 437.

${ }^{85}$ Further information on this feedback can be found here: https://ec.europa.eu/info/law/betterregulation/initiatives/ares-2017-313032_en.

${ }^{86}$ Personal communication via Europe Direct Contact Centre (18 May 2017). [Biofuels voluntary schemes - third answer].

${ }^{87}$ Personal communication via Europe Direct Contact Centre (5 May 2017). [Biofuels voluntary schemes - second answer].

${ }^{88}$ Article 4(2)(f), Aarhus Regulation and Article 5(1), Aarhus Convention. Article 297 TFEU states that "Other directives, and decisions which specify to whom they are addressed, shall be notified to those to whom they are addressed and shall take effect upon such notification."

${ }^{89}$ G. Nastasi, 'Biofuels - Driving best practice in voluntary certification', Client Earth Briefing, (2013), pp. 1-2, p. 2. 
A second issue related to the active dissemination of information to the public by the Commission is the fact that the documents which are made available after the decision to recognise the voluntary schemes is taken have many parts that are blacked out. ${ }^{90}$ It shows that the European Commission treated this information as confidential, but it is not clear which exceptions of the Aarhus Regulation the Commission were relied upon to keep the information confidential. Nevertheless, the blacked-out information may be subject to a request for environmental information. ${ }^{91}$ If the requested information does not fall under one of the exceptions provided in Article 4 of the Aarhus Convention, the information would have to be disclosed. ${ }^{92}$

\subsubsection{Limited dissemination of biofuel-related information: certification of biofuels}

Regarding a decision on the certification of biofuels taken by a voluntary scheme, considering that such a decision can be qualified as "authorisations with significant impact on the environment" or "risk assessments concerning environmental elements", then there would be a legal obligation making to make this decision available to the public according to Article 4 of Regulation 1367/2006. ${ }^{93}$ However, as explained in section 3.3.2, the recognised schemes do not fall under the definition of EU institutions or bodies and therefore the Aarhus Regulation is not applicable.

Nonetheless, considering that actors operating the recognised schemes fall under the definition of public authority under the Aarhus Convention, ${ }^{94}$ the obligations for the dissemination of information will apply. According to Article 5(2) of the Aarhus Convention, there is an obligation for the Parties to ensure, within its national legislation, that public authorities disclose environmental information to the public in a transparent way and that the environmental information is effectively accessible. In this vein, the lack of clear rules in the RED on how the recognised schemes should disseminate information about the certification of biofuels, and the non-applicability of the Aarhus Regulation, shows a breach of Article 5 of the Aarhus Convention by the European Union. ${ }^{95}$

90 See documentation of the voluntary schemes which are available at European Commission. Voluntary schemes, 20 June 2020, https://ec.europa.eu/energy/en/topics/renewableenergy/biofuels/voluntary-schemes.

${ }^{91}$ Article 3, Aarhus Regulation.

${ }^{92}$ Article 6(1), Aarhus Regulation.

${ }_{93}$ Article 4(2)(f) and (g), Aarhus Regulation.

${ }^{94}$ See section 3.3.2 of this chapter.

${ }^{95}$ Moreover, according to Article 3(1) of the Aarhus Convention: "Each Party shall take the necessary legislative, regulatory and other measures, including measures to achieve compatibility between the provisions implementing the information, public participation and access-to-justice provisions in this Convention, as well as proper enforcement measures, to establish and maintain a clear, transparent and consistent framework to implement the provisions of this Convention." 
Even though not all information is made readily available during the application procedure of the recognition of voluntary schemes and the certification of biofuels, in principle, environmental information shall be disclosed upon request, unless an exception applies. ${ }^{96}$ This access to biofuel-related information upon request is discussed in the next section.

\subsection{Requesting biofuel-related information}

This section focuses on the passive form of access to environmental information. The definition of environmental information is broad and it has not yet been crystallised precisely what kind of information is part of the definition and what kind of information falls outside its scope and is, consequently, not covered by provisions on access to environmental information. ${ }^{97}$ Since the array of information that individual and legal persons would like to receive can be manifold, this section will investigate, through the case law of the CJEU, the problems surrounding access to biofuel-related information. The section will use concrete examples to point to the difficulties for ENGOs to access biofuel-related information (sections 3.5.1 and 3.5.2), and it delves into the limits of application of the grounds for refusal to provide environmental information (section 3.5.3) in the context of the recognition of biofuels voluntary schemes.

3.5.1. Delay to disclose information on the application for recognition of biofuels voluntary schemes

Even if there is no registration or information disclosure in the transparency platform of the application for recognition of voluntary schemes, it can happen that a member of the public becomes aware that such a procedure has started. Then, this person might submit a request for information while the schemes are being assessed, trying to get information on, for instance, the application for recognition.

This was what happened with a group of NGOs that discovered during "a conversation with Commission officials that the Commission did not intend to disclose details of the various voluntary certification schemes that had been submitted to it seeking recognition for the purposes described under Article 18 of Directive 2009/28/EC". ${ }^{98}$ This information referred to the first batch of schemes that were recognised in 2011. Due to the potential environmental impact these schemes can have, the NGOs sought, through a formal request under Regulation

\footnotetext{
${ }^{96}$ Article 6, Aarhus Regulation which needs to be read in conjunction with Article 4, Regulation 1049/2001.

${ }^{97} \mathrm{~A}$ further explanation on the definition of environmental information may be found in section 3.3.1 of Chapter III.

${ }^{98}$ ClientEarth, Friends of the Earth Europe, Stichting FERN and Corporate Europe Observatory, 'Application for Annulment under Article 263 of the Treaty on the Functioning of the European Union in Case T-278/11', 2011, http://ec.europa.eu/environment/aarhus/pdf/title_iv/RIR\%20EPS.pdf, p. 13.
} 
1049/2001 and the Aarhus Regulation, to obtain information on the organisations that had applied for recognition of the schemes and all the documents related to the approval of the voluntary certification schemes held by the European Commission. ${ }^{99}$

The Aarhus Regulation, while addressing the right to get access to environmental information upon request, refers to Regulation 1049/2001. According to this Regulation, the public authority shall answer the request within 15 working days, which can be extended for 15 more working days in exceptional cases, such as when the application deals with a very large document. ${ }^{100}$ However, in this case, the Commission did not respect the timeframe set by Regulation 1049/2001. The request was made on 22 October 2010 and on 12 November 2010 the Commission informed the applicants that the period would be extended for another 15 working days. On 7 December 2010, the Commission released only one document which implied a refusal to disclose the other documents. The applicants seeking reconsideration from the Commission to release the documents submitted a confirmatory application in accordance with Article 7(2) of Regulation 1049/2001. ${ }^{101}$ Again the Commission did not respect the time-limit prescribed by Regulation 1049/2001 to answer a confirmatory application, which is also a maximum of 30 working days. ${ }^{102}$ The NGOs exchanged many letters with the Commission expressing their concern with the delay. Faced with the lack of response regarding the release of the documents in time, they started an action for annulment in relation to the implicit refusal of the requested documents. ${ }^{103}$ However, the two-month time limit to start an action for annulment under Article 263 TFEU had already elapsed and the case was found inadmissible. ${ }^{104}$ The applicants argued that the delay to start the action for annulment was due to having to wait for an answer from the Commission. However, the General Court held that the time waiting for an answer from the Commission cannot change the time-limit for bringing actions for annulment, since the time-limit is "a matter of public

\footnotetext{
${ }^{99}$ Article 3, Aarhus Regulation and Article 2, Regulation 1049/2001.

100 Article 7(1) and (3), Regulation 1049/2001.

${ }^{101}$ ClientEarth, Friends of the Earth Europe, Stichting FERN and Corporate Europe Observatory, op. cit. 2011, p. 15. Confirmatory application is the term used in Regulation 1049/2001 to describe the act of the applicant requesting the institution to reconsider its opinion.

102 Article 8(1) and (3), Regulation 1049/2001.

${ }^{103}$ Case T-278/11, ClientEarth, Friends of the Earth Europ Stichting FERN and Stichting Corporate Europe Observatory v. European Commission. This case has been previously discussed by M. Peeters and S. Nóbrega, op. cit. (2014), pp. 361-362.

104 The Court understood that "the contested decision, taking the form of an implied negative decision, was made on 4 February 2011" (Case T-278/11, ClientEarth, Friends of the Earth Europ Stichting FERN and Stichting Corporate Europe Observatory v. European Commission, para 40) and the action was brought on 25 May 2011 (Case T-278/11, ClientEarth, Friends of the Earth Europ Stichting FERN and Stichting Corporate Europe Observatory v. European Commission, para 41).
} 
policy" 105 and is not subject to the discretion of the Parties or the Court. ${ }^{106}$ The Court has not accepted to extend the time-limit for bringing actions for annulment even if the Commission had explicitly extended the time-limit beyond what is allowed by Regulation 1049/2001. It means that, even when the Commission informs an applicant that the time-limits have been extended and the 30 working days have passed, the Court will understand this extension as invalid and the extension cannot be used by the applicant to justify the delay in bringing an action for annulment. ${ }^{107}$

The NGOs finally received the information in September 2011, almost 11 months after the initial request (October 2010) and, notably, after the decisions on the voluntary schemes had been taken (July 2011). ${ }^{108}$ This delay from the European Commission in disclosing the information clearly hindered the access to information right. Unfortunately, however, the Court ruling does not shed any light on the obligation to provide such information within the prescribed time, since the case was found to be inadmissible. ${ }^{109}$ The NGOs also did not bring a complaint before the Compliance Committee of the Aarhus Convention which could have analysed whether the behaviour of the Commission was in compliance with the Convention.

\subsubsection{Delay to disclose information on studies on the impact of biofuels}

In addition to the reporting obligations prescribed in Article 17 RED which were explained in section 2, the European Commission has to report about two important topics which are not included in the biofuel sustainability criteria: indirect land use change and on

${ }^{105}$ Case T-278/11, ClientEarth, Friends of the Earth Europ Stichting FERN and Stichting Corporate Europe Observatory v. European Commission, para 30.

${ }^{106}$ Case T-278/11, ClientEarth, Friends of the Earth Europ Stichting FERN and Stichting Corporate Europe Observatory v. European Commission, para 31.

107 Cases T-494/08 to T-500/08 and T-509/08, Ryanair Ltd v. European Commission, 10 December 2010, ECLI:EU:T:2010:511, para 39 and 40.

It is remarkable that no consideration by the Court has been given to the fact that the behaviour of the Commission has created a state of uncertainty regarding the disclosure of information. This is even more remarkable in light of the Court's different approach concerning similar conduct by national authorities. In the Santex case, for example, the Court of Justice ruled that, taking into consideration the particularities of the case and despite the fact that the parties were aware of the publication of a notice of invitation to tender: "the contracting authority created, by its conduct, a state of uncertainty as to the interpretation to be given to that clause and that that uncertainty was removed only by the adoption of the exclusion decision" (Case C-327/00, Santex SpA v. Unità Socio Sanitaria Locale n. 42 di Pavia, 27 February 2003, ECLI:EU:C:2003:109, para 58). This justified, in the view of the Court, the need for the referring national court to set aside a national time limit for action and hold the action admissible.

${ }^{108}$ L. Krämer, 'The EU, access to environmental information and the open society' 14(4) ERA Forum, (2013), pp. 463-474, p. 472.

${ }^{109}$ Case T-278/11, ClientEarth, Friends of the Earth Europ Stichting FERN and Stichting Corporate Europe Observatory v. European Commission, para 47. 
requirements for the sustainability of solid and gaseous biomass used for electricity, heating and cooling. ${ }^{110}$

With regard to the sustainability of solid and gaseous biomass for electricity, heating and cooling, there were no binding criteria at the EU level until the recast of the Renewable Energy Directive in December 2018. ${ }^{111}$ Under the recast Renewable Energy Directive, the EU sustainability criteria have been extended to cover biomass fuels for electricity, heating and cooling, and Member States have to transpose these rules until 30 June 2021. ${ }^{112}$

With regard to Indirect Land Use, the 2010 Report on Indirect Land Use Change issued by the European Commission recognised that indirect land use change may have an impact on GHG emissions savings of biofuels. ${ }^{113}$ Before this report was published, a group of NGOs requested access to the studies on which the findings of the report were based. More precisely, ClientEarth, the European Federation for Transport and Environment, the European Environment Bureau and BirdLife International in two separated cases requested: (i) access to all documents related to the modelling of the impacts of indirect land-use change caused by the augmentation of biofuels production; ${ }^{114}$ and (ii) access to drafts of a report entitled Global Trade and Environmental Impact of the EU biofuels mandate. ${ }^{115}$ For instance, the Global Trade and Environmental Impact of the EU biofuels mandate, ${ }^{116}$ which is one of the studies used in the elaboration of the 2010 Report on Indirect Land Use Change, was concluded in March 2010 and the NGOs requested access to this information in April 2010. They only got access to part of the documents on 6 December 2010 and the report which was

110 Article 19(6) states that "the Commission shall, by 31 December 2010, submit a report to the European Parliament and to the Council reviewing the impact of indirect land-use change on greenhouse gas emissions and addressing ways to minimise that impact”. Article 17(9) provides that "the Commission shall report on requirements for a sustainability scheme for energy uses of biomass, other than biofuels and bioliquids, by 31 December 2009”. The Commission may also propose new rules: a concrete methodology for emissions from carbon stock changes caused by indirect land-use changes (Article 19(6)); and a sustainability scheme for other energy uses of biomass (Article 17(9)). ${ }^{111}$ European Commission, Report from the Commission to the European Parliament, the Council on sustainability requirements for the use of solid and gaseous biomass sources in electricity, heating and cooling (COM(2010)11 final), (2010d), pp. 8-9. T. Yue, op. cit. (2016), p. 114. M. Peeters, op. cit. (2014), p. 179.

${ }^{112}$ Article 29 of Directive 2018/2001 establishes the sustainability of greenhouse gas emissions saving criteria for biofuels, bioliquids and biomass fuels.

${ }^{113}$ European Commission, Communication from the Commission to the European Parliament, the Council, the European Economic and Social Committee and the Committee of the Regions - Energy Efficiency Plan 2011, COM(2011) 109 final (2010c), p. 14.

${ }^{114}$ Case T-120/10, Client Earth and others v. Commission, para 5.

115 Case T-449/10, ClientEarth and others v. Commission, para 9.

116 P. Al-Rifai, B. Dimaranan and D. Laborde, Global trade and environmental impact of the EU biofuels mandate (2010). 
based on these documents was released on 22 December $2010 .{ }^{117}$ This means that there was no possibility for the NGOs to have access to these documents during the preparation of the report by the Commission.

Again, the Commission did not respect the time-limit to provide the requested information provided in Regulation 1049/2001 ${ }^{118}$ and the applicants considered the non-response of the Commission as an implied negative reply. ${ }^{119}$ The applicants requested the General Court to annul the implied decisions but, before the ruling of Court, the Commission granted access to part of the documents. However, it refused access to other parts on the grounds that this would undermine the protection of commercial interests. ${ }^{120}$ The Court held that the Commission's decisions "in fact withdrew"121 the implied decisions which consequently no longer existed, and there was no need to adjudicate on the actions. ${ }^{122}$ The cases could have received a different ruling if the applicants had amended the form of order sought, i.e., if they had requested the Court to rule on the explicit decision of the Commission. Since the applicants did not amend the form of order sought, they would have had to initiate a new case if they had wished to challenge the new decision of the Commission, which partially withheld the requested information. Since the cases were not further adjudicated, it has not become clear whether it is possible to make the Commission accountable for not providing the requested information within the prescribed time-limits. Meanwhile, the European Ombudsman reached the conclusion that such behaviour amounts to maladministration. ${ }^{123}$

\footnotetext{
117 Case T-449/10, ClientEarth and others v. Commission, para 11.
}

118 According to Regulation 1049/2001, the EU institutions must answer a request for information within 15 working days (Article 7(1)). In exceptional cases, this period can be extended for 15 more working days (Article 7(3)). For requests related to environmental information, Regulation 1049/2001 has to be read in combination with the Aarhus Regulation. The definition of document in Regulation 1049/2001 encompasses environmental information as defined in the Aarhus Regulation.

${ }^{119}$ Article 8(3), Regulation 1049/2001 states: "Failure by the institution to reply within the prescribed time-limit shall be considered as a negative reply and entitle the applicant to institute court proceedings against the institution and/or make a complaint to the Ombudsman, under the relevant provisions of the EC Treaty" (Emphasis added).

120 The Commission refers to the first indent of Article 4(2) of Regulation 1049/2001. Case T-449/10, ClientEarth and others v. Commission, para 11.

${ }^{121}$ Case T-120/10, Client Earth and others v. Commission, para 52; Case T-449/10, ClientEarth and others v. Commission, para 39.

${ }^{122}$ Case T-120/10, Client Earth and others v. Commission, para 51 and 56; Case T-449/10, ClientEarth and others v. Commission, para 38 and 43.

${ }^{123}$ Decision of the European Ombudsman Closing His Inquiry into Complaint 339/2011/AN against the European Commission (19 January 2012), found at: http://www.ombudsman.europa.eu/en/cases/decision.faces/en/11193/html.bookmark. In the event of a total or partial refusal, the applicant may institute court proceedings against the institution and/or make a complaint to the Ombudsman, in accordance with the conditions laid down in Articles 263 TFEU and 228 TFEU, respectively (see Case T-120/10, Client Earth and others v. Commission, para 35). See also 
However, there is no sanction on the basis of a finding of the Ombudsman to force the Commission to act within the timeframe. ${ }^{124} \mathrm{~A}$ way of forcing the Commission to respect the time-limits would be if the Court would establish that the non-compliance with the time for disclosure constitutes a negative answer that cannot be overruled by later disclosure. ${ }^{125}$ The Court has nevertheless understood that "annulment of the implied decisions on grounds of a procedural defect could do no more than give rise to new decisions, identical in substance to the express decisions." 126 The only remaining effort to give effect to the time-limits would be to start an action for damage pursuant to Article 340 TFEU, as it has already been suggested by the General Court that: "Compensation for any loss occasioned by failure to comply with the time-limits for responding can be sought before the General Court, in the context of an action for damages." ${ }^{127}$ However, the potential success of an action for damages brought by an NGO is very limited since "an environmental organization is hardly able to prove damage, when it could not pursue its statutory objectives, due to the fact that it could not accede to information." 128

A new study on the ILUC effect commissioned by the European Commission was also not released by the time of the consultation on the Preparation of a new Renewable Energy Directive for the period after 2020 which was closed on 10 February $2016 .{ }^{129}$ Although, as was reported, the Commission had the study for at least seven months, ${ }^{130}$ the study was released only in March 2016 after the request from the Members of the European Parliament. ${ }^{131}$ It shows that the behaviour of the Commission has not changed even after the considerations of the Ombudsman and the cases brought before the CJEU by NGOs.

Case T-111/11, ClientEarth v. Commission, in which it was decided that the administration does not lose its power to respond to an application, even outside the time-limits laid down for that purpose (para 119).

${ }^{124}$ L. Krämer, op. cit. (2013), p. 471.

${ }^{125}$ L. Krämer, op. cit. (2013), p. 471.

${ }^{126}$ Cases T-494/08 to T-500/08 and T-509/08, Ryanair Ltd v. European Commission, para 46.

127 Joined Cases T-355/04 and T-446/04, Co-Frutta Soc. Coop. v. Commission, 19 January 2010, ECLI:EU:T:2010:15, para 60.

${ }^{128}$ L. Krämer, op. cit. (2013), p. 471.

129 Information about the public consultation can be found here: https://ec.europa.eu/energy/en/consultations/preparation-new-renewable-energy-directive-periodafter-2020

130 G. Gotev. Late publication of biofuels study raises questions, 16 March 2016, https://www.euractiv.com/section/energy/news/late-publication-of-biofuels-study-raises-questions/.

131 G. Gotev. Late publication of biofuels study raises questions, 16 March 2016, https://www.euractiv.com/section/energy/news/late-publication-of-biofuels-study-raises-questions/. 


\subsubsection{Exception for disclosure to protect commercial interest}

In all the three cases dealing with access to biofuel-related information mentioned above, ${ }^{132}$ the European Commission, applying the first indent of Article 4(2) of Regulation No $1049 / 2001$, refused access to environmental information under the argument that the disclosure would undermine the protection of commercial interests. ${ }^{133}$ However, since two of the cases were not adjudicated and one was found inadmissible, there is no clarification on the application of the exception which allows the non-disclosure of information in order to protect commercial interests. ${ }^{134}$ However, although not dealing with biofuels, the Stichting Greenpeace Nederland case clarifies the issue regarding the application of the exception to protect commercial interests in cases where the request for environmental information deals with emissions into the environment. ${ }^{135}$

In 2010, Greenpeace and Pesticide Action Network Europe sought access to documents relating to the authorisation for the placing on the market of glyphosate for use in plant protection products under Directive 91/414. They wanted to access information on the "detailed chemical composition of the active substance produced by each of them, detailed information concerning the process by which each of them produced the substance, information on the impurities, the composition of the finished products and the contractual relations between the various operators which had sought the inclusion of glyphosate". ${ }^{136}$ The Commission refused the disclosure of the requested information on the basis of the exception in the Aarhus Regulation that allows for the protection of commercial interests (Article 6(1) of the Aarhus Regulation that must be read in combination with Article 4(2) Regulation 1049/2001). However, the same provision provides for an absolute obligation for disclosure if the information relates to emissions into the environment. As already discussed

\footnotetext{
132 Case T-120/10, Client Earth and others v. Commission, Case T-449/10, ClientEarth and others v. Commission and Case T-278/11, ClientEarth, Friends of the Earth Europ Stichting FERN and Stichting Corporate Europe Observatory v. European Commission.

${ }^{133}$ Case T-120/10, Client Earth and others v. Commission, para 18; Case T-449/10, ClientEarth and others v. Commission, para 11. ClientEarth, Friends of the Earth Europe, Stichting FERN and Corporate Europe Observatory, op. cit. 2011, p. 14. Article 4(2) of the Regulation 1049/2001 was mostly used in combination with Article 4(3) which allows the non-disclosure of documents in case it would undermine the institution's decision making process, if there is no overriding public interest in the disclosure.

${ }^{134}$ Article 4(2), Regulation 1049/2001. In Cases T-120/10 and T-449/10, the court decided there was no need to adjudicate (para 52 and para 39, respectively); and in Case T-278/11, the court found the action manifestly inadmissible (para 47).

${ }^{135}$ Case C-673/13 P European Commission v. Stichting Greenpeace Nederland and other.

${ }^{136}$ Case T-545/11, Stichting Greenpeace Nederland and other v. European Commission, 8 October 2013, ECLI:EU:T:2013:523, para 7.
} 
in Chapter IV, section 3.3.2, ii, a.2, the Court of Justice ruled that emissions into the environment encompass actual and potential emissions but not hypothetical ones. ${ }^{137}$

Although the Stichting Greenpeace Nederland case deals with plant protection products and not with biofuels, it does clarify the concept of emissions into the environment which can be applied to the discussion of the release of any kind of emission into the environment. By analogy, it is possible to say that, in the biofuels cases discussed so far, all information related to GHG emissions saving from the use of biofuels, including modelling for such a calculation, shall be made available, since, with this information, it is possible to determine the emissions into the environment produced by biofuels.

\subsection{Interim conclusion}

The purpose of this section was three-fold: first, it examined the legal framework for access to biofuel-related information; second, it investigated current and potential legal problems for access to biofuel-related information; third, it determined whether the legislative framework is in compliance with the Aarhus Convention. This interim conclusion summarises the findings.

Section 3.3 demonstrated that biofuel-related information can be considered environmental information within the scope of Article 2(1)(d)(ii) of the Aarhus Regulation, since it is information on energy affecting or likely to affect the environment. Section 3.3 also argued that, even though the evaluator/contractor hired by the Commission to help with the recognition of voluntary schemes and the voluntary schemes themselves do not fall under the Aarhus Regulation definition of public authority, they should be considered as public authorities according to Article 2(2)(c) of the Aarhus Convention, because they are legal persons having public responsibilities or functions under the control of the European Commission. As a consequence, they are subject to the obligation to disseminate and to provide biofuel-related information upon request. Such an interpretation shows that the EU, by limiting public authorities to EU institutions and bodies, has not sufficiently transposed the Aarhus Convention.

Having established that biofuel-related information is environmental information and that the European Commission, the evaluator/contractor and the voluntary schemes themselves are public authorities according to the Aarhus Convention, section 3.4 proceeded to examine the active form of access to environmental information. More precisely, it investigated which biofuel-related information has been made available to the public and if this published information would fulfil the obligations provided by the Aarhus Regulation and the Aarhus Convention. With respect to information held by the European Commission, there is no

${ }^{137}$ Case C-673/13 P European Commission v. Stichting Greenpeace Nederland and other, para 71. See also V. A. Buonsante and A. Friel, op. cit. (2017), p. 457. 
register in the transparency platform of the application for the recognition of voluntary schemes. However, the Commission discloses these documents used for the recognition of the schemes (with some blacked-out parts) via its transparency platform after the decision is taken. The post-decision publication of the decision can still be considered in compliance with the provisions to disseminate information of the Aarhus Regulation and the Aarhus Convention, since the applicable provisions do not prescribe a timeframe for doing so. ${ }^{138}$ However, the way the information is made available leads to two conclusions: (i) the nonregistration in the transparency platform of the application for the recognition of voluntary schemes means that there is no proper early access to information in the procedure for the recognition of voluntary schemes; and (ii) despite the fact that the draft decision is published on the Comitology Registry and there is an opportunity for feedback on the Commission's draft decision, this participation is limited, since there is no access to the scheme documents on which the Commission based its decision. ${ }^{139}$ Whether this procedure is in breach of the right to participate in the decision making process set out in the Aarhus Convention, which stipulates an obligation for effective public participation at an appropriate stage, is discussed further in section 4 .

Concerning the information made available by voluntary schemes, the current Commission's recognition template includes a section on the transparency of the schemes. ${ }^{140}$ This improves the previous situation where there was no mention of transparency standards. Pursuant to Directive 2015/1513, there is an obligation for the voluntary schemes to report to the Commission on many different aspects on the operation of the schemes, including on transparency and stakeholder involvement. ${ }^{141}$ The Commission has to analyse these reports, reviewing the operation of recognised voluntary schemes and identifying best practices and report to the Council and the Parliament. ${ }^{142}$ However, these are only reporting obligations. In contrast, for standards of independent auditing, the Commission may, based on a risk analysis or on these reports, set new standards and require all voluntary schemes to apply those standards. ${ }^{143}$ If the voluntary scheme does not comply with the standards of independent auditing, the Commission may repeal decisions recognising voluntary schemes, which do not comply with the new standards within a prescribed timeframe. ${ }^{144}$ Interestingly, the standard of transparency and reliability did not receive the same treatment. This illustrates the low

138 However, the application of public participation requirements may oblige the disclosure of information at an early stage of the decision making process. For further discussion, see section 4.4.1.

139 The participation will still be limited since "the scheme documents are not published at this stage". Personal communication via Europe Direct Contact Centre (5 May 2017). [Biofuels voluntary schemes - second answer].

${ }^{140}$ European Commission, Assessment Protocol Template (2015a), Section 6.13.

${ }^{141}$ Article 18(6)(d), Renewable Energy Directive, consolidated version.

142 Article 18(6), Renewable Energy Directive, consolidated version.

${ }^{143}$ Article 18(5), Renewable Energy Directive, consolidated version.

${ }^{144}$ Article 18(5), Renewable Energy Directive, consolidated version. 
weight that the EU legislator apparently gives to transparent decision making, also when important environmental decision making, such as assessing the sustainability of biofuels, is outsourced to private actors.

Subsequently regarding the analysis of the active form of access to information, section 3.5 focused on the passive form of access to environmental information. Analysis of case law from the CJEU revealed that the Commission did not respect the prescribed deadlines which amounted to a delay on the disclosure of biofuel-related information. Every single applicant was an NGO with no case so far brought by individuals or by the industry sector. Since the first case before the CJEU dealing with voluntary schemes related information, 14 voluntary schemes have been approved. ${ }^{145}$ However, there are no further cases before the CJEU or any Communication before the ACCC by any member of the public, despite the fact that the recognition process has not changed much since then.

\section{Public participation in voluntary schemes decision making}

\subsection{Introduction}

The purpose of this section is to analyse which obligations the current legal framework provides in terms of public participation for the recognition of biofuels voluntary schemes at the EU level and the certification of biofuels by these recognised schemes. This analysis also includes the identification of the current and potential obstacles individuals and NGOs may face while trying to participate in these processes and whether the current legal framework complies with the obligations imposed by the Aarhus Convention.

The Renewable Energy Directive allows the Commission to adopt decisions regarding the recognition of biofuels voluntary schemes, and these recognised schemes can, in turn, certify biofuels in accordance with the sustainability criteria. Section 4.2 investigates whether the Renewable Energy Directive requires public participation during the decision making process for the adoption of decisions on the recognition of voluntary schemes and certification of biofuels. Since the decision on the recognition of biofuels voluntary schemes is a measure adopted by an EU institution and the decision on the certification of biofuels is adopted by these recognised schemes to which the Commission has delegated its power, section 4.3 examines to what extent the Aarhus Regulation, which implements the Aarhus obligations of EU bodies and institutions, provides a framework for public participation during the adoption of these decisions. Section 4.4 explores if, according to the Aarhus

\footnotetext{
145 These approvals include voluntary schemes that made the application for the first time and those that had their decision expire after the five-year period validity. See: Memo: Certification schemes for biofuels. European Commission. Voluntary schemes, 19 June 2020, https://ec.europa.eu/energy/en/topics/renewable-energy/biofuels/voluntary-schemes.
} 
Convention, obligations regarding public participation remain for the Commission and the recognised schemes.

\subsection{Public participation under the Renewable Energy Directive}

The RED does not provide any specific provision on public participation that applies to all provisions of the Directive. As mentioned in section 3.2, the RED does state that the implementation of the Directive should reflect, where relevant, the provisions of the Aarhus Convention, "in particular as implemented through Directive 2003/4/EC [...]". ${ }^{146}$ Hence while the RED refers to the Directive on Public Access to Environmental Information, it does not refer to the secondary EU legislation on public participation. ${ }^{147}$ Also, the RED does not refer to the Aarhus Regulation which implements the provisions of the Aarhus Convention vis-à-vis the European institutions and bodies.

As identified above, there is no general provision on public participation in the RED, which applies to all measures adopted within the scope of the RED. In this vein, the following step is to analyse if specific provisions will require public participation. Given that this research focuses on the EU level, the analysis concentrates on the measures which are adopted as a consequence of the powers conferred on EU institutions by the RED. Article 18 (4) of the RED gives the Commission the power to adopt decisions regarding the recognition of the voluntary certification schemes. ${ }^{148}$ Article 18(6) of the RED states that the recognition of voluntary schemes shall be adopted in accordance with the examination procedure referred to in Article 25(3) which refers to the Comitology Regulation. ${ }^{149}$ The comitology procedure is a system of procedures for control by Member States of the Commission's exercise of its implementing powers and does not foresee any rule for public participation. ${ }^{150}$

European Commission Communication 160/01 on the recognition of voluntary schemes also does not foresee any possibility for public participation. The communication intends to show the steps the Commission will take to adopt these decisions and to provide information for

\footnotetext{
146 Recital 90, Preamble, Renewable Energy Directive, consolidated version.

147 Directive 2003/35/EC of the European Parliament and of the Council providing for public participation in respect of the drawing up of certain plans and programmes relating to the environment and amending with regard to public participation and access to justice Council Directives 85/337/EEC and 96/61/EC, OJ L156/17.

${ }^{148}$ Article 18 (4), subparagraph 2, Renewable Energy Directive, consolidated version.

${ }^{149}$ Article 18 (6), Renewable Energy Directive, consolidated version. The RED has also been amended in order to align the implementing and delegated powers conferred upon the Commission to Articles 290 and 291 TFEU. Recital 29, Preamble, Directive (EU) 2015/1513.

${ }^{150}$ H. C. Hofmann, G. C. Rowe and A. H. Türk, Administrative law and policy of the European Union: Oxford University Press, 2011), p. 400. G. Winter, 'Theoretical Foundations of Public Participation in Administrative Decision-Making', in G. D. Bándi (ed.), Environmental democracy and law: public participation in Europe, (Groningen: Europa Law Publishing, 2014), pp. 21-36, p. 33.
} 
Member States, third countries, economic operators, and non-governmental organisations; ${ }^{151}$ but none of these steps includes requirements for public participation during the recognition process of the voluntary schemes. ${ }^{152}$ Once a voluntary scheme is recognised by the Commission, the scheme is authorised to certify biofuels in accordance with the sustainability criteria. ${ }^{153}$ The RED requires that the recognised schemes meet adequate standards of reliability, transparency and independent auditing, but it does not define such standards. ${ }^{154}$ The Communication also does not include among these standards the requirement for public participation to be followed by the voluntary schemes during the certification of biofuels. The template used by the Commission for the assessment of the voluntary schemes details what exactly is checked by the Commission. ${ }^{155}$ However, the template does not contain any requirement regarding public participation that would be taken into consideration by the Commission during the recognition process.

Pursuant to Directive 2015/1513, there is an obligation for the voluntary schemes to report to the Commission on many different aspects on the operation of the schemes. The only obligation regarding public participation for the recognised schemes is to report on the "stakeholder involvement, particularly as regards the consultation of indigenous and local communities prior to decision making during the drafting and reviewing of the scheme as well as during audits and the response to their contributions". ${ }^{156}$ Therefore, the voluntary scheme has no legal obligation to provide for public participation during the certification process of biofuels.

\subsection{The Aarhus Regulation and the recognition of voluntary schemes}

Since neither the RED nor the Communication on the recognition of voluntary schemes provides for public participation, it is necessary to investigate if the Aarhus Regulation provides any obligation regarding the decisions on the recognition of voluntary schemes and the certification of biofuels.

\footnotetext{
${ }^{151}$ Communication from the Commission on voluntary schemes and default values in the EU biofuels and bioliquids sustainability scheme, 2010/C 160/01, OJ C 160/1 (2010b), Section 1.

152 The assessment and recognition process is described in Section 2.1, Communication from the Commission on voluntary schemes and default values in the EU biofuels and bioliquids sustainability scheme 2010/C 160/01, OJ C 160/1 (2010b). The words "public", "public participation" and "consultation" are not even mentioned in the text of the Communication.

153 Article 18(4) second subparagraph, Renewable Energy Directive, consolidated version. Communication from the Commission on voluntary schemes and default values in the EU biofuels and bioliquids sustainability scheme, 2010/C 160/01, OJ C 160/1 (2010b), Section 2.1.

154 Article 18(5), Renewable Energy Directive, consolidated version.

${ }^{155}$ European Commission, Assessment Protocol Template (2015a).

${ }^{156}$ Article 18(6)(d), Renewable Energy Directive, consolidated version.
} 
As discussed in Chapter III, although the Aarhus Regulation (in its Article 9) was meant to implement all obligations which derive from the Aarhus Convention for EU institutions and bodies, regarding public participation, this regulation only partially implements Article 7 of the Aarhus Convention. ${ }^{157}$ This means that Articles 6 and 8 have not been implemented at all by the Aarhus Regulation.

According to Article 9 of the Aarhus Regulation, "plans and programmes relating to the environment" are subject to public participation. Plans and programmes relating to the environment are plans and programmes which fulfil the cumulative conditions of Article 9 of the Aarhus Regulation: i.e. those measures (i) which are adopted by EU institutions or bodies; and (ii) which are required by law or administrative provisions; and (iii) which contribute to achieving the objectives of the EU environmental policy. ${ }^{158}$

The decision to recognise a biofuels voluntary scheme is adopted by an EU institution - in this case the Commission - which is required by law, the RED. It contributes to the objectives of EU environmental policy, since it is part of the measures to achieve the EU's renewable energy target. However, can the Commission's decision on the recognition of voluntary schemes be considered a plan or programme? Formally, a decision on the recognition of voluntary certification is not a plan or a programme since it is not titled as such. Substantively, it is necessary to analyse if the measure falls under what can be understood, according to the Aarhus Regulation, as plans and programmes. Since the Aarhus Regulation sets the criteria for plans and programmes relating to the environment but it does not define plans and programmes, it was determined in Chapter III that the possible interpretation of plan and programmes is "an organised and co-ordinated system in order to reach certain objectives". ${ }^{159}$ The decision on the recognition of a voluntary scheme is not per se a system but rather a specific measure (a scheme), which is an option that producers of biofuels may use to prove compliance with the sustainability criteria. Also in view of the implementation of the Renewable Energy Directive, the decision on the recognition of voluntary schemes does not intend to propose how the objectives of the Directive are going to be implemented or carried out, but it is rather one possible step for the achievement of the renewable energy targets. Since the decision is not a plan, neither formally nor substantially, it does not fall under the scope of Article 9 of the Aarhus Regulation.

\footnotetext{
${ }^{157}$ D. Obradovic, 'EU Rules on Public Participation in Environmental Decision-Making Operating at the European and National Levels' The Aarhus Convention at Ten: Interactions and Tensions Between Conventional International Law and EU Environmental Law, (Groningen: Europa Law Publishing, 2011), pp. 149-187, p. 159. For further explanation, see Chapter III, section 6.4.

158 Article 2 (e), Aarhus Regulation. L. Krämer, op. cit. (2015), p. 90.

${ }^{159} \mathrm{An}$ in-depth discussion of the definition of plans and programmes has already been presented in Chapter III, section 6.4.
} 
Regarding the certification of biofuels as sustainable by the voluntary schemes, the voluntary schemes do not fall under the narrow definition of EU institutions or bodies and therefore the Aarhus Regulation will not be applicable in this case. ${ }^{160}$ Consequently, for both types of decision, there is no obligation for public participation under the Aarhus Regulation. Of course, it is possible that obligations for public participation may stem from the Aarhus Convention. This will be examined in the next section.

4.4. Public participation in the recognition process of voluntary schemes and the certification of biofuels: an analysis of the compatibility with the Aarhus Convention $^{161}$

The participatory rights of the Aarhus Convention are laid down in Articles 6, 7 and 8. In order to choose the right legal basis for public participation under the Aarhus Convention, it is important to define the nature of the decisions on the recognition of the voluntary schemes. ${ }^{162}$ Thus, this section will first analyse if the decision can be considered a specific activity, a plan, programme or policy, an executive regulation, and/or other generally applicable legally binding normative instrument. Once the right provision is found, a discussion on the possible legal requirements for public participation will follow, accompanied by a compliance check by the public authorities with the Aarhus requirements.

\subsubsection{Public participation in decisions on specific activities}

i. Scope of application

a) What are specific activities or proposed activities?

The title of Article 6 of the Aarhus Convention refers to decisions on specific activities, while alineas $a$ and $b$ refer to decisions on proposed activities. Despite this difference, it seems that the terms specific activities and proposed activities have the same function: to define which kind of activities the article is referring to. However, neither proposed activities nor specific activities are terms defined in the Aarhus Convention.

\footnotetext{
${ }^{160}$ Article 2(1)(c), Aarhus Regulation defines Community institution or body as "any public institution, body, office or agency established by, or on the basis of, the Treaty except when acting in a judicial or legislative capacity." At the time of the adoption of the Aarhus Regulation, it was the European Community and therefore the definition refers to Community institutions or body.

161 As discussed in section 3.3.2, the Commission, the evaluator/contractor and the operator of the recognised schemes are public authorities according to the broad definition of the Aarhus Convention. Therefore, the public participation requirements of the Aarhus Convention apply and will be discussed in this section.

162 J. Jendrośka, op. cit. (2009), p. 504.
} 
Paragraph 1 of Article 6 states which activities are subject to the public participation requirements and divide these activities in two alineas ( $a$ and $b$ ). Alinea $a$ refers to the activities listed in Annex I of the Aarhus Convention. Article 6 of the Aarhus Convention was drafted based on Directive 85/337 (the old EIA Directive) ${ }^{163}$ and the Integrated Pollution Prevention and Control (IPPC) Directive ${ }^{164}$ (by now replaced by the Industrial Emissions Directive). ${ }^{165}$ Although the list of Annex I of the Aarhus Convention and the one in the EIA Directive are not identical, they are very similar. ${ }^{166}$ It shows that the provision focuses on projects that require approval, via a permit, since they are already predetermined as presumably having a significant effect on the environment. The ACCC, while deciding whether an activity would fall under Article 6 or Article 7, stated that an Article 6-type decision is the one related to "the carrying out of a specific annex I activity in a particular place by or on behalf of a specific applicant". ${ }^{167}$

Alinea $b$ refers to "proposed activities not listed in Annex I which may have a significant effect on the environment". Here the lack of a definition of specific activities becomes more significant, since there is no list to check which activities are included. As explained in Chapter IV of this thesis, ${ }^{168}$ the Implementation Guide to the Aarhus Convention suggests that a source of inspiration can be the definition for the term proposed activity found in the Espoo Convention: "any activity or any major change to an activity subject to a decision of a competent authority in accordance with an applicable national procedure". ${ }^{169}$ As to the

${ }^{163}$ Council Directive 85/337/EEC of 27 June 1985 on the assessment of the effects of certain public and private projects on the environment, OJ L 175/40. The original Directive of 1985 and its three amendments have been codified by Directive 2011/92/EU of the European Parliament and of the Council of 13 December 2011 on the assessment of the effects of certain public and private projects on the environment (codification), OJ L 26/1. Directive 2011/92/EU has been amended in 2014 by Directive 2014/52/EU of the European Parliament and of the Council of 16 April 2014 amending Directive 2011/92/EU on the assessment of the effects of certain public and private projects on the environment, OJ L 124/1.

${ }^{164}$ Council Directive 96/61/EC of 24 September 1996 concerning integrated pollution prevention and control, OJ L 257/26. This Directive was repealed with effect from 7 January 2014 by the Industrial Emissions Directive.

165 J. Jendrośka, 'Public Participation under Article 6 of the Aarhus Convention: Role in Tiered Decision-Making and Scope of Application', in G. Bándi (ed.), Environmental democracy and law: public participation in Europe, (Groningen: Europa Law Publishing, 2014), pp. 113-138, p. 118. J. Ebbesson, H. Gaugitsch, J. Jendrośka, F. Marshall and S. Stec, op. cit. (2014), p. 6.

166 A. Alemanno, 'Unpacking the Principle of Openness in EU Law: Transparency, Participation and Democracy’ 39(1) European Law Review, (2014), pp. 72-90, p. 122.

${ }^{167}$ Alliance for the Protection of the Vlora Gulf with regard to compliance by Albania UN Doc. ECE/MP.PP/C.1/2007/4/Add.1, 31 July 2007, para 67. J. Jendrośka, op. cit. (2014), p. 122.

${ }^{168}$ See section 4.4.1 of Chapter IV.

${ }^{169}$ Article 1(v), Espoo Convention. J. Ebbesson, H. Gaugitsch, J. Jendrośka, F. Marshall and S. Stec, op. cit. (2014), p. 131. 
question of the application of Article 6 of the Aarhus Convention, the Compliance Committee to the Aarhus Convention has already decided that: "The extent to which the provisions of article 6 apply [...] depends inter alia on the extent to which the [decisions] can be considered 'decisions on specific activities', that is, decisions that effectively pave the way for specific activities to take place." ${ }^{170}$ (Emphasis added) Moreover, the Implementation Guide states that the decision making under Article 6 results in directions only to those involved in the particular matter before the authority (such as permits, authorisations or any other required administrative procedures). ${ }^{171}$

Based on the aforementioned observations, it is possible to construct the definition of specific activities as those that are subject to a decision of a competent authority to allow for such an activity to take place and this decision is only addressed to those involved. The characteristic of the decision being addressed only to parties involved is fundamental for a clear-cut distinction with Article 8 of the Aarhus Convention, which encompasses decisions of a general scope. The Implementation Guide states that the term proposed activities is "broad enough to cover both the terms project in the EIA Directive and installation used by the Industrial Emissions Directive." 172 By referring to the old EIA Directive and the Integrated Pollution Prevention and Control Directive (by now replaced by the Industrial Emissions Directive), the line of reasoning presented by the Aarhus Convention Compliance Committee seems to favour the interpretation that Article 6(1)(b) should be interpreted as encompassing only activities in the meaning of paragraph (a), i.e., carrying out of a specific activity in a particular place by or on behalf of a specific applicant. ${ }^{173}$ The question that follows is: would only site-specific activities, such as projects or installations, be included in the activities covered by Article 6(1)(b) of the Aarhus Convention?

The ACCC has not yet provided clear guidance as to the scope of Article 6 (1)(b), ${ }^{174}$ "perhaps due to the fact that it have (sic) not as yet had to undertake a comprehensive examination of the legal scheme envisaged in subparagraph (b)". ${ }^{175}$ However the discussion on the scope of Article 6(1)(b) AC has evolved along the years among scholars and Parties to the Aarhus Convention.

\footnotetext{
${ }^{170}$ Communication by the Center for Regional Development/Transparency International Armenia, the Sakharov Armenian Human Rights Protection Center and the Armenian Botanical Society (Armenia) with regard to compliance by Armenia UN Doc. ECE/MP.PP/C.1/2006/2/Add.1, para 28.

${ }^{171}$ J. Ebbesson, H. Gaugitsch, J. Jendrośka, F. Marshall and S. Stec, op. cit. (2014), p. 182.

172 J. Ebbesson, H. Gaugitsch, J. Jendrośka, F. Marshall and S. Stec, op. cit. (2014), p. 182.

${ }^{173}$ L. Krämer, op. cit. (2015), pp. 89-90. A. Alemanno, op. cit. (2014), p. 123.

${ }^{174}$ J. Jendrośka, op. cit. (2014), p. 133.

175 J. Jendrośka, op. cit. (2014), p. 123.
} 
Among scholars, Krämer ${ }^{176}$ and Wennerås ${ }^{177}$ argue that the broader phrasing of Article $6(1)(b)$ of the Aarhus Convention would encompass decisions authorising the placing on the market of "substances and products, such as pesticides, chemicals or genetically modified food". ${ }^{178}$ Winter reads Article 6(1)(b) as imposing public participation obligations for all activities presenting significant adverse effects on the environment. ${ }^{179}$ However, the author uses significant adverse effects on the environment instead of significant effects on the environment as actually contained in the text of Article 6(1)(b). Such an interpretation could potentially exclude activities which produce positive effects on the environment. The text of the Convention by not qualifying the kind of effect (by using the term significant effect on the environment without any precedent adjective) leads to a broad interpretation: indicating that Article 6(1)(b) includes measures affecting the environment in any way, the effect being either positive or negative.

The documents resulting from the Meeting of the Parties to the Aarhus Convention (MoP) have also revealed that the scope of Article 6(1)(b) of the Aarhus Convention is far from clear and has demanded attention for further interpretation.

The draft of the first Strategic Plan of the Aarhus Convention, from 2009 to 2014, acknowledged that "The scope of public participation gradually expands beyond sitespecific activities and the placing on the market of genetically modified organisms to possibly encompass product-related and other decision-making having a significant impact on the environment through patterns of production and consumption." 180 (Emphasis added) However, the final text adopted by the Parties did not point out the potential evolution of the provision by encompassing not only site-specific activities and did not sign to the potential enlargement of the definition. The final text was rather limited and only called for further assessment and elaboration on what exactly the provision encompasses by saying that: "The provisions on public participation in decisions having a significant impact on the environment, encompassing, inter alia, product-related decision-making are

\footnotetext{
${ }^{176}$ L. Krämer, op. cit. (2015), pp. 89-90.

${ }^{177}$ P. Wennerås, The enforcement of EC environmental law, (Oxford: Oxford University Press, 2007), p. 225 .

${ }^{178}$ L. Krämer, op. cit. (2015), pp. 89-90.

179 G. Winter, 'National Administrative Procedural Law under EU Requirements: With a Focus on Public Participation', in J. H. Jans, R. Macrory and A.-M. Moreno Molina (eds.), National courts and EU environmental law, (Groningen: Europa Law Publishing, 2013), pp. 11-33, p. 17.

${ }^{180}$ Meeting of the Parties to the Convention on Access to Information, Public Participation in Decisionmaking and Access to Justice in Environmental Matters, Draft Decision III/8 Long-term Strategic Plan ECE/MP.PP/2008/L.10 (2008b), p. 8.
} 
assessed, further reflected on and, where appropriate, elaborated on."181 (Emphasis added) Overall, the final text does preserve the idea that the Parties agree that further clarification on the scope of Article 6(1)(b) of the Aarhus Convention is needed. Furthermore, productrelated decision making is one example to be assessed, since by using the term inter alia other decisions might also be included in what the provision encompasses.

The second, and still running, Strategic Plan of the Aarhus Convention, from 2015 to 2020, maintained the same text as the first strategic plan regarding the need for discussion about the scope of decisions having a significant impact on the environment. ${ }^{182}$ Such an unchanged text shows that, although the discussion is considered relevant, the discussion is still very much ongoing and not conclusive.

In addition to the strategic plans, the MoP has also elaborated working programmes, which break down the strategies into more concrete steps to achieve the goals of the plans. The working programme details, for instance, who is responsible for each task and which budget is allocated for each area. For public participation, it is the Task Force on Public Participation in Decision-making, created in 2010, and the Secretariat to the Aarhus Convention that lead the activities to achieve the goals. ${ }^{183}$

By the time of writing, the MoP had released four working programmes. The first working programme put public participation as one of the priority areas and decided to establish an ad hoc expert group to advise the Working Group of the Parties on the creation for a task force on public participation. The objective and expected outcome are generally formulated and centred on the identification of the main problems in this area. The most concrete outcome is draft guidance on the implementation in whole or in part of Articles 6, 7 and 8. ${ }^{184}$ The second working programme focuses on the information collected and on the exchange of the collected information and best practices. Furthermore, it calls for the preparation of draft recommendations on improving the implementation of the public participation

\footnotetext{
${ }^{181}$ Meeting of the Parties to the Convention on Access to Information, Public Participation in Decisionmaking and Access to Justice in Environmental Matters, Decision III/8 Long-term Strategic Plan, ECE/MP.PP/2008/2/Add.16, para 11(c).

${ }^{182}$ Meeting of the Parties to the Convention on Access to Information Public Participation in Decisionmaking and Access to Justice in Environmental Matters, Decision V/5 Strategic Plan for 2015-2020, ECE/MP.PP/2014/2/Add.1, Objective III.4, p. 30.

${ }^{183}$ Meeting of the Parties to the Convention on Access to Information Public Participation in Decisionmaking and Access to Justice in Environmental Matters, Decision EMP.II/1 Public participation in decision-making, ECE/MP.PP/2010/2/Add.1 (2010), para 1.

${ }^{184}$ Meeting of the Parties to the Convention on Access to Information Public Participation in Decisionmaking and Access to Justice in Environmental Matters, Decision III/9 Work Programme for 20092011, ECE/MP.PP/2008/2/Add.17 (2008a), p. 5.
} 
provisions. ${ }^{185}$ The third work programme became more specific regarding the areas in which the discussion on public participation should focus, including: "decision-making for sustainable development; climate change-related decision-making, the nuclear domain; energy-related planning and policymaking, and the extractive sector; and if resources allow, decision-making on chemicals; food and agriculture; emerging technologies (e.g., nanotechnology) and product-related decision-making." 186 The text of the third working programme shows that the Parties acknowledged the need for a further interpretation of the application of the second pillar of the Convention in view of the number of developments which occurred since the adoption of the Convention, in 1998. The fourth working programme, which runs until 2021, ${ }^{187}$ calls for special attention, among other things, for public participation in climate change-related decision making with a focus in the following areas: public participation in decision making on the extractive sector; chemicals; emerging technologies (e.g., nanotechnology); product-related decision making; and energy-related issues. ${ }^{188}$ Again, climate change-related decision making is at the centre of the discussion by the Parties on promoting effective public participation in decision making. Yet, an open question remains what the scope of application of Article 6(1)(b) is.

b) The potential limits on the discretion of the Parties on the application of Article 6(1)(b) AC

Article 6(1)(b) prescribes that Parties shall determine whether a proposed activity not listed in Annex I which may have a significant effect on the environment is subject to Article 6 AC. In other words, Parties have to determine whether a decision on an activity which is not listed in Annex I to the Convention should be subject to Article 6(1)(b), but they have the discretion to choose how to determine. Regarding this discretion, the Aarhus Convention Compliance Committee (ACCC) states that:

\footnotetext{
${ }^{185}$ Meeting of the Parties to the Convention on Access to Information Public Participation in Decisionmaking and Access to Justice in Environmental Matters, Decision IV/6 Work programme for 20122014, ECE/MP.PP/2011/2/Add.1 (2011), p. 31.

${ }^{186}$ Meeting of the Parties to the Convention on Access to Information Public Participation in Decisionmaking and Access to Justice in Environmental Matters, Decision V/6. Work programme for 20152017, ECE/MP.PP/2014/2/Add.1 (2014a), p. 36.

187 The Work Programme for 2018-2021 states that: "The work area will be implemented in accordance with decision $\mathrm{VI} / 2$ on promoting effective public participation in decision making." Meeting of the Parties to the Convention on Access to Information Public Participation in Decision-making and Access to Justice in Environmental Matters, Decision VI/5 Work programme for 2018-2021, ECE/MP.PP/2017/2/Add.1 (2018b), p. 16. For this reason, references will be made to Decision VI/2. ${ }^{188}$ Meeting of the Parties to the Convention on Access to Information Public Participation in Decisionmaking and Access to Justice in Environmental Matters, Decision VI/2 Promoting effective public participation in decision-making, ECE/MP.PP/2017/2/Add.1 (2018a), p. 8.
} 
"[...] article 6, paragraph 1 (b), of the Convention requires Parties to determine whether an activity which is outside the scope of annex I, and which may have a significant effect on the environment, should nevertheless be subject to the provisions of article 6. Therefore, when this is determined for each case individually, the competent authority is required to make a determination which will have the effect of either creating an obligation to carry out a public participation procedure in accordance with article 6 or exempting the activity in question from such an obligation. Under Czech law, that determination is in practice made through the EIA screening conclusions. As such, the Committee considers the outcome of the EIA screening process to be a determination under article 6, paragraph 1 (b). ${ }^{189}$

However, the Committee does not clearly specify how Parties should implement Article 6(1)(b). The question is thus: how should Parties consider a decision which is not listed in the Annex I of the Convention and which may have a significant effect on the environment as falling under Article 6(1)(b)? Jendrośka argues that there is a minimum obligation for the Parties to "provide evidence as to the considering the issue according to some established criteria." 190 This interpretation would impose an obligation on the Parties to consider whether the measure is a specific activity which causes significant effects on the environment. However, such individual tests could result in a very differentiated application of Article 6 among Parties. In order to provide a more uniform interpretation, the Meeting of the Parties endorsed recommendations of the Task Force on Public Participation on the application of Article 6 (1)(b) of the Aarhus Convention. ${ }^{191}$ The recommendation makes it clear that Article 6(1)(b) of the Aarhus Convention requires Parties to establish a mechanism within their national system to determine whether a decision on a proposed activity not listed in Annex I may nevertheless have a significant effect on the environment. ${ }^{192}$ To establish such a mechanism, the first step to be taken by the Parties, as stipulated by the recommendation, is to detect all activities which potentially may have an effect on the environment. ${ }^{193}$ Following this, the Parties need to identify which of them may have a significant effect on the environment. Parties could do so through the establishment of a list (as has been done in

\footnotetext{
${ }^{189}$ Czech organization Environmental Law Service (Ekologiský právní servis) concerning compliance by Czech Republic (ECE/MP.PP/C.1/2012/11), para 82.

190 J. Jendrośka, op. cit. (2014), p. 134.

${ }^{191}$ Task Force on Public Participation under the Aarhus Convention, Maastricht Recommendations on Promoting Effective Public Participation in Decision-making in Environmental Matters ECE/MP.PP/2014/2/Add.2 (2014).

192 Task Force on Public Participation under the Aarhus Convention, Maastricht Recommendations on Promoting Effective Public Participation in Decision-making in Environmental Matters ECE/MP.PP/2014/2/Add.2 (2014), para 43.

193 Task Force on Public Participation under the Aarhus Convention, Maastricht Recommendations on Promoting Effective Public Participation in Decision-making in Environmental Matters ECE/MP.PP/2014/2/Add.2 (2014), para 44.
} 
Article 6(1)(a) AC), ${ }^{194}$ or by requesting public authorities to examine every case (case-bycase approach), ${ }^{195}$ or a mix of the two. ${ }^{196}$ Therefore, even though Parties have the discretion on how to establish the mechanism, there remains the obligation to consider whether the activities that may be authorised may have a significant impact on the environment.

ii. Possible interpretation of the recognition of voluntary schemes and certification of biofuels as decisions which may have a significant impact on the environment

Having discussed what Article 6 of the Aarhus Convention entails, the next step is to analyse whether decisions related to the certification of sustainable biofuels can fall under this provision. There are two types of decisions that need to be analysed: i) the decisions taken by the Commission recognising the biofuels voluntary schemes; and ii) the decisions taken by the voluntary schemes which certify the biofuels as sustainable.

Both types of decision would fall outside the scope of Article 6(1)(a) of the Aarhus Convention, because neither of them constitutes a permit for one of the activities listed in Annex I of the Convention and they have also not been included as part of an impact assessment procedure in accordance with EU law. ${ }^{197}$

Both types of decision may, however, potentially constitute "decisions on proposed activities not listed in Annex I which may have a significant impact on the environment", according to Article 6(1)(b) of the Aarhus Convention. The decisions taken by the Commission to recognise biofuels voluntary schemes are decisions taken by a competent authority, (the European Commission) which allows a specific activity (the functioning of the schemes) to take place, and the decision is addressed only to those involved (the operators of the schemes). Therefore, all the elements identified by the Implementation Guide are present. However, the decision on the recognition of biofuels voluntary schemes is not a decision about site-specific activities as suggested by the Implementation Guide.

\footnotetext{
194 Task Force on Public Participation under the Aarhus Convention, Maastricht Recommendations on Promoting Effective Public Participation in Decision-making in Environmental Matters ECE/MP.PP/2014/2/Add.2 (2014), para 44(a).

195 Task Force on Public Participation under the Aarhus Convention, Maastricht Recommendations on Promoting Effective Public Participation in Decision-making in Environmental Matters ECE/MP.PP/2014/2/Add.2 (2014), para 44(b).

196 Task Force on Public Participation under the Aarhus Convention, Maastricht Recommendations on Promoting Effective Public Participation in Decision-making in Environmental Matters ECE/MP.PP/2014/2/Add.2 (2014), para 44(c).

197 Paragraph 20 of Annex I of the Aarhus Convention reads as follows: "Any activity not covered by paragraphs 1-19 above where public participation is provided for under an environmental impact assessment procedure in accordance with national legislation."
} 
Yet, from the attention given to the topic by the Parties and the interpretation proposed by scholars, it is possible to suggest that the recognition of voluntary schemes may fall under Article 6(1)(b) of the Aarhus Convention for two reasons. First, as suggested earlier in this section, scholars have proposed a broader interpretation of Article 6(1)(b) of the Aarhus Convention and the MoP has recognised the need for a further interpretation of this provision, although no final conclusion has been reached so far. Second, the decision on the recognition of biofuels voluntary schemes is a climate change-related decision and, more specifically, deals with an energy-related issue (since it allows schemes to certify biofuels which are counted towards the $10 \%$ of renewable energy target in transport), which is one of the areas flagged for attention by the MoP for the further implementation of the public participation provisions of the Convention. ${ }^{198}$

The certification of biofuels as sustainable by the voluntary schemes may fall under a broader interpretation of Article 6(1)(b) of the Aarhus Convention, which also encompasses productrelated decision making. These decisions are taken by a competent authority - the recognised scheme which is a public authority in accordance with Article 2(5) of the Aarhus Convention; the decisions allow a specific activity - the placing on the market of sustainable biofuels - to take place; and the decisions are addressed only to those involved - the economic operator which request the certification of its biofuels. Therefore, all the elements identified by the Implementation Guide are present. However, the Implementation Guide indicated that the scope of Article 6 would be limited to site-specific activities and the decision on the certification of biofuels, although, being a specific activity, it is not a site-specific activity. Despite the Implementation Guide interpretation, Krämer ${ }^{199}$ and Wennerås ${ }^{200}$ argue that the placing on the market of products falls under Article 6(1)(b), and the MoP has recognised product-related decision making as one of the areas to be considered while strengthening the implementation of the public participation provisions. ${ }^{201}$ One might still wonder whether the certification of biofuels as sustainable may constitute a procedure for authorising the placing of a substance or product on the market, since even non-certified biofuels may enter the EU market. However, by certifying biofuels as sustainable, the voluntary schemes allow biofuels to be counted towards achieving the renewable energy target in transport. Therefore, de facto decisions on the certification of biofuels constitute an authorisation to be counted towards the renewable energy targets on transport. ${ }^{202}$ As a result, the decisions on the certification of biofuels should be regarded as falling under Article 6 (1)(b) of the Aarhus Convention, although such an interpretation has not been tested by either the ACCC or the Court of Justice of the European Union.

\footnotetext{
198 Decision VI/5 Work programme for 2018-2021 (2018b), p. 8.

${ }^{199}$ L. Krämer, op. cit. (2015), pp. 89-90.

${ }^{200}$ P. Wennerås, op. cit. (2007), p. 225.

${ }^{201}$ Decision VI/5 Work programme for 2018-2021 (2018b), p. 8.

202 J. Lin, op. cit. (2011), pp. 72-73.
} 
The last step for the purpose of checking whether the recognition of voluntary schemes and the certification of biofuels are decisions which may have a significant impact on the environment is to identify whether these activities have a significant impact on the environment. The Commission's decisions on the recognition of voluntary schemes may have an impact on the environment, since they are the bodies which verify compliance with the sustainability criteria. The decision taken by the schemes may also have an impact on the environment, since the certified biofuels count towards the transport target, and an unreliable certification means that non-compliant biofuels may be counted towards the transport target. However, since, at the EU level, there are no criteria defined on the test regarding the significance of an effect, it is difficult to affirm whether the decisions on the recognition of voluntary schemes would fall within the scope of Article 6(1)(b) of the Aarhus Convention. Nevertheless, based on the current evidence, it can be asserted that there is an obligation for the Commission to, at least, consider whether these decisions have a significant impact on the environment or not.

iii. The extent to which the European Commission and the voluntary schemes comply with Article 6 of the Aarhus Convention requirements

The interpretation that the decisions on the recognition of voluntary schemes and on the certification of biofuels may fall within the scope of Article 6(1)(b) of the Aarhus Convention has not been crystallised yet. However, in the scenario that this will be the recognised interpretation (and strong evidence to this end has been shown above), it is thus important to consider whether the EU would comply with the Aarhus Convention requirements.

In the Commission's view, the first part of Article 6 of the Aarhus Convention, which relates to activities listed in Annex I to the Convention (Article 6(1)(a)), did not need implementation at EU level since the "decisions to authorise the listed activities are not taken at Community level, but by Member States, at local, regional or national level". ${ }^{203}$ Likewise, the Commission understood that Article 6(1)(b), which provides for public participation in decisions on other proposed activities "which may have a significant effect on the environment", would also be inapplicable at the EU level on the basis of the following grounds:

"Administrative decisions on the authorisation of chemicals, pesticides and biocides are, as a rule, taken at the level of Member States. Decisions taken at Community level, such as the establishment of lists of active substances or the classification of

\footnotetext{
${ }^{203}$ European Commission, Proposal for a Regulation of the European Parliament and of the Council on the application of the provisions of the Århus Convention on Access to Information, Public Participation in Decision-making and Access to Justice in Environmental Matters to EC institutions and bodies, COM(2003) 622 final C 96/22 (2004), p. 13.
} 
substances, are as such not aimed at as specific activities in the sense of Article 6 . Regulation (EC) No 2037/2000 on ozone-depleting substances provides for administrative decisions at Community level. However, the decisions concerned do not have a significant effect on the environment, as they concern only the management of the different quota for the placing on the market or importation of such substances."204 (Emphasis added)

The interpretation that the decisions on the recognition of voluntary schemes and on the certification of biofuels fall under Article 6(1)(b) of the Aarhus Convention clearly contradicts the point of view presented in the Commission's proposal to Regulation $1367 / 2006$ to not implement this provision, since the Commission stated that there were no decisions taken at the EU level that could significantly affect the environment. The nonimplementation of Article 6 of the Aarhus Convention, under the interpretation proposed above, therefore strongly points to a violation by the EU of public participation requirements set by the Aarhus Convention.

Regarding the decisions on the certification of biofuels, before discussing whether Article 6 of the Aarhus Convention applies, it is necessary to examine whether the voluntary schemes would be considered public authority and therefore subject to the obligations prescribed in Article 6 of the Aarhus Convention. As concluded in section 3.4.2, the voluntary schemes fall under the definition of public authorities of the Aarhus Convention. However, they are not considered public authorities under the definition of EU institutions and bodies contained in the Aarhus Regulation.

In order to achieve compliance with the Aarhus Convention, the EU would thus have to reconsider its position on the implementation of Article 6 of the Aarhus Convention and review the definition of EU institutions and bodies, which would possibly amount to a need for an amendment of the Aarhus Regulation. ${ }^{205}$

\footnotetext{
${ }^{204}$ European Commission, Proposal for a Regulation of the European Parliament and of the Council on the application of the provisions of the Århus Convention on Access to Information, Public Participation in Decision-making and Access to Justice in Environmental Matters to EC institutions and bodies, $\operatorname{COM(2003)~} 622$ final C 96/22 (2004), p. 13.

${ }^{205}$ It is important to note that, under the proposed interpretation, the voluntary schemes would be bound by rules that the Commission would have to comply with during the assessment of the voluntary schemes, even if the countries where they are registered do not impose such requirements. This would amount to a third-party effect, similar to the effects generated by the requirements set by the sustainability criteria. Joanne Scott makes a distinction between extraterritoriality and territorial extension and argues that "while the EU only very rarely enacts extraterritorial legislation, it makes frequent recourse to a mechanism that may be labeled 'territorial extension.' The practice of territorial extension enables the EU to govern activities that are not centered upon the territory of the EU and to shape the focus and content of third country and international law." J. Scott, 'Extraterritoriality and
} 


\subsubsection{Public Participation during the preparation of plans and programmes and policies}

In case the applicability of Article 6 of the Aarhus Convention would be denied, it can be examined whether public participation is required according to Articles 7 and 8 of the Aarhus Convention. The analysis of these articles will be carried out in this and the next section.

Regarding the application of Article 7 of the Aarhus Convention, it has already been established that the decision on the recognition of biofuels voluntary schemes and the decisions certifying biofuels as sustainable do not constitute a plan or programme according to the Aarhus Regulation (see section 4.3). However, it still remains to be seen if they could be considered plans and programmes in accordance with the Aarhus Convention.

The Aarhus Convention does not specifically define plans and programmes. The Implementation Guide to the Aarhus Convention acknowledges that plans and programmes "have common-sense and sometimes legal meanings throughout the ECE region". ${ }^{206}$ The Implementation Guide uses as an example the definition contained in the Kiev Strategic Environmental Assessment Protocol. According to the protocol, plans and programmes include those that are "required by legislative, regulatory or administrative provisions"; and which are prepared and/or adopted "by an authority for adoption, through a formal procedure, by a parliament or a government". ${ }^{207}$ This definition establishes the cumulative requirements for a plan or programme being covered by the definition, i.e. who should produce and via which procedure, but it does not exactly define what plans and programmes are. Formally, the decisions on the recognition of biofuels voluntary schemes and the decisions certifying biofuels as sustainable are not plans or programmes, since they are not called as such. Substantially, since there is no definition in the Convention, and the example proposed by the guide also does not define plans and programmes, it is logical to look at the meaning of the words and combine this with the requirements set out in the definition. Looking at the meaning of the words plan, "a set of decisions about how to do something in the future", 208 or programme, "an officially organized system of services, activities, or opportunities that

Territorial Extension in EU Law' 62(1) The American Journal of Comparative Law, (2014), pp. 87126, doi: 10.5131/AJCL.2013.0009, p. 89. Although this is a relevant discussion for the certification of biofuels, the analysis requires an examination of the extraterritoriality of EU law, which falls outside the scope of the present thesis and demands further research.

${ }^{206}$ J. Ebbesson, H. Gaugitsch, J. Jendrośka, F. Marshall and S. Stec, op. cit. (2014), p. 173.

${ }^{207}$ Article 2(5), Protocol on Pollutant Release and Transfer Registers to the Convention on Access to Information, Public Participation in Decision-Making and Access to Justice in Environmental Matters, Kiev, 21 May 2003, United Nations, Treaty Series, vol. 2626, p. 119. Doc. MP.PP/2003/12 (entered into force on 8 October 2009).

208 Cambridge Dictionary. Meaning of plan in English, 20 September 2020, https://dictionary.cambridge.org/dictionary/english/plan 
help people achieve something", 209 the decision on the recognition of biofuels voluntary schemes and the decisions certifying biofuels as sustainable does not fit under these definitions. This is despite the fact that they fulfil the two requirements present in the definition suggested by the Implementation Guide: they are required by law, the RED, and are adopted by an authority, in this case the Commission and the voluntary scheme.

Article 7 also covers policies but, as with plans and programmes, the Aarhus Convention does not define policies. Policies can be considered as "a course or principle of action adopted or proposed by an organization or individual". ${ }^{210}$ According to the Implementation Guide, policies are subject to a different treatment than plans and programmes because they are less concrete and they "require a more thorough and profound understanding of the legalities and political context of a particular place. Policy incorporates history and culture and entire legal frameworks that extend beyond the finite area in which they are developed." 211 In this sense, the decisions on the recognition of biofuels voluntary schemes and the certification of biofuels as sustainable do not provide for action which has a broad scope and also tries to encompass historical and cultural aspects. In fact, the decisions on the recognition of voluntary schemes and on the certification of biofuels are part of the actions to achieve the renewable energy target, which is part of the EU policy to tackle climate change. As a consequence, they do not qualify as policies.

4.4.3. Public participation during the preparation of executive regulations and/or generally applicable legally binding normative instruments

Article 8 of the Aarhus Convention states that:

"Each Party shall strive to promote effective public participation at an appropriate stage, and while options are still open, during the preparation by public authorities of executive regulations and other generally applicable legally binding rules that may have a significant effect on the environment." (Emphasis added)

Article 8 of the Aarhus Convention stipulates public participation during the preparation of executive regulations and other generally applicable legally binding normative instruments. Thus, it is necessary to verify whether the decisions on the recognition of voluntary schemes and on the certification of biofuels are executive regulations or other generally applicable legally binding rules. Union legislative acts may confer implementing powers on the European Commission, which can then adopt implementing measures (Article 291 TFEU). This is the case in the RED, which gives the Commission the power to adopt decisions

209 Cambridge Dictionary. Meaning of plan in English, 20 September 2020, https://dictionary.cambridge.org/dictionary/english/programme

${ }^{210}$ A. Stevenson and M. Waite, op. cit. (2011), p. 1110.

${ }^{211}$ J. Ebbesson, H. Gaugitsch, J. Jendrośka, F. Marshall and S. Stec, op. cit. (2014), p. 176. 
regarding the recognition of the voluntary certification schemes. ${ }^{212}$ These decisions are adopted according to the Comitology Regulation that applies to implementing acts as governed by Article 291 TFEU. ${ }^{213}$ The recognition of voluntary certification schemes is an implementing act with a specific addressee (the certification scheme). The decision on the certification of biofuels as sustainable, taken by the schemes, also have a specific addressee (economic operators which request the certification of their biofuels). Consequently, both decisions are not of general application and cannot fall under Article 8 of the Aarhus Convention.

\subsection{Interim conclusion}

Section 4 showed that there is no clear framework for public participation at the EU level regarding the decisions on the recognition of biofuels voluntary schemes and on the certification of biofuels. This conclusion is a result of the analysis developed in three main sections.

Section 4.2 revealed that neither the Renewable Energy Directive nor the Commission's Communication on the recognition of biofuels voluntary schemes provides for public participation requirements. However, even if the RED does not refer to Regulation 1367/2006, which implemented the provisions of the Aarhus Convention for the European institutions and bodies, this regulation applies in the framework of the decisions taken under the Directive.

Section 4.3 demonstrated that the Aarhus Regulation only partially implemented Article 7 of the Aarhus Convention, and it only requires public participation for plans and programmes which fulfil the cumulative criteria of its Article 9. The decisions on the recognition of biofuels voluntary schemes do not fall under the scope of Article 9 of the Aarhus Regulation, since they are not a plan or programme required by law or administrative provisions. Regarding the certification of biofuels as sustainable by the voluntary schemes, the voluntary schemes will not fall under the narrow definition of EU institutions or bodies and therefore the Aarhus Regulation will not even be applicable in this case. Consequently, for both types of decision, there is no obligation for public participation under the Aarhus Regulation.

The findings of sections 4.2 and 4.3 show that there is no legal framework for public participation applicable to the decisions on the recognition of voluntary biofuels schemes and on the certification of biofuels at the EU level. However, the question that remained was if such a lack of public participation is in compliance with the Ahus Convention. Therefore, an

\footnotetext{
${ }^{212}$ Article 18 (4), Renewable Energy Directive, consolidated version.

${ }^{213}$ P. P. Craig, op. cit. (2011), p. 671.
} 
examination of the participatory rights of the Aarhus Convention, which are laid down in its Articles 6, 7 and 8, was carried out in section 4.4.

Section 4.4 first explored the scope of the provision of Article 6 for public participation in specific activities. The Aarhus Convention does not provide a definition of specific activities, but it has been shown that Article 6 of the Aarhus Convention was inspired by the Environmental Impact Assessment and IPPC Directives. It indicates that the provision was drafted based on activities which commonly have a specific installation, operate in a precise geographical area and usually require a permit or authorisation to initiate these activities. Article 6(1)(a) provides for public participation for specific activities which are listed in Annex I of the Convention. As the decisions on the recognition of biofuels voluntary schemes and the certification of biofuels are not one of the activities listed in Annex I, they are outside of the scope of this provision. However, the scope of application of Article 6(1)(b) is not as clear as for Article 6 (1)(a). Article 6(1)(b) establishes public participation in decisions on other proposed activities not listed in Annex I which may have a significant effect on the environment. Whether the scope of Article 6(1)(b) should be interpreted as including all activities which may have a significant effect on the environment, and not only those which are similar to activities of Article 6(1)(a), has not been tested yet either by the ACCC or by the Court of Justice of the European Union. However, the developments in the scholarship and in the discussions on the implementation of public participation provisions by the MoP suggest a broader interpretation of Article 6(1)(b), which includes more than site-specific activities. This would mean that the decisions on the recognition of voluntary and on the certification of biofuels would fall under the scope of Article 6(1)(b), as they are decisions on activities not listed in Annex I which may have a significant effect on the environment. ${ }^{214}$ As a consequence, the decisions would be subject to the most precise set of requirements for public participation provided by the Aarhus Convention. This would mean that the public concerned would have to be informed early in the decision making procedure and in an adequate, timely and effective manner. ${ }^{215}$ In this vein, for instance, the documents used by the Commission on the assessment of the voluntary schemes would have to be made available to the public concerned together with the drafts. An extension of the interpretation of the scope of Article 6(1)(b) would also allow the Convention to respond to some of the new measures adopted to tackle climate change.

The proposed broad interpretation has not yet been confirmed by the MoP, for instance, through an interpretative guideline or by the ACCC via its findings and recommendations. In view of this uncertainty, it is not possible to affirm that the EU is in non-compliance with the Aarhus Convention. However, if it turns out that Article 6(1)(b) of the Aarhus Convention has such a broad scope, as proposed in this chapter, the EU would not be in compliance with

\footnotetext{
${ }^{214}$ Regarding the significant effect on the environment, see section 2.

${ }^{215}$ Article 6(2), Aarhus Convention.
} 
the Convention. This is because Article 6 of the Aarhus Convention has not been implemented at the EU level under the argumentation that there are no decisions taken at the EU level that could fall under Article 6 of the Aarhus Convention. ${ }^{216}$ It shows that the EU did not implement public participation for decisions on specific activities which points to a violation of Article 6. In order to achieve compliance with the Aarhus Convention, the EU would thus have to reconsider its position, which would require an amendment to the Aarhus Regulation, or, alternatively, would require to include public participation provisions in the specific laws, such as the Renewable Energy Directive.

Second, section 4.4 focused on Article 7 of the Aarhus Convention that concerns plans, programmes and policies relating to the environment. The Aarhus Convention does not provide a definition of plan, programmes or policies. An investigation of the possible scope of these terms has shown that the decision on the recognition of the biofuels voluntary schemes and on the certification of biofuels cannot be considered as a plan, programme or policy.

Third, section 4.4 analysed the possible application of Article 8 of the Aarhus Convention provides for public participation during the preparation of executive regulation and other generally applicable legally binding normative instruments. It has been shown that the decision on the recognition of voluntary schemes and on the certification of biofuels cannot fall under Article 8 of the Aarhus Convention because these are not decisions of general scope.

\section{Conclusion}

This chapter explored the access to biofuel-related information and public participation in the recognition of voluntary schemes and the certification of biofuels.

Section 2 investigated the requirement of an adequate standard of transparency prescribed by the RED in order to understand whether this requirement provides for access to information. Section 2 found that no definition regarding a transparency standard can be found in the RED or in the assessment reports, on which the Commission decisions for recognising these schemes were based. ${ }^{217}$ This means that there was no information on the transparency standards on which the voluntary certification schemes are assessed and approved. ${ }^{218}$ Surprisingly, all Commission decisions recognising voluntary schemes before the 2015

\footnotetext{
${ }^{216}$ See section 6.3 of Chapter III.

217 The assessment reports may be found here: https://ec.europa.eu/energy/en/topics/renewableenergy/biofuels/voluntary-schemes.

${ }^{218}$ S. Romppanen, op. cit. (2012a), p. 182.
} 
amendment to the RED affirm that adequate standards of reliability, transparency and independent auditing were met. After the amendment brought by Directive 2015/1513, the Commission has prepared a new recognition assessment template that includes a section on the transparency of the schemes. ${ }^{219}$ This section on transparency requires the voluntary certification schemes to make information on the operation of the system or for transparency purposes available, ${ }^{220}$ in particular, the list of economic operators that are or has been recognised under the scheme; information on the withdrawal or suspension of certificates; the latest version of scheme documents; the auditing certification bodies; publication of contact details for the scheme; and the names of the voluntary schemes the scheme is recognising.

Having established what the adequate transparency standard under the RED entails, section 3 moved to understand what the requirements for the dissemination and disclosure upon request of biofuel-related information are. Regarding the active form, most of the information held by the European Commission is only disclosed after the decisions on the recognition of biofuels voluntary schemes have been taken. Concerning the passive form, the case law of the CJEU revealed that the European Commission did not respect the prescribed timeframe for providing environmental information. Since the court proceedings take a few years to provide an answer whether the information should be disclosed by the Commission, it is possible to disrespect the timeframe without any further consequences for the Commission. This is because, on the basis of the case law discussed, by the time the Court reaches a decision on the non-disclosure, challenging the substantive measure may no longer be possible due to the applicable time-limits. Furthermore, if a decision on the recognition of a voluntary scheme has already been taken, the information released could not be used by the members of the public to participate in the decision making process. Furthermore, there is no sanction foreseen in the case the Commission fails to provide the information within the prescribed time-limit. It is true that this failure of the Commission to comply with the applicable time-limits could lead to an action for liability before the General Court, in the context of an action for damages. However, the potential success of an action for damages brought by an NGO is very limited, since the NGO would have to prove that, due to nonaccess to the requested information, the NGO could not pursue its statutory objectives and suffered damage. ${ }^{221}$ Another remarkable point is that all applicants in the discussed case law were NGOs, with no case so far brought by individuals or by the industry sector. In sum, section 3 showed that there is limited access to biofuel-related information.

Regarding public participation, the findings of section 4 have shown that there is no legal framework for public participation in the recognition of voluntary schemes and certification

\footnotetext{
${ }^{219}$ European Commission, Assessment Protocol Template (2015a), Section 6.13.

${ }^{220}$ European Commission, Assessment Protocol Template (2015a), Section 6.13.

${ }^{221}$ L. Krämer, op. cit. (2013), p. 471.
} 
of biofuels. Neither the Renewable Energy Directive nor the Commission's Communication on the recognition of biofuels certification schemes provides for public participation. The Aarhus Regulation only partially implemented Article 7 of the Aarhus Convention requiring public participation only for plans and programmes. The decisions on the recognition of biofuels voluntary schemes and the certification of biofuels do not fall under its definition of plan and programme.

The examination of the participatory rights of the Aarhus Convention, which are laid down in Articles 6, 7 and 8 of the Aarhus Convention, revealed that the decisions on the recognition of voluntary schemes and the decisions on the certification of biofuels may be interpreted as decisions on proposed activities which may have a significant effect on the environment for the purposes of Article 6(1)(b) of the Aarhus Convention and are therefore subject to the requirements of public participation described in this Article. This interpretation of Article 6(1)(b) of the Aarhus Convention has not been confirmed by the MoP or the CJEU. If this interpretation is crystallised, the EU will not be in compliance with the Aarhus Convention. This is because Article 6 of the Aarhus Convention has not been implemented at the EU level under the argumentation that there are no decisions taken at the EU level that could fall under Article 6 of the Aarhus Convention. ${ }^{222}$ Compliance by the EU with this provision could be achieved by an amendment to the Aarhus Regulation (the EU would thus have to reconsider its position), or introducing public participation requirements in the RED or in the Commission's Communication on the recognition of biofuels voluntary schemes.

Finally, it is remarkable that, despite the strong debate on the potential negative impacts of biofuels on the environment, there is no communication before the ACCC challenging the lack of public participation requirements in the recognition of voluntary schemes and the certification of biofuels. Further research into the strategies employed by ENGOs on how to use the rights to get access to environmental information and to participate into environmental decision making, including an investigation of the barriers that may hinder such use, may clarify the reasons for this reluctant use.

\footnotetext{
${ }^{222}$ See section 6.3 of Chapter III.
} 


\section{Chapter VI - Conclusion}

\section{Introduction}

The precise legal obligations for governments to enable individuals and ENGOs to make use of environmental procedural rights, especially access to environmental information and public participation, have so far remained mostly underexplored in EU climate law. This thesis attempted to fill this gap in knowledge by investigating procedural rights with respect to EU climate law. More precisely, it endeavoured to answer the following question:

To what extent do rights of access to environmental information and participation in governmental environmental decision making have to be provided for individuals and ENGOs at the EU level in the field of EU climate change law?

In its journey to uncover the current legal framework for access to information and participation in climate change decision making at the EU level, the thesis was divided into four main chapters, which break down the main research question into sub-questions.

Chapters II and III focus on the international obligations of the EU with regard to providing access to environmental information and enabling the public to participate in environmental decision making. Chapter II examined the legal framework established by the UNFCCC for access to information and public participation in climate change decision making and explored the obligations they entail for the Parties. Chapter III complemented the international picture by delineating the obligations emanating from the Aarhus Convention and examining how these obligations have been implemented by the EU.

Chapters IV and V delve into the question of how the EU legal framework provides for access to information and public participation in the context of acts adopted at the EU level under two core instruments of the EU climate policy, namely the EU ETS Directive (Chapter IV) and the recognition of voluntary schemes for assessing the sustainability of biofuels under the Renewable Energy Directive (Chapter V).

The present chapter, Chapter VI, will summarise the conclusion of these four chapters and will provide a look ahead at the role of procedural rights in the area of climate change decision making, in view of the lessons learned from the EU's experience. 


\section{The UNFCCC requirements for access to climate information and public participation in climate change decision making}

This section presents the main findings of Chapter II, which analysed the following subquestion:

Which provisions regarding access to information and public participation are established in the UNFCCC? What kind of obligation do they entail for the Parties?

Article 6 of the UNFCCC provides an obligation for the Parties to the UNFCCC to promote and facilitate access to information and public participation in climate change decision making. A textual and systematic interpretation revealed that these obligations require the Parties to make an effort towards promoting and facilitating public access to information and public participation, without including any targets or clear and specific commitments. Therefore, the obligations contained in Article 6 are obligations of effort.

In addition to examining Article 6 itself, the decisions establishing the work programmes on Article 6 of the UNFCCC adopted by the Conference of the Parties (CoP) were examined to investigate whether the content of these decisions gives more body to Article 6 of the UNFCCC. For this examination, the methodology proposed by Wiersema was used. Wiersema proposes an analysis of the legal status of the consensus-based CoP activities based on four different axes: voting and level of consent, delegated consent, intent on the original obligations, and effect of the decisions in the implementation of the provision. ${ }^{1}$ She proposes such a method of interpretation, because the traditional classification into hard law, soft law and non-law would not reflect the intricate relationship between consensus-based COP activity and the underlying treaty obligations of the Parties to a specific treaty. ${ }^{2} \mathrm{~A}$ combination of the four axes showed that there is no sign that the CoP decisions hardened the legal effects of Article 6 of the UNFCCC. On the contrary, this thesis identified that the obligations contained in Article 6 of the UNFCCC lean towards soft legal commitments.

Furthermore, the agreements adopted under the umbrella of the UNFCCC were examined, since they potentially could provide for further commitments. First, the Kyoto Protocol establishes in its Article 10(e) that Parties shall facilitate at the national level public awareness of and public access to information on climate change. However, the provision deals with access to information in a vague and imprecise manner, and public participation is not even actually mentioned in this text. Therefore, it does not provide elements that make the general obligations of Article 6 of the UNFCCC more concrete.

\footnotetext{
${ }^{1}$ See Chapter II, section 2.4. A. Wiersema, op. cit. (2009), pp. 250-259.

${ }^{2}$ A. Wiersema, op. cit. (2009), p. 233.
} 
Second, the Paris Agreement establishes in its Article 12 that Parties shall cooperate in taking measures, as appropriate, to enhance climate change education, training, public awareness, public participation, and public access to information. The focus of this provision is on the cooperation between the Parties and it does not provide for more specific provisions compared to Article 6 of the UNFCCC. The mandatory character of Article 12 of the Paris Agreement is the same: it creates legal obligations for Parties to make an effort without specific commitments, also characterising it as an obligation of effort.

All the relevant international provisions analysed in Chapter II were thus regarded as obligations of effort. These provisions are formulated in a vague way and no specific procedural obligations can be derived from them. Consequently, there are no clearly identifiable results that need to be achieved by the Parties. However, while there are no precise legal commitments under the UNFCCC and while a global treaty on procedural rights is also absent, ${ }^{3}$ environmental procedural rights can also be established by other legal sources. Since the EU is also a Party to a regional agreement on procedural rights, which is the first of its kind: the Aarhus Convention (AC), the following step was to study the legal framework established by the Aarhus Convention and its relationship with climate change, followed by the Aarhus Convention's implementation at the EU level.

\section{The Aarhus Convention, the EU and climate change}

Chapter III focused on the specific procedural provisions that confer rights on access to environmental information and on public participation in governmental environmental decision making to individuals and representative associations in their relationships with EU institutions. More specifically, this chapter investigated if the Aarhus Convention encompasses the climate change phenomenon, introduced the rights to access environmental information and to public participation, as foreseen by the Aarhus Convention, and examined the implementation of these rights at the EU level. In this vein, the chapter analysed the following sub-questions:

- Does the climate change phenomenon fall under the scope of the Aarhus Convention?

- If yes, which obligations regarding access to information and public participation are established in the Aarhus Convention?

- How are they implemented at the EU level, as far as the EU institutions and bodies are concerned?

\footnotetext{
${ }^{3}$ See Chapter II, section 2.2.2. J. Razzaque, op. cit. (2010), p. 292.
} 


\subsection{The definition of environmental information and climate change}

The term climate change is not mentioned anywhere in the Aarhus Convention. In the absence of a term, as is the case of climate change in the Aarhus Convention, the interpreter may resort to the context of the treaty. ${ }^{4}$

Although the Aarhus Convention addresses access to information, public participation in decision making and access to justice in environmental matters, it does not provide a definition of the environment. Nonetheless, the Aarhus Convention provides a definition of environmental information. The meaning given to environmental information acts as a guide when interpreting whether environmental issues are covered by the Convention, since it is from this definition that it becomes possible to interpret whether environmental issues, ${ }^{5}$ such as climate change, are covered by the Convention. Therefore, this analysis proceeded with a textual examination of the definition of environmental information contained in Article 2(3) of the Aarhus Convention. Chapter III reached the conclusion that climate change is part of the implied definition of the environment and therefore covered by the scope of the Aarhus Convention. In this vein, in principle, all the provisions of the Aarhus Convention apply to the climate change decision making process. This conclusion was accompanied by the caveat that it is not clear what exactly is encompassed by the definition of the term environment and hence which climate information and decision making are covered by the first two pillars of the Aarhus Convention specifically. This question is further explored in Chapter IV and V.

Subsequent steps were taken to identify the obligations regarding environmental information and public participation in environmental decision making, as it was established that these obligations are applicable to climate change decision making.

3.2. Access to environmental information under the Aarhus Convention and its implementation at the EU level

The framework for access to environmental information under the Aarhus Convention (Articles 4 and 5) provide explicit commitments establishing what has to be done by public authorities and, therefore, are characterised as obligations of result. This means that the Parties not only have to achieve a specific result of ensuring that their public authorities provide environmental information upon request (Article 4) but they also must disseminate environmental information (Article 5).

The EU has adopted the Aarhus Regulation in which several articles of the Aarhus Convention are implemented with regard to access to environmental information and public

\footnotetext{
${ }^{4}$ Article 31(2), VCLT.

${ }^{5}$ J. Ebbesson, H. Gaugitsch, J. Jendrośka, F. Marshall and S. Stec, op. cit. (2014), p. 44.
} 
participation in governmental decision making for EU institutions and bodies. Regarding access to environmental information, it was concluded that the provisions have mostly been transposed in a way which ensures compliance with the Aarhus Convention. However, regarding the implementation of the exceptions to the obligations to provide access to environmental information upon request, the analysis revealed that the EU requirements impose more limitations than those allowed by the Aarhus Convention. For instance, the ground for refusal to protect commercial interests, as it was implemented by the EU, allows for a greater variety of interests to be kept confidential than under the Aarhus Convention. ${ }^{6}$ This amounts to non-compliance with the Aarhus Convention.

The Aarhus Convention provides for access to justice in cases of violation of the right to receive information upon request. According to the Aarhus Regulation, read in combination with Regulation 1049/2001, applicants may seek reconsideration from an EU institution with regard to a decision concerning a request for environmental information, which is followed by the possibility of instituting court proceedings. This shows that the EU's regulatory framework is in compliance with the Aarhus Convention requirements for access to justice to redress a violation of the right to access environmental information upon request.

Regarding the obligation imposed on public authorities to disseminate information, the Aarhus Convention does not contain similar specific provisions for access to justice to redress a violation of the obligation of public authorities to actively disseminate environmental information. Article 9(3) of the Aarhus Convention, which provides for redress in the case of a violation of national environmental law, could be of help to remedy this problem. This would be possible, because the non-dissemination of environmental information amounts to a breach of Article 4 of the Aarhus Regulation. In turn, the violation of the Aarhus Regulation constitutes a breach of national environmental law, in this case EU environmental law, for the purposes of Article 9(3) of the Aarhus Convention. However, Article 9(3) of the Aarhus Convention has not been fully implemented at the EU level. ${ }^{7}$ This means that, in practice, a member of the public would not have access to justice at the EU level in case of a violation of the obligation to disseminate information.

\subsection{Public participation in environmental decision making}

In Chapter III, the examination regarding public participation started with a discussion on whether the Aarhus Convention followed a specific public participation theory. It was found that the Convention is the result of the aspirations and compromises of the negotiating parties and there is no evidence that the Aarhus Convention followed a specific public participation

\footnotetext{
${ }^{6}$ For a further discussion on the implementation by the EU of the grounds for refusal, see section 4.3 of Chapter III.

${ }^{7}$ See Chapter III, section 4.4. M. Eliantonio, op. cit. (2018), pp. 759-762.
} 
theory. Despite not having a background theory for public participation, the Aarhus Convention does provide minimum requirements against which the legal framework of the Parties has to be assessed.

The core provisions of the Aarhus Convention on public participation are Articles 6, 7 and 8 . Concerning the obligations contained in Article 6 of the Aarhus Convention, this provision establishes public participation in decisions on specific activities and it can be generally characterised as an obligation of result. Nevertheless, the explanatory memorandum to Regulation 1367/2006 states that there are no measures related to specific activities which are taken at the EU level. Consequently, the provision was not transposed. It was shown that this approach is controversial, since some EU decisions may amount to a decision on specific activities within the scope of Article 6 of the Aarhus Convention. ${ }^{8}$

Article 7 of the Aarhus Convention on public participation concerning plans, programmes and policies relating to the environment establishes two separate regimes for public participation. First, for plans and programmes, parts of Article 6 of the Aarhus Convention requirements apply to ensure participation during the development of plans and programmes. Therefore, the part of Article 7 which establishes public participation requirements for plans and programmes is characterised by an obligation of result. Second, for policies, Parties are only required, to the extent appropriate, to endeavour to provide opportunities for public participation. This weak and imprecise formulation, which fails to explain the exact result to be achieved, makes the part of Article 7 of the Aarhus Convention concerning policies as an obligation of effort. The Aarhus Regulation only provides for public participation concerning plans and programmes. This is due to the fact that the Aarhus Regulation is limited, according to its explanatory memorandum, to the "legally binding requirements" of the Aarhus Convention. Therefore, only public participation requirements concerning plans and programmes relating to the environment were foreseen. However, it must be noted that, even if they are obligations of efforts, there remains an obligation for EU institutions and bodies to endeavour to provide opportunities for public participation during the preparation of policies.

Article 8 of the Aarhus Convention only requires Parties to strive to promote effective public participation. In this vein, this provision is also characterised as an obligation of effort. There is no implementation of Article 8 of the Aarhus Convention at the EU level, since the European Commission understood Article 8 of the Aarhus Convention as not providing any legally binding requirement. However, Article 8 of the Aarhus Convention creates an obligation to make efforts to achieve it, and this obligation applies to each of the EU institutions and bodies.

\footnotetext{
${ }^{8}$ See section 5.2.1 of Chapter III.
} 
The Aarhus Convention, in its Article 9(2), also provides for access to justice in cases of a violation of the right to participate in decision on specific activities, which is foreseen in Article 6 of the Aarhus Convention. However, since Article 6 of the Aarhus Convention was not implemented at the EU level, there is no specific provision for access to justice in case of a violation of this provision. Regarding the right to participate in the preparation of plans, programmes and policies relating to the environment (Article 7 AC), neither the Aarhus Convention nor the Aarhus Regulation provides for a specific provision on access to justice in the case of a violation of this right. However, since the preparation of plans and programmes needs to follow the requirements of Article 6 (3), (4) and (8) of the Aarhus Convention, they are also subject to the review procedures provided by Article 9(2). In this vein, there is an obligation for the EU to ensure access to justice to redress violations of Articles Article 6 (3), (4) and (8) of the Aarhus Convention.

Regarding policies and executive regulations and/or generally applicable legally binding normative instruments, the Convention does not provide for a specific provision on access to justice in the case of a lack of participation in their elaboration. It was argued that Article 9(3) of the Aarhus Convention, which establishes access to justice in the case of a violation of national law relating to the environment, has the potential to fulfil this gap. This would occur if a Party has adopted public participation requirements in its national law for executive regulations and/or generally applicable legally binding normative instruments and during the preparation of policies relating to the environment, Article 9(3) of the Aarhus Convention may be used to guarantee access to justice. This would be possible, since a breach of the national legislation which implemented public participation requirements would constitute a contravention of provisions of national law relating to the environment, for the purpose of Article 9(3) of the Aarhus Convention. However, as already explained above, Article 9(3) of the Aarhus Convention has not been fully implemented by the EU. Moreover, Article 8 and the obligations concerning policies contained in Article 7 have also not been transposed in the Aarhus Regulation. Hence, even in the case that the EU would have fully implemented Article 9(3) of the Aarhus Convention, it would still not be possible to base a claim on this provision. This is due to the fact that there is no implementation of Articles 7 regarding policies and Article 8 concerning executive regulations and/or generally applicable legally binding normative instruments at the EU level, and, therefore, there would be no breach of national law that could trigger the application of Article 9(3) of the Aarhus Convention.

\section{The EU Emissions Trading System: Access to environmental information and public participation at the EU level}

Chapter IV analysed the EU ETS Directive in view of: (i) legal requirements for access to environmental information and public participation in the decision making of acts adopted under the EU ETS Directive; (ii) the compatibility of this framework with requirements 
imposed by the Aarhus Convention. More precisely, Chapter IV answered the following question:

How does the EU legal framework provide for access to information and public participation in the context of acts adopted at the EU level under the auspices of the EU Emissions Trading System Directive? And how compatible is this framework with the EU's international obligations?

\subsection{Access to environmental information}

Regarding access to environmental information, Chapter IV identified that the general regime for access to environmental information under the EU ETS can be found in Articles 17, 15a, and 19 of the EU ETS Directive. Articles 17 and 15a deal specifically with access to information, while Article 19 focuses on the registries, which disseminate key information to the public about the function of the EU ETS.

The analysis carried out in this chapter showed, first of all, that Article 17 of the EU ETS Directive does not reflect the shift of decision making from the national level to the EU level brought by the 2009 amendments of the EU ETS Directive, since the Article only refers to Directive 2003/4 and not to the Aarhus Regulation. This omission, however, does not change the applicability of the Aarhus Regulation to the access to environmental information requests addressed to the Commission, since EU institutions are bound, in any case, by the Aarhus Regulation. The analysis of Article 17 of the EU ETS Directive also showed that this provision creates a double obligation for public authorities: to disseminate environmental information and to disclose it upon request.

Secondly, the analysis proceeds with observing that Article 15a of the EU ETS Directive refers neither to Directive 2003/4 nor the Aarhus Regulation. However, in the second part of Article 15a of the EU ETS Directive, which regulates an exception to disclosure by means of introducing professional secrecy (an aspect which is not present in Article 17 of the EU ETS Directive), and implicit reference to these two pieces of legislation is given by the mention of "applicable laws, regulations or administrative provisions".

Despite the existence of two specific provisions on access to information (Article 15a and 17 of the EU ETS Directive), their limited scope cannot cover all the possible requests for information under the EU ETS. Therefore, an investigation through the existing CJEU case law on access to environmental information was carried out, particularly in view of how in this case law the Aarhus Regulation is applied with regard to such requests. Hence, the analysis of the case law built further on the definition of environmental information and on the limits of the grounds for disclosure of environmental information. 
Regarding the definition of environmental information, three types of information were discussed in three cases brought before the CJEU as falling under the definition of environmental information. The CJEU confirmed in the Saint-Gobain Glass Deutschland case that the list of installations covered by the EU ETS and also the number of allowances allocated for free by a Member State constitute environmental information within the definition of the Aarhus Regulation. ${ }^{9}$ In two other cases, although not receiving particular attention in the judgment, the opinions of the Advocate General showed that the raw data needed to replicate the calculation should be made available to the public ${ }^{10}$ and that trading data constitutes environmental information. ${ }^{11}$ These cases reveal that a great number of EU ETS-related information potentially falls within the definition of environmental information, although, in the latter two cases, such an interpretation still needs confirmation by the CJEU.

Regarding the grounds for refusal, three cases dealt with two different grounds for refusal: (i) refusal of information when it is requested in the course of the decision making, and (ii) refusal of information in order to protect the confidentiality of commercial and industrial information. For the first ground, the CJEU made clear in the Saint-Gobain case that there is a need to make a distinction between the decision making itself and the entire administrative procedure which leads to a decision. ${ }^{12}$ It concluded that all information that is part of the administrative procedure needs to be disclosed. Second, the Ville de Lyon and Cross-Sectoral Correction Factor cases, ${ }^{13}$ despite not dealing directly with this exception, allowed for the possibility to explore its application, since the public authority relied on the same ground to refuse access to the environmental information. The application of this exception, according to the Aarhus Convention and the Aarhus Regulation when dealing particularly with emissions into the environment, must be even stricter, and the analysis of whether the information should be disclosed has to take into consideration that, in these cases, the ground for refusal (i.e. protection of commercial and industrial information) is not applicable. In sum, the analysis of the three cases revealed that these grounds have to be interpreted in a restrictive way, which is to ensure the right of access to environmental information.

Furthermore, the discussion on what constitutes emissions into the environment suggests that there is a need for an interpretation of the Aarhus Convention in light of the new developments to combat climate change, such as emissions trading. At the time of the

\footnotetext{
${ }^{9}$ Case T-476/12, Saint-Gobain Glass Deutschland GmbH v. European Commission.

${ }^{10}$ Opinion of Advocate General Kokott in Joined Cases C-191/14, C-192/14, C-295/14, C-389/14, and C-391/14 to C-393/14, Borealis Polyolefine GmbH and others v. Bundesminister für Land- und Forstwirtschaft, Umwelt und Wasserwirtschaft and others, para 140.

${ }^{11}$ Case C-524/09, Ville de Lyon v. Caisse des dépôts et consignations, para 33.

${ }^{12}$ Case C-60/15 P, Saint-Gobain Glass Deutschland v. Commission, para 76.

${ }^{13}$ Case C-524/09, Ville de Lyon v. Caisse des dépôts et consignations; and Joined Cases C-191/14, C192/14, C-295/14, C-389/14 and C-391/14 to C-393/14, Borealis Polyolefine GmbH and others v. Bundesminister für Land- und Forstwirtschaft, Umwelt und Wasserwirtschaft and others.
} 
adoption of the Aarhus Convention, emissions trading was still a concept that needed further practical development, and it can be assumed that the broad term emissions was related to the actual release of substances from installations within more classic command-and-control instruments. With the advent of a market-based instrument such as emissions trading, there is a need for further interpretation in view of the potential release of substances and the creation of new concepts, such as greenhouse gas emission allowances.

Regarding the active dissemination of information by the Commission, the Union Registry is the main tool to make information available to the public, according to Article 19 of the EU ETS Directive. However, in reality, the EU ETS information related to the allocation and transaction of allowances is scattered along three webpages. The fact that the EU ETS Directive empowers the Commission to adopt a regulation, which provides for public access and confidentiality as appropriate, allows the Commission to tailor how and when the information is available. ${ }^{14}$

The compatibility of the exercise of this discretion - such as the change in the way the information about international credits or the time transaction-related information is released to the public - with the Aarhus Convention has yet to be tested by the courts.

Nevertheless, on the topic of the dissemination of information, it is important to note that there is no registry available to the public that would provide information on the number and nature of requests to access EU ETS-related information. This is an indication of limitations on access to environmental information rights in the EU. A readily available registry with a compilation of all requests would not only help the members of the public to get information, but it would also prevent civil servants from having to answer the same questions repeatedly. ${ }^{15}$ These examples demonstrate that there is still much room for further and more ambitious interpretations and implementation of the Aarhus Convention with regard to disclosing environmental information under the EU ETS.

\footnotetext{
${ }^{14}$ Article 19(3), EU ETS Directive, consolidated version.

${ }^{15}$ This suggestion is based on an interpretation of Article 5(3)(d) of the Aarhus Convention wich reads that: "Each Party shall ensure that environmental information progressively becomes available in electronic databases which are easily accessible to the public through public telecommunications networks. Information accessible in this form should include: [...] (d) Other information, to the extent that the availability of such information in this form would facilitate the application of national law implementing this Convention, provided that such information is already available in electronic form." Since the requests for EU ETS-related information are based on the Aarhus Regulation read in combination with Regulation 1049/2001, this information can be considered as information that would facilitate the application of national law, in this case EU law, implementing the Aarhus Convention.
} 


\subsection{Public Participation in Environmental Decision Making}

The EU ETS Directive does not have a general provision on public participation, which would apply to all decisions to be taken under this Directive. Therefore, it was investigated whether public participation requirements could be derived from specific provisions under the EU ETS Directive, which serve as the legal basis for the adoption of the Commission's acts under this Directive. This investigation revealed that public participation is not required by the EU ETS Directive for the adoption of most acts. The exception is that the acts regulating the free allocation of allowances and the carbon leakage sector for which the EU ETS Directive (only) prescribes the consultation of stakeholders. However, the provisions do not provide a further explanation on how the relevant stakeholders are to be selected.

Having examined the specific provisions of the EU ETS Directive, the investigation continued by exploring whether the Aarhus Regulation imposes a general obligation regarding public participation for the acts adopted under the auspices of the EU ETS Directive. The Aarhus Regulation only requires public participation requirements for plans and programmes. ${ }^{16}$ It was concluded that the acts adopted by the Commission in the EU ETS context do not constitute plans and programmes, since they are clearly binding provisions setting rules, for instance, for auctioning and benchmarking, and they are hence, in this respect, to be distinguished from plans and programmes. Therefore, the Aarhus Regulation does not impose any obligation regarding public participation for the acts adopted under the EU ETS Directive.

In the absence of public participation provisions under the Aarhus Regulation that would be applicable to these acts, it was examined whether there is still an obligation under the Aarhus Convention for the Commission to provide for public participation in the decision making process under the EU ETS. The analysis carried out demonstrated that these acts qualify as executive regulations and other generally applicable legally binding normative instruments because they are acts of general application, as their addressees are not determined or determinable. ${ }^{17}$ Furthermore, considering their size, location and potential effects on the environment, they have a significant effect on the environment. Therefore, they fall under the scope of application of Article 8 of the Aarhus Convention and, as a consequence, there is a legal obligation for the Commission to strive to promote public participation.

Having established that Article 8 of the Aarhus Convention applies, the final step was to identify whether the Commission has fulfilled its public participation obligation with respect to the measures adopted under the EU ETS Directive. This analysis showed that consultation

\footnotetext{
${ }^{16}$ Article 9, Aarhus Regulation.

17 These non-legislative acts took the form of a regulation or decision. Regulations and decisions are among the legal instruments available to the European institutions to exercise the Union's competences, according to Article 288 TFEU. How they are adopted defines whether they are a legislative act or not.
} 
is seen as one step of the overall ladder of public participation but that consultations do not automatically imply public participation and a further analysis of the legal framework for consultations at the EU level was needed to identify whether the stakeholders' consultations could fulfil the obligations under Article 8 of the Aarhus Convention. Consequently, the consultation requirements applicable at the EU level and contained in the 2002 Communication were examined, ${ }^{18}$ which were applicable at the time the acts adopted by the Commission analysed in this chapter were adopted, and in the Better Regulation Package, ${ }^{19}$ applicable at the time of writing.

Although consultation is not the same as public participation, it was argued that, where the EU ETS Directive requires consultation, and an open consultation is conducted, Article 8 requirements would be fulfilled. For all the other situations, the 2002 Communication cannot fulfil Article 8 requirements. This is due to the fact the 2002 Communication gives discretion to the Commission on whether or not to hold consultations and which type of consultation to conduct. Regarding whether or not to hold consultations, Article 8 of the Aarhus Convention does not foresee such discretion.

Under the current legal framework, even for the cases under the EU ETS Directive where there is no obligation for the Commission to conduct consultations, the 2017 Better Regulation Guidelines provide for stakeholders' feedback on the draft of implementing and delegated acts, which encompasses most of the acts adopted by the Commission discussed in this chapter. This could amount to compliance with Article 8 of the Aarhus Convention when implementing and delegated acts are adopted. However, the acts adopted by the Commission acting alone would not be covered and, therefore, no compliance with Article 8 of the Aarhus Convention could be achieved. Moreover, Article 8 of the Aarhus Convention does not provide for any exception to the rule that the drafts should be subject to public participation, and it requires that the timeframe should be sufficient for effective participation, while the Better Regulation Guidelines provides for the application of exceptions and no flexibility regarding the time-frame. Therefore, the Guidelines, per se, cannot guarantee that the EU fully complies with Article 8 of the Aarhus Convention.

On a more positive note, the chapter identified that, according to the 2017 Better Regulation Guidelines, the default is that all the delegated and implemented acts are now subject to public feedback. Moreover, the Commission made a move towards the recognition of the

\footnotetext{
${ }^{18}$ European Commission, 2002 Communication (2002).

${ }^{19}$ European Commission, Better regulation for better results - An EU agenda (2014c). This 2015 Communication was accompanied by the Commission Staff Working Document - Better Regulation Guidelines, SWD(2015) 111 final (2015b), which was updated in 2017 (European Commission, 2017 Staff Working Document (2017c).
} 
legal implications of the 2017 Guidelines by recognising that the Guidelines may legally bind the Commission. ${ }^{20}$

In light of the conclusions reached in Chapter IV, it can be argued that public participation under the EU ETS could be strengthened if the EU ETS Directive contained a specific provision on public participation. Since the centralisation of major decisions at the EU level, because the 2009 amendments of the EU ETS Directive, the Commission has a prominent role under the current phase of the EU ETS, particularly with regard to its decision making related to the allocation of allowances. However, neither the EU ETS Directive nor the Aarhus Regulation guarantees public participation in the acts the Commission has to take under the EU ETS Directive. A specific approach under the EU ETS Directive regulating, precisely, public participation for the acts the Commission has to adopt would bring the adoption of these acts into line with the requirements of the Aarhus Convention. It should be noted, however, that this recommendation goes against the horizontal approach of the Aarhus Convention, which tries to avoid a fragmented legal framework for specific areas of environmental law. A less fragmented approach would consist of a proper implementation of the Aarhus Convention at the EU level, by making an amendment to the Aarhus Regulation. In addition to this, it remains to be seen whether a common provision would be suitable for all different subject matters in EU environmental law, especially in view of their particularities which may require specific public participation requirements.

\section{Certification of Biofuels: Access to environmental information and public participation at the EU Level}

Chapter $\mathrm{V}$ assessed the regime of access to biofuel-related information and public participation in decision making for the recognition of biofuels voluntary schemes at the EU level in view of the Aarhus Convention requirements. The sub-questions discussed were as follows:

- How does the EU legal framework provide for access to information and public participation in the context of acts adopted at the EU level for the recognition of voluntary schemes under the auspices of the Renewable Energy Directive?

- How compatible is this framework with the EU's international obligations?

\subsection{Access to environmental information}

First, Chapter V investigated the requirement of an adequate standard of transparency prescribed by the Renewable Energy Directive in order to understand whether this

\footnotetext{
${ }^{20}$ European Commission, 2017 Staff Working Document (2017c), p. 43.
} 
requirement encompasses access to information. Despite the fact that all Commission decisions recognising voluntary schemes before the 2015 amendment to the RED affirm that adequate standards of reliability, transparency and independent auditing were met, it was found that neither the RED defines this standard, nor the assessment reports, on which the Commission decisions for recognising these schemes were based, provided clarification regarding the transparency standard. ${ }^{21}$ Therefore, the established legal framework and the subsequent decisions did not contain information on the transparency standards against which the voluntary certification schemes are assessed and approved. ${ }^{22}$ The amendment brought by Directive 2015/1513 has improved this situation. After this amendment, the RED includes more requirements regarding transparency on the recognition of voluntary schemes and an obligation for the Commission to prepare the report on the revision of the operation of the voluntary schemes. ${ }^{23}$ For the voluntary schemes that have been and will be recognised after the amendment, the Commission has prepared a new recognition assessment template that includes a section on the transparency of the schemes. ${ }^{24} \mathrm{~A}$ similar section was not present in the templates used for the recognition of the schemes before the amendment. ${ }^{25}$ This section on transparency from the Commission's template requires the voluntary schemes to make information on their actions performed and operation available, ${ }^{26}$ such as the latest version of scheme documents and the list of economic operators that are recognised under the scheme. Although the changes are motivated by the amendments to the RED, it is important to point out that the requirement to make information available is not part of a legally binding instrument but only of an assessment template.

Having established what transparency standard under the Renewable Energy Directive means, the analysis went on to examine what the requirements for the dissemination and disclosure upon request of biofuel-related information entail. Along these lines, the analysis examined whether information on biofuels is environmental information and whether the information is held by a public authority. These are important delimitations since, according to the Aarhus Convention and the Aarhus Regulation, rights and obligations regarding access to environmental information can only be exercised if the requested information falls under the definition of environmental information and if this information is requested from or disseminated by public authorities. It was demonstrated that biofuel-related information can

21 The assessment reports may be found here: https://ec.europa.eu/energy/en/topics/renewableenergy/biofuels/voluntary-schemes.

${ }^{22}$ S. Romppanen, op. cit. (2012a), p. 182.

${ }^{23}$ Article 18 (6), Renewable Energy Directive, consolidated version.

${ }^{24}$ European Commission, Assessment Protocol Template (2015a), Section 6.13.

${ }^{25}$ All the schemes will have to be subject to a new decision after five years which is the validity of any Commission decision recognising schemes according to Article 18(6) of the Renewable Energy Directive, consolidated version. It means that in the end all schemes will probably be approved in accordance with the new template.

${ }^{26}$ European Commission, Assessment Protocol Template (2015a), Section 6.13. 
be considered environmental information within the scope of Article 2(1)(d)(ii) of the Aarhus Regulation, since it is information on energy affecting or likely to affect the environment. It was also argued that, even though the evaluator/contractor hired by the Commission to help with the recognition of voluntary schemes and the voluntary schemes themselves do not fall under the Aarhus Regulation definition of public authority, they should be considered public authorities according to Article 2(2)(c) of the Aarhus Convention, because they are legal persons having public responsibilities or functions under the control of the European Commission. As a consequence, they are subject to the obligation to disseminate and to provide upon request biofuel-related information, unless an exception to the disclosure of the information would apply. Such an interpretation shows that the EU, by limiting public authorities to EU institutions and bodies, has not sufficiently transposed the Aarhus Convention.

Having established that biofuel-related information is environmental information and that the European Commission, the evaluator/contractor and the voluntary schemes themselves are public authority according to the Aarhus Convention, the next step was to examine the active form of access to environmental information.

With respect to information held by the European Commission, there is no register in the transparency platform for the application for the recognition of voluntary schemes. However, the Commission discloses these documents used for the recognition of the schemes (with some blacked-out parts) via its transparency platform after the decision is taken. The postdecision publication of the decision can still be considered to be in compliance with the provisions to disseminate information of the Aarhus Regulation and the Aarhus Convention, since these provisions do not prescribe a timeframe for doing so. ${ }^{27}$

Concerning the information made available by voluntary schemes, the current Commission's recognition template provides a section on the transparency of the schemes. ${ }^{28}$ This improves the previous situation where there was no mention of transparency standards. Pursuant to Directive 2015/1513, there is an obligation for the voluntary schemes to report to the Commission on many different aspects on the operation of the schemes, including on transparency and stakeholder involvement. ${ }^{29}$ The Commission has to analyse these reports, reviewing the operation of recognised voluntary schemes and identifying best practices and report to the Council and the Parliament. ${ }^{30}$ However, these are only reporting obligations. In contrast, for standards of independent auditing, the Commission may, based on a risk analysis

\footnotetext{
27 However, the application of public participation requirements may oblige the disclosure of information at an early stage of the decision making process. For a further discussion, see section 4.4.1 of Chapter V.

${ }^{28}$ European Commission, Assessment Protocol Template (2015a), Section 6.13.

${ }^{29}$ Article 18(6)(d), Renewable Energy Directive, consolidated version.

${ }^{30}$ Article 18(6), Renewable Energy Directive, consolidated version.
} 
or on these reports, set new standards and require all voluntary schemes to apply those standards. ${ }^{31}$ If the voluntary scheme does not comply with the standards of independent auditing, the Commission may repeal decisions recognising voluntary schemes, which do not comply with the new standards within a prescribed timeframe. ${ }^{32}$ Interestingly, the standard of transparency and reliability did not receive the same treatment. This illustrates the low weight that the EU legislator apparently gives to transparent decision making, also if important environmental decision making, such as assessing the sustainability of biofuels, is outsourced to private actors.

Concerning the passive form, the case law of the CJEU revealed that the European Commission did not respect the prescribed timeframe for providing environmental information. Since the court proceedings take a few years to provide an answer whether the information should be disclosed by the Commission, it is possible to disrespect the timeframe without any further consequences for the Commission. Based on the case law discussed, by the time the Court reaches a decision on the non-disclosure, challenging the substantive measure may no longer be possible due to the applicable time-limits. In addition, if the decision has already been taken, the information released could not be used by the members of the public to participate in the decision making process. Furthermore, there is no sanction foreseen if the Commission fails to provide the information within the prescribed time-limit. It is true that this failure of the Commission to comply with the applicable time-limits could lead to an action for liability before the General Court, in the context of an action for damages. However, the potential success of an action for damages brought by an NGO is very limited, since the NGO would have to prove that, due to lack of access to the requested information, the NGO could not pursue its statutory objectives and suffered damage. ${ }^{33}$ Another remarkable point is that all applicants of the discussed case law were NGOs with no case so far brought by individuals or by the industry sector.

\subsection{Public Participation in Environmental Decision Making}

The findings regarding public participation have shown that there is no legal framework for public participation in the recognition of voluntary biofuels scheme at the EU level. ${ }^{34}$ Neither the Renewable Energy Directive nor the Commission's Communication on the recognition of biofuels certification schemes provides for public participation. The Aarhus Regulation only partially implemented Article 7 of the Aarhus Convention requiring public participation only for plans and programmes and the recognition of biofuels voluntary schemes and the certification of biofuels do not fall under its definition of plan and programme.

\footnotetext{
${ }^{31}$ Article 18(5), Renewable Energy Directive, consolidated version.

32 Article 18(5), Renewable Energy Directive, consolidated version.

${ }^{33}$ L. Krämer, op. cit. (2013), p. 471.

${ }^{34}$ Section 4 of Chapter V.
} 
The examination of the participatory rights of the Aarhus Convention, which are laid down in its Articles 6, 7 and 8 of the Aarhus Convention, revealed that the decisions on the recognition of voluntary schemes and the decisions on the certification of biofuels may be interpreted as decisions on proposed activities which may have a significant effect on the environment for the purposes of Article 6(1)(b) of the Aarhus Convention, and they are therefore subject to the most precise set of requirements for public participation provided by the Aarhus Convention. According to the proposed interpretation, the public concerned would have to be informed early in the decision making procedure and in an adequate, timely and effective manner. ${ }^{35}$ Following this line of reasoning, the non-registration in the transparency platform of applications for the recognition of voluntary schemes means that there is no proper early access to information in the procedure for the recognition of voluntary schemes. Furthermore, despite the fact that the draft decision on the recognition of a voluntary scheme is published on the Comitology Registry and there is opportunity for feedback on the Commission's draft decision, this participation is limited, since there is no access to the scheme documents on which the Commission based its decision and this means that there is no effective participation. ${ }^{36}$

This interpretation proposing an extension of Article 6(1)(b) of the Aarhus Convention would allow the Convention to evolve in order to respond to some of the new measures adopted to tackle climate change. If this interpretation would be confirmed by the Meeting of the Parties to the Aarhus Convention, for instance via an interpretative guideline, or by the ACCC, via its findings and recommendations or, even by the CJEU, ${ }^{37}$ the EU would not be in compliance with the Aarhus Convention. This is because Article 6 of the Aarhus Convention has not been implemented at the EU level, based on the argumentation that there are no decisions taken at the EU level that could fall under Article 6 of the Aarhus Convention. ${ }^{38}$ In order to achieve compliance with the Aarhus Convention, the EU would thus have to reconsider its position, which would require an amendment to the Aarhus Regulation or, alternatively, would require including specific public participation provisions in the specific laws, such as the Renewable Energy Directive. Another possible way of achieving compliance would be by incorporating public participation requirements in the Commission's Communication on the recognition of biofuels voluntary schemes. However, in this case, the requirements would not be part of a legally binding instrument and, therefore, incapable of providing the same legal certainty.

\footnotetext{
${ }^{35}$ Article 6(2), Aarhus Convention.

${ }^{36}$ The participation will still be limited since "the scheme documents are not published at this stage". Personal communication via Europe Direct Contact Centre (5 May 2017). [Biofuels voluntary schemes - second answer].

${ }^{37}$ See section 2.2.3 of Chapter III.

${ }^{38}$ See section 6.3 of Chapter III.
} 
Finally, it is remarkable that, despite the strong debate on the potential negative impacts of biofuels on the environment, there is no communication before the Aarhus Convention Compliance Committee challenging the lack of access to information and public participation requirements in the recognition of voluntary schemes and the certification of biofuels. Further research into the strategies employed by ENGOs on how to use the rights to get access to environmental information, and to participate in environmental decision making, including an investigation of the barriers that may hinder such use, may clarify the reasons for this reluctant use.

\section{Conclusion}

The current EU legal framework seems unable to provide sufficient access to environmental information and public participation in decision making under the EU ETS and the Renewable Energy Directive as is required by the Aarhus Convention. In order for the EU to overcome the challenges identified in this thesis, various measures could be taken.

Regarding access to information, three main challenges need to be addressed by the EU. First, a further interpretation of the definition of environmental information, which would encompass all climate change-related information, would help to address the problem of interpretation on what precisely constitutes climate change-related information. Second, a further interpretation by the CJEU on the application of the grounds for refusal to disclose information in accordance with the limits established by the Aarhus Convention would compel the Commission to apply these grounds accordingly. Third, since there is no sanction in the case of not providing requested information in the prescribed time by the Aarhus Regulation, the EU needs to find a way to steer the behaviour of its institutions. This thesis suggested that a way of forcing the Commission to respect the time limits would be if the CJEU would establish that the non-compliance with the time for disclosure would constitute a negative answer that cannot be overruled by later disclosure. ${ }^{39}$ However, it would require a change in the position of the CJEU in this matter, which would mean the CJEU would have to come back on a past ruling against such a suggestion.

Concerning public participation in decision making, the Aarhus Regulation only provides for public participation concerning plans and programmes which is a fraction of the provisions of the Aarhus Convention. The latter is more demanding by also requiring public participation in decisions on specific activities, policies relating to the environment and on the preparation of executive regulations and other generally applicable legally binding rules, which were not transposed into the Aarhus Regulation. Furthermore, a way of strengthening public participation under the EU ETS, and during the recognition of voluntary schemes and

\footnotetext{
${ }^{39}$ See section 3 of Chapter V.
} 
certification of biofuels, would be if the EU ETS Directive and the Renewable Energy Directive would contain specific provisions on public participation.

Nevertheless, the case study on the EU ETS Directive in this thesis showed that neither the EU ETS Directive nor the Aarhus Regulation guarantee public participation in the decision making process leading to the adoption of acts the Commission is empowered to take under the EU ETS Directive. This shortcoming becomes even more relevant given the centralisation of major decisions at the EU level which give a prominent role to the European Commission. The Aarhus Convention serves as a fallback in cases when implementation at the EU level falls short. Chapter IV argued that the Commission acts adopted under the auspices of the EU ETS Directive fall within the scope of Article 8 of the Aarhus Convention. Therefore, there is an obligation for the Commission to strive to promote effective public participation in the decision making leading to the adoption of acts the Commission is empowered to take under the EU ETS Directive. These findings are not limited to the third phase of the EU ETS, which runs until 2020. They are also valuable for the fourth phase of the EU ETS (20212030), since the Commission will continue to have a prominent role by adopting measures in crucial areas, such as identifying sectors at risk of carbon leakage, establishing the rules for auctioning and the Union-wide rules for the allocation of allowances. ${ }^{40}$

The recognition of biofuels schemes and the certification of biofuels include the outsourcing of functions by the Commission to private actors. The issue here is how the Aarhus Convention could respond to this increased use of this type of arrangements. This thesis argued that the Aarhus Convention's definition of public authority encompasses the private actors that operate the voluntary schemes and, therefore, they should also be under the same obligations as those applying to public authorities, both for access to information and for public participation in decision making. Being able to classify the private actors as public

${ }^{40}$ Directive (EU) 2018/410 which amended the EU ETS Directive by establishing the rules for the period for 2021-2030 empowers the Commission to adopt delegated acts, among others, in respect to: detailed arrangements for the auctioning by Member States of aviation allowances (Articles 3d(3), EU ETS Directive), the timing, administration and other aspects of auctioning (Article 10(4), EU ETS Directive), the Union-wide and fully harmonised rules for the allocation of allowances (Article 10a(1), EU ETS Directive), the rules on the operation of the innovation fund, including the selection procedure and criteria (Article 10a(8), EU ETS Directive), the determination of sectors and subsectors deemed at risk of carbon leakage (Article 10b(5), EU ETS Directive), the requirements concerning the Union Registry (Article 19(3), EU ETS Directive), the issuing of allowances or credits from projects administered by Member States that reduce greenhouse gas emissions not covered by the EU ETS (Article 24a(1), EU ETS Directive).

Directive 2018/04 also empowers the Commission to adopt implementing measures, among others, concerning: the determination of the revised benchmark values for free allocation (Article 10a(2), EU ETS Directive), the detailed arrangements for the monitoring and reporting of emissions (Article 14(1), EU ETS Directive), and the verification of emission reports and for the accreditation and supervision of verifiers (Article 15, EU ETS Directive). 
authorities does not smooth the task of identifying whether there are obligations for public participation in the recognition of biofuels schemes. This thesis reasoned that the recognition of voluntary schemes and the certification of biofuels are specific activities in the sense of Article 6 of the Aarhus Convention. It argued that Article 6 of the Aarhus Convention is not limited to site-specific activities, as proposed, for instance, by the Implementation Guide to the Aarhus Convention. It would be necessary to reinterpret Article 6 of the Aarhus Convention as encompassing not only traditional means of environmental control (as the classic permits of command-and-control instruments) but also specific activities which are not limited to a geographical space, such as the recognition of voluntary schemes. This proposed interpretation could potentially ensure that the public concerned would be informed and would participate in the recognition process voluntary schemes for the certification of biofuels in the years to come. This is because the voluntary schemes continue to be a method of proving compliance with the sustainability criteria under the new Renewable Energy Directive, which provides the legal framework for beyond $2020 .{ }^{41}$ The voluntary schemes assume even more importance, since the EU sustainability criteria are extended to cover biomass fuels for heating and cooling and power generation and voluntary schemes will be also used for biomass fuels. ${ }^{42}$

Overall, this thesis has shown that there is a need for a more consistent and clearer legal framework which should ensure access to climate change-related information and participation in climate change decision making. Climate change challenges will become ever more pressing in coming years and the analysis of two EU measures from a procedural rights perspective provided some insight on how puzzling access to environmental information and public participation can be in the context of new regulatory measures adopted to tackle it. In this complex context, the participation of ENGOs can be of much value on the precondition that they have the resources, the knowledge and the time to engage in the technical discussions climate change decision making may require. In this vein, in many cases where individuals might be reluctant to participate in view the need for an intricate level of knowledge, ENGOs can fill this gap by participating in the decision making with technical arguments.

The market-based nature of the regulatory approach by means of the EU ETS, and also the outsourcing of decision making to private actors in the case of the recognition of biofuel

\footnotetext{
41 Article 30(4), Directive 2018/2001. Directive 2018/2001 is a recast of the Renewable Energy Directive (Directive 2009/28).

42 Article 30(4), Directive 2018/2001. With regard to the sustainability of solid and gaseous biomass for electricity, heating and cooling, there was no binding criteria at the EU level until the recast of the Renewable Energy Directive in December 2018. Under the new Renewable Energy Directive, the EU sustainability criteria, which was applicable only to biofuels and bioliquids, have been extended to cover biomass fuels for electricity, heating and cooling, and Member States have to transpose these rules until 30 June 2021.
} 
voluntary schemes and the certification of biofuels require specific interpretations of the Aarhus Convention, which was adopted at a time with more emphasis on command-andcontrol approaches, particularly the permitting of pollutant activities. This thesis has shown that, despite the fact that the Aarhus Convention did not even mention the term climate change, it already provides for minimum requirements for governments to respect access to environmental information and public participation in climate change decision making. However, it will depend on further interpretations by the Parties to the Aarhus Convention, including their courts, and the Aarhus Convention Compliance Committee, whether the environmental procedural rights, as provided by the Aarhus Convention, will be ambitiously respected in the case of new regulatory developments to combat climate change. 


\section{References}

\section{$\underline{\text { Books, Articles, Documents and Online Sources }}$}

Al-Rifai, P., Dimaranan, B. and Laborde, D., Global trade and environmental impact of the EU biofuels mandate, (2010), Report, http://environmentportal.in/files/biofuelsreportec.pdf.

Alemanno, A., 'Unpacking the Principle of Openness in EU Law: Transparency, Participation and Democracy' 39(1) European Law Review, (2014), pp. 72-90.

Anger, A. and Köhler, J., 'Including aviation emissions in the EU ETS: Much ado about nothing? A review' 17(1) Transport Policy, (2010), pp. 38-46.

Arnstein, S. R., 'A ladder of citizen participation' 35(4) Journal of the American Institute of planners, (1969), pp. 216-224.

Backes, C. and Eliantonio, M., 'Access to court for environmental NGOs at European and national level: improvements and room for improvement since Maastricht?', in de Visser, M. and van der Mei, A. P. (eds.), The Treaty on European Union 1993-2013: Reflections from Maastricht (Cambridge, Antwerp, Portland: Intersentia, 2013), pp. 557-580.

Banner, C., The Aarhus Convention: A Guide for UK Lawyers, (Oxford: Bloomsbury Publishing, 2015).

Barnard, C. and Peers, S., European union law, (Oxford: Oxford University Press, 2014).

Berthier, A. and Krämer, L., 'The Aahrus Convention: Implementation and Compliance in EU Law': ClientEarth, 2014).

Beyerlin, U., 'Different Types Of Norms In International Environmental Law Policies, Principles, And Rules', in Bodansky, D., Brunnée, J. and Hey, E. (eds.), The Oxford Handbook of International Environmental Law, (Oxford: Oxford University Press, 2007).

Bodansky, D., 'The United Nations Framework Convention on Climate Change: a commentary' 18(2) Yale journal of international law, (1993), pp. 451-558.

Bodansky, D., 'The Framework Convention/Protocol Approach' Paper 1(WHO/NDC/TFI/99.1) Framework Convention on Tobacco Control - Technical Briefing Series, (1999), pp. 15-40.

Bodansky, D. (2010). The art and craft of international environmental law. Retrieved from http://public.eblib.com/choice/publicfullrecord.aspx?p=3300858 
Bodansky, D., Brunnée, J. and Rajamani, L., International climate change law (Oxford: Oxford University Press, 2017).

Boisson de Chazournes, L., 'One Swallow Does Not a Summer Make, but Might the Paris Agreement on Climate Change a Better Future Create? 27(2) European Journal of International Law, (2016), pp. 253-256.

Boyle, A., 'Human Rights or Environmental Rights? A Reassessment' 18(3) Fordham Environmental Law Review, (2007), pp. 471.

Brady, K., 'New convention on access to information and public participation in environmental matters' 28(2) Environmental Policy and Law, (1998), pp. 69-76.

Brunnée, J., 'COPing with consent: law-making under multilateral environmental agreements’ 15(1) Leiden Journal of International Law, (2002), pp. 1-52.

Bunea, A., 'Designing stakeholder consultations: Reinforcing or alleviating bias in the European Union system of governance?' 56(1) European Journal of Political Research, (2017), pp. 46-69.

Bunea, A. and Thomson, R., 'Consultations with interest groups and the empowerment of executives: Evidence from the European Union' 28(4) Governance, (2015), pp. 517-531.

Buonsante, V. A. and Friel, A., 'What is Information Relating to Emissions into the Environment?' 8(2) European Journal of Risk Regulation, (2017), pp. 453-460.

Cambridge Dictionary. Meaning of plan in English, 20 September 2020, https://dictionary.cambridge.org/dictionary/english/plan

Cambridge Dictionary. Meaning of plan in English, 20 September 2020, https://dictionary.cambridge.org/dictionary/english/programme

Campaign against Climate Change. Mission Statement, from https://www.campaigncc.org /aboutus/missionstatement, 18 June 2020.

Carbon Market Watch. About, from http://carbonmarketwatch.org/about/, 18 June 202007 March 2019.

Carbon Trade Watch. Filling a critical vacuum, from http://www.carbontradewatch.org /about-us.html, 18 June 2020.

Chalmers, D., Davies, G. and Monti, G. (2010). European Union law: cases and materials Retrieved from Cambridge Books Online http://dx.doi.org/10.1017/CBO9780511841408 
Churchill, R. R. and Ulfstein, G., 'Autonomous institutional arrangements in multilateral environmental agreements: a little-noticed phenomenon in international law' 94(4) American Journal of International Law, (2000), pp. 623-659.

Cittadino, F., 'Public Interest to Environmental Protection and Indigenous Peoples'rights: Procedural Rights to Participate and Substantive Guarantees', in Lohse, E. J., Poto, M. and Parola, G. (eds.), Participatory rights in the environmental decision-making process and the implementation of the Aarhus Convention: a comparative perspective, Berlin: Duncker \& Humblot, 2015), pp. 260.

ClientEarth, Friends of the Earth Europe, Stichting FERN and Corporate Europe Observatory, (2011). Application for Annulment under Article 263 of the Treaty on the Functioning of the European Union in Case T-278/11. Retrieved from: http://ec.europa.eu/environment/aarhus/pdf/title_iv/RIR\%20EPS.pdf,

Climate Action Network. About CAN, from http://www.climatenetwork.org/about/aboutcan, 18 June 2020.

Coglianese, C., Kilmartin, H. and Mendelson, E., Transparency and Public Participation in the Rulemaking Process: A Nonpartisan Presidential Transition Task Force Report, (2008).

Combacau, J., 'Obligations de résultat et obligations de comportement: quelques questions et pas de réponse' Le droit international: unité et diversité. Mélanges offerts à Paul Reuter, (1981), pp. 181-204.

Committee of the Regions, Opinion of the Committee of the Regions on the 'Proposal for a Directive of the European Parliament and of the Council establishing a scheme for greenhouse gas emission allowance trading within the Community and amending Council Directive 96/61/EC (2002/C 192/14), OJ C 192/59, (2002).

Conference of the Parties serving as the meeting of the Parties to the Kyoto Protocol, Decision 3/CPM.1 Modalities and procedures for a clean development mechanism as defined in Article 12 of the Kyoto Protocol FCCC/KP/CMP/2005/8/Add.1.

Conference of the Parties serving as the meeting of the Parties to the Kyoto Protocol, Decision 9/CMP.1 Guidelines for the implementation of Article 6 of the Kyoto Protocol FCCC/KP/CMP/2005/8/Add.2.

Conference of the Parties serving as the meeting of the Parties to the Kyoto Protocol, Decision 13/CMP.1 Modalities for the accounting of assigned amounts under Article 7, paragraph 4, of the Kyoto Protocol FCCC/KP/CMP/2005/8/Add.2.

Conference of the Parties to the UNFCCC, Organizational Matters - Adoption of the Rules of Procedure, (1996). 
Conference of the Parties to the UNFCCC, Report of the Conference of the Parties on its eighth session (Part One: Proceedings), held in New Delhi from 23 October to 1 November 2002 (2002).

Conference of the Parties to the UNFCCC, Report of the Conference of the Parties on its thirteenth session (Part One: Proceedings), held in Bali from 3 to 15 december 2007 (2007).

Conference of the Parties to the UNFCCC, Report of the Conference of the Parties on its eighteenth session (Part One: Proceedings), held in Bali 26 November to 8 December 2012 (2012).

Conference of the Parties to the UNFCCC, Report of the Conference of the Parties on its twenty-fourth session, held in Katowice from 2 to 15 December 2018 (2018).

Craig, P. and De Búrca, G., EU law: text, cases, and materials, Fifth Edition (Oxford: Oxford University Press, 2011).

Craig, P. P., 'Delegated acts, implementing acts and the new Comitology Regulation' 36(5) European Law Review, (2011), pp. 671-687.

Craig, P. P., The Lisbon Treaty: law, politics, and treaty reform, (Oxford: Oxford University Press, 2013).

Craig, P. P., Hofmann, H., Schneider, J.-P. and Ziller, J., ReNEUAL model rules on EU administrative procedure (Oxford: Oxford University Press, 2017).

Dannenmaier, E., 'A European Commitment to Environmental Citizenship: Article 3.7 of the Aarhus Convention and Public Participation in International Forums' 18(1) Yearbook of International Environmental Law, (2008), pp. 32-64.

David, B. and Andrew, J., 'Climate policy instrument choices', in Farber, D. and Peeters, M. (eds.), Climate change law (Cheltenham: Edward Elgar Publishing, 2016), pp. 57-67.

de Cendra de Larragán, J., Distributional choices in EU climate change law and policy: towards a principled approach? (Alphen aan den Rijn: Kluwer Law International, 2011).

Decision IV/5 on accession to the Convention by non-United Nations Economic Commission for Europe member States Adopted by the Meeting of Parties to the Convention on Access to Information, Public Participation in Decision-making and Access to Justice in Environmental Matters at its fourth session (2011).

Delgado Casteleiro, A., 'The Effects of International Dispute Settlement decisions in EU Law', in Cremona, M., Thies, A. and Wessel, R. A. (eds.), The European Union and international dispute settlement, (Oxford: Hart Publishing, 2017), pp. 302. 
Dellinger, M., 'Ten Years of the Aarhus Convention: how Procedural Democracy is Paving the Way for Substantive Change in National and International Environmental Law' Colorado Journal of International Environmental Law and Policy, (2012), pp. 309-366.

Dimas, S., (2005). The Commission's initiatives for shaping future policy Climate change conference. National Library, Vienna. http://europa.eu/rapid/press-release_SPEECH-05567_en.pdf,

Doelle, M., 'The Paris Agreement: Historic Breakthrough or High Stakes Experiment?' 6(12) Climate law, (2016), pp. 1-20.

Dupuy, P.-M., 'Reviewing the difficulties of codification: on Ago's classification of obligations of means and obligations of result in relation to state responsibility' 10(2) European Journal of International Law, (1999), pp. 371-385.

Ebbesson, J., Gaugitsch, H., Jendrośka, J., Marshall, F. and Stec, S., 'The Aarhus Convention: an implementation guide', $2^{\text {nd }}$ edition (Geneva: United Nations, 2014).

Economic and Social Committee, Opinion of the Economic and Social Committee on the Proposal for a Directive of the European Parliament and of the Council establishing a scheme for greenhouse gas emission allowance trading within the Community and amending Council Directive 96/61/EC (2002/C 221/08), OJ C 221/27, (2002).

Economides, C. P., 'Content of the Obligation: Obligation of Means and Obligation of Result', in Crawford, J., Pellet, A., Olleson, S. and Parlet, K. (eds.), The Law of International Responsibility, (Oxford: Oxford University Press, 2010), pp. 371-381.

Eliantonio, M., 'The role of NGOs in environmental implementation conflicts: 'stuck in the middle' between infringement proceedings and preliminary rulings?' 40(6) Journal of European Integration, (2018), pp. 753-767.

Eliantonio, M. and Stefan, O., 'Soft Law Before the European Courts: Discovering a 'common pattern'?' 37 Yearbook of European Law, (2018), pp. 457-469.

Ellison, D., 'Addressing adaptation in the EU policy framework', in Keskitalo, E. C. H. (ed.), Developing adaptation policy and practice in Europe: Multi-level governance of climate change, Dordrecht: Springer, 2010), pp. 39-96.

Etemire, U., 'Law and Practice on Public Participation in Environmental Matters: The Nigerian Example in Transnational Comparative Perspective', (New York: Routledge, 2015).

European Commission-Directorate-General Climate Action. European Union Emissions Transaction log, from https://ec.europa.eu/clima/ets/napMgt.do, 18 June 2020. 
European Commission - DG Climate. EU Emissions Trading System (EU ETS), from https://ec.europa.eu/clima/policies/ets_en, 19 June 2020.

European Commission. Comitology Register - Frequently Asked Questions, from http://ec.europa.eu/transparency/regcomitology/index.cfm?do=FAQ.FAQ, 19 June 2020.

European Commission. Free allocation, from https://ec.europa.eu /clima/policies /ets/allowances_en, 19 June 2020.

European Commission. General Questions and Answers on Registries (05/2013), from https://ec.europa.eu/clima/policies/ets/registry_en\#tab-0-2, 19 June 2020.

European Commission. Help on document types, from https://ec.europa.eu/transparency /regdoc/?fuseaction=helpcote, 19 June 2020.

European Commission. Kyoto Protocol Public Reports, from https://etsregistry.webgate.ec.europa.eu/euregistry/EU/index.xhtml, 19 June 2020.

European Commission. Phases 1 and 2 (2005-2012), from http://ec.europa.eu /clima/policies/ets/pre2013/index_en.htm, 19 June 2020.

European Commission. Questions and Answers on the cross-sectoral correction factor (CSCF), from https://www.karlsruhe.ihk.de/blueprint/servlet/resource/blob/2470276/ 810edae144345f4716c956c99715080e/faq-data.pdf, 19 June 2020.

European Commission. Renewable energy: Moving towards a low carbon economy, from https://ec.europa.eu/energy/en/topics/renewable-energy, 19 June 2020.

European Commission. Transitional free allocation to electricity generators, from https://ec.europa.eu/clima/policies/ets/allowances/electricity_en, 19 June 2020.

European Commission. Union Registry, from https://ets-registry.webgate.ec.europa.eu /euregistry/EU/index.xhtml, 19 June 2020.

European Commission. Union Registry - Phase 3 (2013-2020), from https://ec.europa.eu /clima/policies/ets /registry_en\#tab-0-1, 19 June 2020.

European Commission. Voluntary schemes, from https://ec.europa.eu/energy/en/topics/ renewable-energy/biofuels/voluntary-schemes, 19 June 2020.

European Commission, European Governance: a White Paper, $\operatorname{COM}(2001) 428$ final, (2001a).

European Commission, Proposal for a Directive of the European Parliament and of the Council establishing a scheme for greenhouse gas emission allowance trading within the 
Community and amending Council Directive 96/61/EC, COM/2001/0581 final - COD 2001/0245, (2001b).

European Commission, Communication from the Commission Towards a reinforced culture of consultation and dialogue-General principles and minimum standards for consultation of interested parties by the Commission, COM(2002) 704 final, (2002).

European Commission, Amended proposal for a Directive of the European Parliament and of the Council establishing a scheme for greenhouse gas emission allowance trading within the Community and amending Council Directive 96/61/EC, COM(2002) 680 final, (2003a).

European Commission, Communication from the Commission to the European Parliament pursuant to the second subparagraph of Article 251(2) of the EC Treaty concerning the Common Position of the Council on the adoption of a Directive of the European Parliament and of the Council establishing a scheme for greenhouse gas emission allowance trading within the Community and amending Council Directive 96/61/EC, SEC/2003/0364 final COD 2001/0245, (2003b).

European Commission, Opinion of the Commission pursuant to Article 251 (2), third subparagraph, point (c) of the EC Treaty, on the European Parliament's amendments to the Council's common position regarding the proposal for a Directive of the European Parliament and of the Council establishing a scheme for greenhouse gas emission allowance trading within the Community and amending Council Directive 96/61/EC, COM(2003) 463 final, (2003c).

European Commission, Proposal for a Regulation of the European Parliament and of the Council on the application of the provisions of the Arhus Convention on Access to Information, Public Participation in Decision-making and Access to Justice in Environmental Matters to EC institutions and bodies, COM(2003) 622 final C 96/22, (2004).

European Commission, Communication from the Commission to the European Parliament, the Council, the European Economic and Social Committee and the Committee of the Regions 2020 by 2020 Europe's climate change opportunity, COM(20008) 30 final, (2008a).

European Commission, (2008b). Questions and Answers on the directive on the geological storage of carbon dioxide. Brussels. https://ec.europa.eu/clima/policies/innovationfund/ccs_en\#tab-0-3,

European Commission, Communication from the Commission on the practical implementation of the EU biofuels and bioliquids sustainability scheme and on counting rules for biofuels, 2010/C 160/02, OJ C 160/8, (2010a). 
European Commission, Communication from the Commission on voluntary schemes and default values in the EU biofuels and bioliquids sustainability scheme, 2010/C 160/01, OJ C 160/1, (2010b).

European Commission, Communication from the Commission to the European Parliament, the Council, the European Economic and Social Committee and the Committee of the Regions - Energy Efficiency Plan 2011, COM(2011) 109 final, (2010c).

European Commission, Communication from the Commission to the European Parliament, the Council, the European Economic and Social Committee and the Committee of the Regions - Energy Efficiency Plan 2011(COM(2011) 109 final), (2011a).

European Commission, Impact Assessment of the Commission Decision on determining transitional Union-wide rules for harmonised free allocation pursuant to Article 10a of Directive 2003/87/EC, C(2011) 2772 final, (2011b).

European Commission, Questions and Answers: EU strategy on adaptation to climate change. Memo from 16 April 2013. Brussels.

European Commission, Aarhus Convention Implementation Report, C(2014) 2506 final, (2014a).

European Commission, Communication from the Commission to the European Parliament, the Council, the European Economic and Social Committee and the Committee of the Regions - A policy framework for climate and energy in the period from 2020 to 2030, SWD(2014) 15 final / SWD(2014) 16 final, (2014b).

European Commission, Communication from the Commission to the European Parliament, the Council, the European Economic and Social Committee and the Committee of the Regions Better regulation for better results - An EU agenda, COM(2015) 215 final, (2014c).

European Commission, Assessment Protocol Template, (2015a), https://ec.europa.eu/energy/sites/ener/files/documents/Assessment\%20Protocol\%20templat e_111115.pdf.

European Commission, Commission Staff Working Document - Better Regulation Guidelines, SWD(2015) 111 final, (2015b).

European Commission, Contract notice: Assessment of voluntary schemes and agreements used for sustainability claims (2015/S 060-104704) OJ/S S60, (2015c).

European Commission, Report from the Commission to the European Parliament, the Council, the European Economic and Social Committee and the Comittee of the Regions, SWD(2015) 117 final, (2015d). 
European Commission, The EU Emissions Trading System (EU ETS). In Climate Action (Ed.) (2016), https://ec.europa.eu/clima/sites/clima/files/factsheet_ets_en.pdf, $10.2834 / 6083$.

European Commission, Aarhus Convention Implementation Report, C(2017) 5129 final, (2017a).

European Commission, Better Regulation "Toolbox" which complements the Better Regulation Guidelines presented in SWD(2017) 350, (2017b).

European Commission, Commission Staff Working Document - Better Regulation Guidelines, SWD(2017) 350, (2017c).

European Council, Common Position (EC) No 28/2003 adopted by the Council on 18 March 2003 with a view to adopting Directive 2003/. . . CE of the European Parliament and of the Council establishing a scheme for greenhouse gas emission allowance trading within the Community and amending Council Directive 96/61/EC (2003/C 125 E/05), OJ C 125 E/72, (2003).

European Council, 2030 Climate and Energy Policy Framework, EUCO 169/14, (2014a).

European Council, Conclusions on 2030 Climate and Energy Policy Framework (SN 79/14), (2014b).

European Court of Auditors, The EU system for the certification of sustainable biofuels (2016). Retrieved from: https://www.eca.europa.eu/Lists/ECADocuments/SR16_18 /SR_BIOFUELS_EN.pdf

European Environment Agency. Contribution of different greenhouse gases to the overall greenhouse gas concentration, from http://www.eea.europa.eu/data-and-maps/daviz/ contribution-of-the-different-ghgs-3\#tab-chart_3, 18 June 2020.

European Environmental Bureau. What we do, from https://eeb.org/work-areas/, 18 June 2020.

European Parliament, European Parliament legislative resolution on the proposal for a European Parliament and Council directive establishing a scheme for greenhouse gas emission allowance trading within the Community and amending Council Directive 96/61/EC, COM(2001) 581 - C5-0578/2001 - 2001/ 0245(COD), Codecision procedure: first reading, OJ C $279 \mathrm{E} / 96$, (2002).

European Parliament, European Parliament legislative resolution on the proposal for a European Parliament and Council directive establishing a scheme for greenhouse gas emission allowance trading within the Community and amending Council Directive 
96/61/EC, 15792/1/2002 - C5-0135/2003 - 2001/0245(COD), Codecision procedure: second reading, OJ C $74 \mathrm{E} / 642$, (2003).

Eurostat. Greenhouse gas emission statistics, from http://ec.europa.eu/eurostat/statisticsexplained/index.php/Greenhouse_gas_emission_statistics, 25 Jan.

Forzieri, G., Cescatti, A., e Silva, F. B. and Feyen, L., 'Increasing risk over time of weatherrelated hazards to the European population: a data-driven prognostic study' 1(5) The Lancet Planetary Health, (2017), pp. e200-e208.

Gardiner, R. K., Treaty interpretation, (Oxford: Oxford University Press, 2008).

Gardiner, R. K., Treaty interpretation, Second edition (Oxford: Oxford University Press, 2015).

Gardner, R. C., 'Perspectives on Wetlands and Biodiversity: International Law, Iraqi Marshlands, and Incentives for Restoration' 15 Colorado Journal of International Environmental Law \& Policy, (2004), pp. 1-18.

General Assembly of the United Nations. Sixth Committee (Legal) - 74th session, from https://www.un.org/en/ga/sixth/74/resp_of_states.shtml, 10 January 2020.

Gotev, G. Late publication of biofuels study raises questions, from https://www.euractiv.com /section/energy/news/late-publication-of-biofuels-study-raises-questions/, 16 March 2016.

Government of Tuvalu, (2015). Intended Nationally Determined Contributions Communicated to the UNFCCC on 27 November 2015, https://www4.unfccc.int /sites/ndcstaging/PublishedDocuments/Tuvalu\%20First/TUVALU\%20INDC.pdf.

Greenpeace. \#Climate, from https://www.greenpeace.org/international/tag/climate/, 18 June 2020.

Grimeaud, D. and de Cendra de Larragán, J., (2005). Procedural rights concerning the start of the European emissions trading scheme for greenhouse gases: (information, participation and) access to justice - Industry Project on equal competition and emissions trading.

Gupta S., Tirpak D. A., Burger N., Gupta J., Höhne N., Boncheva A. I., Kanoan G. M., Kolstad C., Kruger J. A., Michaelowa A., Murase S., Pershing J., Saijo T., Sari A., '2007: Policies, Instruments and Co-operative Arrangements' in Metz B., Davidson O.R., Bosch P.R., Dave R., Meyer L.A. (eds), Climate Change 2007: Mitigation. Contribution of Working Group III to the Fourth Assessment Report of the Intergovernmental Panel on Climate Change, (Cambridge, New York: Cambridge University Press, 2007). 
Hamelinck, C., Koper, M., Janeiro, L., Klessmann, C., Kuwahata, R., Nabe, C., Doering, M., Cuijpers, M., van den Bos, A., Spoettle, M., Alberici, S., Ragwitz, M., Steinhilber, S., Nysten, J., Fouquet, D., Resch, G., Liebmann, L., Ortner, A., Panzer, C., Johnson, F., Olsen, O., Godar, J., Karlberg, L. and Fischer, G., Renewable energy progress and biofuels sustainability, (2014).

Hedemann-Robinson, M., 'EU enforcement of International Environmental Agreements: The Role of the European Commission' 21(1) European Energy and Environmental Law Review, (2012), pp. 2-31.

Hey, E., Advanced Introduction to International Environmental Law, (Cheltenham, Northampton: Edward Elgar Publishing, 2016).

Hey, E., 'The interaction between human rights and the environment in the European 'Aarhus space'” Chapters, in Grear, A. and Kotzé, L. J. (eds.), Research Handbook on Human Rights and the Environment (Cheltenham, Edward Elgar Publishing, 2015), pp. 353-376, p. 374.

Hey, E., 'Compliance Procedure: Aarhus Convention' Max Planck Encyclopedia of International Procedural Law [MPEiPro], (2019).

Hillebrandt, M. and Leppävirta, L., 'On the Administration of Pollution: How Much "Space to Think” May the EU Claim?' 8(4) European Journal of Risk Regulation, (2017), pp. 791797.

Hofmann, H. and Türk, A., Legal challenges in EU administrative law: towards an integrated administration, (Cheltenham: Edward Elgar Publishing, 2009).

Hofmann, H. C., Rowe, G. C. and Türk, A. H., Administrative law and policy of the European Union (Oxford: Oxford University Press, 2011).

Intergovernmental Negotiating Committee for a Framework, Report of the Intergovernmental Negotiating Committee for a Framework Convention on Climate Change on the Work of its Third Section, held at Nairobi from 9 to 20 September 1991 (A/AC.237/12), (1991a).

Intergovernmental Negotiating Committee for a Framework, (1991b). Single Text on Elements Relating to Mechanisms.

Intergovernmental Panel on Climate Change, 'Climate change 2007: mitigation: contribution of working group III to the fourth assessment report of the intergovernmental panel on climate change' B. Metz, O. R. D., P.R. Bosch, R. Dave, L.A. Meyer Ed., (Cambridge and New York: Cambridge University Press, 2007). 
Intergovernmental Panel on Climate Change, Climate Change 2014: Impacts, Adaptation, and Vulnerability. Part A: Global and Sectoral Aspects. Contribution of Working Group II to the Fifth Assessment Report of the Intergovernmental Panel on Climate Change (2014a).

Intergovernmental Panel on Climate Change, (2014b). Climate Change 2014: Synthesis Report. Summary for Policymakers (pp. 32). Geneva, Switzerland, https://www.ipcc.ch /pdf/assessment-report/ar5/syr/AR5_SYR_FINAL_SPM.pdf,

Intergovernmental Panel on Climate Change, Climate Change 2014: Synthesis Report. Contribution of Working Groups I, II and III to the Fifth Assessment Report of the Intergovernmental Panel on Climate Change, (2014c).

Intergovernmental Panel on Climate Change and Planton, S. E., 'Annex III: Glossary', in Collins, M., Knutti, R., Arblaster, J., Dufresne, J., Fichefet, T., Friedlingstein, P., Gao, X., Gutowski, W., Johns, T. and Krinner, G. (eds.), Climate Change 2013: The Physical Science Basis. Contribution of Working Group I to the Fifth Assessment Report of the intergovernmental Panel on Climate Change Cambridge, United Kingdom and New York, NY, USA: Cambridge University Press, 2013).

International Law Commission, 'Draft articles on responsibility of states for internationally wrongful acts, with commentaries' 2(Part II) Yearbook of the International Law Commission, A/56/10, (2001), pp. 31-143.

Janssen, K., The availability of spatial and environmental data in the European Union at the crossroads between public and economic interests, (Austin: Wolters Kluwer, 2010).

Jendrośka, J., 'Public Participation and Information in the Emissions Trading Directive' (1) Environmental Law Network International Review, (2004), pp. 7-11.

Jendrośka, J., 'Public Information and Participation in EC Environmental Law: Origins, Milestones and Trends', in Macrory, R. (ed.), Reflections on 30 years of EU environmental law: a high level of protection?, 2006).

Jendrośka, J., 'Public Participation under Article 6 of the Aarhus Convention: Role in Tiered Decision-Making and Scope of Application', in Bándi, G. (ed.), Environmental democracy and law: public participation in Europe, Groningen: Europa Law Publishing, 2014), pp. 113 138.

Jendrośka, J., 'Public participation in the preparation of plans and programs: some reflections on the scope of obligations under Article 7 of the Aarhus Convention' 6(4) Journal for European Environmental \& Planning Law, (2009), pp. 495-515.

Jendrośka, J., 'Aarhus Convention Compliance Committee: Origins, Status and Activities' 8(4) Journal for European Environmental \& Planning Law, (2011a), pp. 301-314. 
Jendrośka, J., 'Public Participation in Environmental Decision-Making: Interactions Between the Convention and EU Law and Other Key Legal Issues in its Implementation in the Light of the Opinions of the Aarhus Convention Compliance Committee', in Pallemaerts, M. (ed.), The Aarhus Convention at ten: interactions and tensions between conventional international law and EU environmental law, (Groningen: Europa Law Publishing, 2011b), pp. 91-147.

Joesten, M. D., Hogg, J. L. and Castellion, M. E., 'The world of chemistry: essentials', Fourth Edition: Cengage Learning, 2007).

Keskitalo, E. C. H., 'Introduction - Adaptation to Climate Change in Europe: Theoretical Framework and Study Design', in Keskitalo, E. C. H. (ed.), Developing adaptation policy and practice in Europe: multi-level governance of climate change, (Dordrecht: Springer, 2010), pp. 1-38.

Kieran Bradley, 'Rulemaking by the European Commission: The New System for Delegation of Powers', in Bergström, C. F. and Ritleng, D. (eds.), Rulemaking by the European Commission: The New System for Delegation of Powers, (Oxford: Oxford University Press, 2016).

Kilmartin, H. and Mendelson, E., 'Transparency and Public Participation in the Rulemaking Process’ Paper 238 Faculty Scholarship, (2008), pp. 924-972.

Kiss, A. and Shelton, D., International Environmental Law, 3rd [rev.] ed. (Ardsley: Transnational Publishers, 2004).

Koester, V., 'The Convention on Access to Information, Public Participation in DecisionMaking and Access to Justice in Environmental Matters (Aarhus Convention)', in Ulfstein, G., Marauhn T. and Zimmermann A. (eds.), Making Treaties Work, Human Rights, Environment and Arms Control, Cambridge: Cambridge University Press, 2007), pp. 179217.

Koester, V., 'The Aarhus Convention Compliance Mechanism and Proceedings before its Compliance Committee', in Banner, C. (ed.), The Aarhus Convention: A Guide for UK Lawyers, Oxford: Bloomsbury Publishing, 2015), pp. 201-216.

Korkea-Aho, E. and Leino, P., 'Who owns the information held by EU agencies? Weed killers, commercially sensitive information and transparent and participatory governance' 54(4) Common market law review, (2017), pp. 1059-1091.

Krämer, L., 'Procedural Environmental Rights: Principle X in Theory and Practice', in Jendroska, J. and Bar, M. (eds.), The Aarhus Convention at Ten. Interactions and Tensions between Conventional International Law and EU Environmental Law, Cambridge, Antwerp, Portland: Intersentia, 2017). 
Krämer, L., Casebook on EU environmental law (Oxford, Portland: Hart Publishing, 2002).

Krämer, L. (2006). Mechanisms at EC level to hold the European Investment Bank accountable. Paper presented at the 'Right to appeal' - International Financial Institutions and accountability - on the way to independent compliance and appeal mechanism for the European Investment Bank - Conference, Brussels. http://old.bankwatch.org /right_to_appeal/background/eib_existing_mechanisms_kramer.pdf

Krämer, L., 'The EU, access to environmental information and the open society' 14(4) ERA Forum, (2013), pp. 463-474.

Krämer, L., 'The Aarhus Convention and the European Union', in Banner, C. (ed.), The Aarhus Convention: a guide for UK lawyers, (Oxford: Hart Publishing, 2015).

Krämer, L. and Berthier, A. (2014). The Aarhus Convention: Implementation and compliance in EU law. Retrieved from: https://www.documents.clientearth.org/wp-content /uploads/library/2014-10-28-the-aarhus-convention-implementation-and-compliance-in-eulaw-ce-en.pdf

Kranenborg, H. and Voermans, W., Access to information in the European Union: a comparative analysis of EC and member state legislation, (Groningen: Europa Law Publishing, 2005).

Kravchenko, S., 'Procedural Rights as a Crucial Tool to Combat Climate Change' 38 Georgia Journal of International and Comparative, (2009), pp. 613.

Kulovesi, K., Morgera, E. and Muñoz, M., 'Environmental integration and multifaceted international dimensions of EU law: unpacking the EU's 2009 Climate and Energy Package”, 48(3) Common market law review, (2011), pp. 829-891.

Laville, S., Taylor, M. and Hurst, D. (2019, 15 March 2019). 'It's our time to rise up': youth climate strikes held in 100 countries, The Guardian. Retrieved from https://www.theguardian.com/environment/2019/mar/15/its-our-time-to-rise-up-youthclimate-strikes-held-in-100-countries

Lavrysen, L., (2009). An introduction to the Aarhus Convention: International Conference on the Practical Implementation of the Aarhus Convention.

Lawrence, P. M., 'Justice for future generations: climate change and international law', (Cheltenham, UK: Edward Elgar Publishing, 2014).

Lee, M., EU environmental law, governance and decision-making, Second edition (Oxford: Hart Publishing, 2014). 
Lee, M. and Abbot, C., 'The Usual Suspects? Public Participation Under the Aarhus Convention’ 66(1) The Modern Law Review, (2003), pp. 80-108.

Legal Service of the Council of the European Union, Application of Articles 290 (delegated acts) and 291 (implementing acts) TFEU, (2011).

Lin, J., 'Governing Biofuels: A principal-agent Analysis of the European Union Biofuels Certification Regime and the Clean Development Mechanism' 24(1) Journal of Environmental Law, (2011), pp. 43-73.

MacDonald, K. and Makuch, Z., 'Emissions Trading and the Aarhus Convention: A Proportionate Symbiosis?', in Peeters, M. and Deketelaere, K. (eds.), EU Climate Change Policy: The Challenge of New Regulatory Initiatives, (Cheltenham, Northampton: Edward Elgar Publishing, 2006), pp. 125-152.

Mach, K. J., Planton, S. and von Stechow(eds.), C., 'Annex II: Glossary', in Pachauri, R. K., Allen, M. R., Barros, V. R., Broome, J., Cramer, W., Christ, R., Church, J. A., Clarke, L., Dahe, Q. and Dasgupta, P. (eds.), Climate change 2014: synthesis report. Contribution of Working Groups I, II and III to the fifth assessment report of the Intergovernmental Panel on Climate Change, Geneva, Switzerland: IPCC, 2014), pp. 117-130.

Maitre, E. and Meissner Pritchard, J., 'Reporting obligations under the Renewable Energy Directive and the Fuel Quality Directive' Legal Briefing ClientEarth, (2011), pp. i-20.

Markandya, A., Halsnaes, K., Lanza, A., Matsuoka, Y., Maya, S., Pan, J., Shogren, J., Seroa de Motta, R., Zhang, T. and Taylor, T., 'Costing Methodologies', in Metz, B. and Davidson, O. (eds.), Climate change 2001: mitigation: contribution of Working Group III to the third assessment report of the Intergovernmental Panel on Climate Change, Vol. 3 (Cambridge: Cambridge University Press, 2001), pp. 455-498.

Marshall, F., 'Two Years in the Life: The Pioneering Aarhus Convention Compliance Committee 2004-2006’ 8(1) International Community Law Review, (2006), pp. 123-154.

Marxsen, C., 'Open Stakeholder Consultations at the European Level-Voice of the Citizens?’ 21(2) European Law Journal, (2015), pp. 257-280.

Mason, M., 'Information disclosure and environmental rights: the Aarhus convention' 10(3) Global environmental politics, (2010), pp. 10-31.

Mason, M., 'So Far but No Further? Transparency and Disclosure in the Aarhus Convention', in Mason, M. and Gupta, A. (eds.), Transparency in Global Environmental Governance: Critical Perspectives, Cambridge, Massachusetts: MIT Press, 2014), pp. 83-106. 
Matz-Luck, N., 'Framework conventions as a regulatory tool' 1(3) Goettingen Journal of International Law, (2009), pp. 439-458.

Mayer, B., 'Obligations of conduct in the international law on climate change: A defence' 27(2) Review of European, Comparative \& International Environmental Law, (2018), pp. 130-140. doi: 10.1111/reel.12237

Mbengue, M. M., 'Rules of Interpretation (Article 32 of the Vienna Convention on the Law of Treaties)' 31(2) ICSID Review-Foreign Investment Law Journal, (2016), pp. 388-412.

Meeting of the Parties to the Convention on Access to Information, Public Participation in Decision-making and Access to Justice in Environmental Matters, Report of the fourth session of the Meeting of the Parties (ECE/MP.PP/2011/2), (2011).

Meeting of the Parties to the Convention on Access to Information, Public Participation in Decision-making and Access to Justice in Environmental Matters, Report of the sixth session of the Meeting of the Parties ECE/MP.PP/2017/2, (2017a).

Meeting of the Parties to the Convention on Access to Information, Public Participation in Decision-making and Access to Justice in Environmental Matters, Report of the sixth session of the Meeting of the Parties - Addendum - Decisions adopted by the Meeting of the Parties ECE/MP.PP/2017/2/Add.1, (2017b).

Meeting of the Parties to the Convention on Access to Information Public Participation in Decision-making and Access to Justice in Environmental Matters, Decision III/8 Long-term Strategic Plan, ECE/MP.PP/2008/2/Add.16.

Meeting of the Parties to the Convention on Access to Information Public Participation in Decision-making and Access to Justice in Environmental Matters, Decision V/5 Strategic Plan for 2015-2020, ECE/MP.PP/2014/2/Add.1.

Meeting of the Parties to the Convention on Access to Information Public Participation in Decision-making and Access to Justice in Environmental Matters, Report of the first Meeting of the Parties - Decision I/7 Review of Compliance, (2002).

Meeting of the Parties to the Convention on Access to Information Public Participation in Decision-making and Access to Justice in Environmental Matters, Decisions II/5 General Issues of ComplianceISSUES OF COMPLIANCE, (2005).

Meeting of the Parties to the Convention on Access to Information Public Participation in Decision-making and Access to Justice in Environmental Matters, Decision III/9 Work Programme for 2009-2011, ECE/MP.PP/2008/2/Add.17, (2008a). 
Meeting of the Parties to the Convention on Access to Information Public Participation in Decision-making and Access to Justice in Environmental Matters, Draft Decision III/8 Longterm Strategic Plan ECE/MP.PP/2008/L.10, (2008b).

Meeting of the Parties to the Convention on Access to Information Public Participation in Decision-making and Access to Justice in Environmental Matters, Decision EMP.II/1 Public participation in decision-making, ECE/MP.PP/2010/2/Add.1, (2010).

Meeting of the Parties to the Convention on Access to Information Public Participation in Decision-making and Access to Justice in Environmental Matters, Decision IV/6 Work programme for 2012-2014, ECE/MP.PP/2011/2/Add.1, (2011).

Meeting of the Parties to the Convention on Access to Information Public Participation in Decision-making and Access to Justice in Environmental Matters, Decision V/6. Work programme for 2015-2017, ECE/MP.PP/2014/2/Add.1, (2014a).

Meeting of the Parties to the Convention on Access to Information, Public Participation in Decision-making and Access to Justice in Environmental Matters, Report of the fifth session of the Meeting of the Parties, ECE/MP.PP/2014/2, (2014b).

Meeting of the Parties to the Convention on Access to Information Public Participation in Decision-making and Access to Justice in Environmental Matters, Decision VI/2 Promoting effective public participation in decision-making, ECE/MP.PP/2017/2/Add.1, (2018a).

Meeting of the Parties to the Convention on Access to Information Public Participation in Decision-making and Access to Justice in Environmental Matters, Decision VI/5 Work programme for 2018-2021, ECE/MP.PP/2017/2/Add.1, (2018b).

Meeting of the Parties to the United Framework Convention on Climate Change, Decision 1/CP.16 The Cancun Agreements: Outcome of the work of the Ad Hoc Working Group on Long-term Cooperative Action under the Convention FCCC/CP/2010/7/Add.1.

Meeting of the Parties to the United Framework Convention on Climate Change, Decision 1/CP.17 Establishment of an Ad Hoc Working Group on the Durban Platform for Enhanced Action, UN Doc FCCC/CP/2011/9/Add.1.

Meeting of the Parties to the United Framework Convention on Climate Change, Decision 1/CP.21 Adoption of the Paris Agreement FCCC/CP/2015/10/Add.1.

Meeting of the Parties to the United Framework Convention on Climate Change, Decision 2/CP.17 Outcome of the work of the Ad Hoc Working Group on Long-term Cooperative Action under the Convention FCCC/CP/2011/9/Add.1 
Meeting of the Parties to the United Framework Convention on Climate Change, Decision 9/CP.13 Amended New Delhi work programme on Article 6 of the Convention FCCC/CP/2007/6/Add.1.

Meeting of the Parties to the United Framework Convention on Climate Change, Decision 11/CP.8 New Delhi work programme on Article 6 of the Convention FCCC/CP/2002/7/Add.1.

Meeting of the Parties to the United Framework Convention on Climate Change, Decision 15/CP.18 Doha work programme on Article 6 of the Convention FCCC/CP/2012/8/Add.2.

Meeting of the Parties to the United Framework Convention on Climate Change, Decision 17/CP.22 Improving the effectiveness of the Doha work programme on Article 6 of the Convention FCCC/CP/2016/10/Add.2.

Meeting of the Signatories to the Convention on Access to Information Public Participation in Decision-making and Access to Justice in Environmental Matters, Report on the first meeting, (1999).

Meeting of the Signatories to the Convention on Access to Information Public Participation in Decision-making and Access to Justice in Environmental Matters, Report on the second meeting, (2000).

Mendes, J., 'Participation and the Role of Law after Lisbon: A Legal View on Article 11 TEU’ 48(6) Common market law review, (2011), pp. 1849-1878.

Mercadié, A., Application of the Aarhus Convention in the Integrated Coastal Zone Management (ICZM) Process' (1999). Retrieved from: https://ec.europa.eu/environment/iczm/pdf/aarhusen.pdf

Misonne, D., 'Access to Information and the Paris Agreement', in Jendrośka, J. and Bar, M. (eds.), Procedural Environmental Rights: Principle $X$ in Theory and Practice, Vol. 4 (Cambridge: Intersentia, 2017).

Moolenaar, T. and Nóbrega, S., 'Access to justice: Environmental Non-Governmental Organisations according to the Aarhus Regulation' (2/2016) ELNI Review, (2016), pp. 7684.

Morgera, E., 'An Update on the Aarhus Convention and its Continued Global Relevance' 14(2) Review of European Community \& International Environmental Law, (2005), pp. 138147. doi: 10.1111/j.1467-9388.2005.00434.x

Moules, R., 'Significant EU Environmental Cases: 2017' 30(1) Journal of Environmental Law, (2018), pp. 157-167. 
Nastasi, G., 'Biofuels - Driving best practice in voluntary certification' Client Earth Briefing, (2013), pp. 1-2.

Nóbrega, S., Personal communication via email with the previous Chair to the Aarhus Convention Compliance Committee, Mr. Veit Koester (09 ${ }^{\text {th }}$ of April of 2013). [Access to Environmental Information].

Nóbrega, S., Personal communication via Europe Direct Contact Centre (12 April 2017). [Biofuels voluntary schemes - first answer].

Nóbrega, S., Personal communication via Europe Direct Contact Centre (5 May 2017). [Biofuels voluntary schemes - second answer].

Nóbrega, S., Personal communication via Europe Direct Contact Centre (18 May 2017). [Biofuels voluntary schemes - third answer].

Nugent, N., Paterson, W. E. and Wright, V., The European Commission, (Houndmills, Basingstoke, Hampshire: Palgrave, 2001).

Oberthür, S. and Bodle, R., 'Legal form and nature of the Paris outcome' 6(1-2) Climate law, (2016a), pp. 40-57.

Oberthür, S. and Bodle, R., 'Legal Form of the Paris Agreement and Nature of Its Obligations', in Klein, D., Pía Carazo, M., Doelle, M., Bulmer, J. and Higham, A. (eds.), The Paris Agreement on Climate Change: Analysis and Commentary, Oxford: Oxford University Press, 2016b), pp. 91-103.

Obradovic, D., 'EU Rules on Public Participation in Environmental Decision-Making Operating at the European and National Levels' The Aarhus Convention at Ten: Interactions and Tensions Between Conventional International Law and EU Environmental Law, Groningen: Europa Law Publishing, 2011), pp. 149-187.

Oliver, P., 'Access to Information and to Justice in EU Environmental Law: The Aarhus Convention' 36 Fordham International Law Journal, (2013), pp. 1423-1470.

Orakhelashvili, A., The interpretation of acts and rules in public international law, (Oxford: Oxford University Press, 2008).

Organization of American States, Inter-American Strategy for the Promotion of Public Participation in Decision-Making for Sustainable Development, (2011).

Paas, L., 'Action for climate empowerment: guidelines for accelerating solutions through education, training and public awareness'(Paris: UNESCO Publishing, 2016). 
Paiement, P., 'Transnational delegation, accountability and the administrative governance of biofuel standards', in Wood, S., Schmidt, R., Abbott, K., Eberlein, B. and Meidinge, E. (eds.), Transnational business governance interactions: Enhancing regulatory capacity, ratcheting up standards and empowering marginalized Actors (Cheltenham: Edward Elgar Publishing, 2019).

Pallemaerts, M., Compliance by the European Community with its obligations on access to justice as a party to the Aarhus Convention: an IIEP report for WWF-UK, (2009).

Pallemaerts, M., 'Access to Environmental Justice at EU Level : has the "Aarhus Regulation" improved the Situation?', in Pallemaerts, M. (ed.), The Aarhus Convention at ten: interactions and tensions between conventional international law and EU environmental law, Vol. 9 (Groningen,Amsterdam: Europa Law Publishing, 2011).

Paltsev, S. V., 'The Kyoto Protocol: Regional and Sectoral Contributions to the Carbon Leakage' 22(4) The Energy Journal, (2001), pp. 53-79.

Paradissis, J. J., (2005). The right to access environmental information: an analysis of UK law in the context of international, European, and comparative law: City University London. http://openaccess.city.ac.uk/8454/1/The_right_to_access_environmental_information_an_analysis_of_UK_law_in_the_context_of_international\%2C_European\%2C_and_comp arative_law.pdf,

Parola, G., 'Environmental democracy at the global level rights and duties for a new citizenship', (London: Versita, 2013).

Peeters, M., 'Legislative choices and legal values: considerations on the further design of the European greenhouse gas Emissions Trading Scheme from a viewpoint of democratic accountability', in Faure, M. and Peeters, M. (eds.), Climate change and European emissions trading: lessons for theory and practice, Cheltenham, UK: Edward Elgar Publishing, 2008), pp. 17-52.

Peeters, M., 'Instrument mix or instrument mess? The administrative complexity of the EU legislative package for climate change', in Peeters, M. and Uylenburg, R. (eds.), EU Environmental Legislation: Legal Perspectives on Regulatory Strategies, (Cheltenham: Edward Elgar, 2014), pp. 173-192.

Peeters, M., 'HvJ EU van 28 april 2016 in de gevoegde zaken C 191/14, C 192/14, C 295/14, C 389/14 en C 391/14 tot en met C 393/14, ECLI:EU:C:2016:311' 44(6) Tijdschrift Milieu \& Recht, (2017), pp. 537-540.

Peeters, M., Chen, H. and Li, Z., 'Contrasting emission trading in the EU and China: An exploration of the role of the courts' 6(1-2) Climate law, (2016), pp. 197-226. 
Peeters, M. and Deketelaere, K., 'Key challenges of EU climate change policy: competences, measures and compliance', in Peeters, M. and Deketelaere, K. (eds.), EU climate change policy: the challenge of new regulatory initiatives, Cheltenham: Edward Elgar Publishing, 2006), pp. 3-21.

Peeters, M. and Nóbrega, S., 'Climate Change-related Aarhus Conflicts: How Successful are Procedural Rights in EU Climate Law?' 23(3) Review of European, Comparative \& International Environmental Law, (2014), pp. 354-366.

Pitea, C., 'Procedures and Mechanisms for Review of Compliance under the 1998 Aarhus Convention on Access to Information, Public Participation and Access to Justice in Environmental Matters', in Treves, T. (ed.), Non-compliance procedures and mechanisms and the effectiveness of international environmental agreements; Non-compliance Procedures and Mechanisms and the Effectiveness of International Environmental Agreements, (The Hague: T.M.C. Asser Press, 2009).

Ponzano, P., 'The Reform of Comitology and Delegated Acts: An Executive's View', in Bergström, C. F. and Ritleng, D. (eds.), Rulemaking by the European Commission: The New System for Delegation of Powers, (Oxford: Oxford University Press, 2016), pp. 37-54.

Posner, R. A., 'In Memoriam: Bernard D. Meltzer (1914-2007)' 74(2) University of Chicago Law Review, (2007), pp. 435-438.

Poto, M., 'Strengths and Weaknesses of Environmental Participation Under the Aarhus Convention: What Lies Beyond Rhetorical Procedualisation?', in Lohse, E. J., Poto, M. and Parola, G. (eds.), Participatory rights in the environmental decision-making process and the implementation of the Aarhus Convention: a comparative perspective (Berlin: Duncker \& Humblot, 2015), pp. 93-104.

Rajamani, L., 'The Nature, Promise, and Limits of Differential Treatment in the Climate Regime’ 16(1) Yearbook of International Environmental Law, (2005), pp. 81-118.

Rajamani, L., 'The United Nations Framework Convention on Climate Change: a framework approach to climate change', in Faber, D. A. and Peeters, M. (eds.), Climate Change Law, Cheltenham, UK: Edward Elgar Publishing, 2016), pp. 205-216.

Razzaque, J., 'Human rights to a clean environment: procedural rights', in Fitzmaurice, M., M. Ong, D. and Merkouris, P. (eds.), Research handbook on international environmental law (Cheltenham, Northampton: Edward Elgar, 2010), pp. 284-300.

Reinaud, J., 'Issues behind Competitiveness and Carbon Leakage: Focus on Heavy Industry', IEA Information Paper, http://citeseerx.ist.psu.edu/viewdoc/download?doi=10.1. 1.177.7190\&rep=rep1\&type=pdf (2008). 
Romppanen, S., 'The EU's Biofuels: Certified as Sustainable?' 3(3) Renewable Energy Law \& Policy Review, (2012a), pp. 173-186.

Romppanen, S., 'Regulating Better Biofuels for the European Union' 21(3) European Energy \& Environmental Law Review, (2012b), pp. 123-141.

Rose-Ackerman, S. and Halpaap, A. A., 'The Aarhus convention and the politics of process: the political economy of procedural environmental rights' Research in law and economics : a research annual, (2002), pp. 1-42.

Ember. Transparency issues compound problems with EU carbon market, from https://ember-climate.org/2014/05/16/transparency-issues-compound-problems-with-eucarbon-market/, 19 June 2020.

Sartoretti, C., 'The Aarhus Convention Between Protection of Human Rights and Protection of the Environment ', in Lohse, E. J., Poto, M. and Parola, G. (eds.), Participatory rights in the environmental decision-making process and the implementation of the Aarhus Convention: a comparative perspective, (Berlin: Duncker \& Humblot, 2015), pp. 45-58.

Schlamann, I., Wieler, B., Fleckenstein, M., Walther-Thoß, J., Haase, N. and Mathe, L., 'Searching for Sustainability: Comparative Analysis of Certification Schemes for Biomass used for the Production of Biofuels', (Düsseldorf: WWF Deutschland, 2013).

Schneider, L., Kollmuss, A. and Lazarus, M., 'Addressing the risk of double counting emission reductions under the UNFCCC' 131(4) Climatic Change, (2015), pp. 473-486.

Scott, J., 'Extraterritoriality and Territorial Extension in EU Law' 62(1) The American Journal of Comparative Law, (2014), pp. 87-126. doi: 10.5131/AJCL.2013.0009

Seinfeld, J. H. and Pandis, S. N., 'Atmospheric chemistry and physics: from air pollution to climate change', Second Edition (Hoboken, New Jersey John Wiley \& Sons, 2006).

Shaw, M. N., International law, Seventh Edition (Cambridge: Cambridge University Press, 2014).

Shelton, D., 'Human rights, environmental rights, and the right to environment' 28(1) Stanford Journal of International Law, (1991), pp. 103-138.

Shelton, D., 'Equity', in Bodansky, D., Brunnée, J. and Hey, E. (eds.), The Oxford Handbook of International Environmental Law, (Oxford: Oxford University Press, 2007), pp. 639-662.

Shelton, D., 'Human Rights and the Environment: Substantive Rights', in Fitzmaurice, M. (ed.), Research handbook on international environmental law, (Cheltenham: Edward Elgar Publishing, 2010). 
Smits, J., 'The mind and method of the legal academic', (Cheltenham: Edward Elgar Publishing, 2012).

Smits, J. 'What is Legal Doctrine?: On the Aims and Methods of Legal-Dogmatic Research' in Gestel, R. van, Micklitz, H.-W. and Rubin, E. L. (eds.), Rethinking scholarship: a transatlantic dialogue (Cambridge, Cambridge University Press, 2017), pp. 207-228.

Spalding-Fecher, R., Achanta, A. N., Erickson, P., Haites, E., Lazarus, M., Pahuja, N., Pandey, N., Seres, S. and Tewari, R., Assessing the impact of the clean development mechanism - Report commissioned by the High Level Panel on the CDM policy Dialogue, (2012).

Sportisse, B., Fundamentals in air pollution: from processes to modelling: Springer Science \& Business Media, 2010).

Stec, S., “'Aarhus" Environmental Rights in Eastern Europe' 5 Yearbook of European environmental law, (2005), pp. 1-22.

Stec, S., Casey-Lefkowitz, S. and Jendrośka, J., (2000). The Aarhus Convention: an implementation guide (Vol. 72): United Nations, Economic Commission for Europe.

Stefan, O., 'European Union Soft Law: New Developments Concerning the Divide Between Legally Binding Force and Legal Effects' 75(5) The Modern Law Review, (2012), pp. 879893.

Stevenson, A. and Waite, M., Concise Oxford English Dictionary, (Oxford: Oxford University Press, 2011), p. 1110.

Stewart, R. B., 'Instrument choice', in Bodansky, D., Brunnée, J. and Hey, E. (eds.), The Oxford Handbook of International Environmental law, Oxford: Oxford university Press, 2007), pp. $147-181$.

Subsidiary Body for Implementation of the UNFCCC, Progress made in implementing the Doha work programme on Article 6 of the Convention FCCC/SBI/2016/6.

Subsidiary Body for Implementation of the UNFCCC, Review of the implementation of the New Delhi work programme on Article 6 of the Convention FCCC/SBI/2007/22.

Subsidiary Body for Implementation of the UNFCCC, Report on progress made in, and the effectiveness of, the implementation of the amended New Delhi work programme on Article 6 of the Convention FCCC/SBI/2012/3, (2012). 
Tanzi, A. and Pitea, C., 'The Interplay between EU law and International Law Procedures in Controlling Compliance with the Aarhus Convention by EU Member States', in Pallemaerts, M. (ed.), The Aarhus Convention at Ten. Interactions and Tensions between Conventional International Law and EU Environmental Law (Groningen: Europa Law Publishing, 2011).

Task Force on Public Participation under the Aarhus Convention, Maastricht Recommendations on Promoting Effective Public Participation in Decision-making in Environmental Matters ECE/MP.PP/2014/2/Add.2, (2014).

Terpan, F., 'Soft Law in the European UnionThe Changing Nature of EU Law' 21(1) European Law Journal, (2015), pp. 68-96.

Thorp, T. M., Climate justice: a voice for the future, (New York: Palgrave Macmillan, 2014).

Tingley, M. W. (2003). Effects of offshore wind farms on birds: Cuisinarts of the sky or just tilting at windmills? (PhD Thesis), Harvard University, Cambridge.

Toth, B., 'Public participation and democracy in practice-Aarhus convention principles as democratic institution building in the developing world' 30(2) Journal of Land Resources \& Environmental Law, (2010), pp. 295-330.

Ugarte, S., van Dam, J., Spijkers, S. and Gaebler, M., 'Recognition of Private Certification Systems for Public Regulation: Lessons Learned from the EU Renewable Energy Directive', (Bonn-Berlin: Deutsche Gesellschaft für Internationale Zusammenarbeit (GIZ) GmbH, 2013).

United Nations Conference on Environment and Development (UNCED) (Rio de Janeiro, 314 June 1992).

United Nations, Terms of Reference and Rules of Procedure of the Economic Commission for Europe (2009).

United Nations Economic Commission for Europe, 'Guidance Document on the Aarhus Convention Compliance Mechanism’(Geneva: United Nations, 2010).

United Nations Economic Commission for Europe, 'Guide to the Aarhus Convention Compliance Committee'(Geneva: United Nations, 2017).

United Nations Economic Commission for Europe, 'Guide to the Aarhus Convention Compliance Committee'(Geneva: United Nations, 2019).

United Nations Treaty Collection. Chapter XXVII - Environment - 7. c Doha Amendment to the Kyoto Protocol, from https://treaties.un.org/Pages/ViewDetails.aspx?src=TREATY \&mtdsg_no=XXVII-13\&chapter=27\&lang=en, 15 April 2019. 
United Nations Treaty Collection. Chapter XXVII - Environment - 13. Convention on Access to Information, Public Participation in Decision-Making and Access to Justice in Environmental Matters, from https://treaties.un.org/Pages/ViewDetails.aspx?src =TREATY\&mtdsg_no=XXVII-13\&chapter=27\&lang=en, 26 June 2019.

Valin, H., Peters, D., van den Berg, M., Frank, S., Havlik, P., Forsell, N., Hamelinck, C., Pirker, J., Mosnier, A., Balkovič, J., Schmid, E., Dürauer, M. and di Fulvio, F., The land use change impact of biofuels consumed in the EU: Quantification of area and greenhouse gas impacts, $\quad$ https://ec.europa.eu/energy/sites/ener/files/documents/Final\%20Report_ GLOBIOM_publication.pdf (2015).

Van Dam, J., Ugarte, S. and van Iersel, S., Selecting a biomass certification system-a benchmark on level of assurance, costs and benefits, https://jvdconsultancy.com/wp-content /uploads/2019/11/Selecting-a-biomass-certific-ation-system---a-benchmark-on-level-ofassurance-costs-and-benefits-March-2012-.pdf (2012).

Van Zeben, J., The allocation of regulatory competence in the EU emissions trading scheme (Cambridge: Cambridge University Press, 2014).

Vogelpohl, T. and Perbandt, D., 'Biofuel sustainability certifications in the EU: democratically legitimate and socio-environmentally effective?', in Vogt, M. (ed.), Sustainability certification schemes in the agricultural and natural resource sectors: outcomes for society and the environment, (Abingdon, Oxon: Routledge, 2019), pp.179-198.

Voigt, C., 'The Paris Agreement: What is the Standard of Conduct for Parties?' 24 Questions of International Law, (2016), pp. 17-28.

Voigt, C. and Ferreira, F., 'Dynamic Differentiation': The Principles of CBDR-RC, Progression and Highest Possible Ambition in the Paris Agreement' 5(2) Transnational Environmental Law, (2016), pp. 285-303.

von Holleben, H., 'Judgment of the General Court of the EU on Access to Information Under Substance Law: Case T-545/11, Judgment of 08 October 2013' 4(4) European Journal of Risk Regulation, (2013), pp. 565-578.

Wates, J., 'The future of the Aarhus Convention: Perspectives Arising from the Third Session of the Meeting of the Parties', in Pallemaerts, M. (ed.), The Aarhus Convention at Ten: Interactions and Tensions between Conventional International Law and EU Environmental Law, (Groningen: Europa Law Publishing, 2011).

Wates, J., Nagy, M. T. and Stec, S., ECO Report on the Fourth Negotiating Session and Preparatory Meetings, (1997). 
Wennerås, P., The enforcement of EC environmental law, (Oxford: Oxford University Press, 2007).

Wewerinke-Singh, M. and Doebbler, C., 'The Paris agreement: Some critical reflections on process and substance' 39(4) The University of New South Wales Law Journal, (2016), pp. 1486-1517.

Wiersema, A., 'The new international law-makers? Conferences of the parties to multilateral environmental agreements' 31(1) Michigan Journal of International Law, (2009), pp. 231287.

Winkler, H. and Rajamani, L., 'CBDR\&RC in a regime applicable to all' 14(1) Climate Policy, (2014), pp. 102-121.

Winter, G., 'National Administrative Procedural Law under EU Requirements: With a Focus on Public Participation', in Jans, J. H., Macrory, R. and Moreno Molina, A.-M. (eds.), National courts and EU environmental law, (Groningen: Europa Law Publishing, 2013), pp. 11-33.

Winter, G., 'Theoretical Foundations of Public Participation in Administrative DecisionMaking', in Bándi, G. D. (ed.), Environmental democracy and law: public participation in Europe, Groningen: Europa Law Publishing, 2014), pp. 21-36.

Woerdman, E., 'The EU Greenhouse Gas Emissions Trading Scheme', in Woerdman, E. R., M.M.; Holwerda, M. (ed.), Essential EU Climate Law, (Cheltenham: Edward Elgar, 2015).

Woerdman, E., Clò, S. and Arcuri, A., 'European emissions trading and the polluter-pays principle: assessing grandfathering and over-allocation', in Faure, M. and Peeters, M. (eds.), Climate Change and European Emission Trading, (Cheltenham: Edward Elgar, 2008), pp. 128-150.

Wolf, S., 'Access to EU environmental information: EU compliance with Aarhus Convention’ 14(4) ERA Forum, (2013), pp. 475-491.

Working Group for the preparation of a draft convention on access to environmental information and public participation in environmental decision-making, Report on the ninth session.

Working Group for the preparation of a draft convention on access to environmental information and public participation in environmental decision-making, Draft elements for the Convention on Access to Environmental Information and Public Participation in Environmental Decision-making, (1996). 
Working Group for the preparation of a draft convention on access to environmental information and public participation in environmental decision-making, Report of the fifth session, (1997a).

Working Group for the preparation of a draft convention on access to environmental information and public participation in environmental decision-making, Report of the fourth session, (1997b).

Working Group for the preparation of a draft convention on access to environmental information and public participation in environmental decision-making, Report of the sixth session, (1997c).

Working Group for the preparation of a draft convention on access to environmental information and public participation in environmental decision-making, Report of the third session, (1997d).

WWF. Climate and Energy, from http://wwf.panda.org/our_work/climate_and_energy/, 18 June 2020

Yue, T., 'Different paths towards sustainable biofuels? A Comparative Study of the International, EU, and Chinese Regulation of the Sustainability of Biofuels', (Cambridge, Antwerp, Portland: Intersentia, 2016).

\section{European Union Legislation}

Comission Regulation (EU) No 1123/2013 of 8 November 2013 on determining international credit entitlements pursuant to Directive 2003/87/EC of the European Parliament and of the Council, OJ L 299/32.

Comission Regulation (EU) No 1210/2011 of 23 November 2011 amending Regulation (EU) No 1031/2010 in particular to determine the volume of greenhouse gas emission allowances to be auctioned prior to 2013 , OJ L308/2.

Commission Decision 2001/937/EC of 5 December 2001 amending its rules of procedure, OJ L 345/94.

Commission Decision 2006/780/EC of 13 November 2006 on avoiding double counting of greenhouse gas emission reductions under the Community emissions trading scheme for project activities under the Kyoto Protocol pursuant to Directive 2003/87/EC of the European Parliament and of the Council, OJ L 316/12.

Commission Decision 2007/589/EC of 18 July 2007 establishing guidelines for the monitoring and reporting of greenhouse gas emissions pursuant to Directive 2003/87/EC of 
the European Parliament and of the Council (notified under document number C(2007) 3416), OJ L 229/1.

Commission Decision 2010/02/EU determining a list of sectors and subsectors which are deemed to be exposed to a significant risk of carbon leakage $C(2009)$ 10251, OJ L 1/10.

Commission Decision 2010/384/EU of 9 July 2010 on the Community-wide quantity of allowances to be issued under the EU Emission Trading Scheme for 2013 (notified under document C(2010) 4658), OJ L 175/36.

Commission Decision 2010/634/EU of 22 October 2010 adjusting the Union-wide quantity of allowances to be issued under the Union Scheme for 2013 and repealing Decision 2010/384/EU (notified under document C(2010) 7180), OJ L 279/34.

Commission Decision 2011/278/EU of 27 April 2011 determining transitional Union-wide rules for harmonised free allocation of emission allowances pursuant to Article 10a of Directive 2003/87/EC of the European Parliament and of the Council, OJ L 130/1.

Commission Decision 2011/745/EU amending Decisions 2010/2/EU and 2011/278/EU as regards the sectors and subsectors which are deemed to be exposed to a significant risk of carbon leakage C(2011) 8017, OJ L 299/9.

Commission Decision 2012/498/EU amending Decisions 2010/2/EU and 2011/278/EU as regards the sectors and subsectors which are deemed to be exposed to a significant risk of carbon leakage C (2012) 5715, OJ L 241/52.

Commission Decision 2014/9 amending Decisions 2010/2/EU and 2011/278/EU as regards the sectors and subsectors which are deemed to be exposed to a significant risk of carbon leakage C (2013) 9186, OJ L 9/9.

Commission Decision 2014/746/EU of 27 October 2014 determining, pursuant to Directive 2003/87/EC of the European Parliament and of the Council, a list of sectors and subsectors which are deemed to be exposed to a significant risk of carbon leakage, for the period 2015 to $2019 \mathrm{C}(2014) 7809$, OJ L 308/114.

Commission Decision (EU) No 2013/448/EU concerning national implementation measures for the transitional free allocation of greenhouse gas emission allowances in accordance with Article 11(3) of Directive 2003/87/EC of the European Parliament and of the Council, OJ L $240 / 27$.

Commission Decision (EU) No 2017/126 of 24 January 2017 amending Decision 2013/448/EU as regards the establishment of a uniform cross-sectoral correction factor in accordance with Article 10a of Directive 2003/87/EC of the European Parliament and of the Council, OJ L 19/93. 
Commission Decision concerning the unilateral inclusion of additional installations by the Republic of Latvia in the Community emission allowance trading scheme pursuant to Article 24 of Directive 2003/87/EC of the European Parliament and of the Council (C(2009)3032/F1).

Commission Decision of 6.6.2011 concerning the unilateral inclusion of additional greenhouse gases and activities by the United Kingdom in the scheme for greenhouse gas emission allowance trading within the Union pursuant to Article 24 of Directive 2003/87/EC of the European Parliament and of the Council (C(2011)3798).

Commission Decision of 6.7.2012 concerning the application pursuant to Article 10c (5) of Directive 2003/87/EC of the European Parliament and of the Council to give transitional free allocation for the modernisation of electricity generation notified by Bulgaria $(C(2012) 4560$ final).

Commission Decision of 6.7.2012 concerning the application pursuant to Article 10c (5) of Directive 2003/87/EC of the European Parliament and of the Council to give transitional free allocation for the modernisation of electricity generation notified by Romania (C(2012) 4564 final).

Commission Decision of 6.7.2012 concerning the application pursuant to Article 10c (5) of Directive 2003/87/EC of the European Parliament and of the Council to give transitional free allocation for the modernisation of electricity generation notified by the Czech Republic (C(2012) 4576 final).

Commission Decision of 13.7.2012 concerning the application pursuant to Article 10c (5) of Directive 2003/87/EC of the European Parliament and of the Council to give transitional free allocation for the modernisation of electricity generation notified by Poland (C(2012) 4609 final).

Commission Decision of 17.12.2008 concerning the unilateral inclusion of additional greenhouse gases and activities by the Netherlands in the Community emissions trading scheme pursuant to Article 24 of Directive 2003/87/EC of the European Parliament and of the Council (C(2008) 7867), OJ L 175/36.

Commission Decision of 23.5.2012 concerning the application pursuant to Article 10c (5) of Directive 2003/87/EC of the European Parliament and of the Council to give transitional free allocation for the modernisation of electricity generation notified by Cyprus (C(2012) 3260 final).

Commission Decision of 23.5.2012 concerning the application pursuant to Article 10c (5) of Directive 2003/87/EC of the European Parliament and of the Council to give transitional free 
allocation for the modernisation of electricity generation notified by Estonia $(C(2012) 3271$ final).

Commission Decision of 23.5.2012 concerning the application pursuant to Article 10c (5) of Directive 2003/87/EC of the European Parliament and of the Council to give transitional free allocation for the modernisation of electricity generation notified by Lithuania $(C(2012) 3237$ final).

Commission Decision of 30.11.2012 concerning the application pursuant to Article 10c (5) of Directive 2003/87/EC of the European Parliament and of the Council to give transitional free allocation for the modernisation of electricity generation notified by Hungary $(\mathrm{C}(2012)$ 8675 final).

Commission Implementing Decision 2013/634/EU of 31 October 2013 on the adjustments to Member States' annual emission allocations for the period from 2013 to 2020 pursuant to Decision No 406/2009/EC of the European Parliament and of the Council, OJ L 292/19.

Commission Regulation 600/2012 on the verification of greenhouse gas emission reports and tonne-kilometre reports and the accreditation of verifiers pursuant to Directive 2003/87/EC of the European Parliament and of the Council, OJ L 181/1.

Commission Regulation 601/2012 on the monitoring and reporting of greenhouse gas emissions pursuant to Directive 2003/87/EC of the European Parliament and of the Council, OJ L 181/30.

Commission Regulation (EC) No 920/2010 of 7 October 2010 for a standardised and secured system of registries pursuant to Directive 2003/87/EC of the European Parliament and of the Council and Decision No 280/2004/EC of the European Parliament and of the Council, OJ L 270/1.

Commission Regulation (EC) No 2216/2004 of 21 December 2004 for a standardised and secured system of registries pursuant to Directive 2003/87/EC of the European Parliament and of the Council and Decision No 280/2004/EC of the European Parliament and of the CouncilText with EEA relevance, OJ L 386/1.

Commission Regulation (EU) 2017/1902 of 18 October 2017 amending Commission Regulation (EU) No 1031/2010 to align the auctioning of allowances with Decision (EU) 2015/1814 of the European Parliament and of the Council and to list an auction platform to be appointed by the United Kingdom, OJ L 269/13.

Commission Regulation (EU) No 389/2013 of 2 May 2013 establishing a Union Registry pursuant to Directive 2003/87/EC of the European Parliament and of the Council, Decisions 
No 280/2004/EC and No 406/2009/EC of the European Parliament and of the Council and repealing Commission Regulations (EU) No 920/2010 and No 1193/2011, OJ L 122/1.

Commission Regulation (EU) No 550/2011 of 7 June 2011 on determining, pursuant to Directive 2003/87/EC of the European Parliament and of the Council, certain restrictions applicable to the use of international credits from projects involving industrial gases, $\mathrm{OJ} \mathrm{L}$ $149 / 1$.

Commission Regulation (EU) No 784/2012 of 30 August 2012 amending Regulation (EU) No 1031/2010 to list an auction platform to be appointed by Germany and correcting Article 59(7) thereof, OJ L 234/4.

Commission Regulation (EU) No 1031/2010 of 12 November 2010 on the timing, administration and other aspects of auctioning of greenhouse gas emission allowances pursuant to Directive 2003/87/EC of the European Parliament and of the Council establishing a scheme for greenhouse gas emission allowances trading within the Community, OJ L 302/1.

Commission Regulation No 176/2014 of 25 February 2014 amending Regulation (EU) No $1031 / 2010$ in particular to determine the volumes of greenhouse gas emission allowances to be auctioned in 2013-20, OJ L 56/11.

Commission Regulation No 1042/2012 of 7 November 2012 amending Regulation (EU) No $1031 / 2010$ to list an auction platform to be appointed by the United Kingdom, OJ L 310/9.

Commission Regulation No 1143/2013 of 13 November 2013 amending Regulation (EU) No $1031 / 2010$ on the timing, administration and other aspects of auctioning of greenhouse gas emission allowances pursuant to Directive 2003/87/EC of the European Parliament and of the Council establishing a scheme for greenhouse gas emission allowances trading within the Community in particular to list an auction platform to be appointed by Germany, OJ L $303 / 10$.

Consolidated Version of the Treaty on European Union, OJ C 326/13.

Consolidated Version of the Treaty on the Functioning of the European Union, OJ C 326/47.

Convention on Environmental Impact Assessment in a Transboundary Context, Espoo, Finland, 25 February 1991, United Nations Treaty Series, vol. 1989, p. 309 (entrered into force on 10 September 1997).

Council Decision 1999/468/EC of 28 June 1999 laying down the procedures for the exercise of implementing powers conferred on the Commission, OJ L 184/23. 
Council Decision of 28 June 1999 laying down the procedures for the exercise of implementing powers conferred on the Commission (1999/468/EC), OJ L 184/23.

Council Directive 85/337/EEC of 27 June 1985 on the assessment of the effects of certain public and private projects on the environment, OJ L 175/40.

Council Directive 96/61/EC of 24 September 1996 concerning integrated pollution prevention and control, OJ L 257/26.

Council Directive 2013/18/EU of 13 May 2013 adapting Directive 2009/28/EC of the European Parliament and of the Council on the promotion of the use of energy from renewable sources, by reason of the accession of the Republic of Croatia, OJ L 158/230.

Decision 2005/370/EC on the Conclusion, on Behalf of the European Community, of the Convention on Access to Information, Public Participation in Decision-Making and Access to Justice in Environmental Matters, OJ L124/1.

Décision de la Commission concernant l'inclusion unilatérale par l'Autriche de gaz à effet de serre et d'activités supplémentaires dans le système communautaire en application de l'article 24 de la directive 2003/87/CE du Parlement européen et du Conseil (C(2009)9849/F1).

Décision de la Commission concernant l'inclusion unilatérale, par l'Italie, de gaz à effet de serre et d'activités supplémentaires dans le système d'échange de quotas d'émission de gaz à effet de serre dans l'Union en application de l'article 24 de la directive 2003/87/CE du Parlement européen et du Conseil Commission (C(2012)497/1).

Decision No 406/2009/EC of the European Parliament and of the Council of 23 April 2009 on the effort of Member States to reduce their greenhouse gas emissions to meet the Community's greenhouse gas emission reduction commitments up to 2020, OJ L 140/136.

Decision No 1359/2013/EU of the European Parliament and of the Council of 17 December 2013 amending Directive 2003/87/EC clarifying provisions on the timing of auctions of greenhouse gas allowances Text with EEA relevance, OJ L 343/21.

Directive 2001/18 of the European Parliament and of Council on the deliberate release into the environment of genetically modified organisms, OJ. L 106/1.

Directive 2003/4/EC of 28 January 2003 on Public Access to Environmental Information and Repealing Council Directive 90/313/EEC, OJ L41/26.

Directive 2003/35/EC of the European Parliament and of the Council providing for public participation in respect of the drawing up of certain plans and programmes relating to the environment and amending with regard to public participation and access to justice Council Directives 85/337/EEC and 96/61/EC, OJ L156/17. 
Directive 2003/87/EC of the European Parliament and of the Council of 13 October 2003 establishing a scheme for greenhouse gas emission allowance trading within the Community and amending Council Directive 96/61/EC, OJ L 275/32.

Directive 2003/87/EC of the European Parliament and of the Council of 13 October 2003 establishing a scheme for greenhouse gas emission allowance trading within the Community and amending Council Directive 96/61/EC, OJ L 275/32 (consolidated version).

Directive 2004/101/EC of the European Parliament and of the Council of 27 October 2004 amending Directive 2003/87/EC establishing a scheme for greenhouse gas emission allowance trading within the Community, in respect of the Kyoto Protocol's project mechanisms, OJ L 338/18.

Directive 2008/101/EC of the European Parliament and of the Council of 19 November 2008 amending Directive 2003/87/EC so as to include aviation activities in the scheme for greenhouse gas emission allowance trading within the Community, OJ L 8/3.

Directive 2009/28/EC of the European Parliament and of the Council of 23 April 2009 on the promotion of the use of energy from renewable sources and amending and subsequently repealing Directives 2001/77/EC and 2003/39, OJ L 140/16.

Directive 2009/28/EC of the European Parliament and of the Council of 23 April 2009 on the promotion of the use of energy from renewable sources and amending and subsequently repealing Directives 2001/77/EC and 2003/39, OJ L 140/63, as amended by Directive (EU) 2015/1513 of the European Parliament and of the Council of 9 September 2015 amending Directive 98/70/EC relating to the quality of petrol and diesel fuels and amending Directive 2009/28/EC on the promotion of the use of energy from renewable sources, OJ L 239/1.

Directive 2009/29/EC of the European Parliament and of the Council of 23 April 2009 amending Directive 2003/87/EC so as to improve and extend the greenhouse gas emission allowance trading scheme of the Community, OJ L 140/63.

Directive 2009/31/EC of the European Parliament and of the Council of 23 April 2009 on the geological storage of carbon dioxide and amending Council Directive 85/337/EEC, European Parliament and Council Directives 2000/60/EC, 2001/80/EC, 2004/35/EC, 2006/12/EC, 2008/1/EC and Regulation (EC) No 1013/2006, OJ L 140/63.

Directive 2010/75/EU of the European Parliament and of the Council of 24 November 2010 on industrial emissions (integrated pollution prevention and control), OJ L 334/17. 
Directive 2011/92/EU of the European Parliament and of the Council of 13 December 2011 on the assessment of the effects of certain public and private projects on the environment (codification), OJ L 26/1.

Directive 2012/27/EU of the European Parliament and of the Council of 25 October 2012 on energy efficiency, amending Directives 2009/125/EC and 2010/30/EU and repealing Directives 2004/8/EC and 2006/32/EC, OJ L 315/1.

Directive 2014/52/EU of the European Parliament and of the Council of 16 April 2014 amending Directive 2011/92/EU on the assessment of the effects of certain public and private projects on the environment, OJ L 124/1.

Directive (EU) 2015/1513 of the European Parliament and of the Council of 9 September 2015 amending Directive 98/70/EC relating to the quality of petrol and diesel fuels and amending Directive 2009/28/EC on the promotion of the use of energy from renewable sources, OJ L 239/1.

Directive (EU) 2018/410 of the European Parliament and of the Council of 14 March 2018 amending Directive 2003/87/EC to enhance cost-effective emission reductions and lowcarbon investments, and Decision (EU) 2015/1814, OJ L 76/3.

Directive (EU) 2018/2001 of the European Parliament and of the Council of 11 December 2018 on the promotion of the use of energy from renewable sources (recast), OJ L 328/82.

European Commission, Rules of Procedure of the European Commission C(2000) 3614, OJ L 308/26, (2000).

Regulation 525/2013 of the European Parliament and of the Council of 21 May 2013 on a mechanism for monitoring and reporting greenhouse gas emissions and for reporting other information at national and Union level relevant to climate change and repealing Decision No 280/2004/EC, OJ L 165/13.

Regulation (EC) No 166/2006 of the European Parliament and of the Council of 18 January 2006 concerning the establishment of a European Pollutant Release and Transfer Register and amending Council Directives 91/689/EEC and 96/61/EC, OJ L33/1.

Regulation (EC) No 219/2009 of the European Parliament and of the Council of 11 March 2009 adapting a number of instruments subject to the procedure referred to in Article 251 of the Treaty to Council Decision 1999/468/EC with regard to the regulatory procedure with scrutiny — Adaptation to the regulatory procedure with scrutiny — Part Two, OJ L 87/109.

Regulation (EC) No 1049/2001 of the European Parliament and of the Council of 30 May 2001 regarding public access to European Parliament, Council and Commission documents, OJ L145/43. 
Regulation (EC) No 1367/2006 of the European Parliament and of the Council of 6 September 2006 on the application of the provisions of the Aarhus Convention on Access to Information, Public Participation in Decision-making and Access to Justice in Environmental Matters to Community institutions and bodies, OJ L 264/13.

Regulation (EU) 2017/2392 of the European Parliament and of the Council of 13 December 2017 amending Directive 2003/87/EC to continue current limitations of scope for aviation activities and to prepare to implement a global market-based measure from 2021, OJ L 350/7.

Regulation (EU) No 182/2011 of the European Parliament and of the Council of 16 February 2011 laying down the rules and general principles concerning mechanisms for control by Member States of the Commission's exercise of implementing powers, OJ L 55/13.

Regulation (EU) No 421/2014 of the European Parliament and of the Council of 16 April 2014 Amending Directive 2003/87/EC Establishing a Scheme for Greenhouse Gas Emission Allowance Trading within the Community, in View of the Implementation by 2020 of an International Agreement Applying a Single Global Market-Based Measure to International Aviation Emissions, OJ L 129/1.

Treaty on the accession of the Republic of Croatia to the European Union, OJ L 112/10.

\section{European Union Case-law and Opinions of Advocate-Generals}

AG Opinion in Joined Cases C-401/12 P to C-403/12 P Council of the European Union, European Parliament and European Commission v. Vereniging Milieudefensie and Stichting Stop Luchtverontreiniging Utrecht, 8 May 2014, ECLI:EU:C:2014:310.

Case C-51/92, Hercules Chemicals v. Commission, 8 July 1999, ECLI:EU:C:1999:357.

Case C-57/16 P, ClientEarth v. European Commission, 4 September 2018, ECLI:EU:C:2018:660.

Case C-60/15 P, Saint-Gobain Glass Deutschland v. Commission, 13 July 2017, ECLI:EU:C:2017:540.

Case C-182/10, Marie-Noëlle Solvay and Others v. Région Wallonne 16 February 2012, ECLI:EU:C:2012:82.

Case C-204/09, Flachglas Torgau GmbH v. Federal Republic of Germany, 14 February 2012, ECLI:EU:C:2012:71.

Case C-240/09, Lesoochranárske zoskupenie VLK v. Ministerstvo životného prostredia Slovenskej republiky, 8 March 2011, ECLI:EU:C:2011:125. 
Case C-260/11, David Edwards and other v. Environment Agency, 11 April 2013, ECLI:EU:C:2013:221.

Case C-263/08, Djurgården-Lilla Värtans Miljöskyddsförening v. Stockholms kommun genom dess marknämnd, 15 October 2009, ECLI:EU:C:2009:631.

Case C-279/12, Fish Legal and Emily v. Information Commissioner, United Utilities Water plc, Yorkshire Water Services Ltd, Southern Water Services Ltd, 19 December 2013, ECLI:EU:C:2013:853.

Case C-327/00, Santex SpA v. Unità Socio Sanitaria Locale n. 42 di Pavia, 27 February 2003, ECLI:EU:C:2003:109.

Case C-362/08 P, Internationaler Hilfsfonds eV v. European Commission 26 January 2010, ECLI:EU:C:2010:40.

Case C-387/97, Commission v. Greece, 04 July 2000, ECLI:EU:C:2000:356.

Case C-442/14, Bayer CropScience SA-NV and other v. College voor de toelating van gewasbeschermingsmiddelen en biociden, 23 November 2016, ECLI:EU:C:2016:890.

Case C-515/11, Deutsche Umwelthilfe eV v. Bundesrepublik Deutschland 18 July 2013, ECLI:EU:C:2013:523.

Case C-524/09, Ville de Lyon v. Caisse des dépôts et consignations, 22 December 2010, ECLI:EU:C:2010:822.

Case C-552/07 Commune de Sausheim v. Azelvandre, 17 February 2009, ECLI:EU:C:2009:96.

Case C-673/13 P European Commission v. Stichting Greenpeace Nederland and other, 23 November 2016, ECLI:EU:C:2016:889.

Case C-556/14 P, Holcim (Romania) SA v. European Commission 7 April 2016, ECLI:EU:C:2016:207.

Case C-321/96, Wilhelm Mecklenburg v. Kreis Pinneberg - Der Landrat, 17 June 1998, ECLI:EU:C:1998:300.

Case T-7/89, Hercules Chemicals v. Commission 17 December 1991, ECLI:EU:T:1991:75.

Case T-111/11, ClientEarth v. Commission, 13 September 2013, ECLI:EU:T:2013:482.

Case T-120/10, Client Earth and others v. Commission, 9 November 2011, ECLI:EU:T:2011:646. 
Case T-168/13, European Platform Against Windfarms (EPAW) v. European Commission, 18 March 2013, ECLI:EU:T:2014:47.

Case T-381/11, Eurofer v. Commission, 4 June 2012, ECLI:EU:T:2012:273.

Case T-449/10, ClientEarth and others v. Commission, 9 November 2011, ECLI:EU:T:2011:647.

Case T-476/12, Saint-Gobain Glass Deutschland GmbH v. European Commission, 11 December 2014, ECLI:EU:T:2014:1059.

Case T-19/13, Frank Bold Society v. European Commission, 29 June 2015, ECLI:EU:T:2015:520.

Case T-278/11, ClientEarth, Friends of the Earth Europ Stichting FERN and Stichting Corporate Europe Observatory v. European Commission, 13 November 2012, ECLI:EU:T:2012:593.

Case T-545/11, Stichting Greenpeace Nederland and other v. European Commission, 8 October 2013, ECLI:EU:T:2013:523.

Cases T-494/08 to T-500/08 and T-509/08, Ryanair Ltd v. European Commission, 10 December 2010, ECLI:EU:T:2010:511.

Joined Cases C-191/14, C-192/14, C-295/14, C-389/14 and C-391/14 to C-393/14, Borealis Polyolefine $\mathrm{GmbH}$ and others v. Bundesminister für Land- und Forstwirtschaft, Umwelt und Wasserwirtschaft and others, 28 April 2016, ECLI:EU:C:2016:311.

Joined cases C-401/12 P to 403/12 P, Council of the European Union, European Parliament and European Commission v. Vereniging Milieudefensie and Stichting Stop Luchtverontreiniging Utrecht 13 January 2015, ECLI:EU:C:2015:4.

Joined Cases T-355/04 and T-446/04, Co-Frutta Soc. coop. v. Commission, 19 January 2010, ECLI:EU:T:2010:15.

Opinion of Advocate General Kokott in Case C-266/09 Stichting Natuur en Milieu, Vereniging Milieudefensie, Vereniging Goede Waar \& Co. v. College voor de toelating van gewasbeschermingsmiddelen en biociden, 23 September 2010, ECLI:EU:C:2010:546.

Opinion of Advocate General Kokott in Joined Cases C-191/14, C-192/14, C-295/14, C389/14 and C-391/14 to C-393/14, Borealis Polyolefine GmbH and others v. Bundesminister für Land- und Forstwirtschaft, Umwelt und Wasserwirtschaft and others, 12 November 2015, ECLI:EU:C:2015:754. 
Opinion of Advocate General Szpunar in Case C-60/15 P Saint-Gobain Glass Deutschland v. Commission, 23 September 2010, ECLI:EU:C:2016:778.

Opinion of the Advocate General Kokott in Case C-524/09, Ville de Lyon v. Caisse des dépôts et consignations, 14 October 2010, EU:C:2010:613, ECLI:EU:C:2010:613.

\section{International Treaties and International Documents}

Application of the Convention on the Prevention and Punishment of the Crime of Genocide (Bosnia and Herzegovina v. Serbia and Montenegro), 26 February 2007.

Convention on Access to Information, Public Participation in Decision-making and Access to Justice in Environmental Matters, Aarhus, Denmark, 25 June 1998, United Nations, Treaty Series, vol. 2161, p. 447 (entered into force on 30 October 2001).

Declaration by the Ministers of Environment of the region of the United Nations Economic Commission for Europe (UNECE).

Declaration of the United Nations Conference on the Human Environment (16 June 1972).

Doha Amendment to the Kyoto Protocol, Qatar, 8 December 2012, C.N.718.2012.TREATIES-XXVII.7.c (not into force).

Draft Rules of Procedure of the Conference of the Parties and its Subsidiary Bodies FCCC/CP/1996/2, (1996).

Kyoto Protocol to the United Nations Framework Convention on Climate Change, 19, Kyoto, 11 December 1997, United Nations Treaty Series, vol. 2303, No. 30822, p. 162 (entrered into force on 16 February 2005).

Paris Agreement, Paris, 12 December 2015, United Nations Treaty Series, No. 54113. C.N.63.2016.TREATIES-XXVII.7.d of 16 February 2016 (Opening for signature) and C.N.92.2016.TREATIES-XXVII.7.d of 17 March 2016 (Issuance of Certified True Copies) (entered into force on 4 November 2016).

Protocol on Pollutant Release and Transfer Registers to the Convention on Access to Information, Public Participation in Decision-Making and Access to Justice in Environmental Matters, Kiev, 21 May 2003, United Nations, Treaty Series, vol. 2626, p. 119. Doc. MP.PP/2003/12 (entered into force on 8 October 2009).

Regional Agreement on Access to Information, Public Participation and Justice in Environmental Matters in Latin America and the Caribbean, Escazú on 4 March 2018 (not yet entered into force). 
Request for Interpretion of the Judgment of 31 March 2004 in the Case Concerning Avena and other Mexican Nationals (Mexico v. United States of America), 19 January 2009.

Rio Declaration on Environment and Development, UN Doc. A/CONF.151/26 (vol. I) / 31 ILM 874 (1992).

UNECE Protocol on Strategic Environmental Assessment to the Convention on Environmental Impact Assessment in a Transboundary Context Kiev, 21 May 2003, United Nations, Treaty Series , vol. 2685, p. 140. Doc. ECE/MP.EIA/2003/2.C.N.951.2016 (entered into force on 8 October 2009).

United Nations Framework Convention on Climate Change, New York, 9 May 1992, United Nations Treaty Series, vol. 1771, No. 30822, p. 107 (entrered into force on 21 March 1994).

Vienna Convention on the Law of Treaties, Vienna on 23 May 1969, Treaty Series, vol. 1155, p. 331 (entered into force on 27 January 1980).

\section{Communications before the Aarhus Convention Compliance Committee}

Alburnus Maior concerning compliance by Romania ECE/MP.PP/2008/5/Add.7, 16 April 2008.

Alliance for the Protection of the Vlora Gulf with regard to compliance by Albania UN Doc. ECE/MP.PP/C.1/2007/4/Add.1, 31 July 2007.

Caucasus Environmental NGO Network with regard to compliance by Georgia UN Doc. ECE/MP.PP/C.1/2010/4/Add.1, 11 May 2010.

Center for Regional Development/Transparency International Armenia, the Sakharov Armenian Human Rights Protection Center and the Armenian Botanical Society (Armenia) with regard to compliance by Armenia UN Doc. ECE/MP.PP/C.1/2006/2/Add.1, 10 May 2006.

Czech organization Environmental Law Service (Ekologiský právní servis) concerning compliance by Czech Republic (ECE/MP.PP/C.1/2012/11), 02 October 2012.

ClientEarth concerning compliance by the European Union (Part I) UN ECE/MP.PP/C.1/2011/4/Add.1, 24 August 2011.

ClientEarth concerning compliance by the European Union (Part II) UN Doc. ECE/MP.PP/C.1/2017/7, 17 March 2017.

Environmental Law Foundation concerning compliance by the United Kingdom of Great Britain and Northern Ireland ECE/MP.PP/C.1/2016/10, 17 June 2015. 
Environmental Law Service (Ekologiský právní servis) concerning compliance by the Czech Republic UN Doc. ECE/MP.PP/C.1/2014/9, 20 December 2013.

Green Salvation (Kazakhstan) with regard to compliance by Kazakhstan UN Doc. ECE/MP.PP/C.1/2005/2/Add.1, 11 March 2005.

Mr. Pat Swords concerning compliance by the European Union UN Doc. ECE/MP.PP/C.1/2012/12, 2 October 2012.

Ms. Christine Metcalfe on behalf of the Avich and Kilchrenan Community Councilconcerning compliance by the European Union and the United Kingdom of Great Britain and Northern Ireland ECE/MP.PP/C.1/2014/5, 24 September 2013.

Ms. Brigitte Artmann concerning compliance by Czechia ECE/MP.PP/C.1/2017/3, 13 September 2016.

The Albanian non-governmental organization Civic Alliance for the Protection of the Bay of Vlora regarding compliance by the European Community UN Doc. ECE/MP.PP/C.1/2009/2/Add.1, 8 February 2011.

The non-governmental organization Alburnus Maior (Romania) with regard to compliance by Romenia UN Doc. ECE/MP.PP/2008/5/Add.7, 10 May 2006.

The non-governmental organization Eco-TIRAS International Environmental Association of River Keepers regarding compliance by the Republic of Moldova UN Doc. ECE/MP.PP/C.1/2009/6/Add.3, 8 February 2011. 
Annex - Voluntary schemes approved by the European Commission

\begin{tabular}{|c|c|c|}
\hline Abbreviation & Name of Sustainability scheme & $\begin{array}{l}\text { Date of EC } \\
\text { recognition or re- } \\
\text { recognition }\end{array}$ \\
\hline ISCC-EU & $\begin{array}{l}\text { International Sustainability and Carbon } \\
\text { Certification EU Scheme }\end{array}$ & $\begin{array}{l}\text { 19 July } 2011 \\
9 \text { August } 2016\end{array}$ \\
\hline Bonsucro EU & Bonsucro EU Certification Scheme & $\begin{array}{l}\text { 19 July } 2011 \\
21 \text { March } 2017\end{array}$ \\
\hline RTRS EU RED & $\begin{array}{l}\text { Round Table on Responsible Soy EU RED } \\
\text { Scheme }\end{array}$ & $\begin{array}{l}19 \text { July } 2011 \\
17 \text { November } 2017\end{array}$ \\
\hline RSB EU RED & $\begin{array}{l}\text { Roundtable on Sustainable Biofuels EU } \\
\text { RED Scheme }\end{array}$ & $\begin{array}{l}19 \text { July } 2011 \\
9 \text { August } 2016\end{array}$ \\
\hline RBSA & $\begin{array}{l}\text { Abengoa RED Bioenergy Sustainability } \\
\text { Assurance Scheme }\end{array}$ & $\begin{array}{l}19 \text { July } 2011 \\
\text { (expired) }\end{array}$ \\
\hline Greenergy & $\begin{array}{l}\text { Greenergy Brazilian Bioethanol } \\
\text { Verification Programme }\end{array}$ & $\begin{array}{l}19 \text { July } 2011 \\
\text { (expired) }\end{array}$ \\
\hline 2BSvs & Biomass Biofuels Voluntary Scheme & $\begin{array}{l}19 \text { July } 2011 \\
26 \text { August } 2016\end{array}$ \\
\hline ENSUS & $\begin{array}{l}\text { Voluntary Scheme under RED for Ensus } \\
\text { Bioethanol Production }\end{array}$ & $\begin{array}{l}23 \text { April } 2012 \\
\text { (expired) }\end{array}$ \\
\hline Red Tractor & $\begin{array}{l}\text { Red Tractor Farm Assurance Combinable } \\
\text { Crops \& Sugar Beet Scheme }\end{array}$ & $\begin{array}{l}16 \text { July } 2012 \\
13 \text { December } 2017\end{array}$ \\
\hline SQC & $\begin{array}{l}\text { Scottish Quality Farm Assured Combinable } \\
\text { Crops Scheme Agricultural }\end{array}$ & 24 July 2012 \\
\hline
\end{tabular}




\begin{tabular}{|c|c|c|}
\hline & & 9 June 2015 \\
\hline REDCert & $\begin{array}{l}\text { Renewable Energy Directive Certification } \\
\text { Scheme }\end{array}$ & $\begin{array}{l}24 \text { July } 2012 \\
10 \text { August } 2017\end{array}$ \\
\hline NTA 8080 & $\begin{array}{l}\text { Netherlands Technical Agreement } 8080 \\
\text { Certification Scheme }\end{array}$ & $\begin{array}{l}\text { 24 July } 2012 \\
\text { (expired) }\end{array}$ \\
\hline \multirow[t]{3}{*}{ RSPO EU RED } & $\begin{array}{l}\text { Roundtable on Sustainable Palm Oil } \\
\text { Production RED Scheme Palm }\end{array}$ & $\begin{array}{l}23 \text { November } 2012 \\
\text { (expired) }\end{array}$ \\
\hline & Biograce GHG calculation tool & $\begin{array}{l}30 \text { May } 2013 \\
\text { (expired) }\end{array}$ \\
\hline & $\begin{array}{l}\text { HVO Renewable Diesel Scheme for } \\
\text { Verification of Compliance with the RED } \\
\text { sustainability criteria for biofuels }\end{array}$ & $\begin{array}{l}9 \text { January } 2014 \\
\text { (expired) }\end{array}$ \\
\hline GTAS & Gafta Trade Assurance Scheme & $\begin{array}{l}3 \text { June } 2014 \\
\text { (expired) }\end{array}$ \\
\hline \multirow[t]{2}{*}{ KZR INIG System } & $\begin{array}{l}\text { INIG System of certification of biofuels } \\
\text { and bioliquids }\end{array}$ & 3 June 2014 \\
\hline & $\begin{array}{l}\text { Trade Assurance Scheme for Combinable } \\
\text { Crops }\end{array}$ & $\begin{array}{l}17 \text { September } 2014 \\
13 \text { December } 2018\end{array}$ \\
\hline UFAS & Universal Feed Assurance Scheme & $\begin{array}{l}17 \text { September } 2014 \\
\text { (expired) }\end{array}$ \\
\hline SSAP EU & $\begin{array}{l}\text { U.S. Soybean Sustainability Assurance } \\
\text { Protocol EU }\end{array}$ & 29 January 1019 \\
\hline
\end{tabular}




\section{Summary}

It is now scientifically proven that humans' activities interfere with the climate system. ${ }^{1}$ One of the consequences of the increase of greenhouse gas emissions in the Earth's atmosphere is climate change. The fact that humans contribute to climate change raises the question how the public engages in the decision making on measures to tackle climate change. Based on this premise, this thesis investigated to what extent rights of access to environmental information and participation in governmental environmental decision making have to be provided for individuals and ENGOs at the EU level in the field of EU climate change law in the light of international treaty law, more particularly the UNFCCC and the Aarhus Convention. In order to answer this question, the thesis was divided into four main chapters, which break down the main research question into sub-questions.

Chapter II examined the legal framework established by the UNFCCC for access to information and public participation in climate change decision making and explored the obligations they entail for the Parties. Article 6 of the UNFCCC provides an obligation for the Parties to the UNFCCC to promote and facilitate access to information and public participation in climate change decision making. A textual and systematic interpretation revealed that these obligations require the Parties to make an effort towards promoting and facilitating public access to information and public participation, without including any targets or clear and specific commitments. Therefore, the obligations contained in Article 6 are obligations of effort. In addition to examining Article 6 itself, the decisions establishing the work programmes on Article 6 of the UNFCCC adopted by the Conference of the Parties (CoP) were examined to investigate whether the content of these decisions gives more body to Article 6 of the UNFCCC. This thesis identified that the obligations contained in Article 6 of the UNFCCC do not have clear and specific commitments, which renders the provision lacking a precise result to be achieved. Furthermore, the agreements adopted under the umbrella of the UNFCCC were examined, since they potentially could provide for further commitments. This thesis concluded that neither Article 10(e) of the Kyoto Protocol nor Article 12 of the Paris Agreement provide elements that make the general obligations of Article 6 of the UNFCCC more concrete. In sum, all the relevant international provisions analysed in Chapter II were thus regarded as obligations of effort and there are no clearly identifiable results that need to be achieved by the Parties.

\footnotetext{
${ }^{1}$ The IPCC stated: "It is extremely likely that more than half of the observed increase in global average surface temperature from 1951 to 2010 was caused by the anthropogenic increase in GHG concentrations and other anthropogenic forcings together." Intergovernmental Panel on Climate Change, Climate Change 2014: Synthesis Report. Summary for Policymakers, 2014b, https://www.ipcc.ch/pdf/assessment-report/ar5/syr/AR5_SYR_FINAL_SPM.pdf, p. 5.
} 
Chapter II demonstrated that there are no precise legal commitments under the UNFCCC. However, the EU is also a Party to a regional agreement on procedural rights: the Aarhus Convention (AC). In this vein, Chapter III studied the legal framework established by the Aarhus Convention and its relationship with climate change, followed by the implementation of the Aarhus Convention at the EU level. Although there is no mention of the term climate change in the text of the Aarhus Convention, the interpretation of the definition of environmental information demonstrates that the term environmental encompasses the climate change phenomenon.

The framework for access to environmental information of the Aarhus Convention provides for explicit commitments as to what has to be done by public authorities. Therefore, the commitments contained in these provisions can be characterised as obligations of result. This means that the Parties have to achieve a specific result, ensuring that their public authorities provide upon request (Article 4) and disseminate environmental information (Article 5). At the EU level, the implementation of the provisions has taken place via the Aarhus Regulation, which should be read in combination with Regulation 1049/2001 regarding requests for environmental information. Concerning access to environmental information, it was concluded that the provisions of the Aarhus Regulation are mostly in compliance with the Aarhus Convention. However, regarding the implementation of the exceptions to the obligations to provide access to environmental information upon request, the analysis revealed that the EU requirements impose more limitations than those allowed by the Aarhus Convention.

The obligations contained in Article 6 of the Aarhus Convention establishing public participation in decisions on specific activities can be generally characterised as an obligation of result. Nevertheless, the explanatory memorandum to the Aarhus Regulation's proposal clarifies that there are no measures related to specific activities which are taken at the EU level. As a consequence, the provision was not transposed. It was shown that this approach is controversial, since some EU decisions may amount to decisions on specific activities within the scope of application of Article 6 of the Aarhus Convention. Article 7 of the Aarhus Convention on public participation concerning plans, programmes and policies relating to the environment establishes two separate regimes for public participation. First, parts of the requirements contained in Article 6 of the Aarhus Convention apply to ensure participation during the development of plans and programmes. This first part of Article 7 of the Aarhus Convention is characterised by an obligation of result. The second part, for policies, Parties are only required, to the extent appropriate, to endeavour to provide opportunities for public participation. This weak and imprecise formulation, which fails to explain the exact result to be achieved, makes the second part of Article 7 of the Aarhus Convention an obligation of effort. The Aarhus Regulation only provides for public participation concerning plans and programmes. Article 8 of the Aarhus Convention concerning public participation during the preparation of executive regulations and/or generally applicable legally binding normative 
instruments does not require parties to achieve effective public participation and it is also characterised as an obligation of effort. There is no implementation of Article 8 of the Aarhus Convention at the EU level, since the European Commission understood that Article 8 does not provide any legally binding requirement. However, Article 8 creates an obligation to make efforts to achieve effective public participation, and this obligation applies to the EU institutions and bodies.

Chapters IV and V delved into the question of how the EU legal framework provides for access to information and public participation in the context of acts adopted at the EU level under two core instruments of the EU climate policy, namely the EU ETS Directive (Chapter IV) and the recognition of voluntary schemes for assessing the sustainability of biofuels under the Renewable Energy Directive (Chapter V).

Chapter IV analysed the EU ETS Directive in view of: (i) legal requirements for access to environmental information and public participation in the decision making for acts adopted under the EU ETS Directive; and (ii) the compatibility of this framework with requirements imposed by the Aarhus Convention.

Chapter IV identified that there is a general regime for access to environmental information under the EU ETS. Despite the existence of specific provisions on access to information, their limited scope cannot cover all the possible requests for information under the EU ETS. Therefore, an investigation through the existing CJEU case law on access to environmental information was carried out, particularly in view of how the Aarhus Regulation is applied with regard to such requests. Hence, the analysis of the case law built further on the definition of environmental information and on the limits of the grounds for a refusal to disclose environmental information. These cases revealed that: (i) a great number of EU ETS-related information potentially falls within the definition of environmental information; and (ii) the grounds for refusal have to be interpreted in a restrictive way, to ensure the right of access to environmental information.

The EU ETS Directive does not have a general provision on public participation, which would apply to all decisions to be taken under this Directive. Therefore, it was investigated whether public participation requirements could be derived from specific provisions under the EU ETS Directive. This investigation revealed that public participation is not required by the EU ETS Directive for the adoption of most acts. It was also demonstrated that the Aarhus Regulation does not impose any obligation regarding public participation for the acts adopted under the EU ETS Directive. Further, it was examined whether there is nevertheless an obligation under the Aarhus Convention for the Commission to provide for public participation in the decision making process under the EU ETS. The analysis demonstrated that these acts qualify as executive regulations and other generally applicable legally binding normative instruments, because they are acts of general application, as their addressees are 
not determined or determinable. ${ }^{2}$ Furthermore, considering their size, location and potential effects on the environment, they have a significant effect on the environment. Therefore, they fall under the scope of application of Article 8 of the Aarhus Convention and, as a consequence, there is a legal obligation for the Commission to strive to promote public participation. According to the 2017 Better Regulation Guidelines, stakeholders can provide feedback on the draft of implementing and delegated acts, which encompasses most of the acts adopted by the Commission discussed in chapter IV. This could amount to compliance with Article 8 of the Aarhus Convention when implementing and delegated acts are adopted. However, the acts adopted by the Commission acting alone would not be covered and, therefore, no compliance with Article 8 of the Aarhus Convention could be achieved. Moreover, Article 8 of the Aarhus Convention does not provide for any exception to the rule that the drafts should be subject to public participation, and it requires that the timeframe should be sufficient for effective participation, while the Better Regulation Guidelines provides for the application of exceptions and no flexibility regarding the time-frame. Therefore, the Guidelines, per se, cannot guarantee that the EU fully complies with Article 8 of the Aarhus Convention. In light of the conclusions reached in Chapter IV, it can be argued that public participation under the EU ETS could be strengthened if the EU ETS Directive contained a specific provision on public participation.

Chapter $\mathrm{V}$ assessed the regime of access to biofuel-related information and public participation in decision making for the recognition of biofuels voluntary schemes at the EU level in view of the Aarhus Convention requirements. The European Commission is empowered by the Renewable Energy Directive to recognise voluntary schemes as capable of checking for compliance with the EU's biofuels sustainability criteria. Only the biofuels that fulfil certain sustainability criteria established in the RED count towards national renewable energy targets. It was found that biofuel-related information is environmental information and that the European Commission, the evaluator/contractor and the voluntary schemes themselves are public authorities according to the Aarhus Convention, and therefore these entities are under the obligation to disclose information. However, the case law of the CJEU revealed that the European Commission did not respect the prescribed timeframe for providing environmental information. Regarding public participation, the findings have shown that there is no legal framework for public participation in the recognition of voluntary biofuels schemes at the EU level. The examination of the participatory rights of the Aarhus Convention, which are laid down in Articles 6,7 and 8 of the Aarhus Convention, revealed that the decisions on the recognition of voluntary schemes and the decisions on the certification of biofuels may be interpreted as decisions on proposed activities which may have a significant effect on the environment for the purposes of Article 6(1)(b) of the Aarhus

\footnotetext{
2 These non-legislative acts took the form of a regulation or decision. Regulations and decisions are among the legal instruments available to the European institutions to exercise the Union's competences, according to Article 288 TFEU. How they are adopted defines whether they are a legislative act or not.
} 
Convention, and they are therefore subject to the most precise set of requirements for public participation provided by the Aarhus Convention.

Overall, this thesis has shown that there is a need for a more consistent and clearer legal framework which should ensure access to climate change-related information and participation in climate change decision making. Climate change challenges will become ever more pressing in the coming years and the analysis of two EU measures from a procedural rights perspective provided some insight into how puzzling access to environmental information and public participation can be in the context of the new regulatory measures adopted to tackle it. 


\section{Valorisation Addendum}

\section{Relevance:}

Climate change is real and greenhouse gases produced by human activities are interfering with the Earth's temperature. ${ }^{1}$ The imminent threat of climate change and the clear contribution of humankind to this process call for concrete responses from all to tackle this problem. This has prompted the public to take action in diverse forms around the world. For instance, a movement started by the Swedish teenager Greta Thunberg in August 2018 pushed thousands of students around the world to engage in demonstrations calling for action against climate change. ${ }^{2}$

In addition to individuals taking to the streets, many non-governmental organizations (NGOs) have been using legal instruments to attempt to force action on climate changerelated issues. This thesis highlights as examples ClientEarth and Friends of the Earth, which have repeatedly used legal tools available to influence the decision making by governments in a more environmentally friendly direction. ${ }^{3}$

The engagement of the public, particularly environmental NGOs (ENGOs), demanding for a suitable and timely response prompts the question of what rights members of the public actually have to access climate change-related information and to participate in climate change decision making. This thesis, therefore, examined how these procedural rights are provided for in the EU emissions trading system (EU ETS) Directive and the Renewable Energy Directive at the EU level, and assessed their compatibility with the Aarhus Convention. ${ }^{4}$ The findings from this research have filled an important gap in the extant academic literature by showing that, in the area of EU climate change - in particular regarding

\footnotetext{
${ }^{1}$ The IPCC stated: "It is extremely likely that more than half of the observed increase in global average surface temperature from 1951 to 2010 was caused by the anthropogenic increase in GHG concentrations and other anthropogenic forcings together." Intergovernmental Panel on Climate Change, Climate Change 2014: Synthesis Report. Summary for Policymakers, 2014b, https://www.ipcc.ch/pdf/assessment-report/ar5/syr/AR5_SYR_FINAL_SPM.pdf, p. 5.

${ }^{2}$ S. Laville, M. Taylor and D. Hurst, 'It's our time to rise up': youth climate strikes held in 100 countries, The Guardian, 15 March 2019, https://www.theguardian.com/environment/2019/mar/15/itsour-time-to-rise-up-youth-climate-strikes-held-in-100-countries.

${ }^{3}$ At the EU level, these NGOs, for instance, have started legal action against the European Union (EU) in view of the denial to access environmental information. See Case T-278/11, ClientEarth, Friends of the Earth Europe, Stichting FERN and Stichting Corporate Europe Observatory v. European Commission, 13 November 2012, ECLI:EU:T:2012:593.

${ }^{4}$ The regional Convention on Convention on Access to Information, Public Participation in DecisionMaking and Access to Justice in Environmental Matters (known as the Aarhus Convention).
} 
access to information and participation in the EU emissions trading system (EU ETS) and in the recognition of biofuels schemes-, adjustments in the legal framework are needed.

In addition to its academic scope, this thesis could have important social, environmental and economic relevance. There is clearly a large part of society that is interested in engaging in the discussion on how to best tackle climate change. This thesis provides a clear description of the EU legal framework available to the public (individuals, NGOs and economic actors alike) for access to environmental information and public participation in climate change decision making. It also identifies opportunities to engage in the debate more actively, such as the possibility for the public in general to provide feedback on acts adopted by the European Commission, ${ }^{5}$ but also shortcomings, such as the delay on the disclosure of information by the European Commission ${ }^{6}$ that can become points of action for individuals and ENGOs. The findings are also useful for governments, since the thesis discusses the compatibility of the EU legal framework with international law. From an environmental perspective, if the public uses the results of this thesis to participate more in the decision making concerning the measures to tackle the adverse effects of climate change, this could eventually help to voice the diversity of possible solutions to the climate change problem. From an economic perspective, measures taken to mitigate the effects of climate change, such as emissions trading, involve economic costs as they put a price on carbon used to produce goods consumed by the public. The European Union has established the EU ETS, which was developed through numerous legal instruments. To participate in the acts adopted under the EU ETS, the public needs to possess sufficient knowledge of the system and of the specific legislation applicable. This thesis, by providing thorough analysis of the measures adopted under the EU ETS in view of access to information and public participation may provide the public tools to engage in the discussion of how to implement such a complex system.

The outcome of this research, hence, does not only provide an important contribution to the academic debate by providing an in-depth understanding of the minimum requirements for procedural rights given by international and EU law in view of legal instruments aiming to decrease greenhouse gas emissions and stimulating renewable energy, but it also provides crucial information that can be used directly in the practice of climate policies.

\footnotetext{
${ }^{5}$ See section 4.5 of Chapter IV.

${ }^{6}$ See section 3.5 of Chapter V.
} 


\section{Target groups:}

The climate change problem reverberates throughout society and the findings of this thesis may be of interest to a wide range of interest groups. Apart from academics, individual, NGOs, economic actors, and governments are target groups, since all these actors may interact through procedural rights in the context of climate change decision making.

The public, including individuals, NGOs and economic actors, by addressing the findings of the thesis, may rely on the rights to access to environmental information and public participation to engage in climate change decision making at EU level. For instance, by engaging in the public consultations and feedbacks opportunities provided the European Commission. Moreover, in many instances, environmental NGOs need to acquire specific knowledge in order to assess whether an intended action may be successful. The results of this thesis identify restrictive access to environmental information and limited public participation in the EU legal framework that could serve as starting point for these actions.

In a broader perspective, the thesis, by discussing the climate change problem from a procedural rights perspective, may have an impact on public awareness regarding the legal instruments available to get access to climate change-related information and public participation in climate change decision making, which has the potential of putting the public closer to governmental decision making.

Concerning governments, especially at the EU level, this thesis provides a careful analysis of the EU legal framework on access to information and public participation regarding the EU ETS and the recognition of biofuels schemes and its compatibility with its international commitments. The legal and policy shortcomings identified in this thesis can foster further discussions on the steps needed to achieve compliance and prioritize actions. The lessons learned under the analysis of the EU legal framework may also benefit other governmental actors, which can reflect upon the results while implementing and/or improving their own legal framework.

\section{Activities/Products:}

The research findings emerging from this thesis may benefit the public, including NGOs, by strengthening the arguments for litigation and advocacy for the protection of the environment.

Besides Europe, which already has seen the entry into force of the Aarhus Convention, the UN Economic Commission for Latin America and the Caribbean (ECLAC) adopted a regional treaty on access to environmental information, public participation and access to 
justice in environmental matters. ${ }^{7}$ This new development is highly influenced by the experience with the Aarhus Convention, even while facing challenges in responding to the measures created to tackle climate change. The unique experience of the EU described in this thesis may be, therefore, an important source for countries to learn about the success and obstacles to the implementation of a convention on environmental procedural rights.

\section{Innovation:}

No other study has provided an in-depth examination of the rights of access to environmental information and participation in governmental environmental decision for the public, especially individuals and ENGOs, at the EU level in the field of EU climate change law. Therefore, it is another piece of the complex puzzle on how procedural rights may eventually contribute to the achievement of a fossil-free economy and society.

\section{Planning \& Implementation:}

This thesis will be on open access, ${ }^{8}$ which makes access to the results of this thesis unrestricted. In addition, the outcome of the research is not only provided through a written $\mathrm{PhD}$ thesis, but will also be made accessible to the public in the form of a summary of the research (in accessible language) to be put on the internet and to be directly sent to ENGOs.

Part of the findings have also been publicised through two academic publications and through several conferences and workshops where I have given oral presentations.

Furthermore, part of the findings had been incorporated in the teaching of Environmental Law to bachelor students in a university of applied science. Many of these students have heard about environmental procedural rights for the first time and they can apply this knowledge in their professional life.

\footnotetext{
${ }^{7}$ Regional Agreement on Access to Information, Public Participation and Justice in Environmental Matters in Latin America and the Caribbean, Escazú on 4 March 2018 (not yet entered into force).

${ }^{8} \mathrm{The} \mathrm{PhD}$ theses of Maastricht University can be found here: https://cris.maastrichtuniversity.nl/en/ publications $/$ ?nofollow $=$ true $\&$ format $=\&$ type $=\% 2 \mathrm{Fdk} \% 2 \mathrm{Fatira} \% 2 \mathrm{Fpure} \% 2 \mathrm{Fresearchoutput} \% 2 \mathrm{Fresear}$ choutputtypes\%2Fthesis\%2Fdoc.
} 


\section{Curriculum Vitae}

Sandra Nóbrega (Natal - Brazil, 1982) has a Law Degree (2009) from Federal University of Rio Grande do Norte, an Environmental Sciences Degree (2004) from the Federal Institute of Rio Grande do Norte, and an LL.M in Comparative, European and International Law (2010) from Maastricht University. She is a member of the Brazilian Bar Association since 2010. The research for this PhD thesis was carried out at Maastricht University, where Sandra Nóbrega worked as a PhD Researcher and junior Lecturer in the Department of Public Law from 2013 to 2019. Since January 2020, she works as a Lecturer in Environmental Law at The Hague University of Applied Sciences. 